\title{
Evaluation of deck casting on the construction performance of straight and skewed steel I-girder bridges
}

Jason J. Jackson

West Virginia University

Follow this and additional works at: https://researchrepository.wvu.edu/etd

\section{Recommended Citation}

Jackson, Jason J., "Evaluation of deck casting on the construction performance of straight and skewed steel I-girder bridges" (2013). Graduate Theses, Dissertations, and Problem Reports. 643.

https://researchrepository.wvu.edu/etd/643

This Thesis is protected by copyright and/or related rights. It has been brought to you by the The Research Repository @ WVU with permission from the rights-holder(s). You are free to use this Thesis in any way that is permitted by the copyright and related rights legislation that applies to your use. For other uses you must obtain permission from the rights-holder(s) directly, unless additional rights are indicated by a Creative Commons license in the record and/ or on the work itself. This Thesis has been accepted for inclusion in WVU Graduate Theses, Dissertations, and Problem Reports collection by an authorized administrator of The Research Repository @ WVU. For more information, please contact researchrepository@mail.wvu.edu. 


\title{
Evaluation of Deck Casting ON THE CONSTRUCTION \\ PERFORMANCE OF STRAIGHT AND SKEWED STEEL I-GIRDER BRIDGES
}

\author{
Jason J. Jackson \\ Thesis submitted to the \\ Benjamin M. Statler College of Engineering and Mineral Resources \\ at West Virginia University \\ in partial fulfillment of the requirements \\ for the degree of \\ Master of Science \\ in \\ Civil and Environmental Engineering
}

Karl E. Barth, Ph.D., Chair

Fei Dai, Ph.D.

Udaya B. Halabe, Ph.D.

Department of Civil and Environmental Engineering

Morgantown, West Virginia

2013

Keywords: lateral flange bending, steel bridge, finite element modeling 


\begin{abstract}
Evaluation of Deck Casting on the Construction Performance of STRAIGHT AND SKEWED STEEL I-GIRDER BRIDGES
\end{abstract}

\author{
Jason J. Jackson
}

The use of skew in bridges is becoming increasingly more popular with the number of urban or geographical restraints that require unique abutment and pier orientations. The increasing transportation needs in highly-populated areas require more complicated interchanges, along with the use of skewed or even curved bridges. However, the use of skew complicates the design and performance of the bridge. In straight bridges, girder stress and rotations are fairly easy to predict. However, the use of skew in steel I-girder bridges can cause uneven loading and detailing issues with girders and cross-frames. In particular, skew can result in increased warping, which produces a stress phenomenon known as lateral flange bending.

Lateral flange bending (LFB) is the torsional effect in flanges of an I-section that results from warping. Since the st. Venant torsional stiffness for an open cross-section is low, torsional loads are resisted by the girder in the form of lateral bending stresses. The current AASHTO LRFD Specifications use a fixed-end moment approximation to account for LFB in the design phase. The method assumes that cross-frames act as fixed supports and employs fixed-end moment equations to compute LFB moments in respective unbraced segments. During this study, it was found that this approximation is quite accurate for estimating LFB stresses at cross-frame locations; however, the method tends to overestimate LFB in between cross-frame locations.

Therefore, the goal of this project was to assess the AASHTO LRFD approximation for LFB. To accomplish this, a commercial finite element software package (Abaqus) was employed. The finite element modeling technique was used in several parametric matrices of simple-span bridges to determine the key parameters that affect LFB. Once key parameters were identified and assessed, a modification factor was developed which includes the effect of these parameters and directly adjusts the AASHTO LFB approximation. Observing the data developed in this study, it can be seen that the empirical modification significantly improves the accuracy of the approximation in those regions between the cross-frames, which can improve the efficiency of the design of simple span I-girder bridges. 


\section{ACKNOWLEDGMENTS}

The Author would like to thank the following:

1. Dr. Karl E. Barth, for the opportunity to pursue a Master of Science. In addition his guidance, encouragement, and presence was helpful and made the Graduate experience a pleasant experience for that he was greatly appreciated.

2. Dr. Fei Dai, and Dr. Udaya Halabe, for their participation on this graduate advisory committee.

3. Greg Michealson, for advice and assistance in this project. His valued experience saved valuable time and made it possible to accomplish this project.

4. Crew of ESB-B11, for making the office atmosphere an enjoyable place to come to everyday.

I would like to give a special thank you to my family for all their support during the graduate school process without them none of this would have been possible and for that they are greatly appreciated. Last but certainty not least I would like to give thanks to God without him nothing is possible. 


\section{TABLE OF CONTENTS}

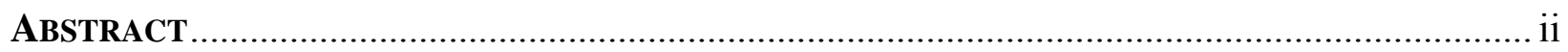

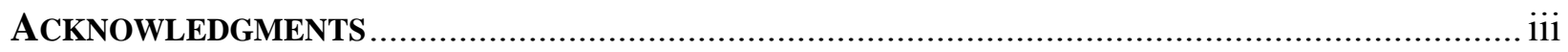

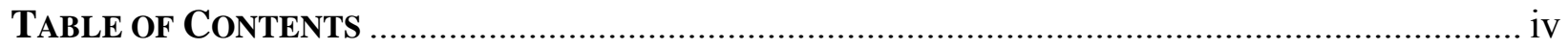

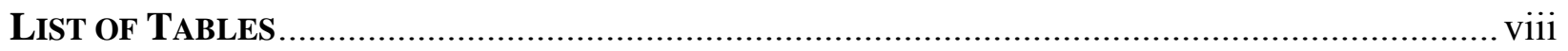

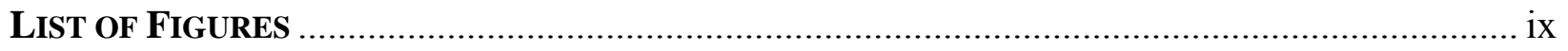

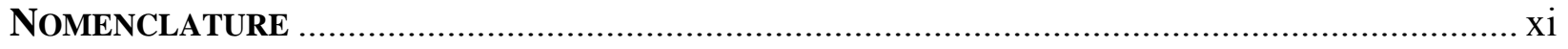

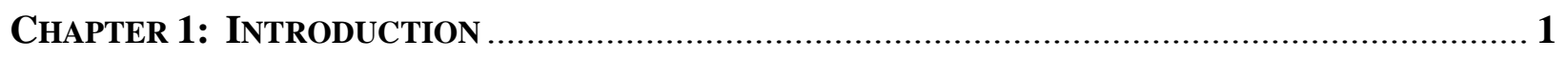

1.1 BACKGROUND / OVERVIEW..................................................................................................................... 1

1.2 PROJECT SCOPE \& OBJECTIVES.................................................................................................... 2

1.3 THESIS ORGANIZATION........................................................................................................................

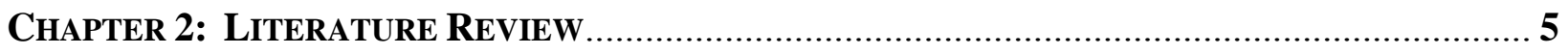

2.1 INTRODUCTION ................................................................................................................................

2.2 LATERAL FLANGE BENDING IN STEEL I-GIRDER BRIDGES............................................................. 5

2.2.1 Fundamentals of Lateral Flange Bending ......................................................................... 5

2.2.2 Lateral Flange Bending Studies........................................................................................ 7

2.2.3 LFB Effects on Bridge Design and Fabrication ................................................................. 9

2.3 Construction LoAding and Deck Placement in SteEl I-GIRder BRidges........................ 10

2.3.1 Stay-in-Place (SIP) Metal Forms..................................................................................... 11

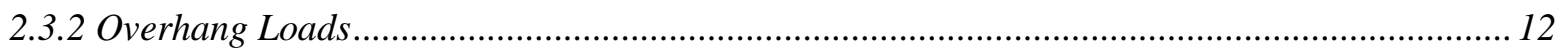

2.3.3 Concrete Finishing Machine / Wet Concrete ……………………………………………....... 14

2.4 SPECIFICATIONS RELATED TO LFB IN STEEL I-GIRDER BRIDGES ................................................ 15

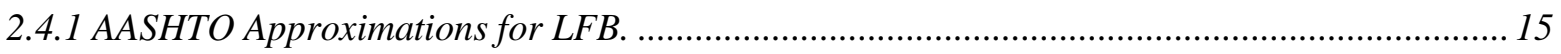

2.4.2 AASHTO Flexural Limit States for Constructibility ............................................................... 16

2.4.2.1 Discretely Braced Flanges in Compression ................................................................... 16

2.4.2.2 Discretely Braced Flanges in Tension .............................................................................17

2.4.2.3 Continuously Braced Flanges .................................................................................... 17

2.4.3 AISC Provisions for LFB .......................................................................................... 18

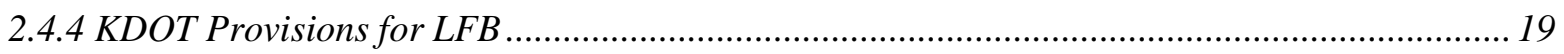

2.5 OVERVIEW OF CRosS-FrAME ForCES AND ASSOCIATED DETAILING ISSUES .............................. 23

2.5.1 Cross-Frame Detailing Issues ........................................................................................ 23

2.5.2 Cross-Frame Forces and Measures of Cross-Frame Stiffness ................................................ 27 


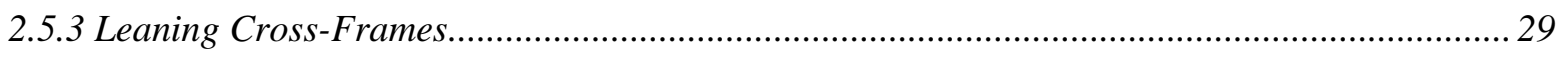

2.5.4 Effect of Girder Plumbness on Cross-Frame Forces............................................................ 31

2.6 SUMMARY AND RESEARCH NEEDS ................................................................................................ 32

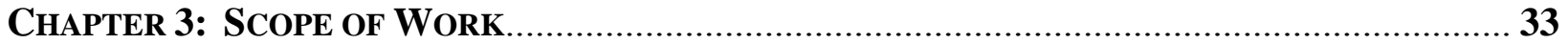

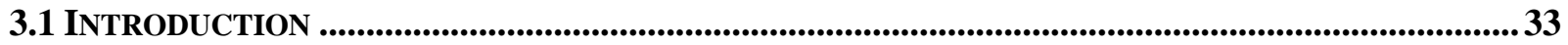

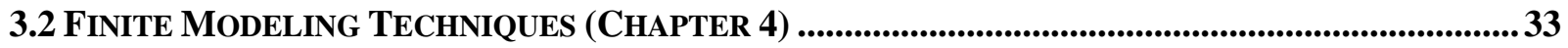

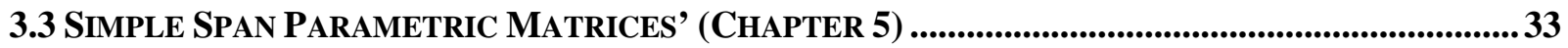

3.4 FoRMULATION OF THE MODIFIED APPROXIMATION (CHAPTER 6) ...........................................34

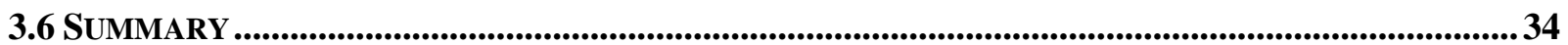

ChAPTER 4: Finite Element Modeling TeCHNiQUES .................................................. 35

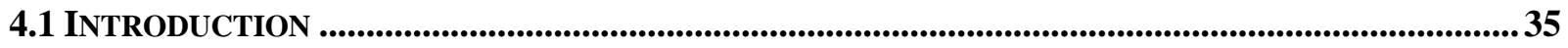

4.2 SELECTION OF ELEMENTS....................................................................................................................... 35

4.3 MESH DISCRETIZATION ................................................................................................................... 35

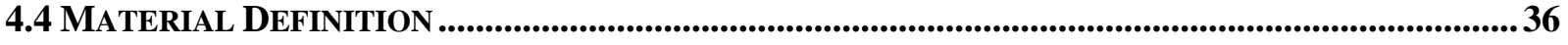

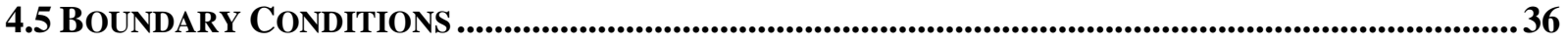

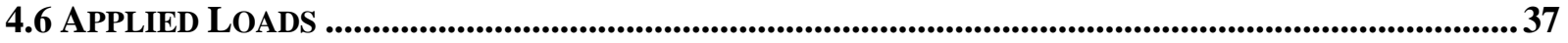

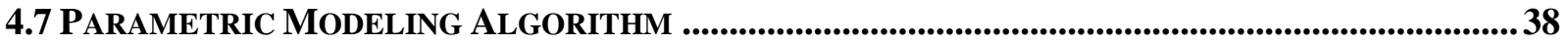

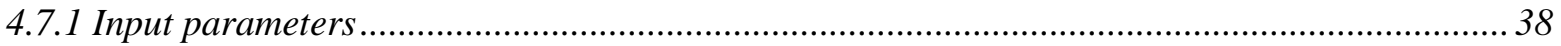

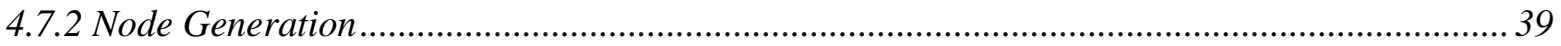

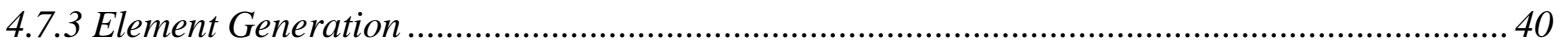

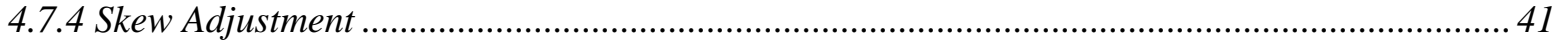

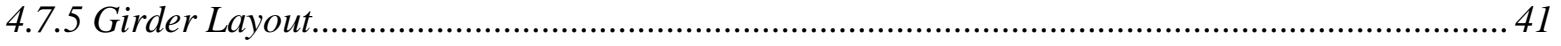

4.7.6 Stiffener \& Cross-frames Generation ....................................................................................... 41

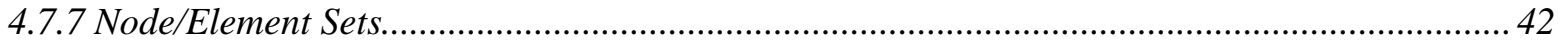

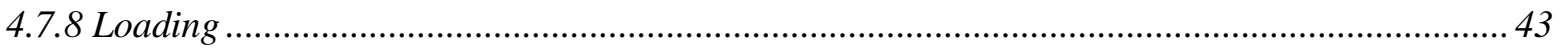

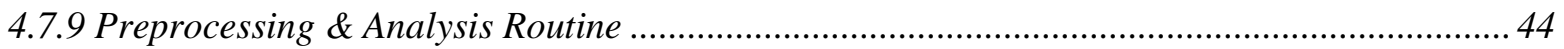

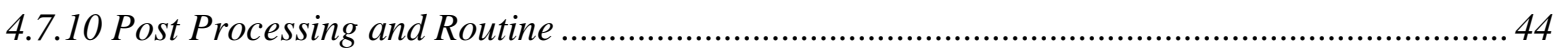

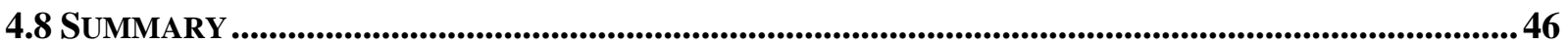

Chapter 5: InVestigation of LAteral Flange Bending in Simple-Span I-Girder

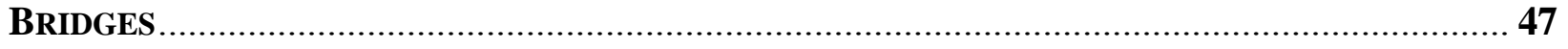

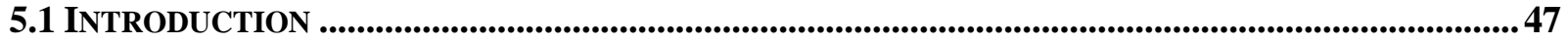

5.2 PARAMETRIC STUDY \#1 (SKEW/UNBRACED LENGTH).................................................................47

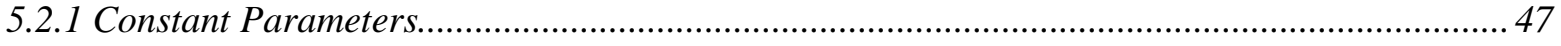

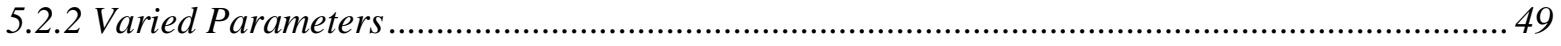




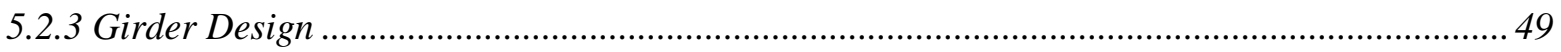

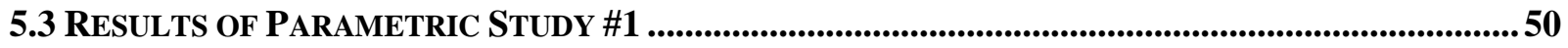

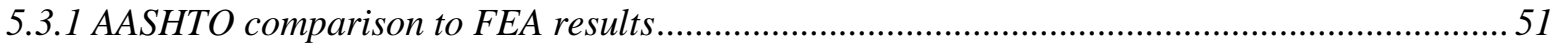

5.3.2 Assessment of Staggered Cross-frames..................................................................................... 52

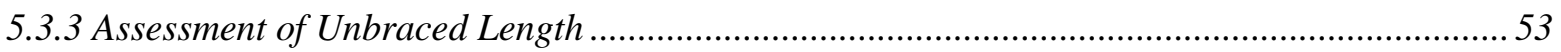

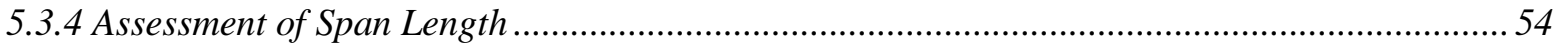

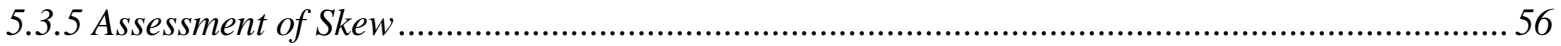

5.4 PARAMETRIC STUDY \#2 (SPAN LENGTH/GIRDER SPACING)...................................................56

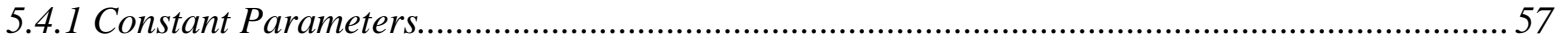

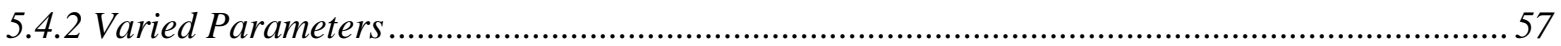

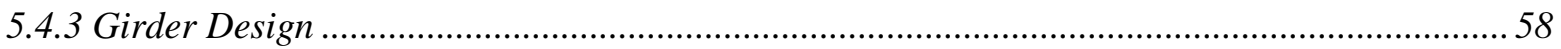

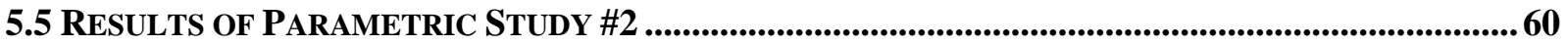

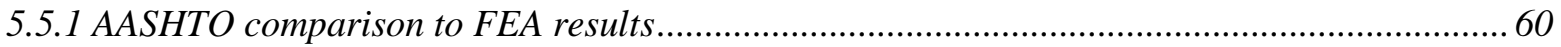

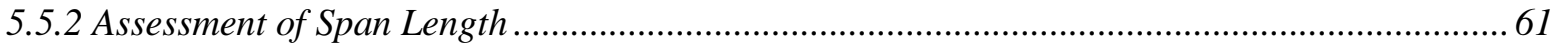

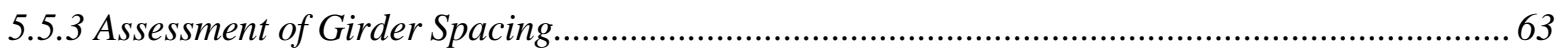

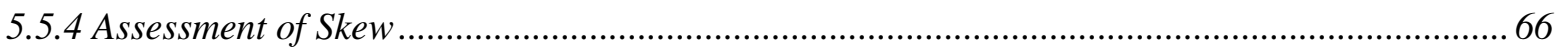

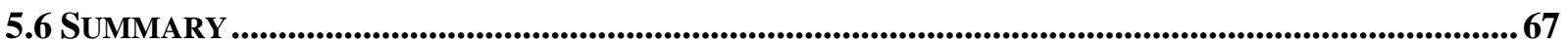

Chapter 6: Development of THE MOdified AASHTO APPROXimAtion for LATERAL

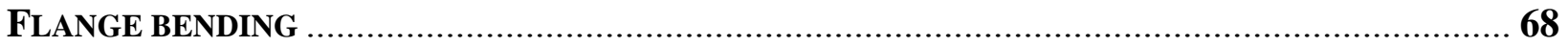

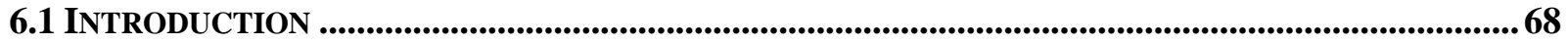

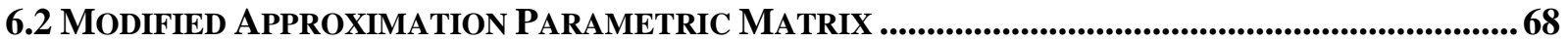

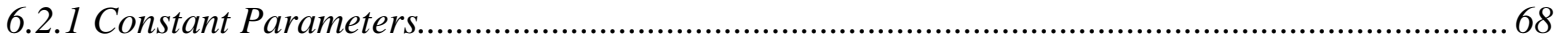

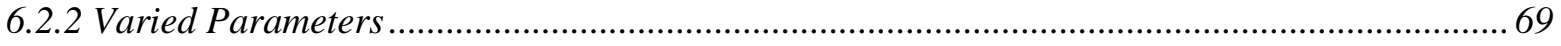

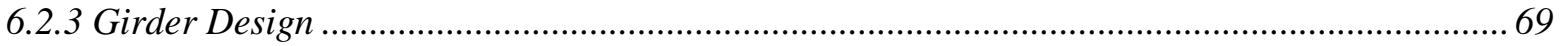

6.3 DEVELOPMENT OF MODIFIEd LFB MOMENT APPROXIMATION ............................................. 70

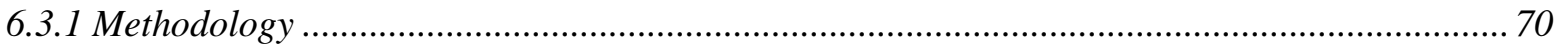

6.3.2 Proposed Modification Factor for Simple-Span Bridges...................................................... 70

6.4 ASSESSMENT OF MODIFICATION FACTOR FOR SIMPLE SPAN BRIDGES ......................................... 72

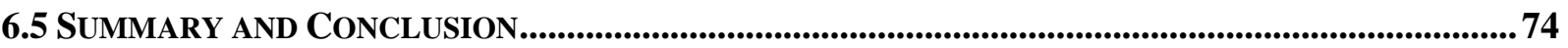

CHAPTER 7: SUMMARY AND CONCLUDING REMARKS......................................................... 75

7.1 PROJECT SUMMARY .................................................................................................................................. 75

7.2 RECOMMENDATIONS FOR FUTURE WORK........................................................................................ 76

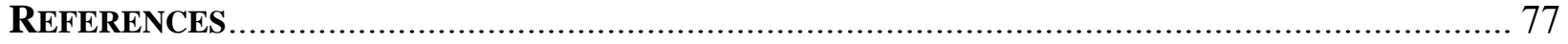

APPENDiX A: LATERAL Flange BENDING In Simple-SPAN I-GIRDER BRIDGES ................... 80 


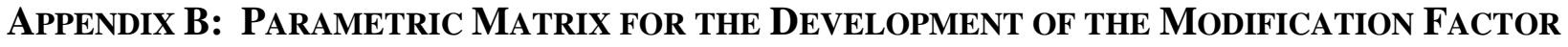
100

B.1 ReSUlts OF PARAMETRIC MATRIX 100

B.2 COMPARISON OF FEA VS. MODIFICATION FACTOR....................................................................... 128

APPENDix C: Algorithm for MODELING Simple SPAN STEEL I-GIRDER BRIDGES .......... 130

C.1 PARAMETRIC Modeling AlgorithM...................................................................................... 130

C.2 PARAmetric Modeling Post-Processing AlgorithM ......................................................163 


\section{LIST OF TABLES}

Table 5.1: Girder Dimensions Parallel Cross-frames.......................................................... 50

Table 5.2: Girder Dimensions Staggered Cross-frames ........................................................ 50

Table 5.3: Girder Dim. For Const. Bottom Flange Thickness (Girder Spacing = 6 ft.)............ 59

Table 5.4: Girder Dim. For Varying Bottom Flange Thickness (Girder Spacing = 6 ft.) .......... 59

Table 5.5: Girder Dim. For Const. Bottom Flange Thickness (Girder Spacing = 10.5 ft.)........ 59

Table 5.6: Girder Dim. For Varying Bottom Flange Thickness (Girder Spacing = 10.5 ft.) ...... 59

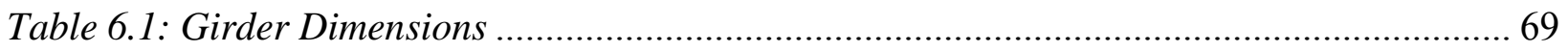




\section{LIST OF FIGURES}

Figure 2.1: General Bending Stresses in an I-Girder Section (Coletti \& Yadlosky, 2005) ........... 6

Figure 2.2: General Shear Stresses in an I-Girder Section (Coletti \& Yadlosky, 2005) .............. 6

Figure 2.3: Maximum Vertical Displacements (Norton et. al., 2003)...................................... 8

Figure 2.4: LFB Stresses vs. Rotations (Morera, 2010)......................................................... 9

Figure 2.5: Brace Orientation for Bridges with Skewed Supports (Wang \& Helwig, 2008) ....... 10

Figure 2.6: Bottom View of SIPs (Guthrie, 2006) ................................................................. 11

Figure 2.7: Deck Forming Brackets on Exterior Girders (Galindez, 2009) ............................ 12

Figure 2.8: Overhang Formwork and Overhang Brackets (Seongyeong et. al., 2010) .............. 13

Figure 2.9: Torsional Effects on Exterior Girders Produced by Overhang Loads ..................... 13

Figure 2.10: Finishing Machine Placing Wet Concrete (Seongyeong et. al., 2010)................... 14

Figure 2.11: Deck Placements Methods (Choo et. al., 2004)................................................ 15

Figure 2.12: Plan View of Bottom Flange: A. (original) B. (equivalent approximation) ............ 18

Figure 2.13: Model to Calculate the Weakest Rigidity of Elastic Spring (Roddis et. al., 2003).. 22

Figure 2.14: Three-span, Elastic, Spring-supported Beam (Roddis et. al., 2003) .................... 22

Figure 2.15: Cross-frames Oriented Perpendicular to the Girders (Coletti \& Yadlosky, 2005). 24

Figure 2.16: Cross-frames Oriented Parallel to the Girders (Coletti \& Yadlosky, 2005)........... 24

Figure 2.17: Leaning Bracing in a Four-girder Bridge (Herman et. al., 2005) ....................... 30

Figure 2.18: Plan View of Leaning Cross-frame Layout for a Four-girder Bridge (Herman et.

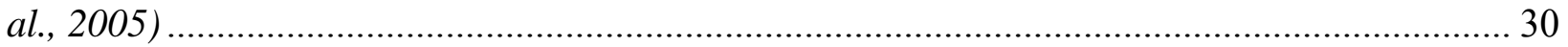

Figure 4.1: Abaqus Screen Capture of Bridge Model .......................................................... 37

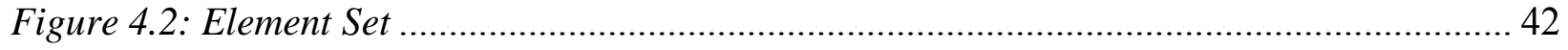

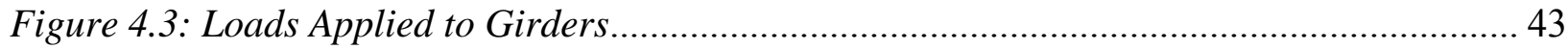

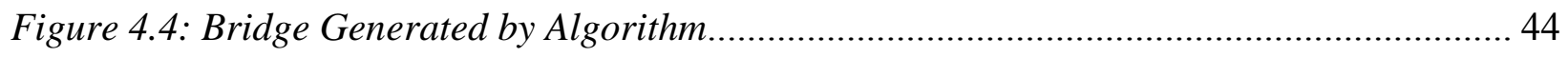

Figure 4.5: Identification of $f_{e}$ and $f_{b u}$ from Total Flange Bending (Galindez, 2009)................ 45

Figure 4.6: Plot of Stresses Generated by Post Processing File ............................................. 46

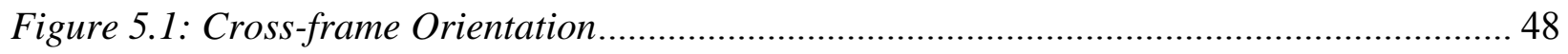

Figure 5.2: Parametric Matrix \# 1 Bridge Cross-section ....................................................... 48

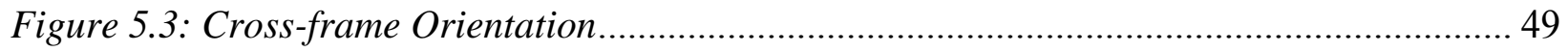

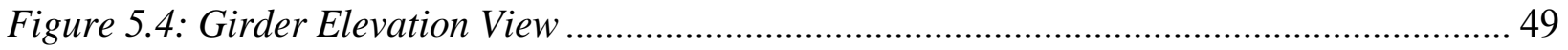


Figure 5.5: Simple Span FEA Results vs. AASHTO Approximation ....................................... 51

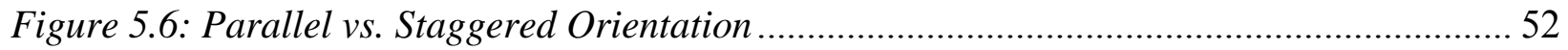

Figure 5.7: Moment Ratio Plot for $L_{b}$ Comparison............................................................ 53

Figure 5.8: FEA $L_{b}$ Comparison Plot ............................................................................. 54

Figure 5.9: Moment Ratio Plot for Span Length Comparison ............................................... 55

Figure 5.10: FEA Span Length Comparison Plot ........................................................... 55

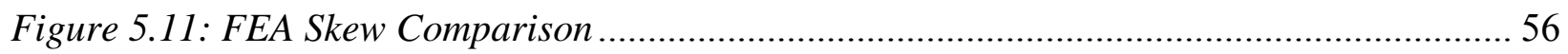

Figure 5.12: Cross-Section with 6 ft. Girder Spacing .......................................................... 57

Figure 5.13: Cross-section with 10.5 ft. Girder Spacing ..................................................... 58

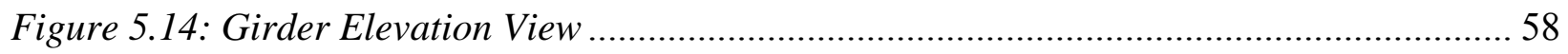

Figure 5.15: Girder with Bottom Flange Transition Elevation View ....................................... 59

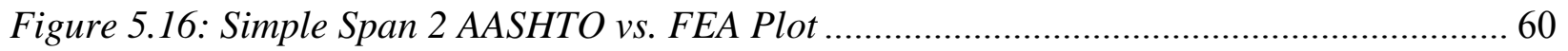

Figure 5.17: Moment Ratio Plot (Girder Spacing=6') .................................................... 61

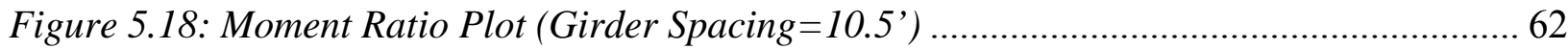

Figure 5.19: FEA Span Length Comparison Plot ................................................................. 63

Figure 5.20: Moment Ratio Plot Span Length/Girder Spacing Comparison ............................ 64

Figure 5.21: Moment Ratio Plot Span Length/Girder Spacing Comparison \#2 ........................ 64

Figure 5.22: Girder Spacing Comparison for Span Length $=60 \mathrm{ft}$. ...................................... 65

Figure 5.23: Girder Spacing Comparison for Span Length=120 ft. ..................................... 66

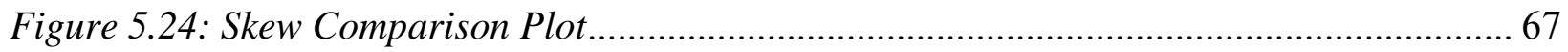

Figure 6.1: Comparison of FEA Results vs. Modification Factor ......................................... 71

Figure 6.2: Comparison of FEA Results vs. Modification Factor........................................ 72

Figure 6.3: Parallel Cross-frame Results with Modification Factor Comparison .................... 73

Figure 6.4: Staggered Cross-frame Results with Modification Factor Comparison .................. 73 


\section{NOMENCLATURE}

$A_{s}=\quad$ cross-section area of the flange

$C_{b}=$ moment gradient modifier

$C_{b b}=C_{b}$ corresponding to the fully braced beam

$C_{b u}=C_{b}$ corresponding for the unbraced beam

$C_{m}=$ coefficient accounting for nonuniform moment

$C_{t}=$ top flange loading factor

$D=$ girder depth

$D_{c}=$ depth of the web in compression in the elastic range

$E=$ modulus of elasticity of steel

$F_{c r}=$ critical buckling stress of the flange

$F_{c r w}=$ nominal web bend-buckling resistance

$F_{e}=$ Euler buckling stress of the flange in the plane of bending

$F_{\ell}=\quad$ statically equivalent uniformly distributed lateral force due to the factored loads from concrete deck overhang brackets

$F_{n c}=$ nominal flexural resistance of a compression flange

$F_{y}=\quad$ specified minimum yield strength of steel

$F_{y c}=$ specified minimum yield strength of a compression flange

$F_{y f}=$ specified minimum yield strength of a flange

$F_{y t}=$ specified minimum yield strength of a tension flange

$I_{y}=$ moment of inertia of the beam about the vertical axis in the plane of the web

$I_{y c}=$ moment of inertia of the compression flange of a steel section about the vertical axis in the plane of the web

$J=\quad$ St. Venant torsional constant

$L=$ span length

$L_{b}=$ unbraced length

$L_{p}=$ limiting unbraced length to achieve the nominal flexural resistance $M_{p}$ under uniform ending

$L_{r}=$ limiting unbraced length to achieve the onset of nominal yielding in either flange under uniform bending with consideration of compression-flange residual stress effects 


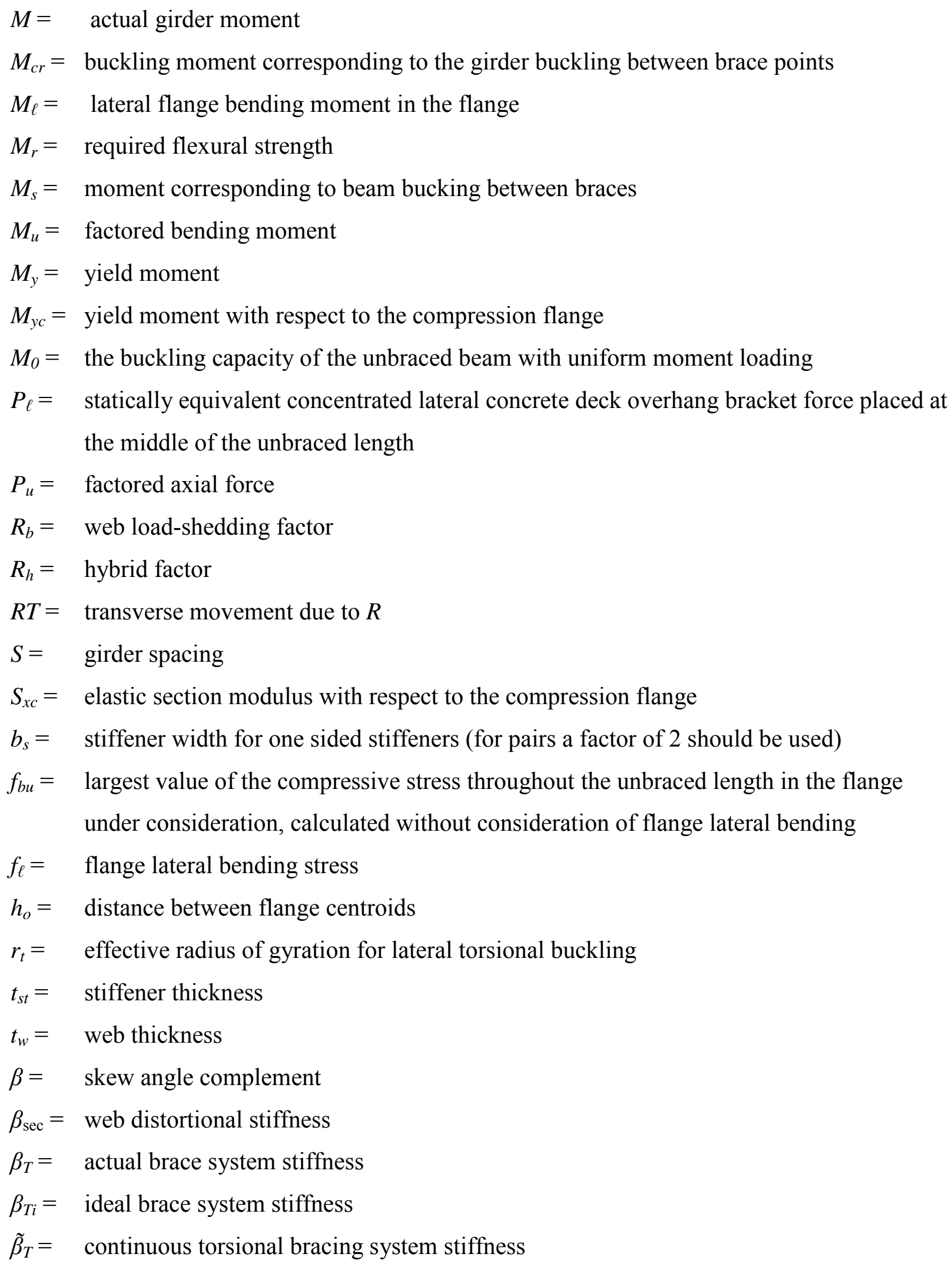




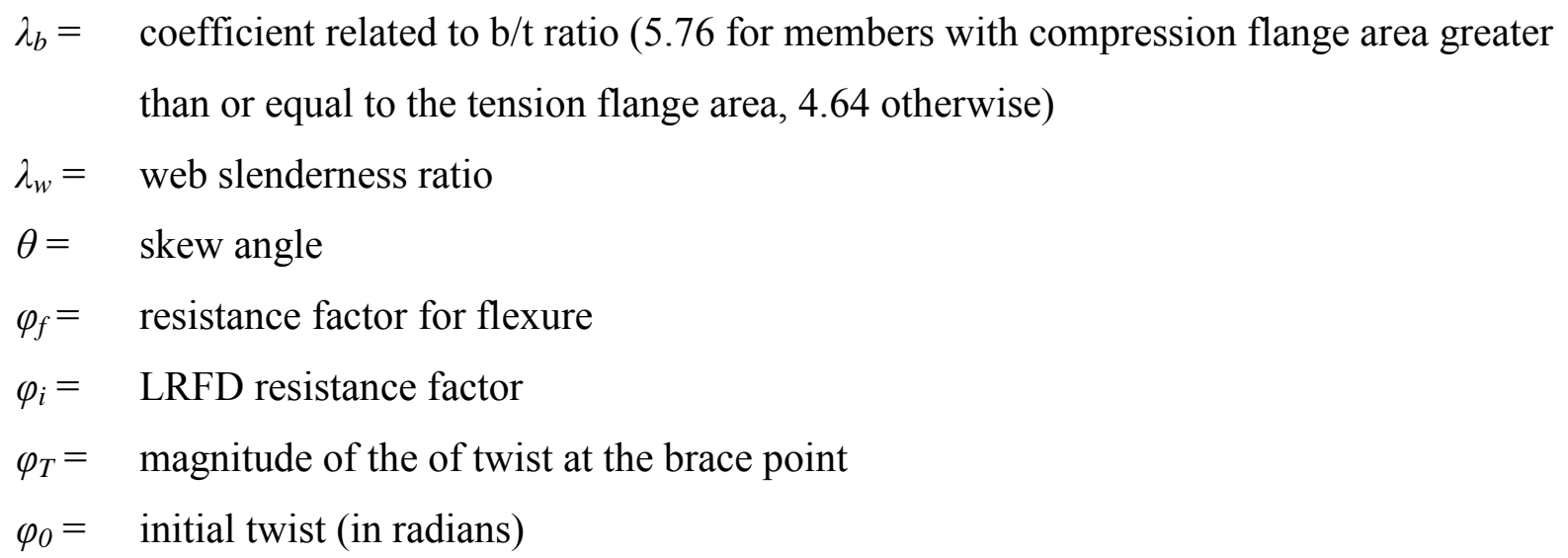




\section{CHAPTER 1: INTRODUCTION}

\subsection{BACKGROUND / OVERVIEW}

The use of skewed bridges is becoming more necessary with the number of urban or geographical restraints that require unique abutment and pier orientations. This presents a problem because increasing skew in a bridges structure increases the bridges complexity as well, thus making the design and construction of the bridge more difficult.

One of the major concerns of skewed bridges is the phenomenon of lateral flange bending (LFB). LFB is the torsional effect in flanges of an I-Section that results from warping stresses that are carried in the form of bending stresses as warping is the primary means to resist torsion in an I-Section since the Venant Torsional Stiffness for an open cross-section is low.

The ability to effectively predict LFB in a skewed bridge becomes more complicated as the skew of a bridge increases. The current AASHTO LRFD Specifications list fixed end moment equations for the determination of LFB moments based on the unbraced length and the torsional loads from overhangs.

It's a common practice to ignore skew effects in the structural behavior of skewed bridges; therefore there are a limited amount of studies addressing the effects of skew. Of the limited studies there have been results that found factors that affect deflections and rotations in a bridge as a result of skew. There has been a lack of research of the AASHTO approximation on LFB moments in terms of skew. Therefore, there is a need to assess these approximations in skewed bridges and if needed determine a more accurate approximation for these cases. 


\subsection{Project Scope \& OBJectives}

The focus of this project was to develop a modification to the AASHTO approximation for LFB moments for steel I-girder bridges in order to make a more accurate approximation for LFB. Specifically, this was accomplished in this manner.

- A literature review is presented that focuses on lateral flange bending, the causes and parameters that are known to have a significant effect. A series of research projects on lateral flange bending are presented as well.

- A description of the finite element modeling technique is presented along with a description of an algorithm developed to model simple span bridges.

- A pair of parametric matrices for simple span bridges was developed in an attempt to identify key parameters that have a direct effect on lateral flange bending. These bridges were modeled and analyzed (with the aforementioned modeling technique) using a commercial finite element software package (Dassault Systèmes, 2009).

- The key parameters from results of the simple span bridges were used to develop a larger simple span parametric matrix. The results from this matrix were used to develop a modification to the AASHTO approximation for lateral flange bending. The modified equation was developed with a commercial data correlation software tool (Oaskdale Engineering, 2008). 


\subsection{THESIS ORgANIZATION}

A brief overview of the organization of this thesis is as follows:

- Chapter 2:

o This chapter summarizes previous LFB research, highlighting various affecting parameters, limit states, methods used by various researchers for assessing deflection and rotation, and previous investigations, on several types of bridge configurations.

- Chapter 3:

o This chapter outlines the remaining chapters in detail giving the reader more of an insight into Chapters 4 through 6.

- Chapter 4:

o This chapter describes the finite element modeling techniques used as well as the algorithm developed for modeling bridges.

- Chapter 5:

o This chapter describes the parametric matrices of the simple span bridges assessed and gives a discussion the obtained results from the finite element analysis.

- Chapter 6:

o This chapter describes the formation of the modified lateral flange bending approximation and provides discussion on its application to bridges in comparison to the currents approximations.

- Chapter 7:

o This chapter provides a summary of the work conducted for this study and highlights the key findings. In addition this chapter provides suggestions for future efforts in this subject. 
In addition to these chapters, the following appendices are included:

- Appendix A:

o This appendix summarizes the results of both parametric matrices discussed in Chapter 5.

- Appendix B

o This appendix summarizes the results of the parametric matrix discussed in Chapter 6 and provides tables for the comparison of the modified approximation against FEA results.

- Appendix C

o This appendix provides the algorithm developed for modeling short span steel Igirder bridges along with the developed post-processing file. 


\section{CHAPTER 2: LITERATURE REVIEW}

\subsection{INTRODUCTION}

The purpose of this chapter is to discuss previous research efforts related to evaluating lateral flange bending and forces on cross-frame members in straight and skewed steel I-girder bridges due to construction loading and skew effects. A better understanding of lateral flange bending (LFB) in straight and skewed steel I-girder bridges can produce bridge designs that are more efficient and cost effective. In addition, this chapter presents current AASHTO LRFD specifications for LFB and constructibility of steel I-girder bridges along with a comprehensive overview of previous studies focused on the concepts of lateral flange bending and cross-frame forces.

\subsection{LATERAL FLANGE BENDING IN STEEL I-GIRDER BRIDGES}

\subsubsection{Fundamentals of Lateral Flange Bending}

General cross-sections resist torsion in the form of pure torsion and restrained warping (Seaburg \& Carter, 1997). Pure torsion resistance is obtained by means of shear stresses. If warping is restrained, additional shear and normal stresses are incorporated to the original state of stresses. Warping becomes the primary mean to resist torsion in I-shaped girders since the St. Venant torsional stiffness for open cross sections is low. Therefore, the additional torsional effects are added to the initial axial and bending stresses produced by the gravity loads, as shown in Figure $2.1 \& 2.2$. The warping normal stresses are basically carried by the girder flanges in the form of bending stresses and represent one of the factors introducing a phenomenon known as lateral flange bending (LFB). The overhang load in exterior girders is an example of a structural configuration where the LFB is caused by torsional effects. Another source of LFB is given in skewed bridges, where the cross-frames induce additional lateral forces in the girders flanges. 

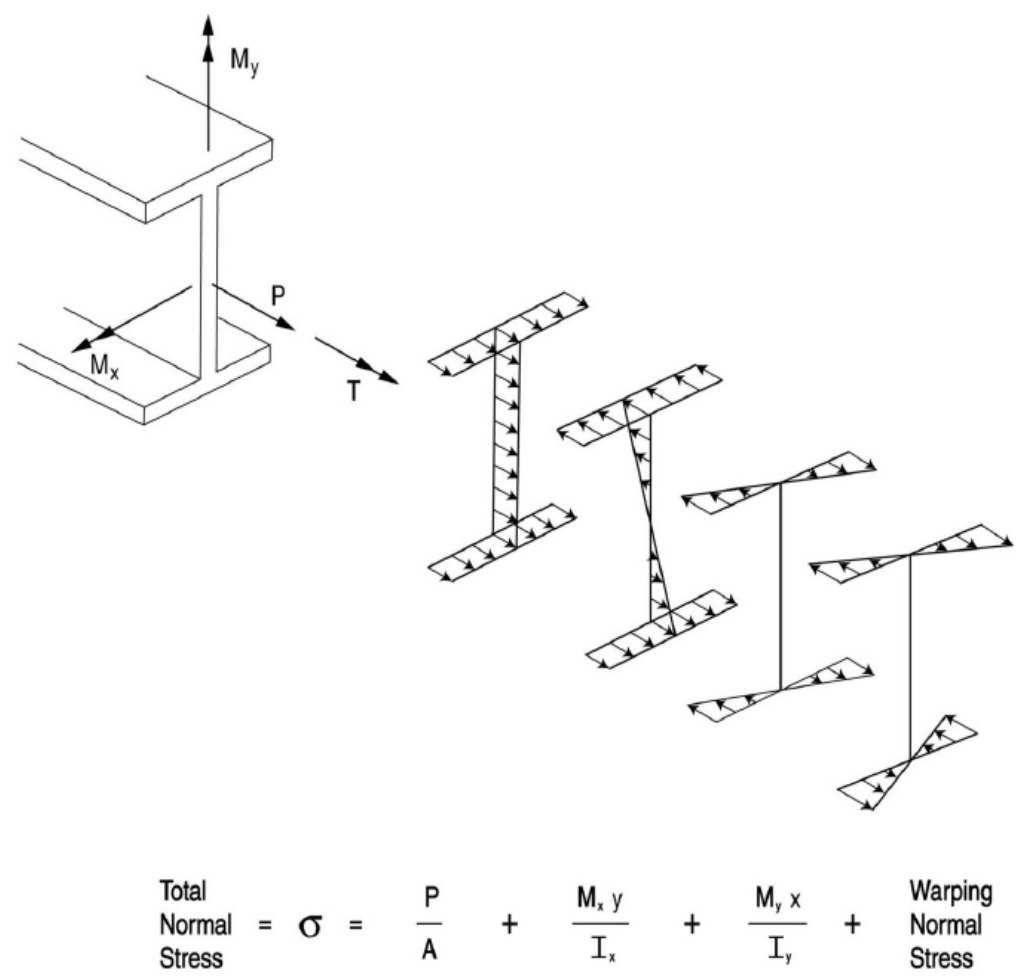

Figure 2.1: General Bending Stresses in an I-Girder Section (Coletti \& Yadlosky, 2005)
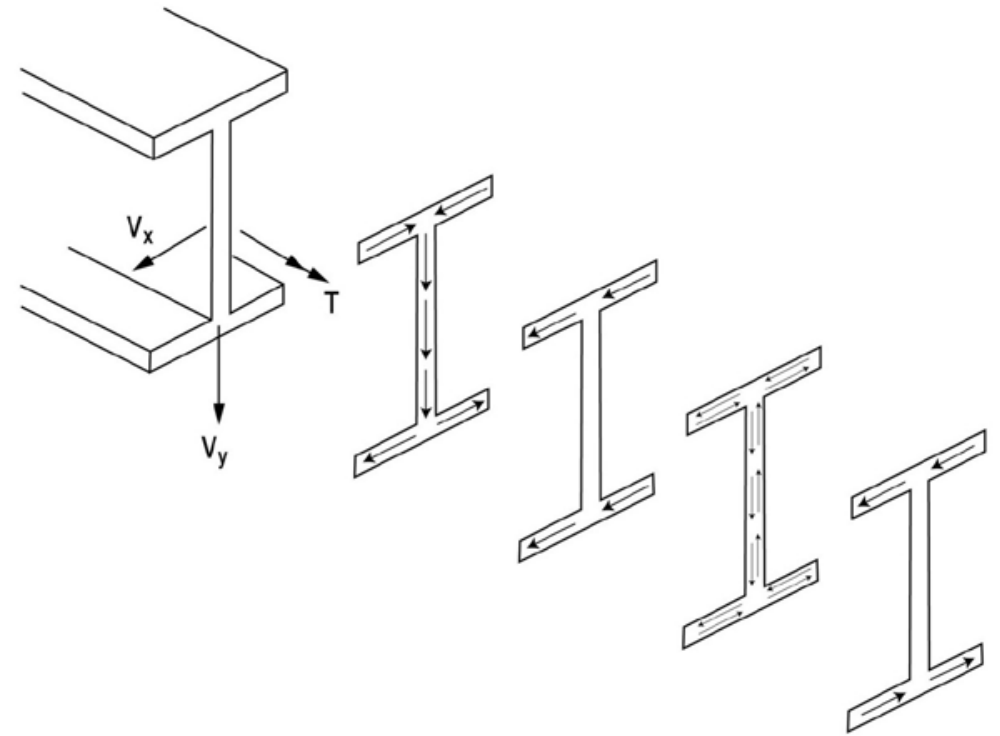

$$
\begin{aligned}
& \text { Total } \\
& \text { Shear } \\
& \text { Stress }
\end{aligned}=\tau=\frac{V_{y} Q_{x}}{I_{x} t}+\frac{V_{x} Q_{y}}{I_{y} t}+\begin{aligned}
& \text { St. Venant } \\
& \text { Torsion }
\end{aligned}+\begin{aligned}
& \text { Warping } \\
& \text { Torsion }
\end{aligned}
$$

Figure 2.2: General Shear Stresses in an I-Girder Section (Coletti \& Yadlosky, 2005) 


\subsubsection{Lateral Flange Bending Studies}

There are a limited number of studies addressing the effects of skew on steel I-girder bridges. This is because it is a common practice to ignore the skew effects in the structural behavior of skewed bridges. Bakht (1988) did a review on the analysis of skewed bridges as straight bridges. The author proposed the simplified method for analyzing bridges as equivalent right bridges as long as they meet the requirement expressed in Equation 2-1.

$$
S \tan \left(\frac{\phi}{L}\right) \leq 0.05
$$

Equation 2-1

Norton et. al. (2003) investigated the response of a 244-foot simple-span skewed I-girder bridge in central Pennsylvania during deck placement. Concrete placement began the east abutment and proceeded across the structure with the screeds oriented perpendicular to the center line of the bridge. Strain transducers manufactured by Bridge Diagnostics, Inc. (BDI), and linear variable differential transformers (LVDTs) were used to measure the lateral displacements and stresses, respectively. Two models were developed; a two-dimensional grillage model developed with STAAD/Pro and a three-dimensional finite element model developed with SAP2000 for prediction of the skewed bridge during construction. The SAP2000 model was used to examine the effect of placing the screed parallel to the skew (Case B) and perpendicular to the centerline of the bridge (Case A). Loads were placed in 4 stages; stage one being the self weight of the steel, stage two was the load of the screed and wet concrete on a quarter of the span. Stage three included these loads on one half of the span and lastly stage four applied the same loads on three quarters of the span. It was concluded that higher support reactions and higher displacements occurred when the screed was oriented perpendicular to centerline of the roadway. Figure 2.3 shows the maximum vertical displacements for girders one through seven. 


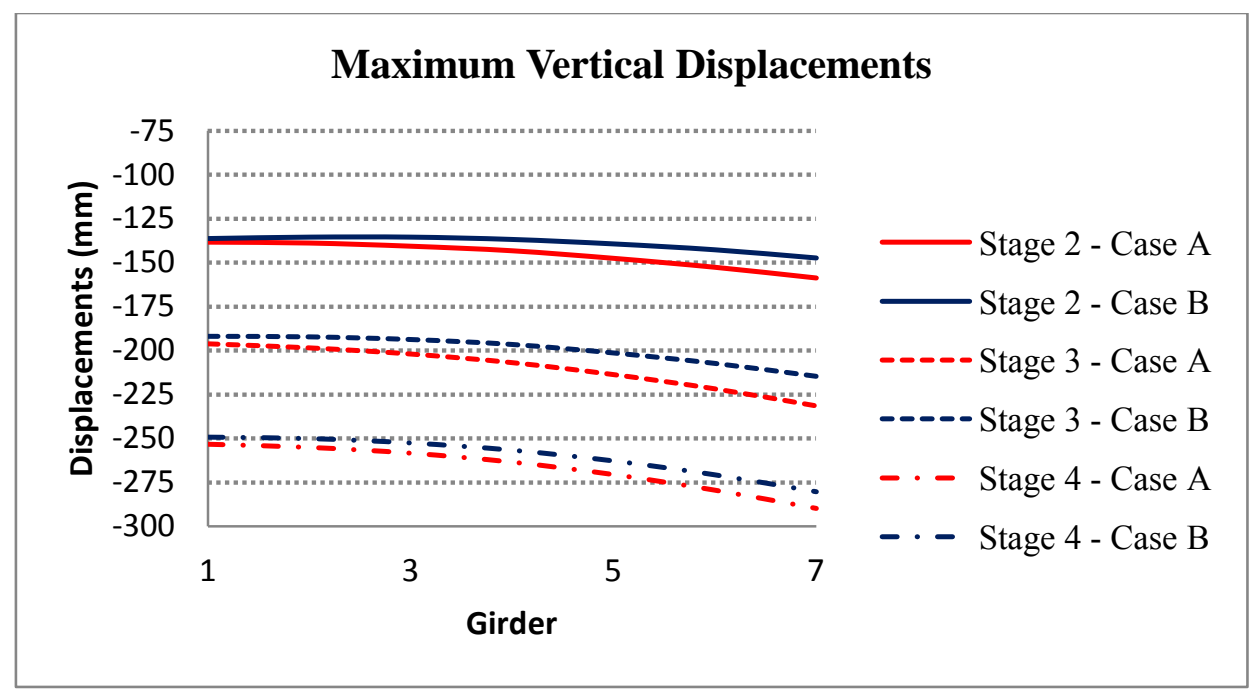

Figure 2.3: Maximum Vertical Displacements (Norton et. al., 2003)

Choo et. al., (2004) performed a study on a continuous-span skewed bridge in Ohio. Concrete placement began at the south abutment and proceeded across the structure with the screed oriented perpendicular to the centerline of the bridge. Strain transducers were used to obtain strain data during the pour and converted to stresses. A three-dimensional finite element model of the bridge was developed using SAP2000. The model was evaluated with the screed placed parallel to the skew and perpendicular to the centerline of the bridge. The author found that placing the concrete parallel to the skew shows less significant reductions in deflections and stresses in a bridge with continuous support conditions than simply supported.

Morera (2010) completed a dissertation on the study of two different skewed I-girder bridges: a 133-foot simple-span bridge (Chicken Road Bridge) and a 73.5-foot simple-span bridge (Roaring Fork Bridge), both of which are located in North Carolina. Models were developed for both bridges using ANSYS v11.0 in an effort to identify the key components that allow characterization of torsional rotation, lateral displacements, and the LFB stress profile. The author concluded that the skew angle was a determinant parameter on the LFB behavior. Also, the displacements resulting from LFB were negligible when compared to torsional rotations; however, both LFB and rotations profiles showed the same trends. Figure 2.4 illustrates profiles between LFB and rotations for the left and right side of the bottom flange. 


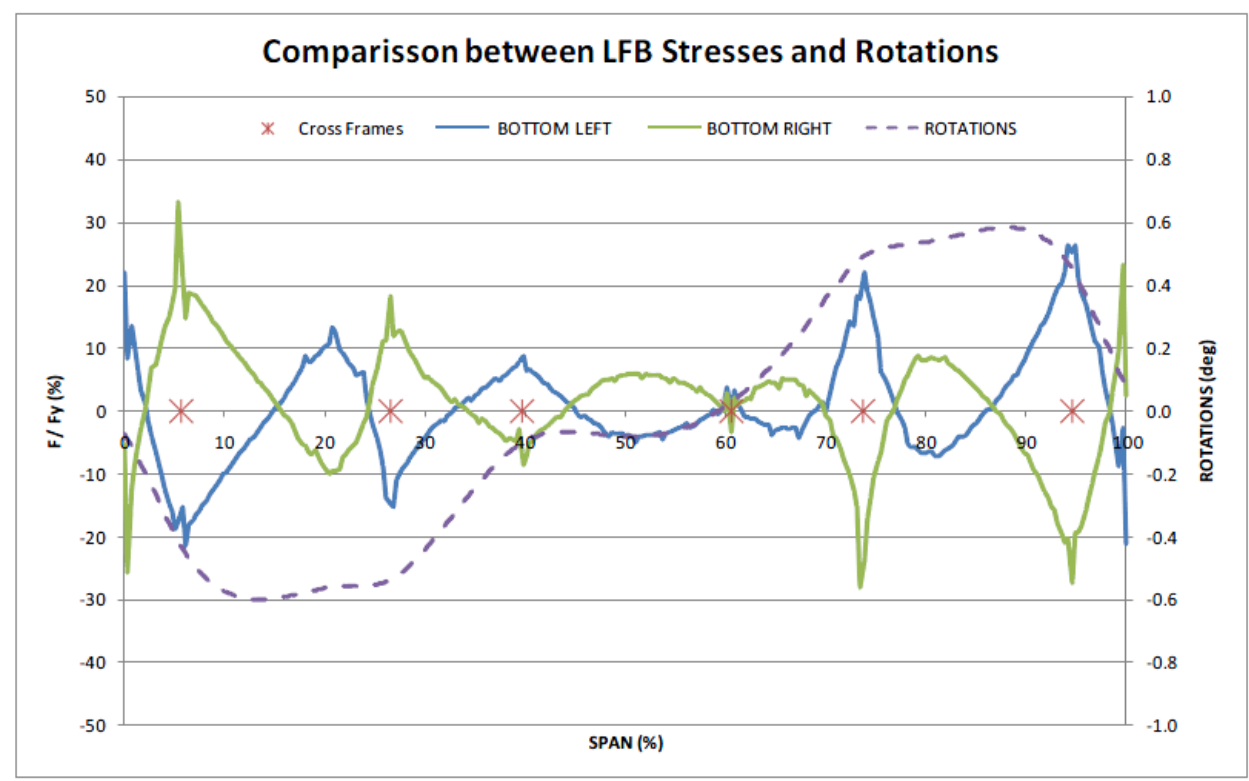

Figure 2.4: LFB Stresses vs. Rotations (Morera, 2010)

\subsubsection{LFB Effects on Bridge Design and Fabrication}

The use of skew in bridges is becoming increasingly more popular, with the number of urban or geographical restraints that require unique abutment and pier orientations, increasing with the growth of infrastructure. The increasing transportation needs in highly populated areas require more complicated interchanges along with the use of skewed or even curved bridges. However, the use of skew complicates the design and performance of the bridge. If the skew angle is less than $20^{\circ}$, AASHTO (2010) permits the cross-frames to be orientated parallel to the skew. However for angles of skew greater than $20^{\circ}$, AASHTO states that cross-frames orientations are to be perpendicular to longitudinal axis of the girder due to limited space in the angle between cross-frame and girder for connections. The two cross-frame orientations can be seen below in Figure 2.5. 


\section{A}

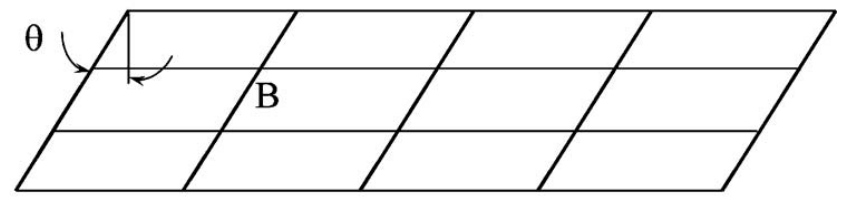

a) For $\theta<20$ degrees

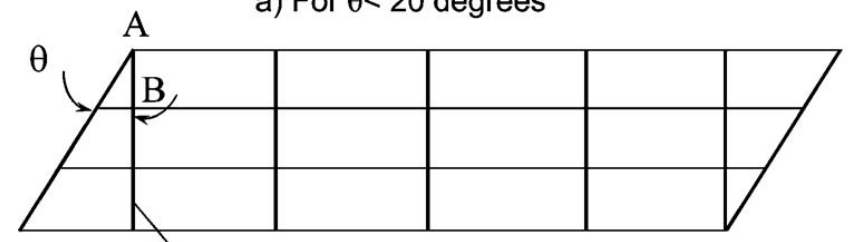

b) For $\theta>20$ degrees

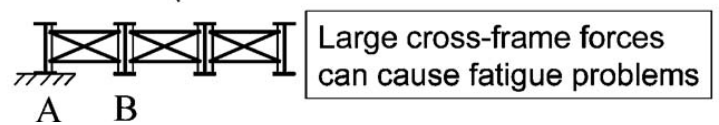

Figure 2.5: Brace Orientation for Bridges with Skewed Supports (Wang \& Helwig, 2008)

Girder deflections associated with LFB can also complicate the cross-frame design. As mentioned before, bridges with skew greater $20^{\circ}$ require cross-frames to be perpendicular to centerline of the bridge making cross-frames connect to girders at two different points longitudinally along the span of the girder. These points have different deflections causing design issues that will be discussed later in this chapter. Skew also has significant affects on the stresses that occur in a bridge's structure. Skew greatly complicates the behavior of steel I-girder bridges by introducing alternate load paths and greater interaction between the main girders and secondary framing members. In many cases, the severity of these complications in the behavior of the structure are minor and reasonably negligible, but in cases with large skews, they are more pronounced and can lead to significant issues with fit-up, plumbness and distortion-induced loading, including adverse fatigue performance (Coletti et. al., 2011).

\subsection{Construction LoAding AND Deck Placement in STEel I-GiRder BRIDgeS}

Structural stability is one of the most relevant aspects that engineers have to address when designing steel structures. In the case of I-girder bridges, the stability of each individual girder between braced points and the stability of the entire system are the primary concerns. These two limit states are of particular interest during the construction of the bridge, when the 
steel framing has to resist the combination of its own weight, the weight of the wet concrete, and other construction loads (Sanchez, 2011). Construction loads consist of the materials and components required to place the materials during construction. These loads that have major affects on LFB occur during the deck placement phase of the bridge construction. Stay in place metal forms (SIPs), overhang brackets/walkway, finishing machine, and wet concrete are all loads that occur in the deck placement that contribute to the affects of LFB in steel I-girder bridges.

\subsubsection{Stay-in-Place (SIP) Metal Forms}

Various types of formwork are used for construction of concrete bridge decks. Thin, corrugated sheets of galvanized steel or SIPs are one of the most commonly used types of formwork. SIPs provide a base for the bridge deck to be placed. Angles welded to the top flange of the girders hold the SIPs in place at a set depth for deflections. SIPs have become popular due to being cost effective because they are prefabricated and save on labor cost. They also provide a working surface and reduce safety hazards by not requiring the removal of formwork after bridge deck has been placed (Grace, 2004).

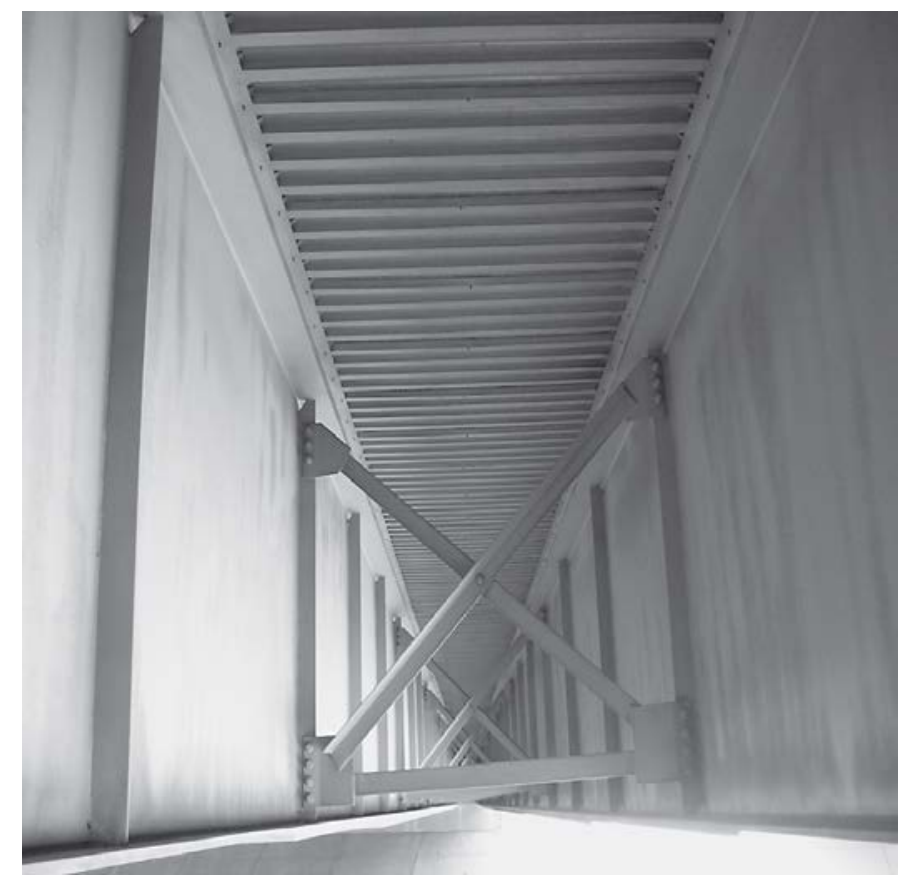

Figure 2.6: Bottom View of SIPs (Guthrie, 2006) 


\subsubsection{Overhang Loads}

Exterior girders are most affected during deck placement by overhang bracket loads. These loads are applied to the exterior girders by deck forming brackets placed every three to four feet, as shown in Figure 2.7. These brackets are the source of support for the plywood formwork of the overhang. This formwork includes space for the overhang of the bridge and work platform for construction workers. The overhang loads include the weight of the concrete over the deck overhang length, the overhang forms, the concrete finishing machine along with its corresponding railing accessories, and a live load component representing the construction workers.

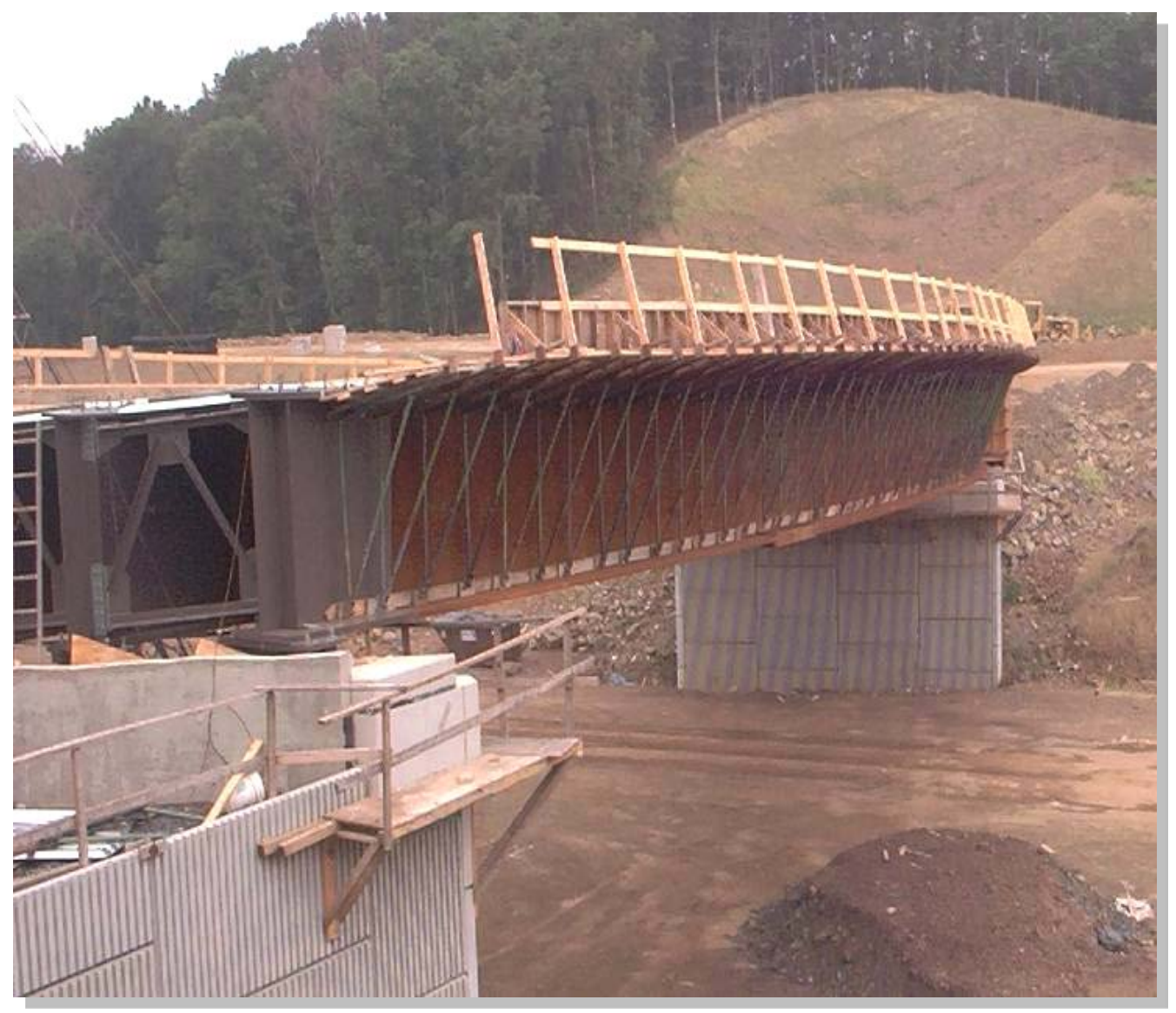

Figure 2.7: Deck Forming Brackets on Exterior Girders (Galindez, 2009) 


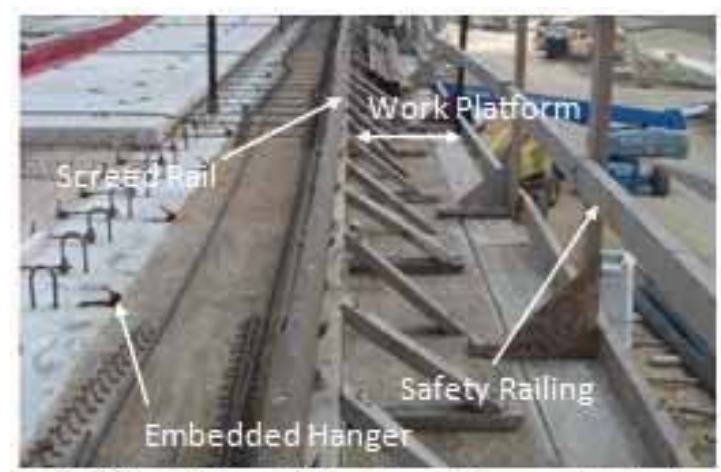

(a) Top View of Overhang Formwork System

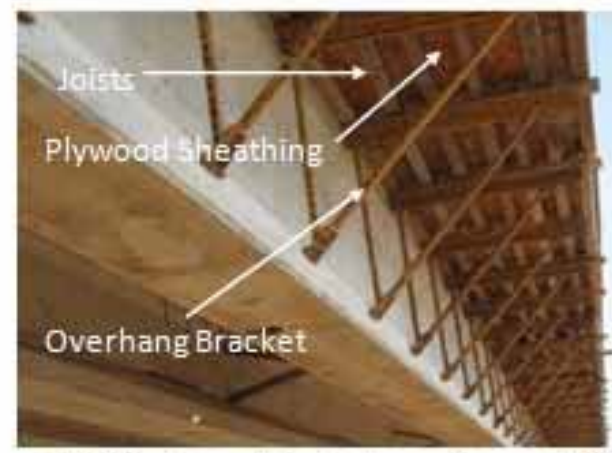

(b) Overhang Brackets on Concrete Girder

Figure 2.8: Overhang Formwork and Overhang Brackets (Seongyeong et. al., 2010)

The overhang loads have a relatively large eccentricity with respect to the exterior girder compared to the construction loads previously mentioned, producing a net torque on the exterior girder. For steel girder bridges, the torque from the overhang can lead to both global and local stability issues. (Seongyeong et. al., 2010). An approximation for these torsional loads can be seen visually in Figure 2.9, where "R" represents the resultant of the uniformly distributed deck load on the overhang.

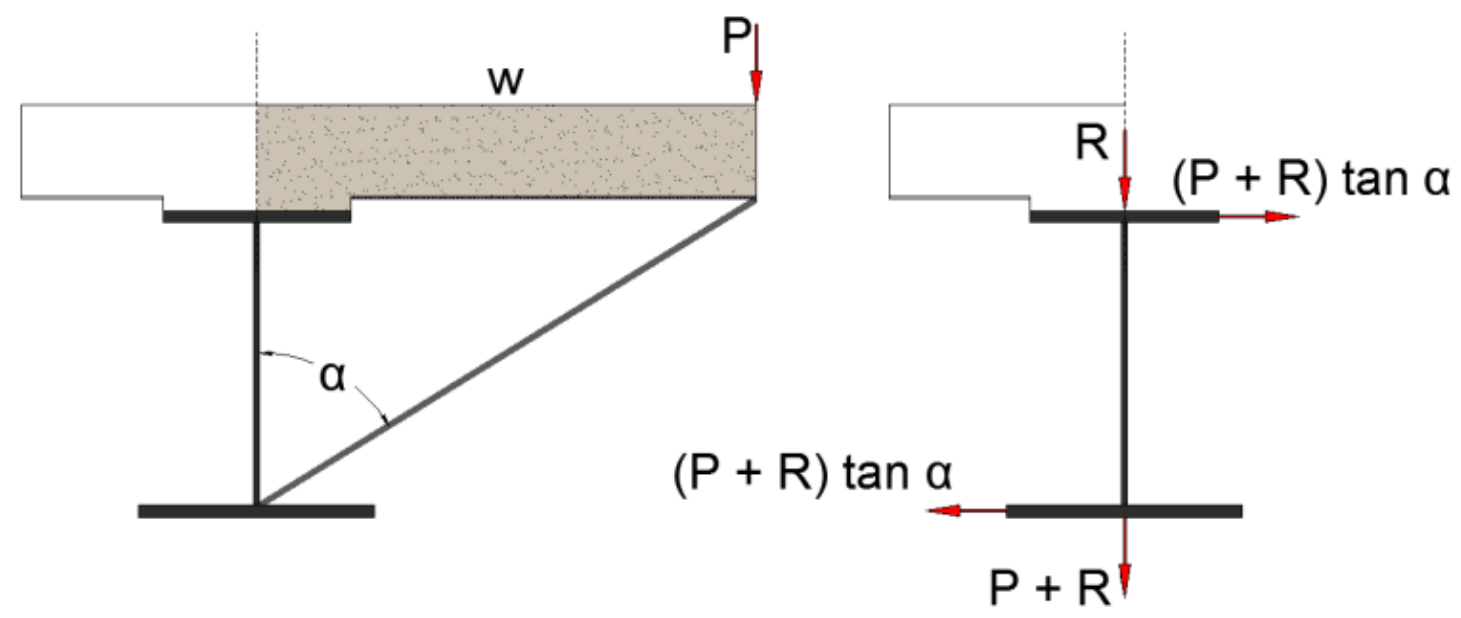

Figure 2.9: Torsional Effects on Exterior Girders Produced by Overhang Loads 


\subsubsection{Concrete Finishing Machine / Wet Concrete}

The finishing machine and the wet concrete are the two most significant loads for overhangs. The finishing machine sits on screed rails on supports that rest on the overhang brackets. Concrete is pumped evenly onto the bridge deck and vibrated to eliminate voids. The finishing machine proceeds across the bridge deck, screeding and finishing the wet concrete. The figure below shows a finishing machine in operation. The orientation of finishing machine and how the concrete is placed to the bridge deck affects how loads are distributed to the I-girders and the magnitude of LFB.

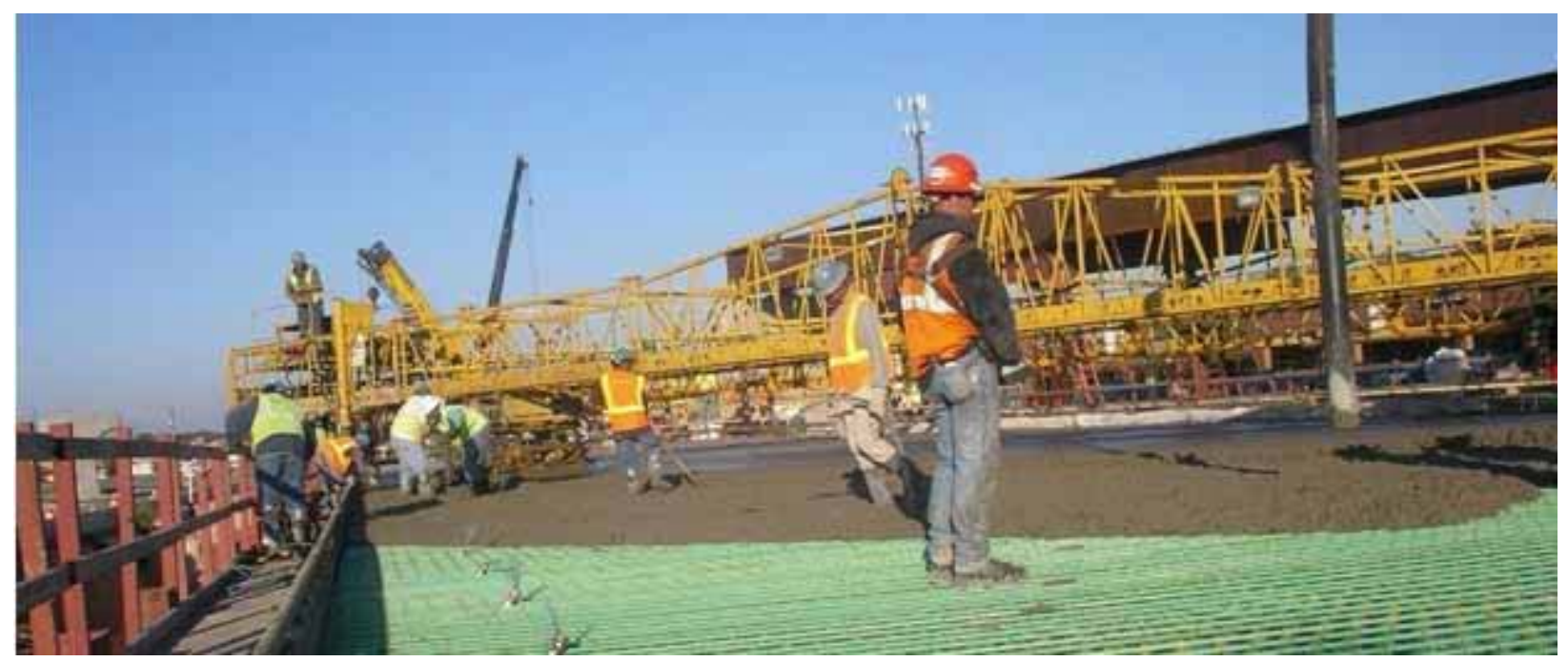

Figure 2.10: Finishing Machine Placing Wet Concrete (Seongyeong et. al., 2010)

As mentioned before, the center-of-gravity of the wet concrete on the overhang has an eccentricity with respect to the center of the exterior girder, causing a torsion moment on the fascia girder. In addition, the screed rail is usually located at the edge of the deck, resulting in another source for torsional moment (Seongyeong et. al., 2010). In bridges without skews, this torsion is uniform as both exterior girders are loaded simultaneously and is a direct result of the overhang loads. However, in skewed bridges, the orientation of the finishing machine will affect the LFB on the exterior girders. Torsional moments developed in steel bridges with large skews are difficult to predict during construction, as the alignment of the screed can result in an even distribution of the wet concrete dead loads across the superstructure that increase the skew 
effects (Choo et. al., 2004). Figure 2.11 shows the two different finishing machine orientations. Concrete placed perpendicular to the centerline of the bridge will result in an uneven distribution of dead loads across the superstructure in skewed bridges. The weight of the wet concrete placed by the screed near the acute corner will cause girders near this corner to deflect more than girders near the obtuse corner. Differential deflections that result under this dead load can cause gross rotation of the bridge cross section (Norton et. al., 2003).

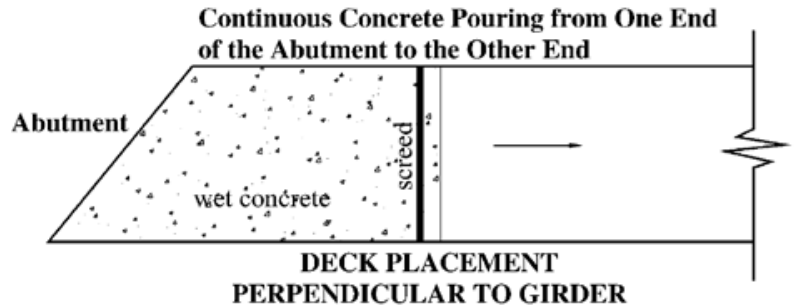

Figure 2.11: Deck Placements Methods (Choo et. al., 2004)

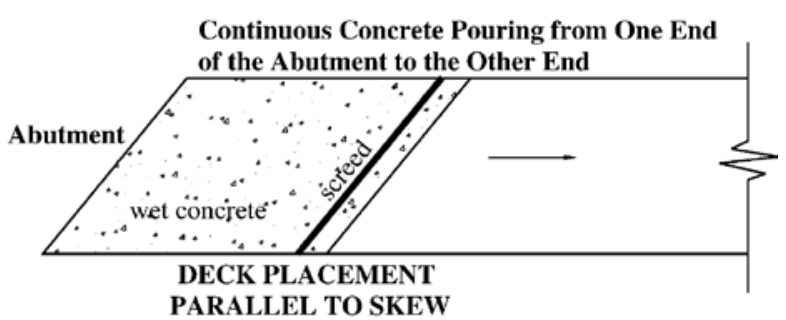

PARALLEL TO SKEW

\subsection{SPECIFICATIONS RELATED TO LFB IN STEEL I-GIRDER BRIDGES}

\subsubsection{AASHTO Approximations for LFB.}

AASHTO (2010) provisions require considering the torsional effects due to construction loads on the strength and the stability of girders and cross-frames. The approximate equations used to compute the lateral flange moments due to eccentric loads applied on the overhang deck are as follows. These equations are based on the assumption that the interior unbraced lengths are torsionally fixed.

$$
\begin{aligned}
& M_{\ell}=\frac{F_{\ell} L_{b}^{2}}{12} \\
& M_{\ell}=\frac{P_{\ell} L_{b}}{8}
\end{aligned}
$$

AASHTO does not include an equation to approximate the effects of skew on LFB. However, the code provisions recommend using $10 \mathrm{ksi}$ as a conservative estimation of the total 
unfactored LFB in bridges with discontinuous cross-frame lines and skew angles exceeding $20^{\circ}$ in lieu of a refined analysis. The total unfactored LFB is distributed between the load types in the same proportion as the unfactored major-axis stresses.

\subsubsection{AASHTO Flexural Limit States for Constructibility}

After the sources of LFB during the deck-placement sequence are identified, the combined effect of the resulting LFB stresses and the major-axis bending, stresses, $f_{\ell}$ and $f_{b u}$, are evaluated using the flexural limit states for constructibility. These limit states are classified according to the state of stress at the flange and its bracing condition.

During some phases of the deck placement, the girders are required to resist loads in a noncomposite state. Moreover, the most critical condition is exhibited by the top flanges of the positive bending regions which are laterally supported by the cross-frames. In addition, compression flanges in positive bending regions are usually smaller than the tension flanges since they are designed to act as composite sections for service loads (i.e. the compression flanges are continuously braced by the deck).

The bottom flanges in negative bending regions are also compression flanges, discretely braced by the cross-frames. In this case, this condition exists during the construction phase and the service life of the bridge. As a result, typically larger flange sizes are used.

\subsubsection{Discretely Braced Flanges in Compression}

The limit states that govern the behavior of discretely braced flanges in compression are yielding, ultimate strength and web-bend buckling:

- Compression Flange Yielding: This limit state shall not be checked for sections with slender webs and $f_{\ell}=0$.

$$
f_{b u}+f_{\ell} \leq \phi_{f} R_{h} F_{y c}
$$


- Compression Flange Capacity: This limit state considers lateral torsional buckling (LTB) and flange local buckling (FLB) limit states.

$$
f_{b u}+\frac{1}{3} f_{\ell} \leq \phi_{f} F_{n c}
$$

- Web Bend-Buckling: This limit state shall not be checked for sections with compact or noncompact webs.

$$
f_{b u} \leq \phi_{f} F_{c r w}
$$

\subsubsection{Discretely Braced Flanges in Tension}

During construction, the bottom flanges in positive bending regions and the top flanges in the negative bending regions are examples of tension flanges which are discretely braced by the cross-frames. In the positive bending regions, this bracing condition remains during the service life of the bridge, but it changes in the negative bending regions when the girder starts to act as a composite section. The only limit state that governs in tension flanges is the yielding limit state since stability is not an issue.

$$
f_{b u}+f_{\ell} \leq \phi_{f} R_{h} F_{y t}
$$

\subsubsection{Continuously Braced Flanges}

During certain stages of deck casting, the top flange may be continuously braced by the concrete deck. In this case, continuously braced flanges must meet the following limit state for critical stages of construction.

$$
f_{b u}+f_{\ell} \leq F_{y}
$$

Equation 2-8 


\subsubsection{AISC Provisions for LFB}

In 1991, a design guide was published by AISC, detailing procedures for the design of steel I-girders for deck overhangs loads (Grubb, 1991). This design guide contains a procedure much like that in AASHTO, where it is assumed that cross-frames act as torsionally rigid supports that prevent out of plane warping. Therefore, the flanges of the exterior girders that resist the torsion imposed by overhang loads are taken as a laterally loaded fixed-end beam with a span length equal to the distance between the cross-frames as shown in Figure 2.12 for the bottom flange.
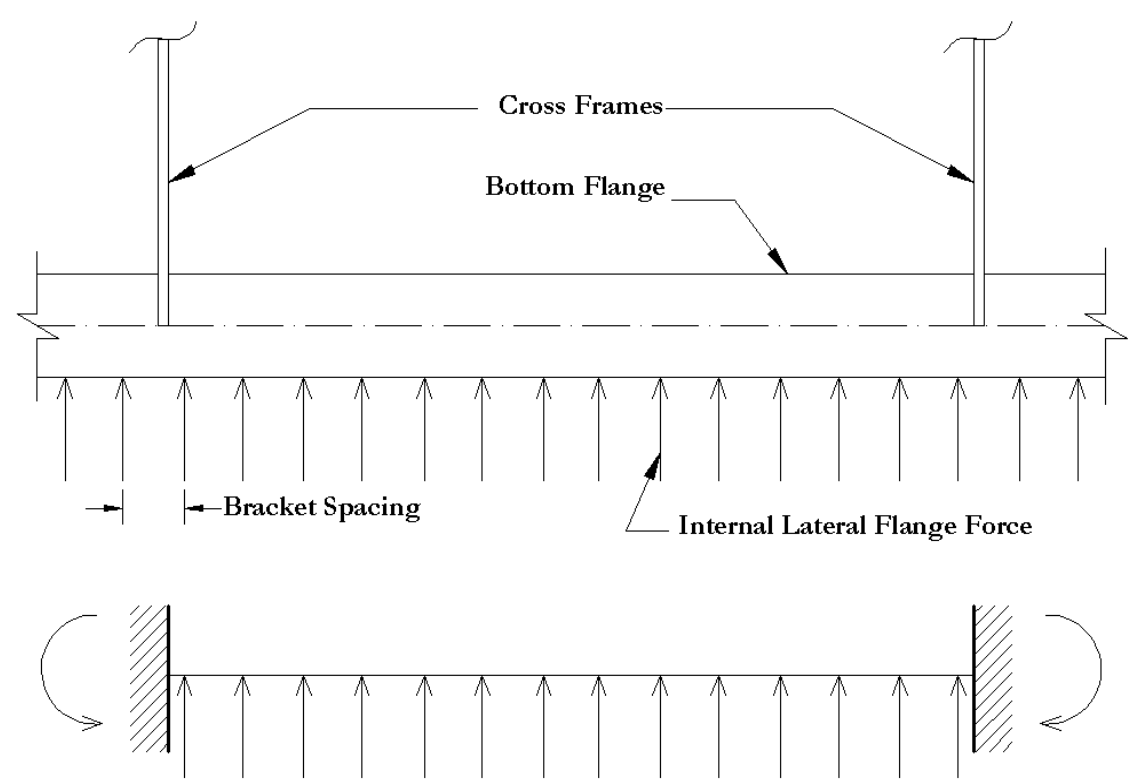

Figure 2.12: Plan View of Bottom Flange: A. (original) B. (equivalent approximation)

The design guide includes a simplified analysis where maximum fixed-end moment $\left(M_{f w}\right)$ is calculated from the square of the cross-frame spacing multiplied by tabulated coefficients in terms of overhang length and girder height. The factored maximum moment in-between crossframes $\left(M_{+}\right)$is determined by multiplying the corresponding $M_{f w}$ by a conservative value of 0.53 for the uniform overhang loads (slab, overhang form and walkway live load) or by 0.60 for the finish machine loads.

In addition, the guide recommends the use of rebar ties attached to the shear stud connectors at the third points of the cross-frame spacing for the top flanges on the exterior 
girders. This configuration reduces the lateral moment and increases the buckling strength of the top flange. Top flanges that meet this requirement, while having an unbraced length less than 25 feet are assumed to control inelastic deformations caused by yielding and ensure adequate ultimate strength without requiring an explicit checking procedure.

The following limit states are defined for the bottom flanges:

- Strength Limit States:

1. Yielding Limit State: This limit state is intended to control permanent deformations of flanges at and between cross-frames.

$$
f_{b u}+f_{\ell} \leq F_{y}
$$

2. Ultimate Limit State: This limit state is an interaction equation of axial and bending effects for compression flanges in between the cross-frames.

$$
\frac{P_{u}}{0.85 A_{s} F_{c r}}+\frac{M_{\ell} C_{m}}{M_{u}\left(1-\frac{P_{u}}{A_{s} F_{e}}\right)} \leq 1.0
$$

- Stability Limit States:

o To control potential web instabilities, the guide suggests that the cantilever overhang brackets bear on the web of the girder at a minimum of six inches from the bottom flange of the girder. It is also suggested to use a plate at the point of contact to spread the load.

o An alternative to this method is to frame the bracket into a properly sized wale. These suggestions are intended to prevent direct contact of the brackets on the web's compressive zone.

\subsubsection{KDOT Provisions for $L F B$}

The University of Kansas and the Kansas Division of Transportation (KDOT) developed a software program (validated by physical test data and numerical analyses) called "Torsional 
Analysis for Exterior Girders - TAEG" (Roddis et. al., 1999). This program improves some of the assumptions of the AISC and AASHTO approaches in which the segments between crossframes are idealized as a beam with fixed ends. In addition to the program's torsional analysis capabilities, TAEG also has the ability to design concrete deck overhangs, select appropriate cross-frame members, determine adequate cross-frame spacing and assess false work patterns for concrete deck placement. The following basic assumptions were adopted in the KDOT approach according to the results obtained in the research work:

- The flange flexure analogy is valid to represent the torsional effects.

- A simplified flange model with three continuous and fixed ends is sufficient to achieve good accuracy compared to the AISC simple-span assumption.

- The lateral support in the bottom flange needs to be considered and varies with the type of support (cross-frames or diaphragms).

- The effect of temporary supports needs to be considered.

- The dynamic effects due to the movement of the motor carriage are negligible.

- Impact loads during deck placement are also negligible.

Three basic load schemes are considered along the three-span beam to define the maximum demands:

1. Dead load, live construction load, and concrete for the initial span of the beam.

2. Dead load, live construction load, and the finishing machine for the middle span.

3. Dead load and live construction load for the remaining span.

The load position in scheme 2 is varied within the second span of the continuous girder to identify the critical location that generates the maximum effects. All the loads are uniformly distributed, including the wheel loads applied over the width of the finish machine supports. The cross-frames and diaphragms are modeled as pinned supports for the top flange. For the bottom flange, the cross-frames are also considered as pinned supports while the diaphragms and temporary supports are modeled with equivalent springs.

The principal calculations that the program performs based on the three-span continuous beam model and the stiffness method are:

- Maximum stresses in the flanges

- Ultimate strength check for the top flanges

- Deflection of the flanges 
- Rotation and deflection of the girder at the screed rail

- Internal forces of the overhang brackets

- Support reactions

- Stresses in the diaphragm

- The bolt load and critical bolt load in case of bolted connections between the girder and diaphragms.

When compared with the AISC approach, stresses obtained with TAEG are approximately $20 \%$ higher for the positive bending regions and $20 \%$ lower for the negative bending regions. Therefore, an economical benefit is obtained using TAEG, since the negative bending regions typically govern the design.

Roddis et. al. presented a paper (2003) discussing an updated version of the KDOT program, TAEG 2.0. TAEG 2.0 changed the basic analytical model from a three-span rigidly supported beam to a 3-span spring supported beam. This new method produces the largest negative warping stress (local torsional stress) and largest positive warping stress by changing the stiffness of the elastic springs in the model to reflect the structure's behavior. The model, as mentioned before, is a three-span beam with multiple elastic spring supports. In TAEG 2.0, it is assumed that the supports with the largest stiffness are at pier locations; as a result, pinned supports are used at these locations. TAEG 2.0 then uses the force method to calculate the deflection of the diaphragms or cross-frames used in the system. Figure 2.13 is the model used by the authors to calculate the spring stiffness. The overall bridge structure's lateral behavior is modeled using an equivalent single-span bridge. The effective single-span girder $\mathrm{L}_{\mathrm{EFF}}$ is equal to the span of the bridge or L. For the side span of a multi-span girder the largest of $\mathrm{L}_{\mathrm{SIDE}}$ or $\mathrm{L}_{\mathrm{MID}}$ is used as $\mathrm{L}_{\mathrm{EFF}}$, where $\mathrm{L}_{\mathrm{SIDE}}$ is $0.8 \mathrm{~L}$ of the side span and $\mathrm{L}_{\mathrm{MID}}$ is $0.6 \mathrm{~L}$ of the middle span. 


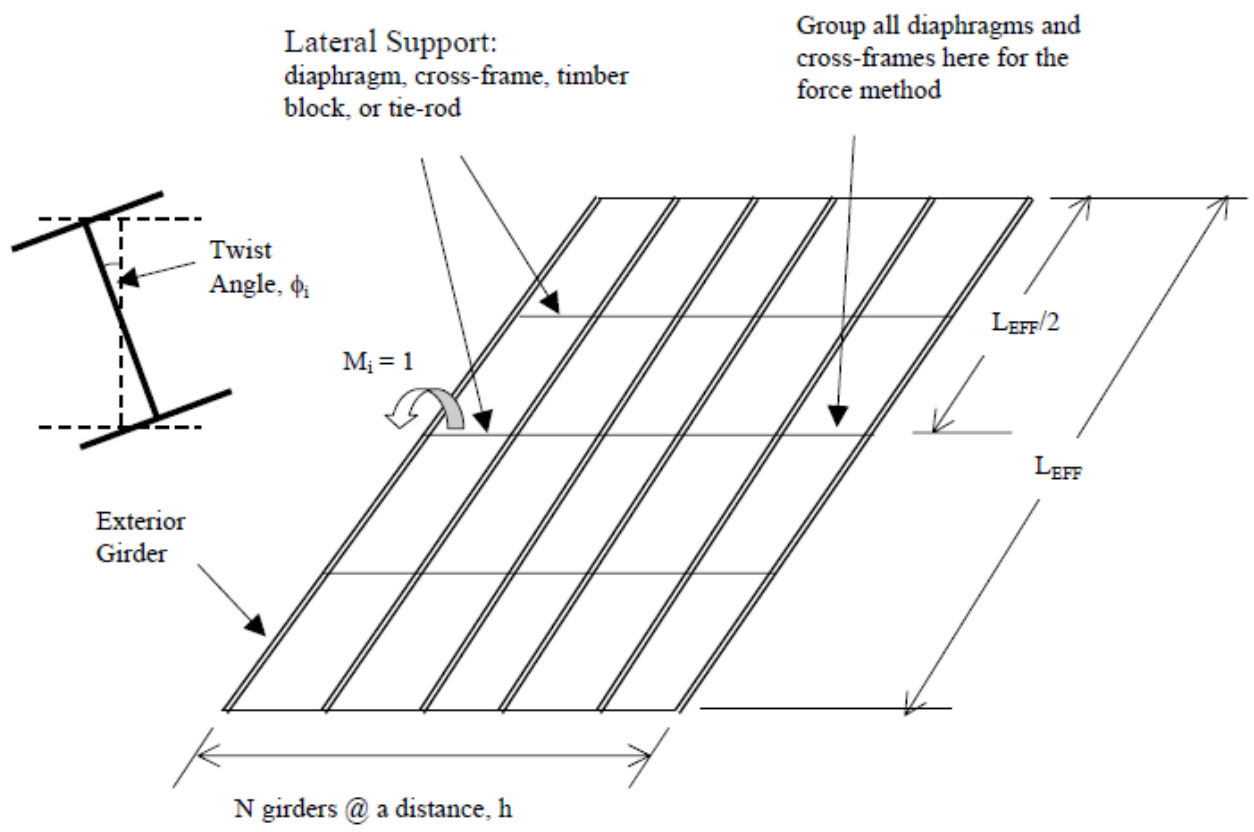

Figure 2.13: Model to Calculate the Weakest Rigidity of Elastic Spring (Roddis et. al., 2003)

Model A in Figure 2.14 is used to calculate the largest positive section stress by using $K_{i}$ (spring stiffness). Model B in Figure 2.14 is used to calculate the largest negative section stress by using $K_{i}$ as well.
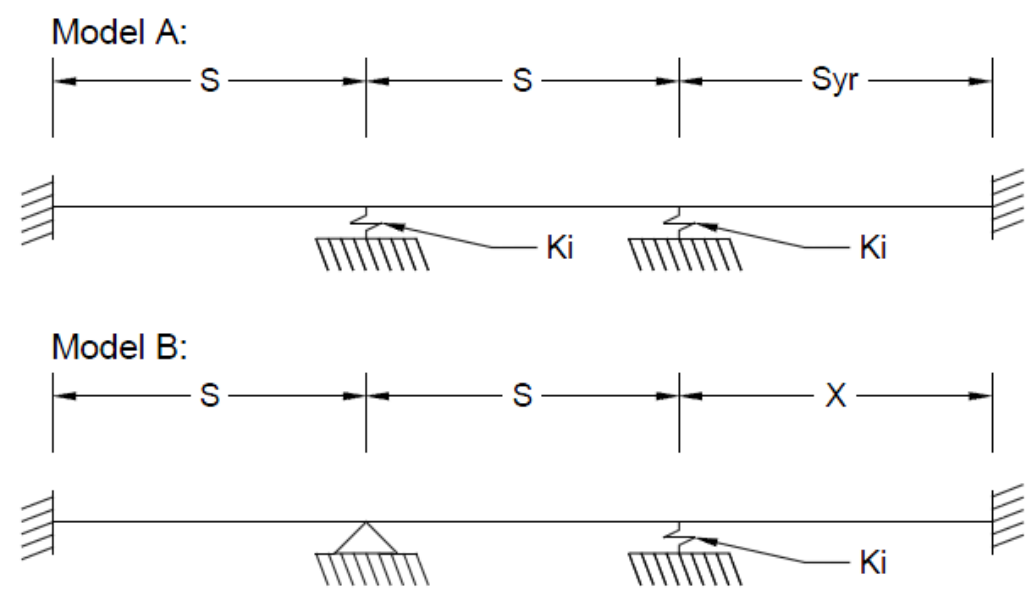

$S=$ the distance between two diaphragms or cross-frames

Figure 2.14: Three-span, Elastic, Spring-supported Beam (Roddis et. al., 2003) 
When TAEG 2.0 was compared to TAEG 1.0, TAEG 2.0 tends to predict softer responses of the structure (i.e. larger deformations and lower stress values). TAEG 2.0 results in slightly higher negative stress values and slightly lower positive stress values. The torsional response of the structure with the addition of temporary supports showed larger decreases in gross rotation in TAEG 2.0. In addition, when permanent lateral supports are only used in the outside bays, higher deflections and lower stress values are predicted in TAEG 2.0.

\subsection{Overview of Cross-Frame ForCES AND Associated DetaILiNg Issues}

Cross-frames are predominantly useful in the noncomposite stage of a bridge's life to resist torsional buckling of girders during placement of wet concrete. After a bridge enters a composite state, the bridge deck becomes the main stabilizing element for the girders. Crossframes have been historically required to provide stability to the girders during construction prior to the hardening of the concrete deck and in negative bending areas where the bottom flange is in compression. In addition, they are also relied upon to distribute lateral loads such as wind and seismic effects. (Murphy and Linzell, 2012). AASHTO (2010) requires cross-frames to perform the following tasks:

1. To assist with the transfer of lateral loads to the bearings

2. To assist with the transfer of lateral seismic loads

3. To assist with the control of deformations and cross-section geometry during fabrication, erection, and placement of the deck

\subsubsection{Cross-Frame Detailing Issues}

Detailing issues arise in skewed bridges when cross-frames connect to girders at different girder points along a bridges span. To avoid this issue some detailers may be orient cross-frames parallel to the skew. However, as mentioned before, AASHTO requires cross-frames to be oriented perpendicular to center line of the bridge for skews above $20^{\circ}$. Figure 2.15 shows crossframes oriented perpendicular to the bridge centerline. The cross-frames connect adjacent girders 
at different points along the span length of each girder, producing different displacements at the points of connection. As a result, internal forces are generated in the cross-frames that produce LFB in the girders (Coletti \& Yadlosky, 2005).

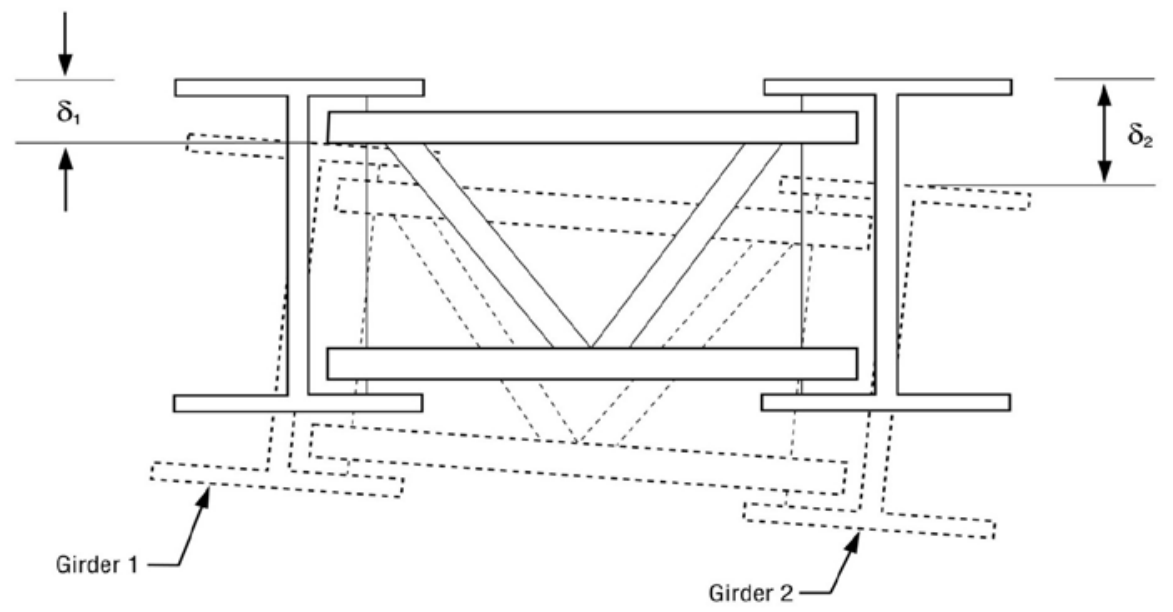

Figure 2.15: Cross-frames Oriented Perpendicular to the Girders (Coletti \& Yadlosky, 2005)
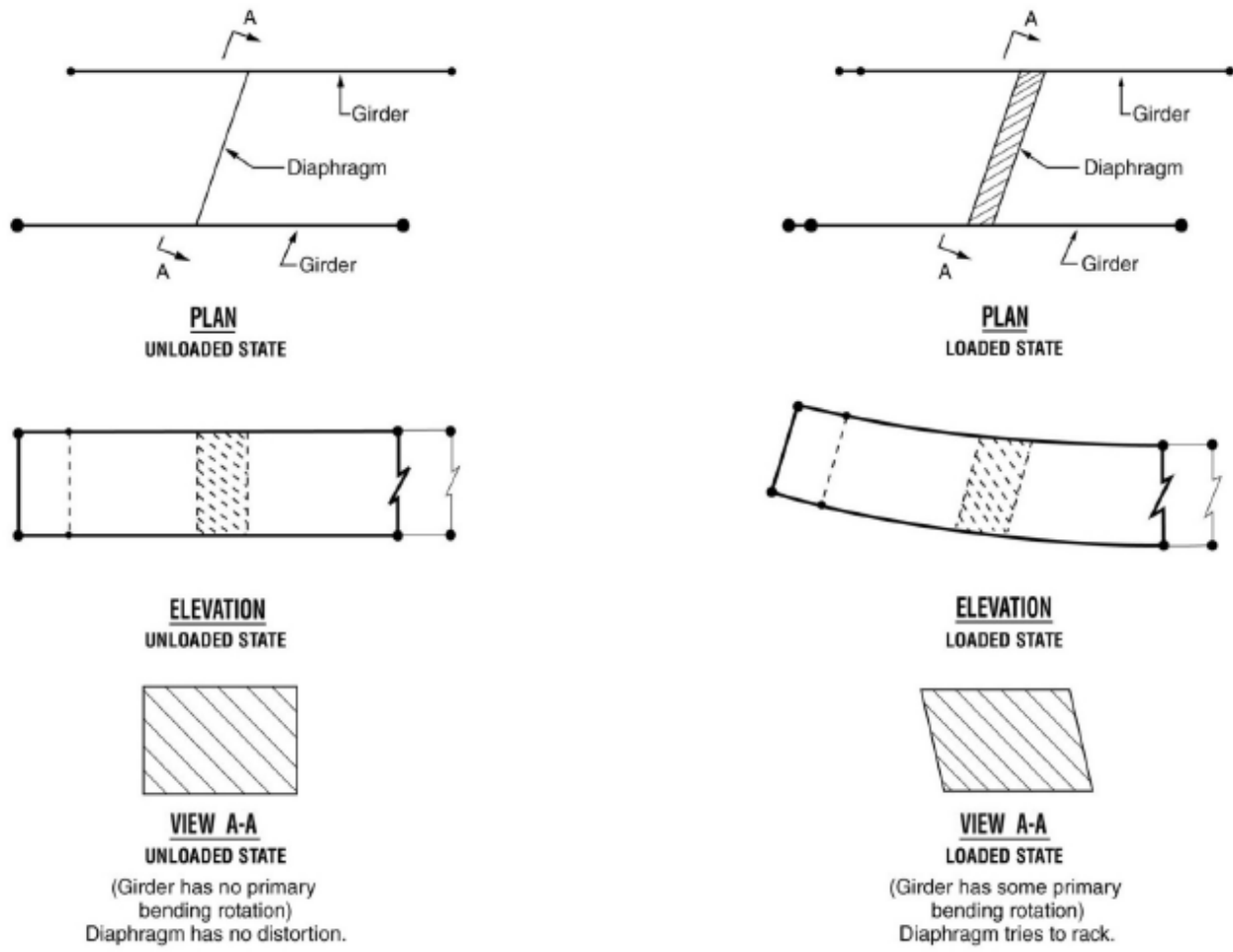

Figure 2.16: Cross-frames Oriented Parallel to the Girders (Coletti \& Yadlosky, 2005) 
Cross-frames oriented parallel to the skew angle can reduce the effects of skew. However, LFB is still present in the girders of skewed bridges at the cross-frame locations due to rotation of the bridge cross-section about an axis parallel to the skew (Beckmann \& Medlock, 2005). This rotation and additional deflection produce a lateral displacement between the flanges that distorts the original shape of the cross-frames generating additional LFB as shown in Figure 2.16.

Mertz (2001) completed a design guide for intermediate cross-frames for the American Iron and Steel Institute based on AASHTO (1998) specifications. In this guide, Mertz gives guidelines for the determination of bracing locations. The author notes that the LRFD specifications can be vague on where permanent bracing and/or temporary bracing is required. The clarification of this problem is listed below.

- Simple-span steel girder bridges or continuous-span steel girder bridges are not required to have permanent intermediate cross-frame diaphragms.

- Temporary bracing is required for compression flanges of simple-span bridges and for compressions flanges in the positive bending regions of continuous-span steel girder bridges.

- Negative bending regions of continuous-span steel girder bridges do not require permanent intermediate cross-frame diaphragms.

- Negative bending regions of continuous-span steel girder bridges are required to have permanent bracing on the compression flanges.

Note that bracing requirements for top flanges are temporary since the bracing is only needed until the cast-in-place concrete has cured while the bottom flange bracing requirements are always permanent. The author also provides step-by-step procedures for determining bracing locations for positive and negative bending regions in a noncomposite section under constructibility loads. These steps replace the traditional 25 foot cross-frame spacing limits used in previous specifications, which allows for more cost-effective bridge designs and increased cross-frame spacings. These procedures are as follows (it should be noted that updated equations are provided accordingly from the most recent edition of the AASHTO LRFD Specifications): 
- Bracing location requirements for positive bending regions:

1. Select convenient trial bracing spacing.

2. Determine the web-slenderness ratio, $\lambda_{w}$.

$$
\lambda_{w}=\frac{2 D_{c}}{t_{w}}
$$

3. Determine the limiting unbraced lengths, $L_{p}$ and $L_{r}$.

$$
\begin{aligned}
& L_{p}=r_{t} \sqrt{\frac{E}{F_{y c}}} \\
& L_{r}=4.44 \sqrt{\frac{I_{y c} D}{S_{x c}} \frac{E}{F_{y c}}}
\end{aligned}
$$

4. Determine if the noncomposite section's resistance is sufficient to resist the loads present (one of three cases are used for this computation):

$$
\begin{aligned}
& \text { If : } \lambda_{w} \leq \lambda_{b} \sqrt{\frac{E}{F_{y c}}} \\
& M_{n}=3.14 E C_{b} R_{h}\left(\frac{I_{y c}}{L_{b}}\right) \sqrt{0.772\left(\frac{J}{I_{y c}}\right)+9.87\left(\frac{D}{L_{b}}\right)^{2}} \\
& \text { If : } \lambda_{w}>\lambda_{b} \sqrt{\frac{E}{F_{y c}}} \text { and } L_{b} \leq L_{r} \\
& M_{n}=C_{b} R_{b} R_{h} M_{y}\left(1-0.5\left(\frac{L_{b}-L_{p}}{L_{r}-L_{p}}\right)\right] \\
& \text { If : } \lambda_{w}>\lambda_{b} \sqrt{\frac{E}{F_{y c}}} \text { and } L_{b}>L_{r} \\
& M_{n}=C_{b} R_{b} R_{h} \frac{M_{y}}{2}\left(\frac{L_{r}}{L_{b}}\right)^{2}
\end{aligned}
$$

Equation 2-14

Equation 2-15

Equation 2-16

5. If the noncomposite resistance is lower or higher than the required resistance, the brace spacing should be decreased or increased respectively until the noncomposite resistance is slightly greater than the required resistance. 
- Bracing location requirements for negative bending regions:

1. Select convenient trial bracing spacing.

2. Determine the limiting unbraced length, $L_{p}$.

- $L_{b}$ in negative bending regions is limited to $L_{p}$.

- In lieu of using Equation 2-12, Equation 2-17 can be used, where moment is not assumed to be constant.

$$
L_{p}=\left(1.33-\frac{1}{C_{b}}\right)\left(\frac{r_{t}}{0.187}\right) \sqrt{\frac{E}{F_{y c}}}
$$

3. Iterate until the bracing length is less than or equal to the calculated maximum unbraced length, $L_{p}$.

\subsubsection{Cross-Frame Forces and Measures of Cross-Frame Stiffness}

Wang and Helwig (2008) investigated torsional bracing behavior of steel I-girders of skewed supports. The authors used a commercial three-dimensional finite-element software package, ANSYS (2000) to model 2-girder, 3-girder, and 4-girder bridge systems with bracing oriented either parallel to the skew angle or perpendicular to the centerline of the bridge. Comparisons were made between the FEA results and the proposed strength equations (Equation 2-18) and stiffness equations (Equations 2-19 and 2-20).

$$
\begin{aligned}
& M_{c r}=\sqrt{C_{b u}^{2} M_{0}^{2}+\frac{C_{b b}^{2} \tilde{\beta}_{T} E I_{y}}{C_{t}} M_{s}} \leq M_{y} \\
& \phi_{T}=\frac{\phi_{0}}{1-\frac{\beta_{T i}}{\beta_{T}} \frac{M}{M_{c r}}} \\
& M_{b r}=\beta_{T}\left(\phi_{T}-\phi_{0}\right)
\end{aligned}
$$

The author found that, when cross-frames were oriented perpendicular to the centerline of the bridge, effects of skew were small. However, when cross-frames were oriented parallel to the skew angle, a larger deviation from the stiffness and strength requirements was found. The author suggested modifications to Equation 2-21 that produces a closer agreement between the 
FEA results and the equations. The modified equation squares the " $M / M_{c r}$ " term and is listed below.

$$
\phi_{T}=\frac{\phi_{0}}{1-\frac{\beta_{T i}}{\beta_{T}}\left(\frac{M}{M_{c r}}\right)^{2}}
$$

American Institute of Steel Construction (AISC, 2010) gives strength and stiffness requirements for torsional bracing. The required stiffness of bracing is acquired using Equation 2-22.

$$
\beta_{T b}=\frac{\beta_{T}}{\left(1-\frac{\beta_{T}}{\beta_{\text {sec }}}\right)}
$$

where:

$$
\begin{aligned}
& \beta_{T}=\frac{1}{\phi_{i}}\left(\frac{2.4 L M_{r}^{2}}{n E I_{y} C_{b}^{2}}\right) \\
& \beta_{\mathrm{sec}}=\frac{3.3 E}{h_{o}}\left(\frac{1.5 h_{o} t_{w}^{3}}{12}+\frac{t_{s t} b_{s}^{3}}{12}\right)
\end{aligned}
$$

It should be noted that if $\beta_{\mathrm{sec}}<\beta_{T}$, Equation 2-22 is negative, this indicates inadequate web distortional stiffness, making lateral bracing ineffective. The required strength is then given by Equation 2-25 as follows.

$$
M_{r b}=\frac{0.024 M_{r} L}{n C_{b} L_{b}}
$$

Murphy and Linzell (2012) performed a study on a 55-foot simply-supported $60^{\circ}$ skewed bridge in central Pennsylvania. Bridge Diagnostics, Inc. (BDI) strain transducers were used to 
record strains on angle members in selected cross-frames. Sixteen models with varying parameters (skew and parapets) were created for a parametric study. The authors concluded from the field tests that

1. cross-frame at the obtuse angle experience the highest compressive live load forces;

2. cross-frames near the supports experience greater compressive forces then the intermediate cross-frames;

3. no axial forces or bending moments were significant compared to member capacities when only considering live loads.

From the parametric study it was concluded that:

1. as skew decreased tensile forces become larger while compressive forces decreased for cross-frames near the supports;

2. intermediate cross-frames showed a typical increase in tensile forces and a slight increase in compressive forces for deceasing skew angle;

3. parapets effects showed an increase the tensile forces and reduction in compressive forces in intermediate cross-frame member;

4. the increase in skew reduced the impact of parapets on cross-frames.

\subsubsection{Leaning Cross-Frames}

In most cases, standard cross-frames are used in every bay between girders in steel Igirder bridges, resulting in cross-frames that are larger and stiffer than required for system stability. These cross-frames tend to attract larger live load forces which can lead to fatigue cracks at bracing locations. This is particular in largely skewed bridges where perpendicular cross-frames frame into girders at differential deflection points that can intensify the chance for fatigue cracks. Using lean on bracing concepts can alleviate these concerns allowing for the reduction of the number of cross-frames used and minimize the live-load forces introduced to the supports. The concept of lean on bracing has only a few cross-frames combined with top and bottom struts between the remaining girders that allow these girders to lean on the cross-frames in a given bracing line. The use of fewer cross-frames allows for cross-frames to be positioned so that smaller forces are induced due to the differential displacement of girders (Fasl et. al., 2009). 
Figures 2.17 and 2.18 show a lean on bracing system and how designers have the flexibility of positioning the full cross-frame to reduce stress.

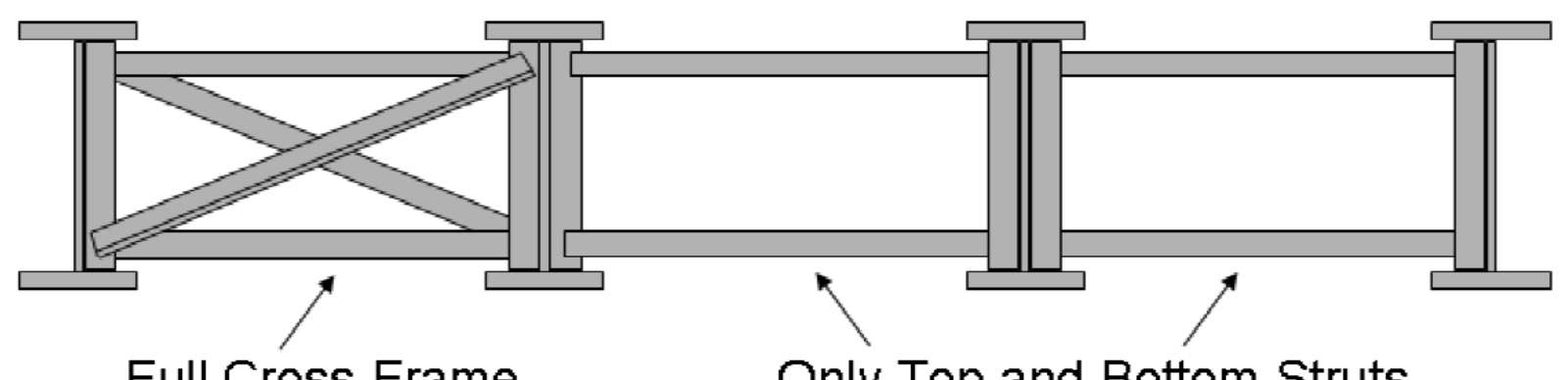

Figure 2.17: Leaning Bracing in a Four-girder Bridge (Herman et. al., 2005)

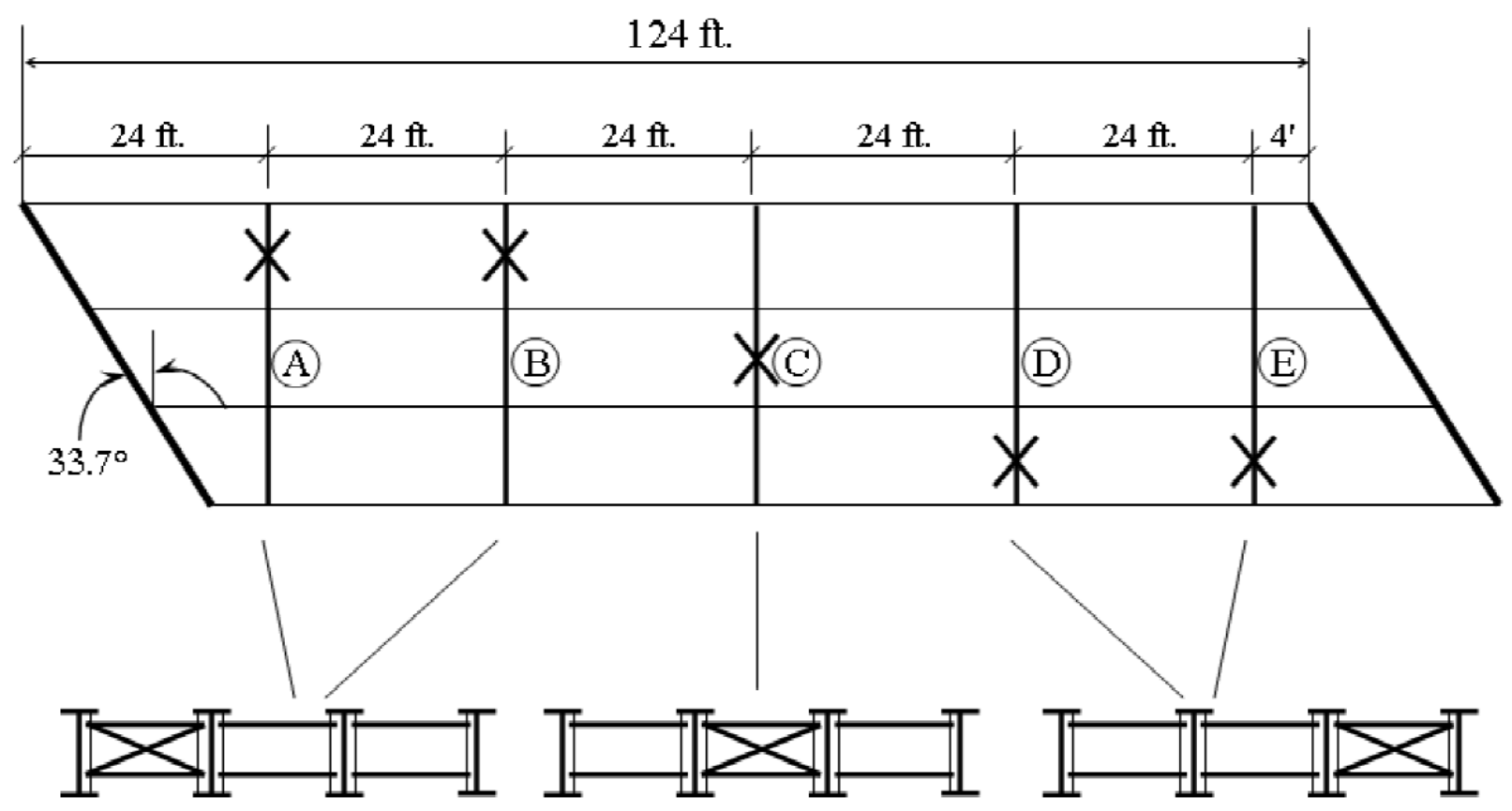

Figure 2.18: Plan View of Leaning Cross-frame Layout for a Four-girder Bridge (Herman et. al., 2005)

It should be noted that cross-frames should be positioned far away from the supports as possible. Cross-frames near the supports connect girders with little or no live load deflections to adjacent girders with larger deflections. This induces large cross-frame forces that can be avoided by placing the first line of cross-frames a few feet from the skewed support. This 
increases the girder flexibility near the bracing line which substantially reduces the live load forces that develop in the braces while still providing enough stiffness to the girders (Herman et. al., 2005). Lean-on cross-frames is a method of bracing that can be advantageous due to its flexibility in design, ability to reduce cross-frame forces, and finally it reduces cost of material along with labor.

\subsubsection{Effect of Girder Plumbness on Cross-Frame Forces}

Beckmann \& Medlock (2005) discussed the issues of girder rotations. Girders must be detailed for one of three conditions.

1. No-load fit condition, where girder webs are theoretically vertical with no dead load applied.

2. Steel dead-load fit, where girder webs are theoretically vertical when the cross-frames are installed.

3. Full dead-load fit, where girder webs are theoretically vertical when concrete deck has been poured.

Movement of girders at the supports for straight bridges is predictably uniform. Girders are fabricated with a camber with the dead load deflection calculated such that the girders will be in its intended profile when dead load is applied. When the dead load is applied the top flange will shorten and the bottom flange will lengthen. The ends of the girders will rotate to accommodate the length changes. At a fixed bearing the top and bottom flange will lengthen by an amount " $R$ " if top and bottom flanges are the same size. If bearings are floating the bottom flange will move outward by $0.5 R$, while the top flange will move inward in ward by $0.5 R$. For skewed bridges the movements are more complicated. The expression below shows the transverse movement of the top flange with respect to the bottom flange.

$$
R T=\frac{R}{\tan (\beta)}
$$

This transverse movement with respect to the bottom flange has large effects on construction and the out-of-plumb conditions that need to be addressed by the designer. In the 
case where bearings are not at the same elevation a $\theta$ term representing the positive or negative slope should be added or subtracted to the $\beta$ term. For small slopes, this term can be ignored.

Norton et. al., (2003) performed a study on a single span bridge with a skew of $55^{\circ}$ in central Pennsylvania. Girders for this bridge were erected out-of-plumb with an angle between $0.57^{\circ}$ and $0.61^{\circ}$. Concrete was placed with the screeds oriented perpendicular to the center line of the bridge. Strain transducers were used on the girders and cross-frames and LVDT's to measures displacements at the abutments. Two models were created a grillage model and a 3demensional finite element model for comparison to the field study. The author found that the final positions of the girder webs were not plumb and the vertical deflection of the girders were not uniform. The vertical deflection increased from girder one to girder seven (the two exterior girders).

\subsection{SUMMARY AND RESEARCH NEEDS}

The need for skewed bridges is increasing in our highway infrastructure, which, in turn, increases the complexity of bridge design and construction. Deflections and girder rotations are fairly easy to calculate in straight bridges; however, when skew is introduced, the forces and associated deformations become much more challenging to predict. In addition, detailing associated with cambers and fit-up becomes increasingly more complex. This reflects a definite need for more research on the uncertainties associated with skewed bridge design and construction.

It is a common practice for designers to analyze bridges with small skew angles as straight bridges; however, research has shown significant effects from skew on LFB characteristics and cross-frame forces in steel I-girder bridges. Construction and overhang loads along with cross-frame forces and girder plumbness are all directly affected by skew. The effects of uneven loading due to skew can make determining LFB more difficult. Several approaches for estimating these effects were presented in this chapter; however, many of these approaches have some shortcomings, such as analysis methods which are far too simplistic to accurately capture the characteristics of LFB during stages of construction. Therefore, the goal of this thesis is to investigate the characteristics of LFB in straight and skewed bridges in order to develop a more accurate means of estimating these quantities. 


\section{CHAPTER 3: SCOPE OF WORK}

\subsection{INTRODUCTION}

This chapter provides an overall description of Chapters 4 through 6, which constitutes the body of work contained in this thesis. Each chapter will be discussed individually, summarizing the respective components of work pertinent to this research effort.

\subsection{Finite MOdeling Techniques (ChAPTER 4)}

Abaqus 6.10-1/CAE (Dassault Systèmes, 2009) was used for the modeling and analysis of steel I-girder bridges in this project. The appropriate elements, mesh densities, and other associated model parameters (boundary conditions, material definitions, etc.) were adapted from previous research to achieve accurate results (Galendez, 2009). Loads applied are representative of typical construction sequences, including overhangs, formwork, screed/rail, walkway and finishing machine.

A parametric algorithm was formulated in MATLAB that develops finite element meshes using input parameters defined by a user. Using the appropriate input data, the algorithm calculates loads, assigns node and element information associated with the bridge's geometry, and generates a .inp file necessary for analysis in ABAQUS. Once the .inp file is generated and analyzed using ABAQUS/Standard, the algorithm post-processes the results of the finite element analysis and computes both the lateral flange bending present from finite element analysis as well as the associated AASHTO approximation.

\subsection{Simple Span PARAMetric Matrices’ (Chapter 5)}

Two parametric matrices were developed for the investigation of the accuracy of the AASHTO LFB approximation in simple-span I-girder bridges. The first matrix was developed to study the effects of skew and unbraced length on lateral flange bending moments. Skew and 
unbraced length were varied and compared to see the direct effect of each parameter. Along with skew and unbraced length, parallel cross-frame and staggered cross-frame orientations were investigated to assess their respective impacts. The algorithm discussed in Section 3.2 was used to model the bridges developed in this Chapter.

The first parametric matrix was limited on span length and girder spacing. Therefore, a second parametric study was conducted to investigate the effects of girder spacing and span length on LFB. The results from these two parametric matrices were queried and organized into a series of plots for investigation. The plots were used to identify the key parameters that have the most significant effect on LFB. The comparison of AASHTO approximation and the finite element analysis (FEA) results were compared and plotted as well.

\subsection{FORMULATION OF THE MOdifiEd APPROXIMATION (CHAPTER 6)}

The parametric matrices from Chapter 5 were used to identify key parameters that have an effect on LFB. These parameters were used to develop a new larger parametric matrix that varies the parameters of interest. The algorithm discussed in Section 3.2 was used to model the bridges developed from the new matrix in order to use the FEA results to develop an empirical equation using a commercial data correlation software package called DataFit 9.0.59 (Oakdale Engineering, 2008). Finally, the newly developed modification factor is compared to the current AASHTO approximation and the FEA results.

\subsection{SUMMARY}

In summary an overview of the scope of the work done in this study is presented in this chapter. A brief over view of each chapter was presented in hopes to give the reader a preview and understanding of the work presented in the subsequent chapters. 


\section{CHAPTER 4: Finite ELEMENT MODELING TECHNIQUES}

\subsection{INTRODUCTION}

This chapter discusses the finite element modeling methods used in the analysis of the steel bridges selected for this project. Discussed herein are the types of elements used, material definitions, discretization of meshes, applied boundary conditions and finally the loading scheme. Abaqus 6.10-1/CAE (Dassault Systèmes, 2009) was used to model and analyze the steel I-girder bridges used in this research project. In addition this chapter will also present an algorithm developed to formulate geometries for simple span bridges.

\subsection{SELECTION OF ELEMENTS}

Two elements were selected for modeling in this research project; S4R shell elements and B33 beam elements. The S4R elements were used for the simulation of the concrete deck, the girder webs and the girder flanges. The S4R is a 4 node, quadrilateral, stress/displacement shell element with reduced integration. The B33 element, or a 2 node cubic beam in space employing Euler-Bernoulli Bending Theory, was used to simulate the cross-frame members and stiffener elements.

\subsection{MESH DisCRETIZATION}

AASHTO LRFD states in Section 4.6.3.3 that the ratio of finite elements and grid panels should not exceed 5.0 and abrupt changes in size and/or shape of finite elements and grid panels should be avoided (American Association of State Highway and Transportation Officials, 2010). A mesh was developed to achieve accurate results as well as in accordance to the AASHTO LRFD Specifications. Element sizing was developed based on a targeted 0.5 feet square element. Element sizes varied depending on bridge geometries. For the girders, four to six elements were used across the width of the flanges and approximately seven to eleven elements along the width 
of web. The varying element numbers are due to the different parametric bridge geometries. Finally, in the longitudinal direction the mesh was discretized such that the elements are approximately four to twelve inches long. This element discretization was proven by Galindez (2009) to be accurate.

\subsection{MATERIAL DEFinition}

The scope of this research investigates the linear elastic AASHTO approximation for lateral flange bending. Therefore, all materials were modeled as linear, elastic, isotropic mediums. There was no need for non-linear analysis as the yield strength of steel or the compressive strength of concrete were not exceeded in the in this project.

\subsection{BOUNDARY CONDITIONS}

It is common practice to find "hinge-roller" conditions in bridge construction. Hence "hinge-roller" boundary conditions were applied to the nodes along the edges of the bottom flange at the supports of each girder on all bridges in the parametric matrix. In addition all girders were restricted from having any lateral movement as this is also common in bridge construction. An image of a simple span bridge from the 2nd parametric matrix of Chapter 5 is provided in Figure 4.1. The figure shows the boundary conditions in orange along with typical mesh discretization. 

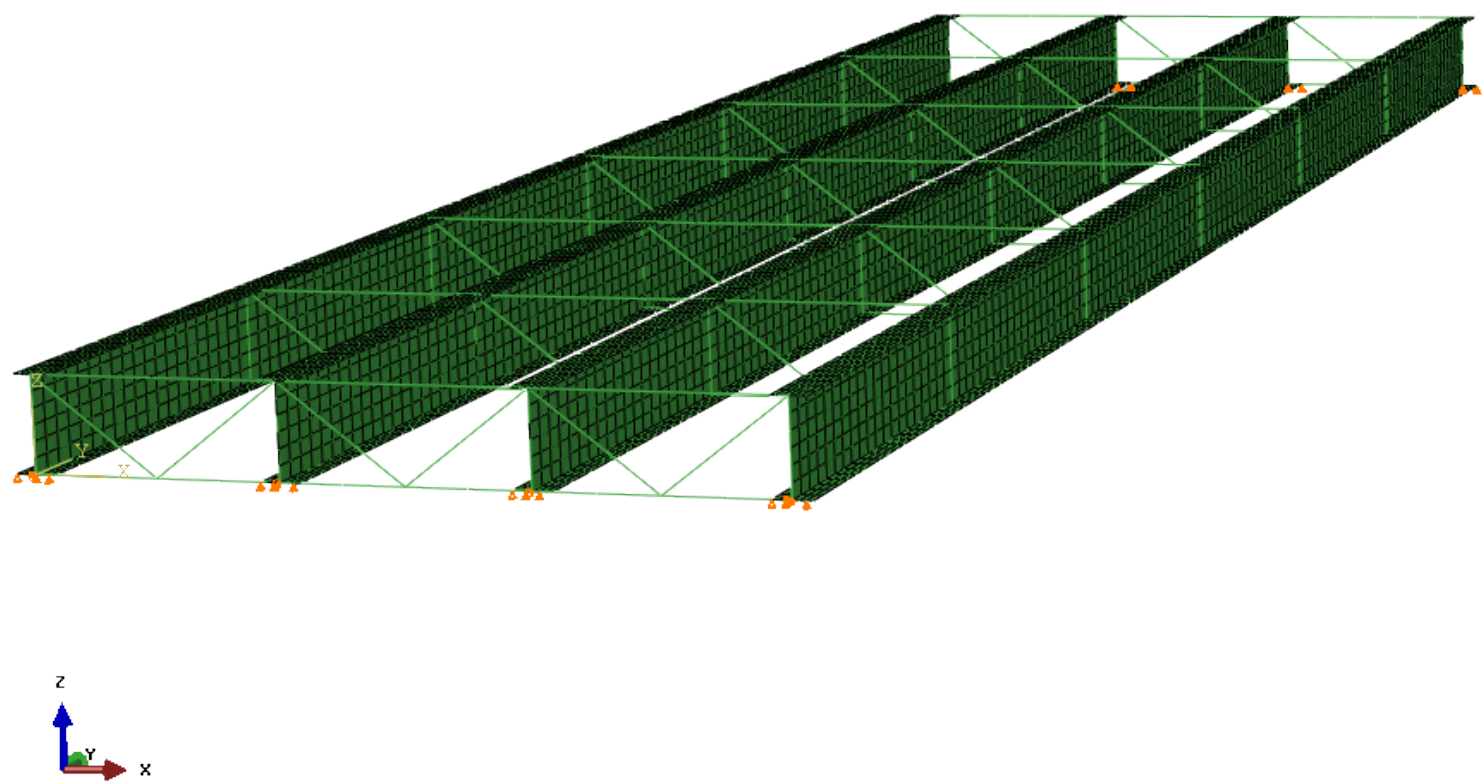

Figure 4.1: Abaqus Screen Capture of Bridge Model

\subsection{APPLIED LOADS}

Loads applied to the series of bridges used in this parametric matrix represent the loads acting during a deck casting sequence. These loads consist of permanent dead loads and construction loads. Permanent loads being the self weight of the structural member and construction loads include the following loads (NSBA 2013):

- Overhang Brackets : $50 \mathrm{lbs}$ each on $3 \mathrm{ft}$ spacing

- Formworks: $10 \mathrm{lb} / \mathrm{ft}^{2}$

- Screed Rail: $85 \mathrm{lb} / \mathrm{ft}^{2}$

- Railing: $25 \mathrm{lb} / \mathrm{ft}^{2}$

- Walkway: $50 \mathrm{lb} / \mathrm{ft}^{2}$ 
The Strength Load Combination I of the AASHTO Specifications Section 3.4.2 was used to factor the loads at 1.25 for the deads loads and 1.5 for construction loads.

\subsection{Parametric Modeling Algorithm}

This section provides an outline of the algorithm developed in MATLAB to generate simple span steel I-girder bridge geometry for modeling in ABAQUS. The developed algorithm generates a .inp file that is compatible with ABAQUS. Once the user has defined a set of parameters it is easy to generate a matrix of ABAQUS .inp files to cover the range of user defined parameters. A user can define multiple bridge geometries and run multiple bridges in succession. This allowed for the generation of a large number of bridge geometries with minimal time and effort provided by the user. While the development of this program took a significant amount of time to develop the time saved in modeling the bridges makes the algorithm worth the time spent in its development. Once the ABAQUS .inp files are generated a separate MATLAB post processing program calls the files generated by the initial MATLAB algorithm to run the analysis of the bridges through ABAQUS Software. It should be noted that these algorithms were tailored for simple span I-girder bridges with varying skew in the construction stages of a bridge with a noncomposite deck.

\subsubsection{Input parameters}

Parameters need to be defined by the user for the desired bridges to be generated. Parameters that are constant in the bridges assessed in the parametric matrix of this study are assigned internally in the algorithm saving time and effort. These parameters include:

- Material Properties

- Modulus of Elasticity - $29600 \mathrm{ksi}$

- Possions Ratio - 0.320

- Specific Weight of Concrete - $145 \mathrm{lbs} / \mathrm{ft}^{3}$

- Specific Weight of Steel - $490 \mathrm{lbs} / \mathrm{ft}^{3}$

- Integral Wearing Surface - 0.25 in

- Load Factors (provided in Section 4.6) 
- Loads (provided in Section 4.6)

The parameters that vary from bridge to bridge must be defined by the user in the MATLAB interface. These parameters are easily assembled in Microsoft Excel spreadsheet and are transferred into the MATLAB input module. Multiple bridges are defined on a line by line basis; therefore the algorithm can process multiple bridges automatically. The parameters defined by the user include bridges geometry and finite element dimensions:

- Girder Dimensions

- Girder Spacing

- Length of Bridge

- Number of Girders

- Number of Cross-frames

- Skew Angle

- Overhang width

- Slab Thickness

- Length of elements in longitudinal direction

- Number of elements across the width of bottom flange

- Number of elements across the width of top flange

- Number of elements along depth of web

\subsubsection{Node Generation}

Finite element meshes for bridge girders were constructed in stages starting with the bottom flange, then top flange, and finally the web. The process for each cross-sectional component was the same; therefore only the bottom flange formation is described. The first step in the algorithm is to define the nodes of the bottom flange.

Using the information input by the user, the spacing and position of the nodes can be defined. To create nodes in a bottom flange, four properties are required: the width of the flange, the span length of the bridge, the transverse mesh density (or the density along the width of the flange), and the longitudinal mesh density (or the density along the length of the bridge). The first node of the bottom flange is placed at the flange's left edge, with an x-coordinate equal to - 
$1 / 2$ of the flange width. Next, the remaining nodes along the width are placed incrementally by a distance equal to the flange width divided by the transverse mesh density. This is incremented until an $x$-coordinate of $+1 / 2$ of the flange width is reached, indicating that the mesh along the width of the flange is complete. Once this first row of nodes is defined, this pattern is repeated along the length of the flange (i.e. the y-direction) until the grid of nodes is defined for the bottom flange.

An empty matrix is then created that is the total number of nodes by four in size. The first column denotes the node numbers and remaining three columns denote the $\mathrm{x}-\mathrm{y}$ - and $\mathrm{z}-$ coordinates of each node, respectively. Once the spacing and position of the nodes are defined, a series if-then statements and for loops are used to iterate the node numbers and node coordinates for the entire bottom flange and entered into the empty matrix.

This process is repeated for the top flange and web. For the top flange, the only difference in the generation of the mesh is the inclusion of a z-coordinate (equal to the depth of the girder). It should also be noted that, in the formation of the web node layouts, the nodes shared between the flanges and the web must be identified and reused to ensure the sections are acting as one complete girder. Also, node numbers in a new cross-sectional component need to start at 1 plus the number of nodes in the previous components; otherwise, the previous nodes will be copied over by the new section.

\subsubsection{Element Generation}

Once the nodes have been generated and defined the elements are then defined and generated for the bottom flange. The number of elements in both the longitudinal and horizontal directions will be one less than the number of nodes in both directions. Once this is determined the total number of elements in the section is the product of the number of elements in both directions. An empty matrix that is the total number elements long by five is created to define the elements. The first column denotes the element number definition and remaining four columns denote the four nodes that define that element. The element number definition is defined using a for-loop to iterate until the total numbers of elements are reached. The first row of elements are

created using a for-loop and inserted into the empty matrix. Once the first row of elements is defined another for-loop is used to repeat the remaining rows of elements in the section. Like 
before, this process is repeated for the top flange and the web with the element numbers from the previous section being added to the new section.

\subsubsection{Skew Adjustment}

A skew adjustment is made to the nodes of the girder if a skew angle is defined by the user. An if-then statement is used to apply the skew adjustment. If the skew is defined as zero by the user, the skew adjustment is not applied; otherwise the adjustment is made to the nodes in the bottom and top flange.

\subsubsection{Girder Layout}

Once one girder's finite element mesh has been developed, multiple girders can be formulated by copying the information for the first girder. The node and element numbers of the initial girder are increased by the number of nodes and elements in the previous girder successively for the number of girders defined by the user. The node locations, however, need to be redefined for each girder. This is done by adding the girder spacing to each node coordinate successively for each girder until all girders are placed evenly at the specified girder spacing. In addition, if a skew angle is specified by the user, the skew adjustment is made which adjust the girders' respective position along the span.

\subsubsection{Stiffener \& Cross-frames Generation}

As mentioned before, stiffeners and cross-frames are modeled as B33 elements. Crossframes are spaced evenly in the simple span bridge algorithm. The user inputs a number of crossframes desired for a given bridge. The user must layout cross-frames, ensuring the number of cross-frames used will fit evenly in the bridge span and fall on the mesh points created by the user. An unbraced length is determined by taking the total length divided by one less the number of cross-frames. Using this unbraced length, nodes in the girder are located and B33 elements are created for each of the stiffeners through a serious of if-then statements and for loops. Once the stiffeners are created for one girder, they can be replicated for the remaining girders as 
previously described for the nodes of the girders. Cross-frames require location of the nodes at flange-web junctions. These nodes were used as the connection point between the girders and the cross-frames. In addition, new nodes need to be defined for the cross-frame elements between the girders. The elements are then created using the nodes from the girders and the newly created cross-frame nodes.

\subsubsection{Node/Element Sets}

Node and elements sets are defined for the sections of the girder, stiffeners, cross-frames, boundary conditions, load sets, and stress query sets. Sets are a list of the numbers that define the nodes or elements and will be used for application of materials, loads, thickness application, and to query stresses. Figure 4.2 shows an image of the element set created for querying the LFB stresses in the exterior girder. The element set is selected and is highlighted in red.
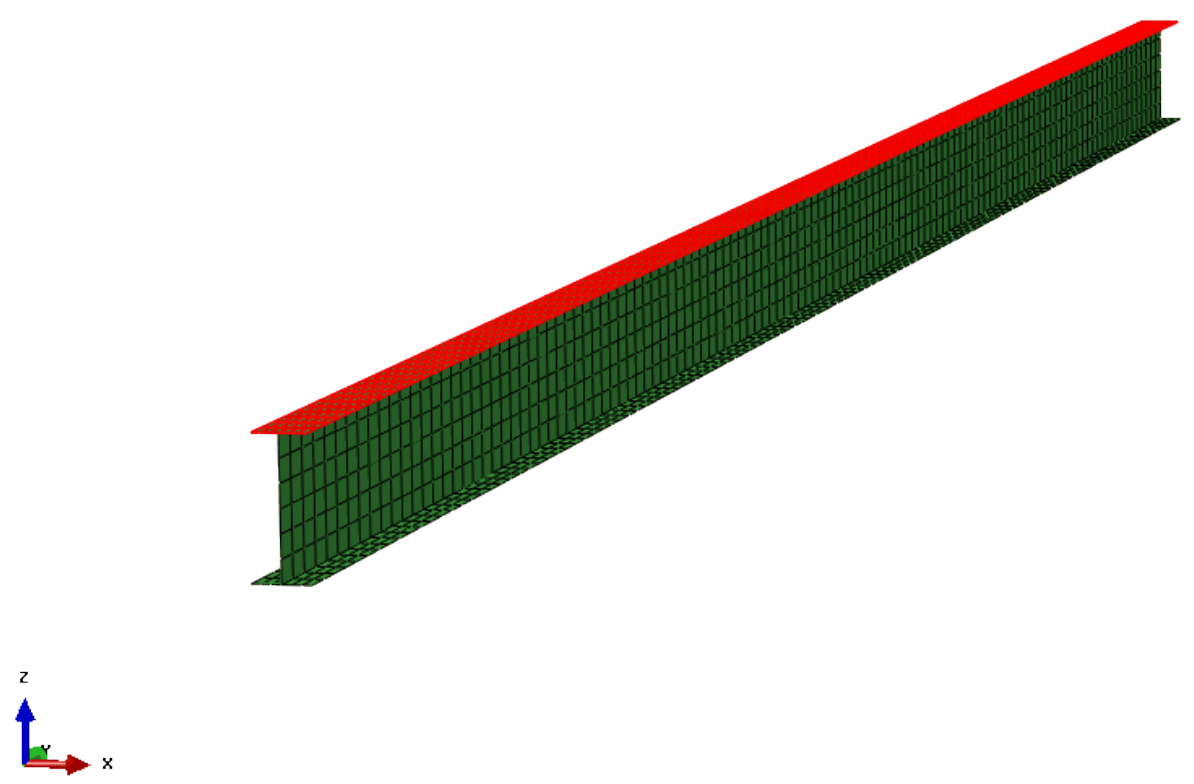

Figure 4.2: Element Set 


\subsubsection{Loading}

Loads are applied to the node sets created as discussed in the previous section in three steps to represent the loading during a bridges erection and deck casting phase.

- Step One: Gravity Load- the self weight of the steel super structure

- Step Two: Construction loads (Overhang brackets, SIP forms, Formwork, etc.)

- Step Three: Weight of wet concrete in addition to construction loads.

It should be noted in the simple-span bridges the worst case scenario was known to be the full pour of the concrete thus only one load state was investigated ( Barth et all, 2011). Loads were calculated internally from the given loads to be applied as either a horizontal load or vertical load to a node point to represent how the load was applied during the load steps. In Figure 4.3 the loads can been seen applied directly to the girder nodes as yellow arrows. The exterior girders are loaded horizontally and vertically at top and bottom joints as that's where the overhangs connect to the girder. Refer to Figure 2.9 for a description of the calculation of these loads.

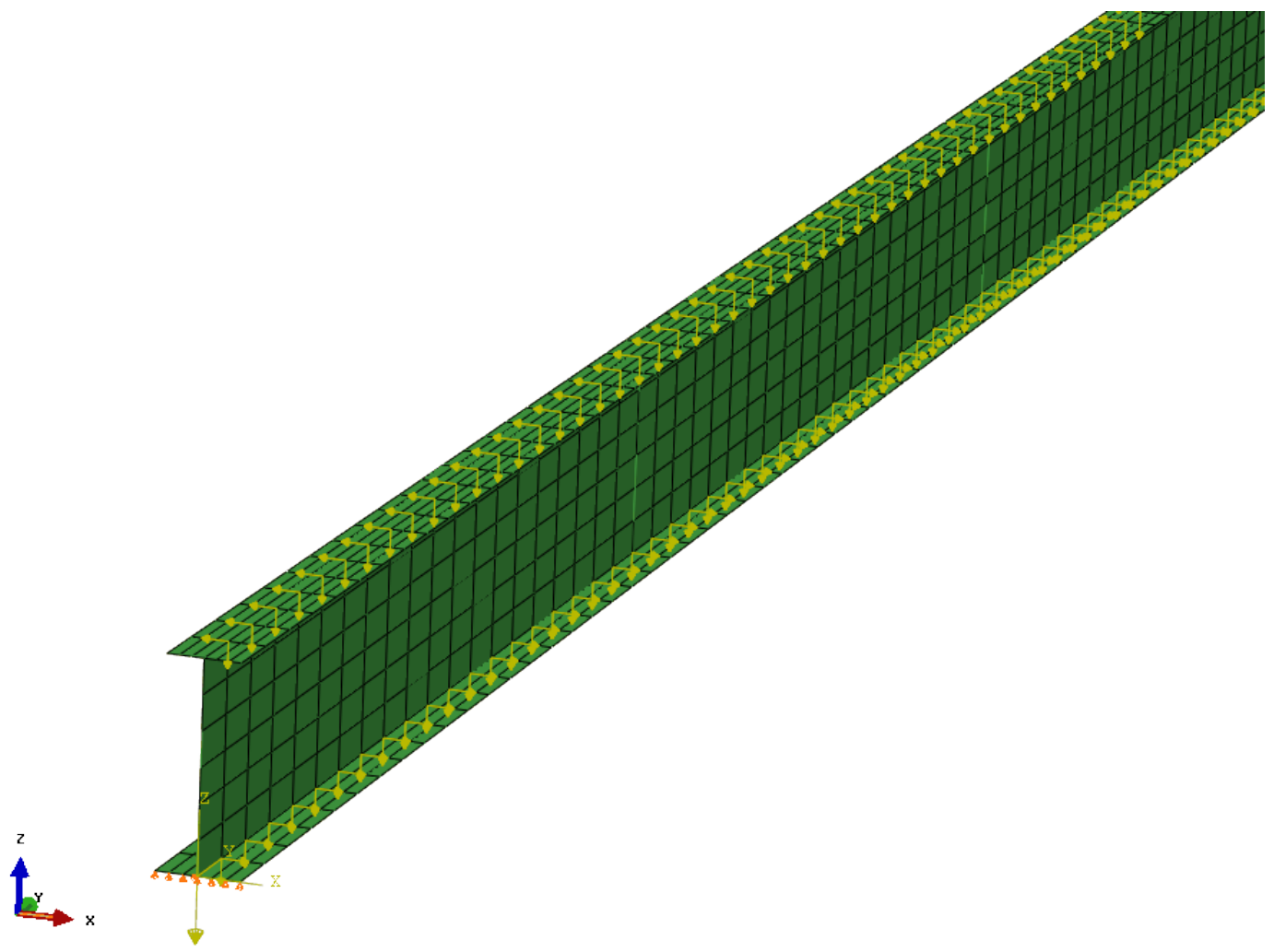

Figure 4.3: Loads Applied to Girders 


\subsubsection{Preprocessing \& Analysis Routine}

Once the parameters necessary for the generation of an ABAQUS input file have been determined and/or computed the fprintf command is used to print information generated in the algorithm into an .inp file. A list of all the nodes, elements, sets, loads/load steps, and material definitions are created with the proper syntax necessary for an ABAQUS input file. Figure 4.4 illustrates a bridge in the Abaqus CAE interface that results from using the MATLAB routine to generate an inp file. This example bridge has a span length of 60 feet and is comprised of 4 girders spaced at 10.5 feet.
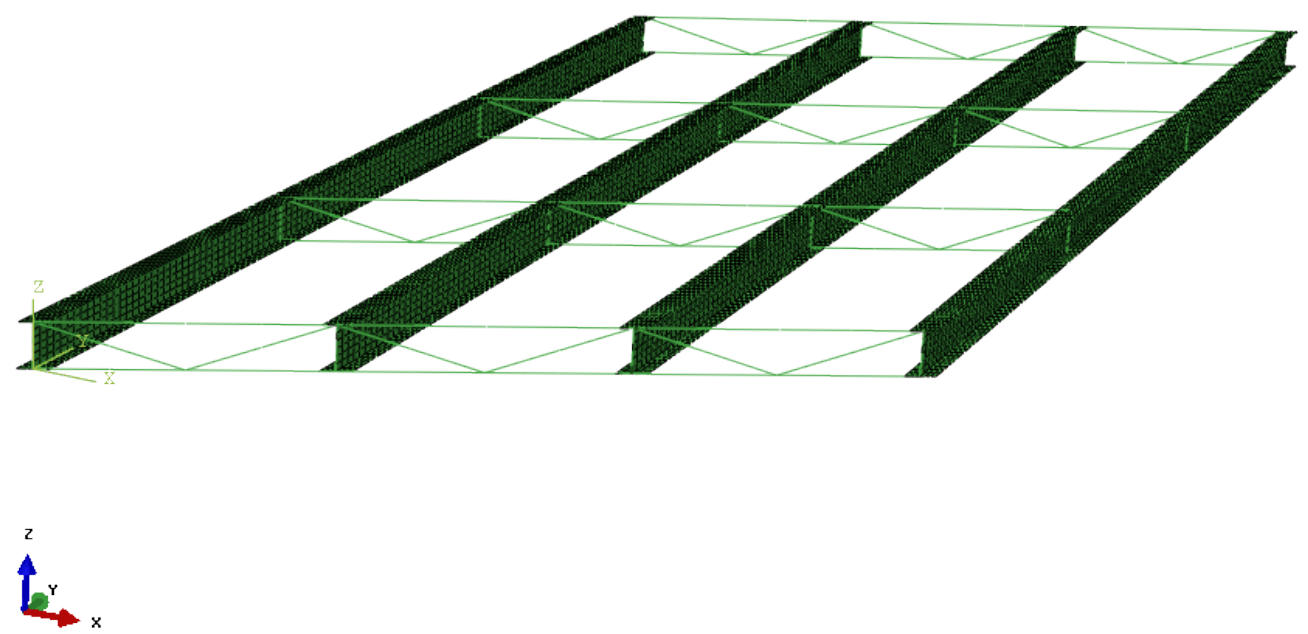

Figure 4.4: Bridge Generated by Algorithm

\subsubsection{Post Processing and Routine}

A MATLAB post processing file was developed to run the analysis portion of the model in ABAQUS. Once the analysis has been performed stresses can be queried from the dat file created by ABAQUS. In addition to the analysis the post processing file calculates the major axis 
bending $\left(f_{b u}\right)$ and LFB $\left(f_{\ell}\right)$ stresses from $f_{1}$ and $f_{2}$ using equations 4.1 and 4.2. Figure 4.5 illustrates these calculations.

$$
\begin{aligned}
& f_{b u}=\frac{f_{1}+f_{2}}{2} \\
& f_{\ell}=f_{\text {total }}-f_{b u}
\end{aligned}
$$

Equation 4.2

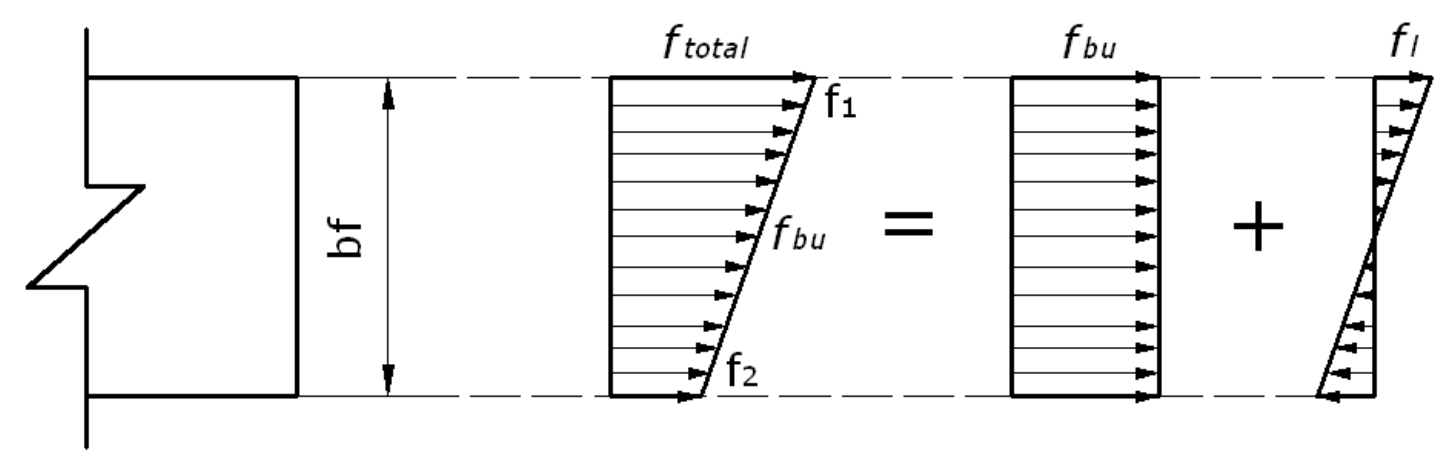

Figure 4.5: Identification of $f_{e}$ and $f_{b u}$ from Total Flange Bending (Galindez, 2009)

The post processing file generates a normalized plot of the LFB moments and the current AASHTO approximation for LFB moments. Figure 4.6 shows a sample of one of the plots generated by ABAQUS. Where $\mathrm{L}$ is the length of the bridge, $\mathrm{S}$ is the girder spacing, $\mathrm{SK}$ is the skew angle, $\mathrm{CF}$ is the number of cross-frames and $\mathrm{PG}$ denotes a plate girder. 


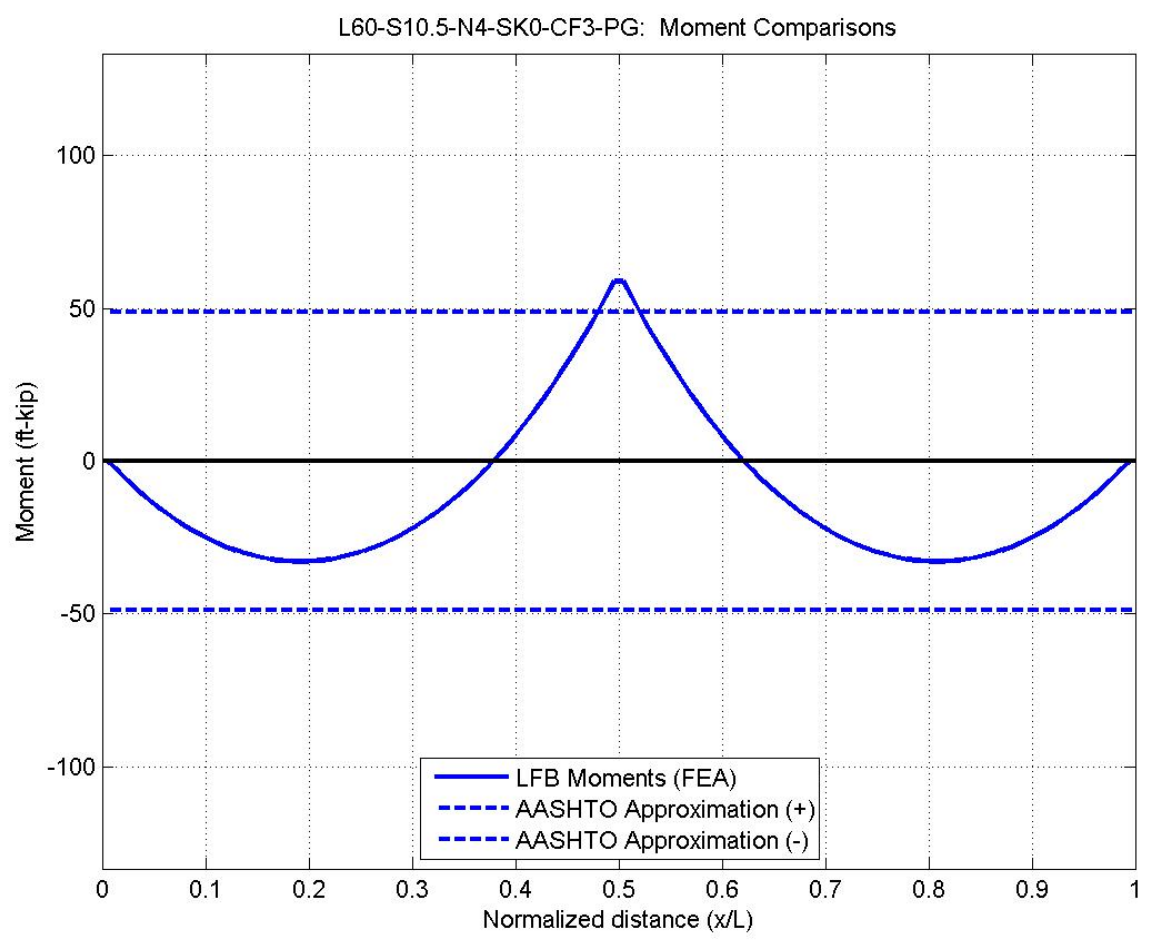

Figure 4.6: Plot of Stresses Generated by Post Processing File

\subsection{SUMMARY}

The proceeding chapter outlined finite element modeling techniques used for this research project. Element selections, material definitions, mesh discretization, boundary conditions used, and load applications were all details discussed in this chapter. In addition the formulation of a MATLAB algorithm for the modeling of simple span bridges was presented as well. It should be noted that the algorithm and the post-processing file are provided in Appendix C. 


\section{CHAPTER 5: INVESTIGATION OF LATERAL FLANGE BENDING IN SIMPLE-SPAN I-GIRDER BRIDGES}

\subsection{INTRODUCTION}

This chapter discusses the simple span bridges modeled for the investigation of LFB. Two separate parametric matrices were developed in this study. The first matrix focuses on the effects of skew and the unbraced length $(\mathrm{Lb})$ on LFB, while the second matrix focuses on the effects of girder spacing and total span length on LFB. Details of both parametric matrices are provided along with a detailed discussion of the results of the study.

\subsection{PARAMeTric STUdy \#1 (SKeW/UnBRACED LENGTH)}

A total 21 bridges were modeled in this parametric matrix to determine the effects of skew and the unbraced length on LFB. This section will discuss the constant and varied parameters in detail. In addition, this section will discuss the results from the FEA modeling of the bridges in this parametric matrix.

\subsubsection{Constant Parameters}

The following parameters were kept constant in the parametric matrix:

- Slab thickness $=8.25$ inches

- Integral wearing surface $=0.25$ inches

- Effective slab thickness $=8.5$ inches

- Haunch $=2$ inches

- Number of Girders $=4$

- Girder spacing $=10.5$ feet

- Overhang $=39$ inches

- K-style cross-frames ( see Figure 5.1) 
Figure 5.2 shows a cross section of the bridge employed in this parametric matrix.

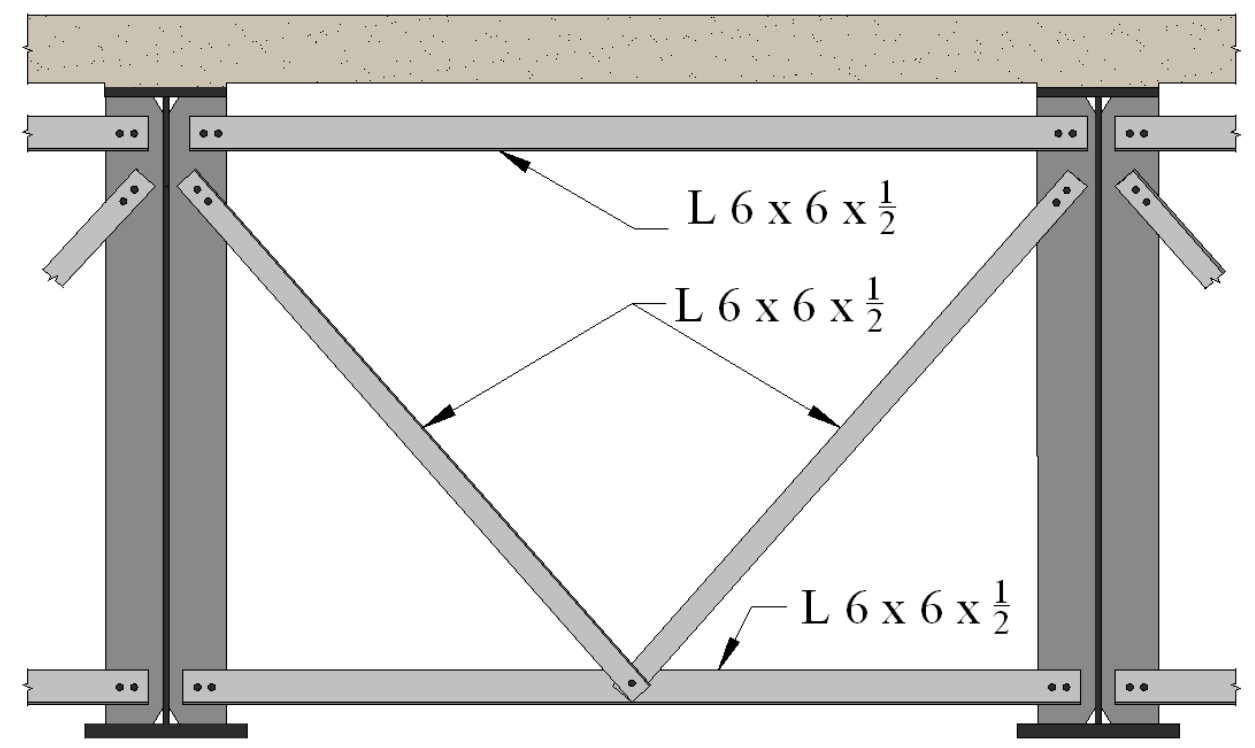

Figure 5.1: Cross-frame Orientation

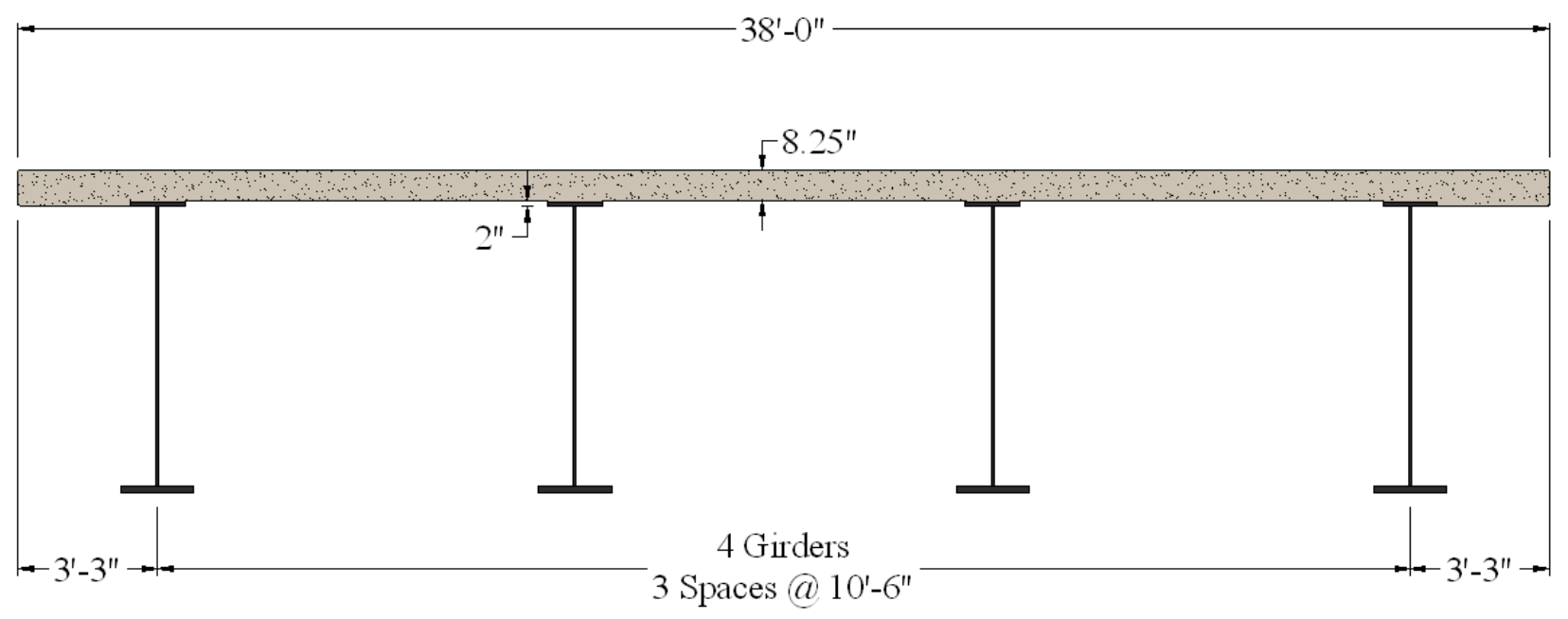

Figure 5.2: Parametric Matrix \# 1 Bridge Cross-section 


\subsubsection{Varied Parameters}

The following parameters were varied in the parametric matrix:

- Two span lengths: 40 feet and 60 feet.

- Four skew angles: $0^{\circ}, 15^{\circ}, 30^{\circ}$, and $45^{\circ}$.

- Two unbraced $\left(\mathrm{L}_{\mathrm{b}}\right)$ lengths: 20 feet and 30 feet.

- Two cross-frame orientations: parallel and staggered (see Figure 5.3)

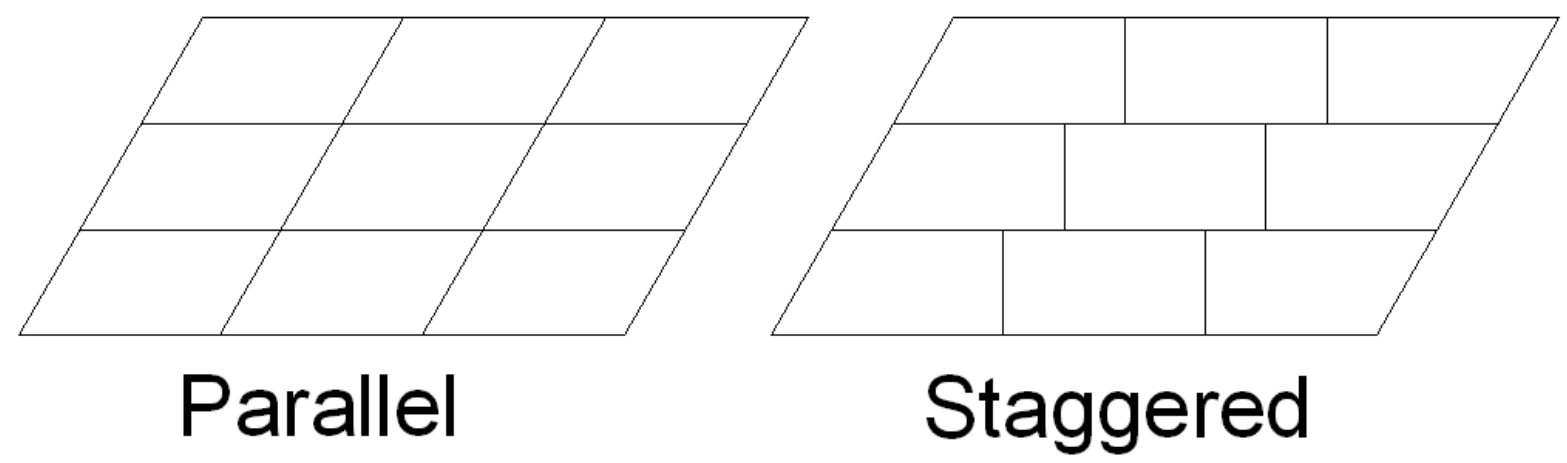

Figure 5.3: Cross-frame Orientation

\subsubsection{Girder Design}

The bridges used in this study were designed according to current AASHTO LRFD Specifications (American Association of State Highway and Transportation Officials, 2010). Figure 5.4 along with Table 5.1 shows elevation view of the girder and plate size information.

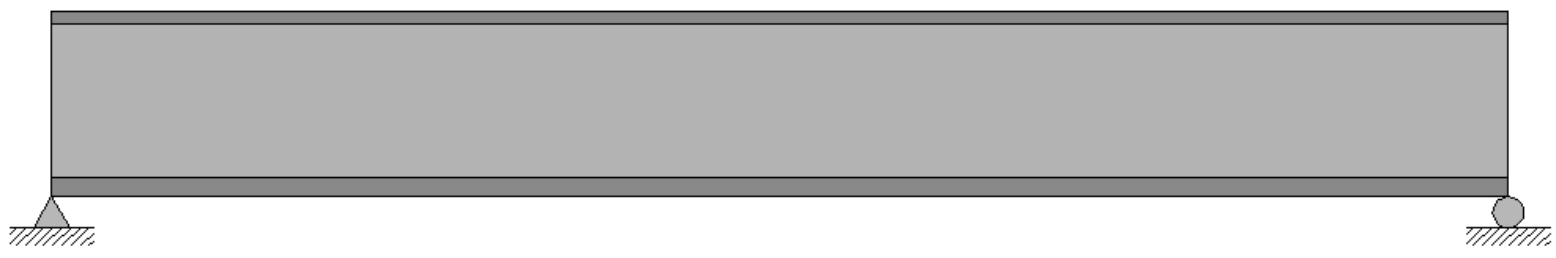

Figure 5.4: Girder Elevation View 
Table 5.1: Girder Dimensions Parallel Cross-frames

\begin{tabular}{|c|c|c|c|c|c|c|c|c|}
\hline \multirow{2}{*}{$L(f t)$} & \multicolumn{2}{|c|}{ Top Flange } & \multicolumn{2}{c|}{ Bottom Flange } & \multicolumn{2}{c|}{ Web } & \multicolumn{2}{c|}{ Stiffeners } \\
\cline { 2 - 9 } & $b_{t f}$ (in) & $t_{\text {tf }}($ in $)$ & $b_{\text {tf }}($ in $)$ & $t_{\text {tf }}($ in $)$ & $d_{w}($ in $)$ & $t_{w}$ (in) & $t_{\text {brg }}$ (in) & $t_{\text {int }}$ (in) \\
\hline 40 & 16 & 0.75 & 16 & 0.75 & 24 & 0.5 & 0.625 & 0.625 \\
$60(\mathrm{Lb}=30)$ & 16 & 1.25 & 18 & 1 & 32 & 0.5 & 0.625 & 0.625 \\
$60(\mathrm{Lb}=20)$ & 14 & 1 & 16 & 1.5 & 28 & 0.5 & 0.625 & 0.625 \\
\hline
\end{tabular}

Table 5.2: Girder Dimensions Staggered Cross-frames

\begin{tabular}{|c|c|c|c|c|c|c|c|c|}
\hline \multirow{2}{*}{$L(f t)$} & \multicolumn{2}{|c|}{ Top Flange } & \multicolumn{2}{c|}{ Bottom Flange } & \multicolumn{2}{c|}{ Web } & \multicolumn{2}{c|}{ Stiffeners } \\
\cline { 2 - 9 } & $b_{t f}$ (in) & $t_{\text {tf }}($ in $)$ & $b_{\text {tf }}($ in $)$ & $t_{\text {tf }}($ in $)$ & $d_{w}($ in $)$ & $t_{w}$ (in) & $t_{\text {brg }}$ (in) & $t_{\text {int }}$ (in) \\
\hline 40 & 16 & 0.75 & 16 & 0.75 & 24 & 0.5 & 0.625 & 0.625 \\
$60(\mathrm{Lb}=30)$ & 16 & 1.25 & 18 & 1 & 32 & 0.5 & 0.625 & 0.625 \\
$60(\mathrm{Lb}=20)$ & 16 & 1 & 16 & 1.5 & 28 & 0.5 & 0.625 & 0.625 \\
\hline
\end{tabular}

\subsection{Results of Parametric Study \#1}

As stated before the AASHTO approximations for lateral flange bending moments are given again for the purpose of discussion in this chapter.

$$
\begin{aligned}
& M_{\ell}=\frac{F_{\ell} L_{b}^{2}}{12} \\
& M_{\ell}=\frac{P_{\ell} L_{b}}{8}
\end{aligned}
$$

Equation 5-1 accounts for distributed lateral loads from the forming brackets while Equation 5-2 accounts for the concentrated lateral loads due to the concrete screed machine. In the study performed on the simple span bridges discussed in this chapter, only the full pour was considered as this was the worst case scenario. Therefore, only Equation 5-1 applies, and the point load of the finishing machine is not included. 
Plots provided in this chapter and the subsequent chapters are named using the following letter symbols to denoted variables:

- L - Span Length

- $\mathrm{L}_{\mathrm{b}}$ - Unbraced length between cross-frames

- $\theta$ - Skew Angle

- S- Girder Spacing

\subsubsection{AASHTO comparison to FEA results}

Figure 5.5 shows the FEA results from a $15^{\circ}$ simple span with a parallel cross-frame orientation. The dashed lines represent the AASHTO approximation for LFB moments, while the solid lines represent the FEA results. The regions where the FEA results peak indicate a crossframe location. At these locations the AASHTO approximation is proven to be adequate as indicated by the plot in Figure 5.5. At the location between the cross-frames it can be seen that the AASHTO approximation over estimates the LFB Moments.

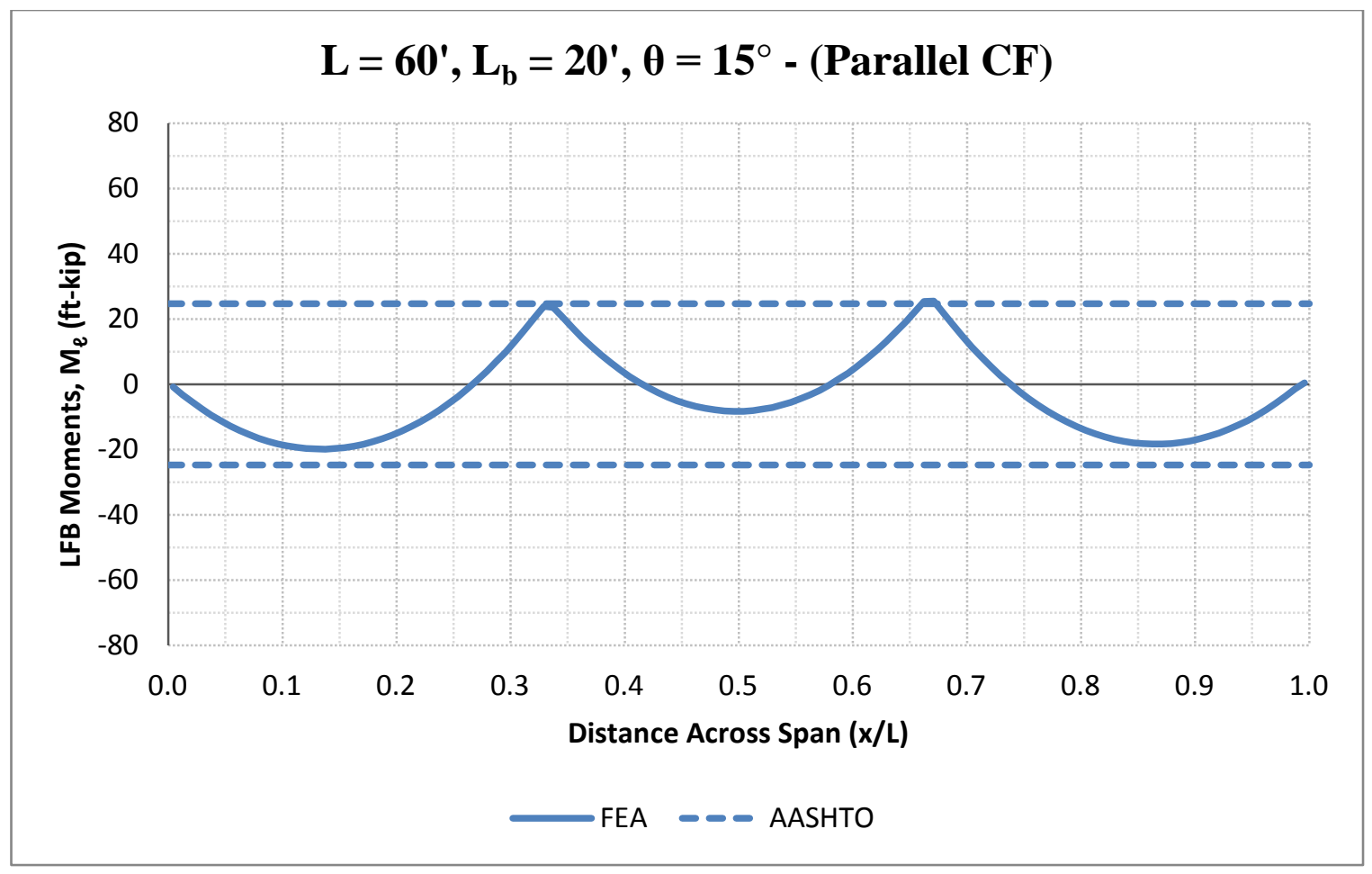

Figure 5.5: Simple Span FEA Results vs. AASHTO Approximation 


\subsubsection{Assessment of Staggered Cross-frames}

Figure 5.6 shows a plot of a staggered cross-frame orientation in comparison to a parallel cross-frame orientation. It can be seen from the plot that there is a reasonable difference in LFB between the two cross-frame orientations. However, a staggered cross-frame orientation presents multiple varying parameters. The unbraced length in a staggered cross-frame orientation varies with the skew angle making it difficult to isolate a single parameter for having an effect on LFB. Therefore, parameters were investigated in a parallel cross-frame orientation in order to keep certain parameters constant while varying the parameter of concern.

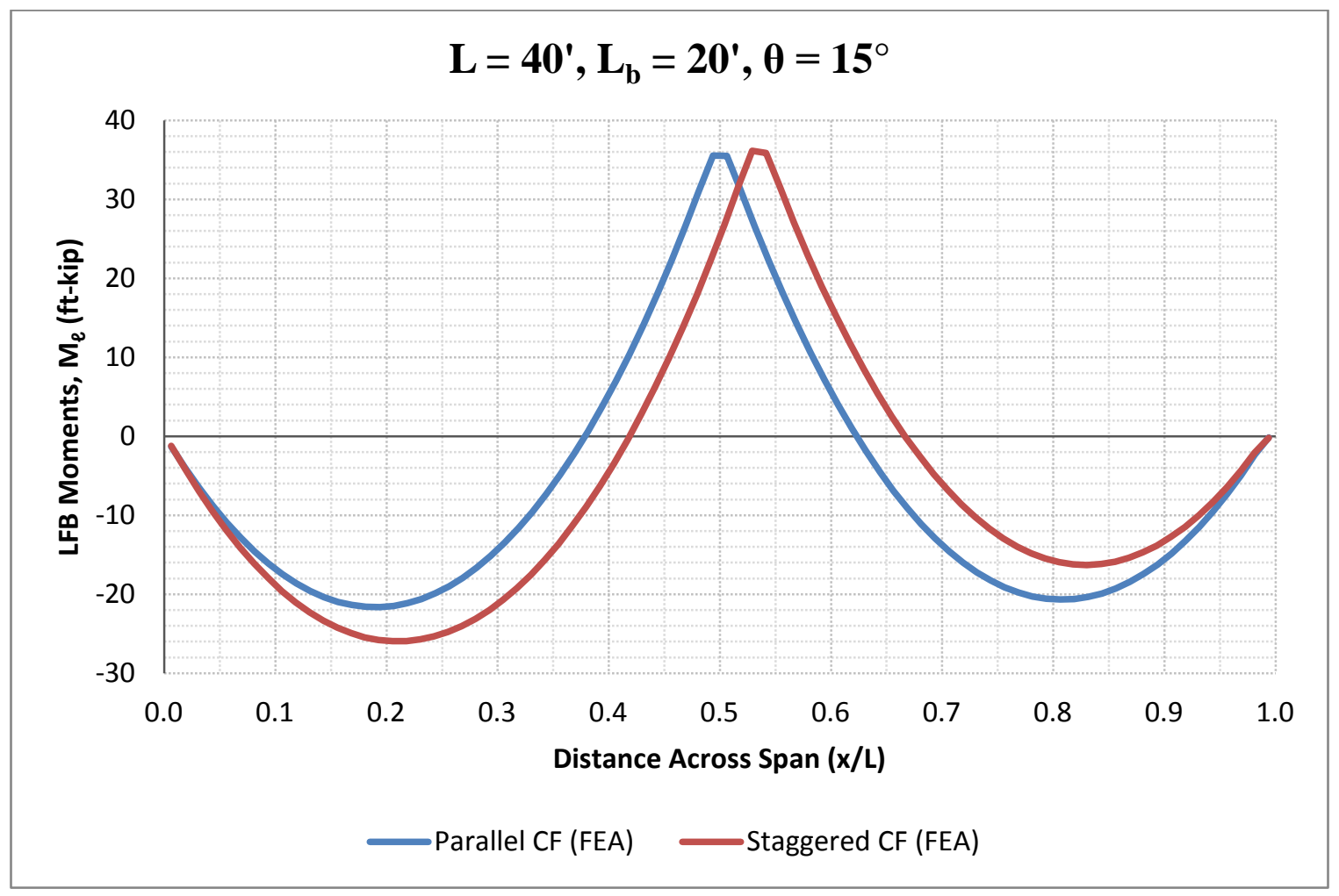

Figure 5.6: Parallel vs. Staggered Orientation 


\subsubsection{Assessment of Unbraced Length}

Moment ratio plots were generated that take the ratio of the FEA result that occurs at the mid span of the first unbraced length and the AASHTO approximation. The FEA result at this point is shown in the data to be the worst case for LFB moments thus was used for the moment ratio. These plots give a better view of FEA results in comparison to the AASHTO approximation and are used in subsequent sections. The moment ratio plot in Figure 5.7 shows that an increase in the $\mathrm{L}_{b}$ creates a larger deviation from the AASHTO approximation. The unbraced length of 30 feet has moment ratio values with a larger deviation from the value of one which is the AASHTO approximation value. This observation is supported by the plot shown in Figure 5.8. Figure 5.8 shows comparison of LFB moments between two simple span bridges with only the $L_{b}$ varying. It can be seen that there is a significant increase in LFB with an increase in $\mathrm{L}_{\mathrm{b}}$ as would be expected.

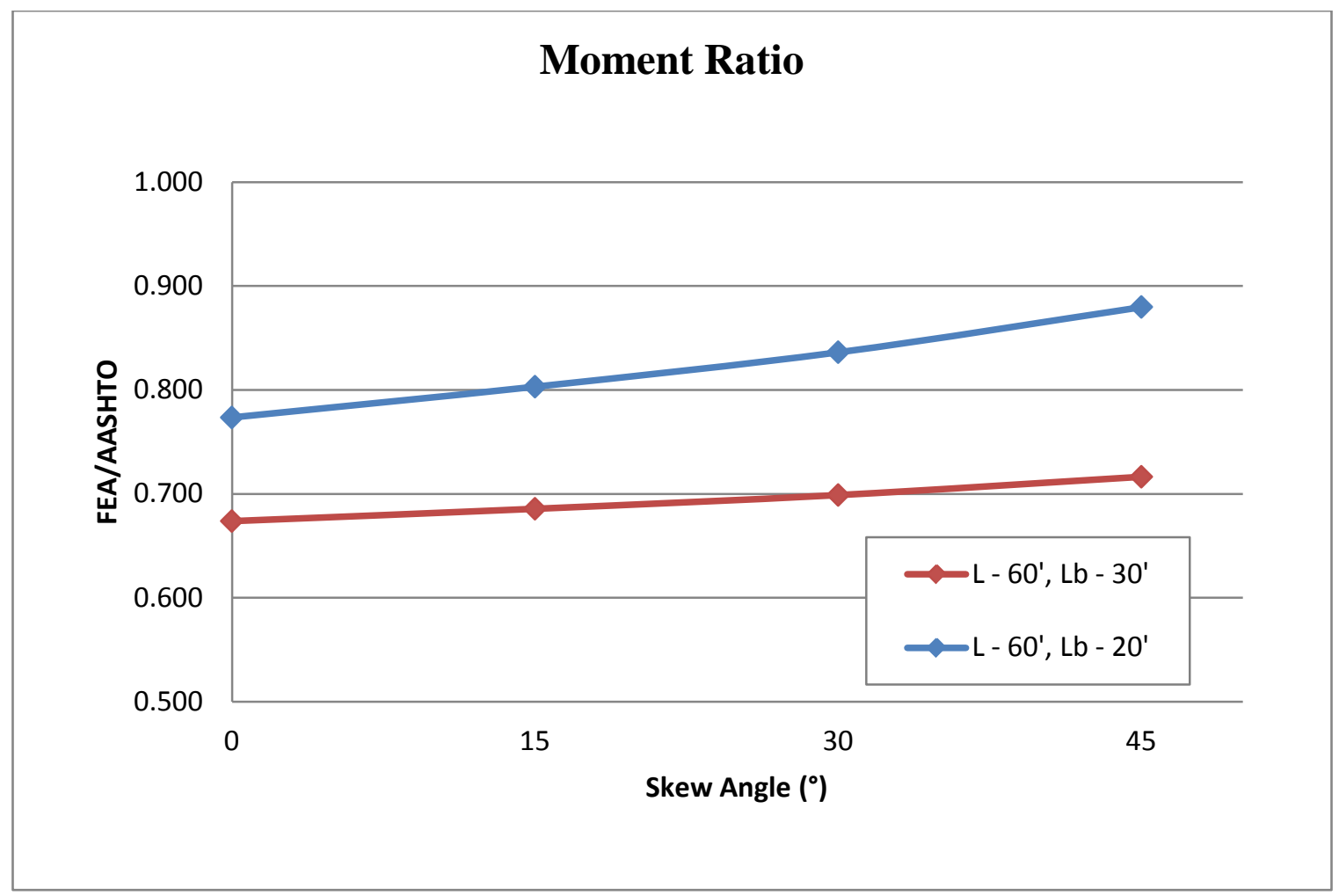

Figure 5.7: Moment Ratio Plot for $L_{b}$ Comparison 


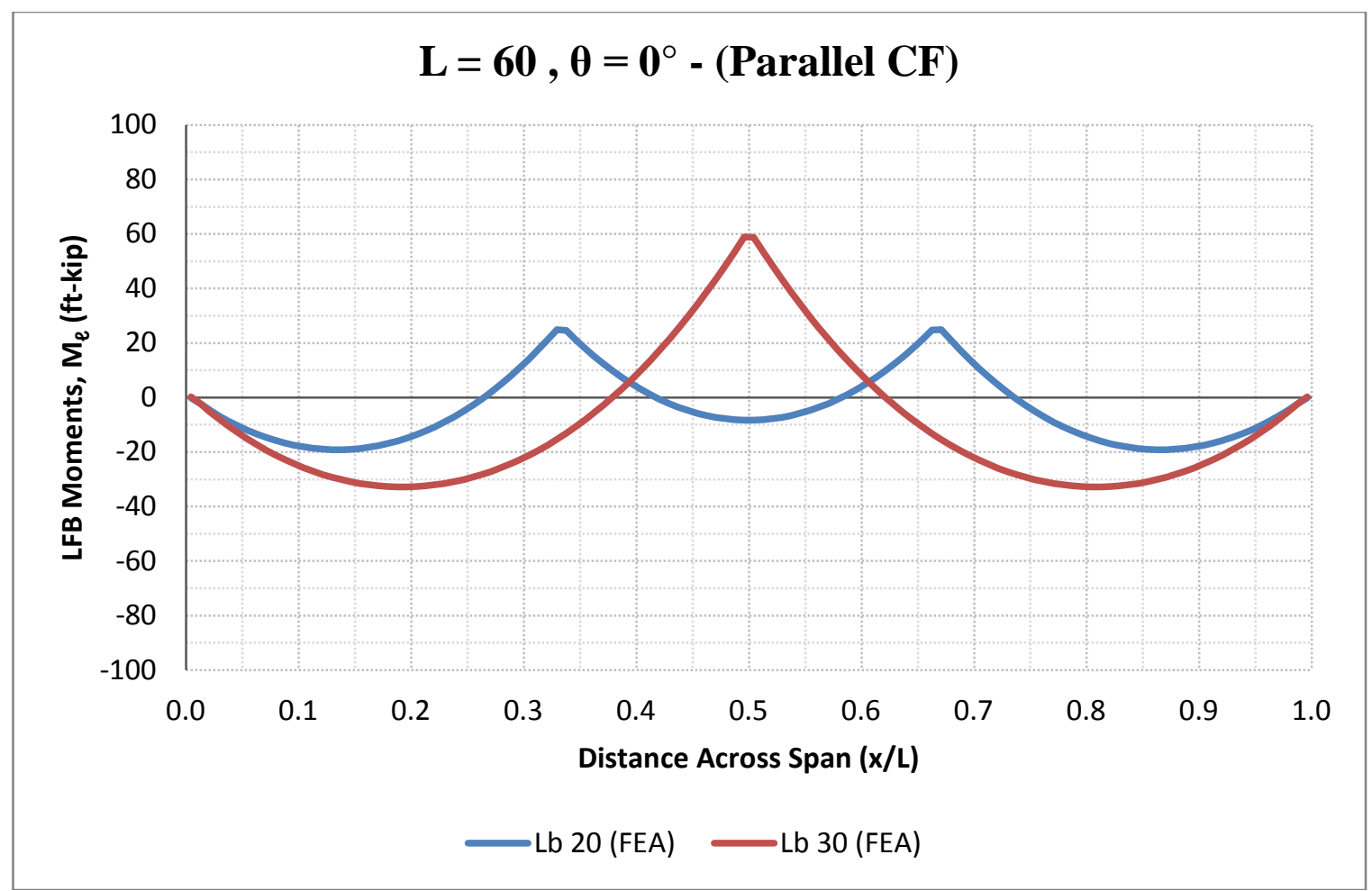

Figure 5.8: FEA $L_{b}$ Comparison Plot

\subsubsection{Assessment of Span Length}

The moment ratio plot shown in Figure 5.9 shows a comparison of two bridges with varying span length. It can be seen from the plot that the AASHTO approximation becomes more accurate as the span length increases. The moment ratios of the larger span length are closer to the AASHTO approximation value of one. Figure 5.10 shows a comparison of two bridges with a constant $\mathrm{L}_{\mathrm{b}}$ and varying in span length. In comparing the minimum LFB of the first unbraced length of each bridge; it can be seen that there are larger LFB moments on the shorter span bridge. 


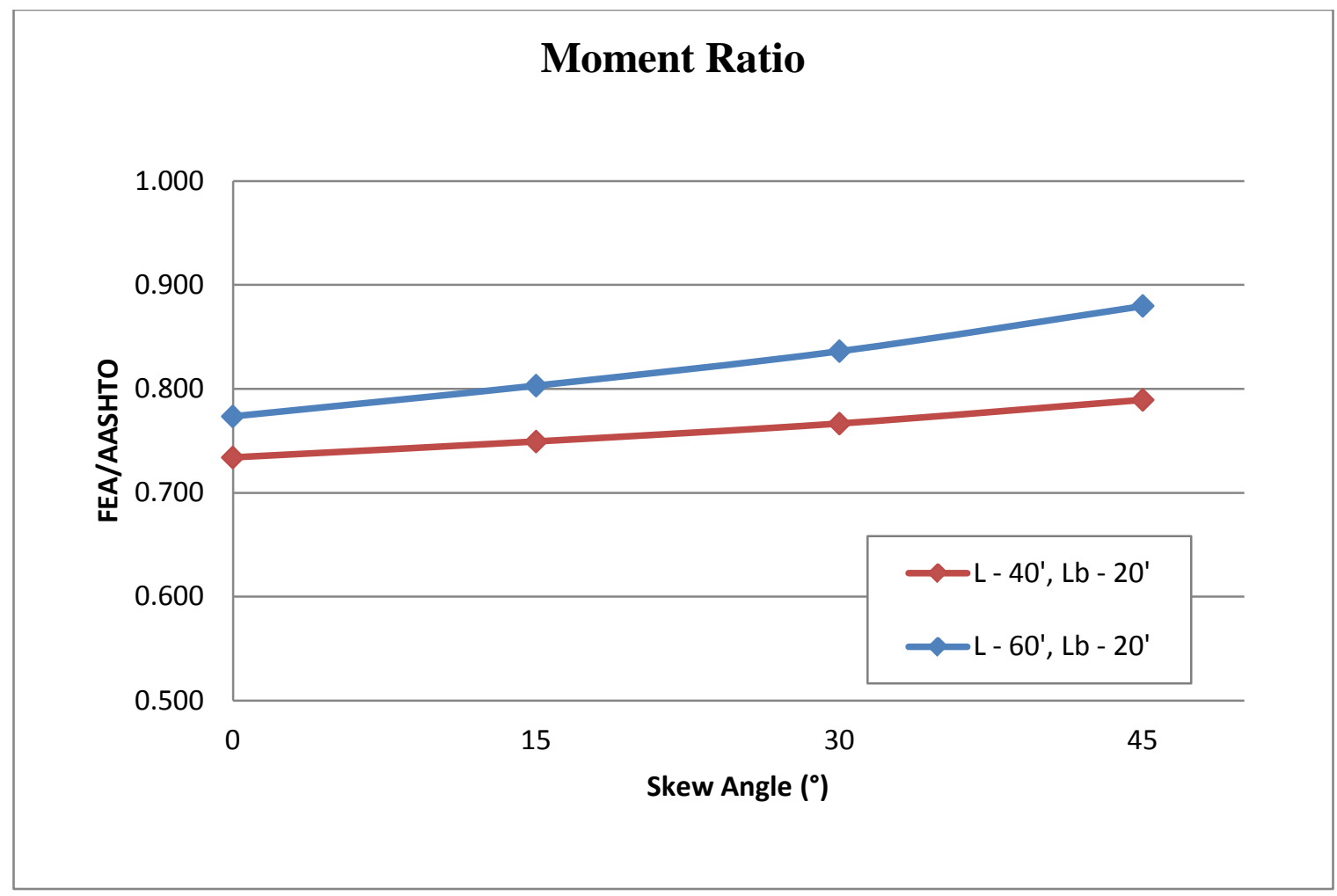

Figure 5.9: Moment Ratio Plot for Span Length Comparison

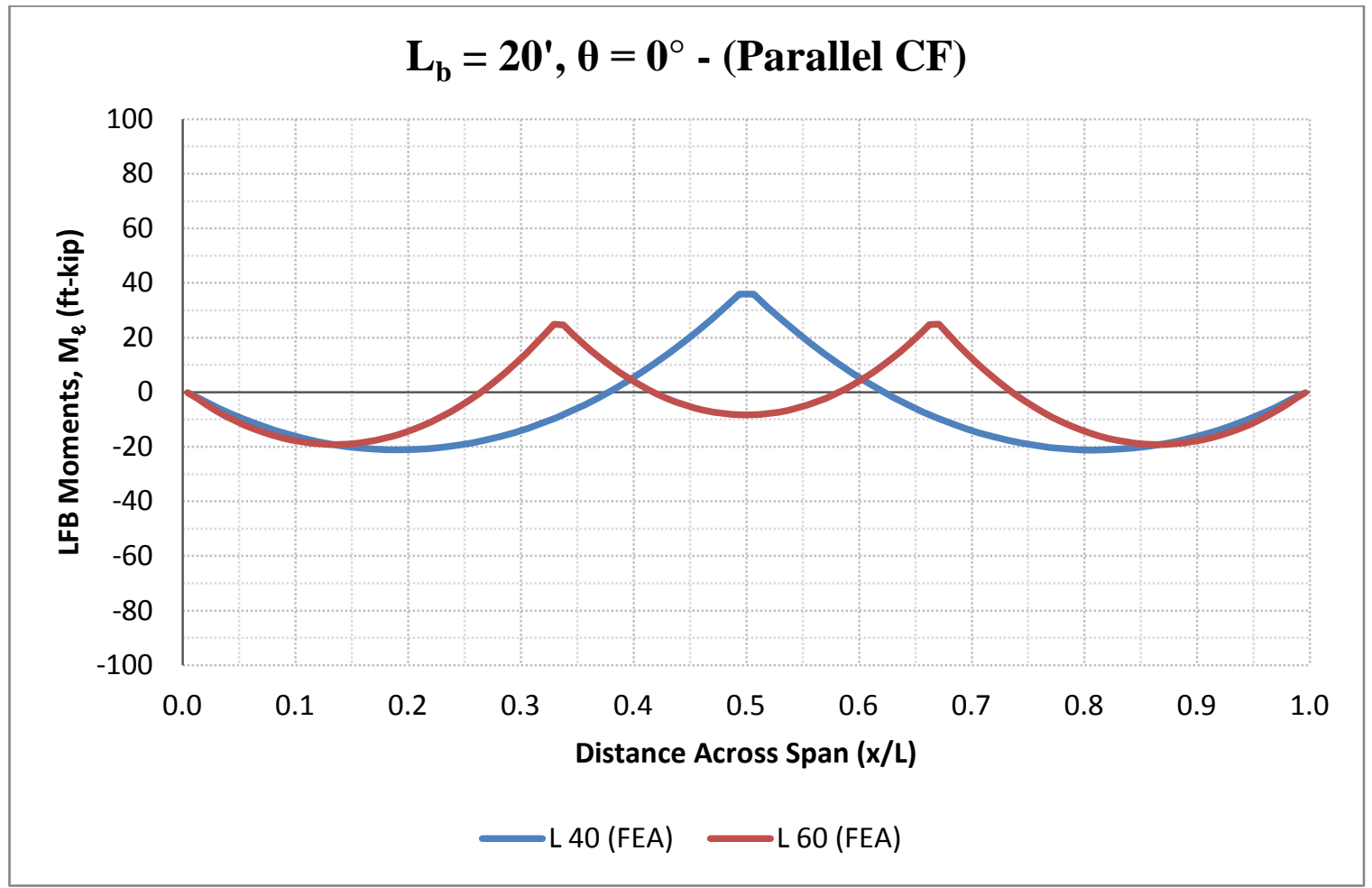

Figure 5.10: FEA Span Length Comparison Plot 


\subsubsection{Assessment of Skew}

Figures 5.7 and 5.9 both show an increase in the moment ratio with increase in skew, which indicates an increase in LFB with increase in skew. This observation is supported by the plot provided in Figure 5.11. The plot shows the first unbraced length of a single bridge's FEA results skewed at a $0^{\circ}$ skew and a $45^{\circ}$ skew. Figure 5.11 shows a slight increase in LFB from the $0^{\circ}$ skew bridge to the $45^{\circ}$ skew bridge.

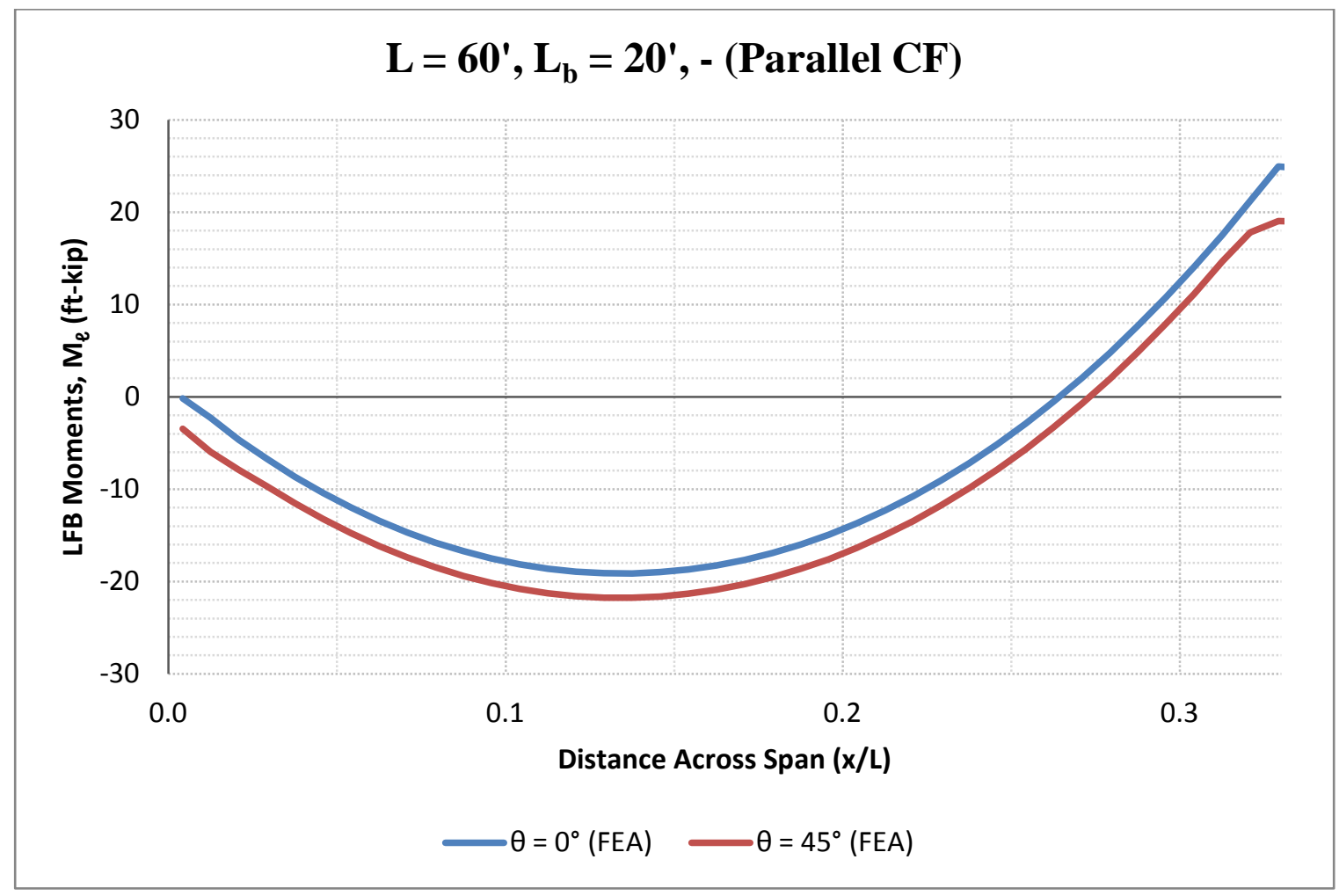

Figure 5.11: FEA Skew Comparison

\subsection{PARAmetric Study \#2 (SPAN Length/Girder Spacing)}

An additional matrix was developed to incorporate differential girder spacing and longer spans lengths to determine if these parameters have an effect on LFB. A total number of 16 bridges were modeled to investigate these parameters. As with the previous matrix the algorithm presented in Section 4.7 was used to model the bridges in this parametric matrix. 


\subsubsection{Constant Parameters}

The following parameters were kept constant in the parametric matrix:

- Slab thickness $=8.25$ inches

- Integral wearing surface $=0.25$ inches

- Effective slab thickness $=8.5$ inches

- Haunch $=2$ inches

- Number of Girders $=4$

- Overhang $=39$ inches

- Unbraced Length $=20$ feet

- Parallel cross-frame orientations

- K-style cross-frames ( see Figure 5.1)

\subsubsection{Varied Parameters}

The following parameters were varied in the parametric matrix:

- Four span lengths: 60, 80, 100, and 120 feet.

- Two skew angles: $0^{\circ}$ and $20^{\circ}$.

- Two Girder spacing's were used $6.0 \mathrm{ft}$ and $10.5 \mathrm{ft}$. and can be seen in the crosssection images in Figures 5.12 and 5.13.

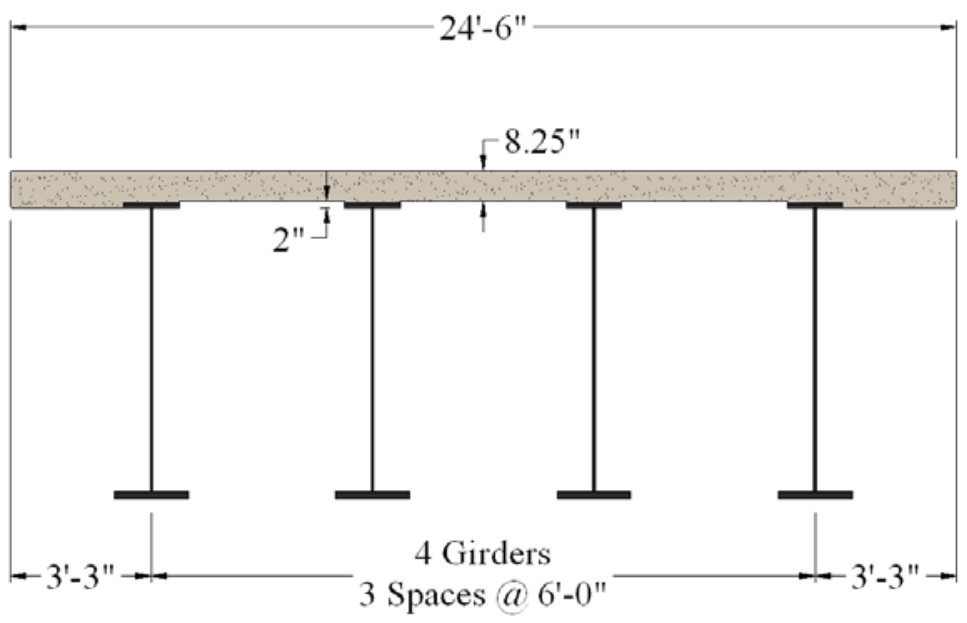

Figure 5.12: Cross-Section with 6 ft. Girder Spacing 


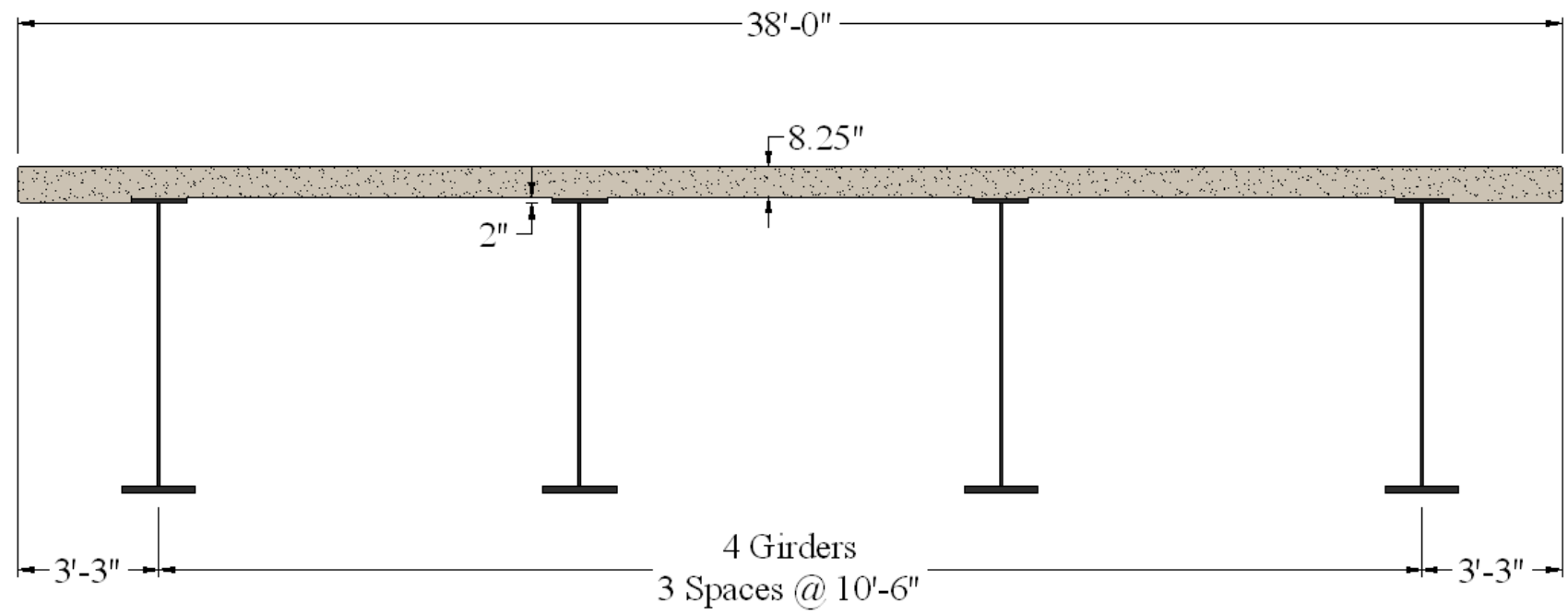

Figure 5.13: Cross-section with $10.5 \mathrm{ft}$. Girder Spacing

\subsubsection{Girder Design}

The girders selected for this parametric matrix were selected from the Steel Market Development Institute (SMDI) Short Span Bridge Standards (Morgan, 2010). Figures 5.14 and 5.15 shows the two girder elevations used in this parametric matrix. Tables 5.2 through 5.5 list the plate sizes for each of the girders in this parametric matrix.

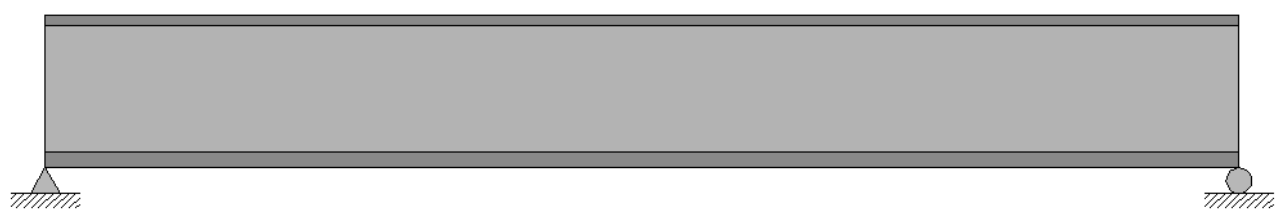

Figure 5.14: Girder Elevation View 


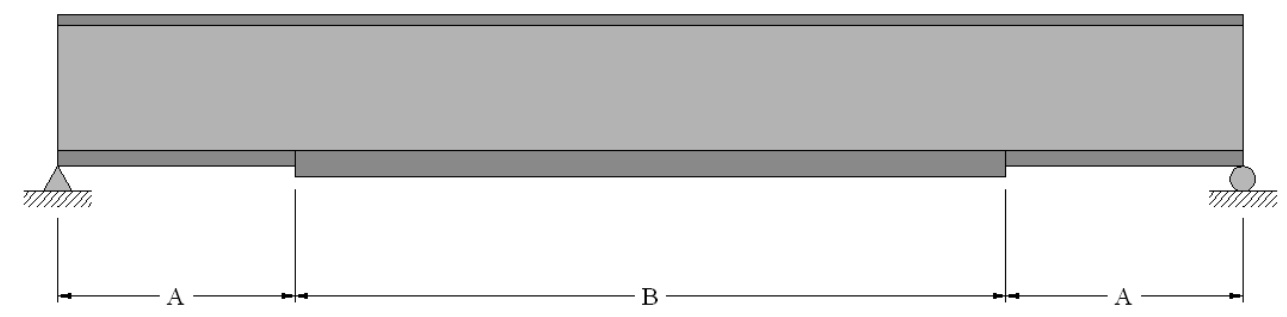

Figure 5.15: Girder with Bottom Flange Transition Elevation View

Table 5.3: Girder Dim. For Const. Bottom Flange Thickness (Girder Spacing = 6 ft.)

\begin{tabular}{|c|cc|c|c|c|c|c|c|}
\hline \multirow{2}{*}{ L(ft) } & \multicolumn{2}{|c|}{ Top Flange } & \multicolumn{2}{c|}{ Bottom Flange } & \multicolumn{2}{c|}{ Web } & \multicolumn{2}{c|}{ Stiffeners } \\
\cline { 2 - 9 } & $b_{t f}$ (in) & $t_{\text {tf }}($ in $)$ & $b_{t f}($ in $)$ & $t_{\text {tf }}($ in $)$ & $d_{w}($ in $)$ & $t_{w}($ in $)$ & $t_{\text {brg }}$ (in) & $t_{\text {int }}$ (in) \\
\hline 60 & 12 & 1 & 14 & 0.75 & 24 & 0.5 & 0.625 & 0.625 \\
80 & 12 & 0.75 & 18 & 1 & 32 & 0.5 & 0.625 & 0.625 \\
\hline
\end{tabular}

Table 5.4: Girder Dim. For Varying Bottom Flange Thickness (Girder Spacing = 6 ft.)

\begin{tabular}{|c|c|c|c|c|c|c|c|c|c|c|}
\hline \multirow{2}{*}{$\mathbf{L}(\mathbf{f t})$} & \multicolumn{2}{|c|}{ Top Flange } & \multicolumn{2}{|c|}{ Bottom Flange (A) } & \multicolumn{2}{|c|}{ Bottom Flange (B) } & \multicolumn{2}{|c|}{ Web } & \multicolumn{2}{|c|}{ Stiffeners } \\
\hline & $b_{t f}(i n)$ & $t_{t f}(i n)$ & $b_{t f}(\mathrm{in})$ & $t_{t f}(\mathrm{in})$ & $b_{t f}(\mathrm{in})$ & $t_{t f}(\mathrm{in})$ & $d_{w}($ in $)$ & $t_{w}(i n)$ & $t_{b r g}(\mathrm{in})$ & $t_{\text {int }}$ (in) \\
\hline 100 & 14 & 0.75 & 16 & 1 & 16 & 1.5 & 40 & 0.5 & 0.625 & 0.625 \\
\hline 120 & 16 & 0.75 & 18 & 1 & 18 & 1.5 & 46 & 0.5 & 0.625 & 0.625 \\
\hline
\end{tabular}

Table 5.5: Girder Dim. For Const. Bottom Flange Thickness (Girder Spacing = 10.5 ft.)

\begin{tabular}{|c|c|c|c|c|c|c|c|c|}
\hline \multirow{2}{*}{$L(f t)$} & \multicolumn{2}{|c|}{ Top Flange } & \multicolumn{2}{c|}{ Bottom Flange } & \multicolumn{2}{c|}{ Web } & \multicolumn{2}{c|}{ Stiffeners } \\
\cline { 2 - 10 } & $b_{t f}$ (in) & $t_{\text {tf }}($ in $)$ & $b_{t f}($ in $)$ & $t_{\text {tf }}($ in $)$ & $d_{w}($ in $)$ & $t_{w}($ in) & $t_{\text {brg }}$ (in) & $t_{\text {int }}$ (in) \\
\hline 60 & 12 & 0.75 & 14 & 1.5 & 24 & 0.5 & 0.625 & 0.625 \\
\hline
\end{tabular}

Table 5.6: Girder Dim. For Varying Bottom Flange Thickness (Girder Spacing = 10.5 ft.)

\begin{tabular}{|c|c|c|c|c|c|c|c|c|c|c|}
\hline \multirow{2}{*}{$\mathbf{L}(\mathbf{f t})$} & \multicolumn{2}{|c|}{ Top Flange } & \multicolumn{2}{|c|}{ Bottom Flange (A) } & \multicolumn{2}{|c|}{ Bottom Flange (B) } & \multicolumn{2}{|c|}{ Web } & \multicolumn{2}{|c|}{ Stiffeners } \\
\hline & $b_{t f}(i n)$ & $t_{t f}(\mathrm{in})$ & $b_{t f}(i n)$ & $t_{t f}(\mathrm{in})$ & $b_{t f}(\mathrm{in})$ & $t_{t f}(i n)$ & $d_{w}(\mathrm{in})$ & $t_{w}(i n)$ & $t_{b r g}$ (in) & $t_{\text {int }}$ (in) \\
\hline 80 & 16 & 1 & 16 & 1 & 16 & 1.5 & 32 & 0.5 & 0.625 & 0.625 \\
\hline 100 & 18 & 0.75 & 18 & 1 & 16 & 2 & 40 & 0.5 & 0.625 & 0.625 \\
\hline 120 & 18 & 1 & 20 & 1 & 18 & 2 & 48 & 0.5 & 0.625 & 0.625 \\
\hline
\end{tabular}




\subsection{Results OF PARametric StUdy \#2}

\subsubsection{AASHTO comparison to FEA results}

This section provides comparisons between the results of parametric study 2 and the AASHTO LFB approximation equations. The same observation of the AASHTO approximation made with the first parametric matrix was made in this parametric matrix as well. The plot provided in Figure 5.16 shows the over estimation of LFB moments in the span between the cross-frames.

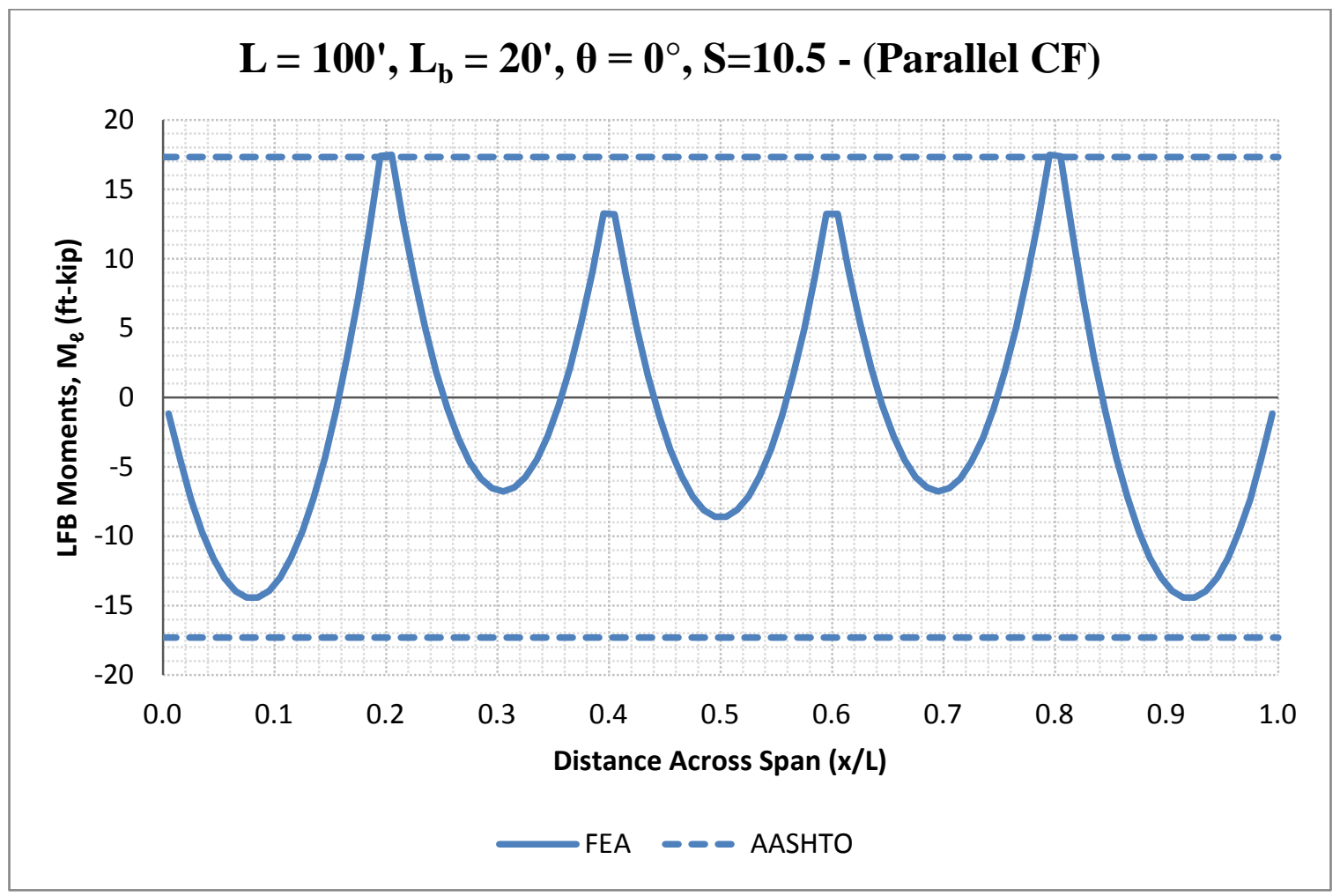

Figure 5.16: Simple Span 2 AASHTO vs. FEA Plot 


\subsubsection{Assessment of Span Length}

Figures 5.17 and 5.18 shows the Moment Ratio plots for 0 and 20 degree skewed bridges ranging from 60 feet to 120 feet at girder spacing's of 6 feet and 10.5 feet. It can be seen from these plots that as the span length increases the moment ratio also increases, indicating that as span length increases the AASHTO approximation becomes more accurate as was previously observed.

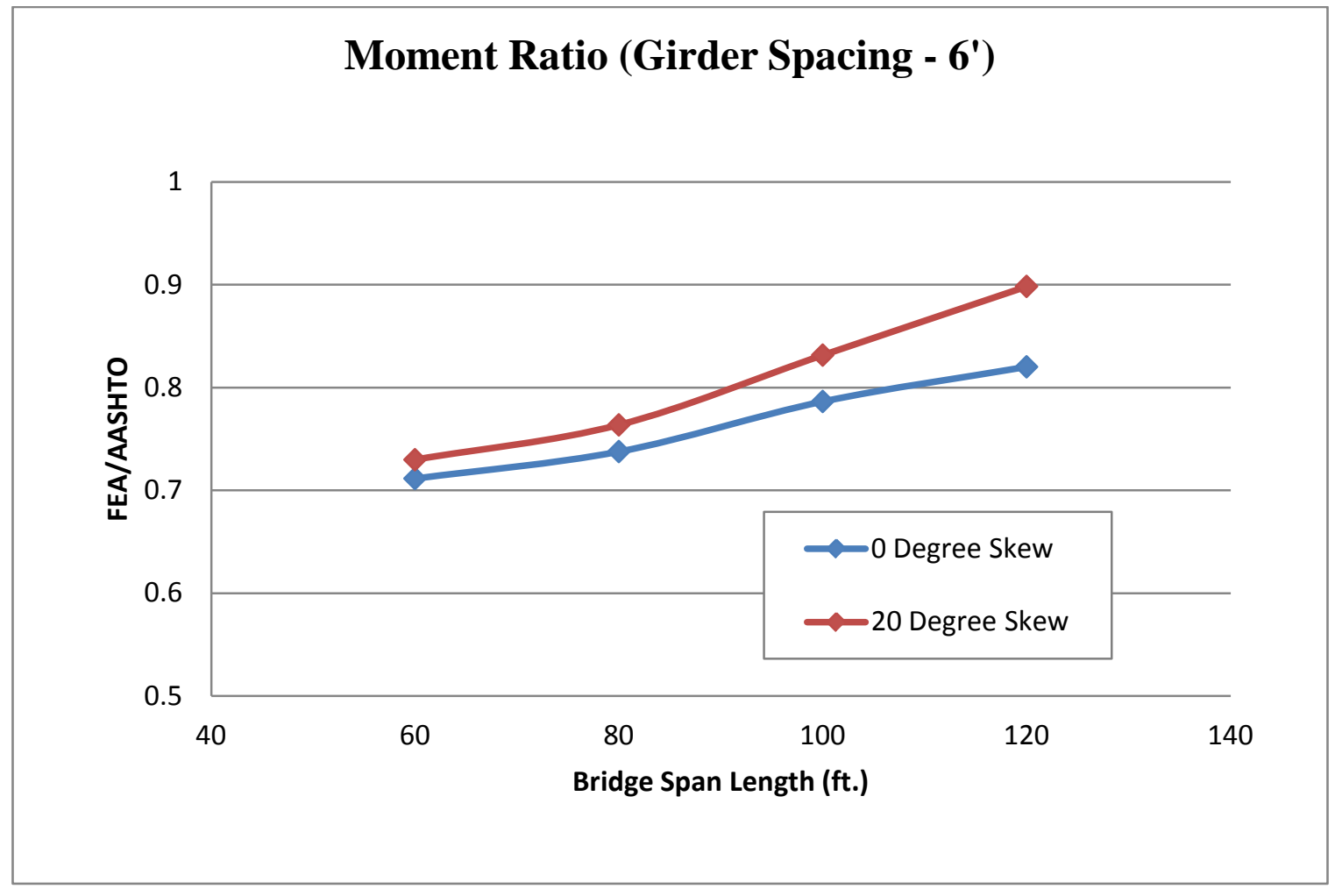

Figure 5.17: Moment Ratio Plot (Girder Spacing=6') 


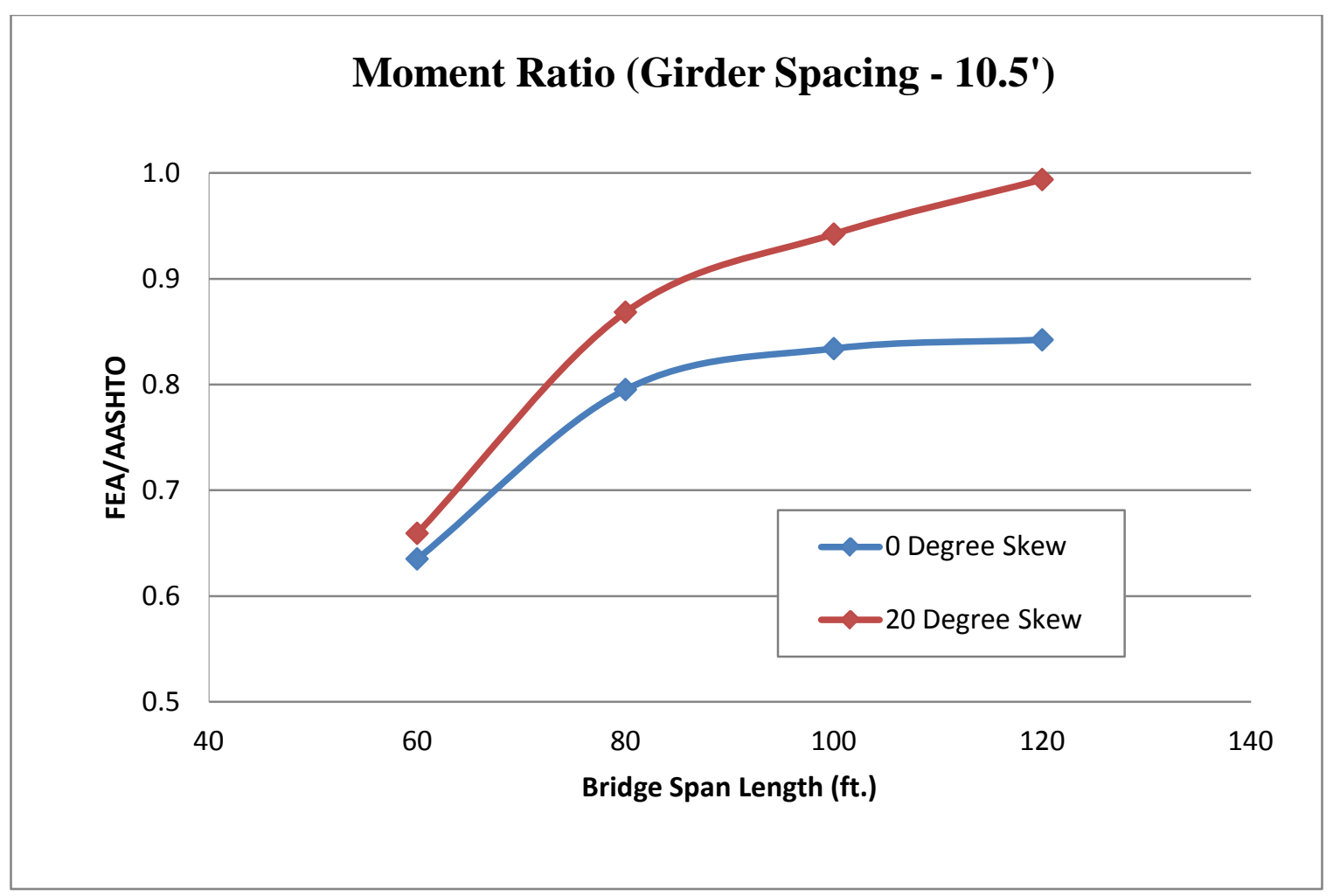

Figure 5.18: Moment Ratio Plot (Girder Spacing=10.5’)

Figure 5.19 shows a plot comparison of bridges with varying span length at a constant skew, girder spacing and unbraced length. For clarity, the x-axis is limited to the length of the first unbraced length. It can be seen from the plot that the LFB moment decreases from the 60 foot span bridge to the 120 foot span bridge. 


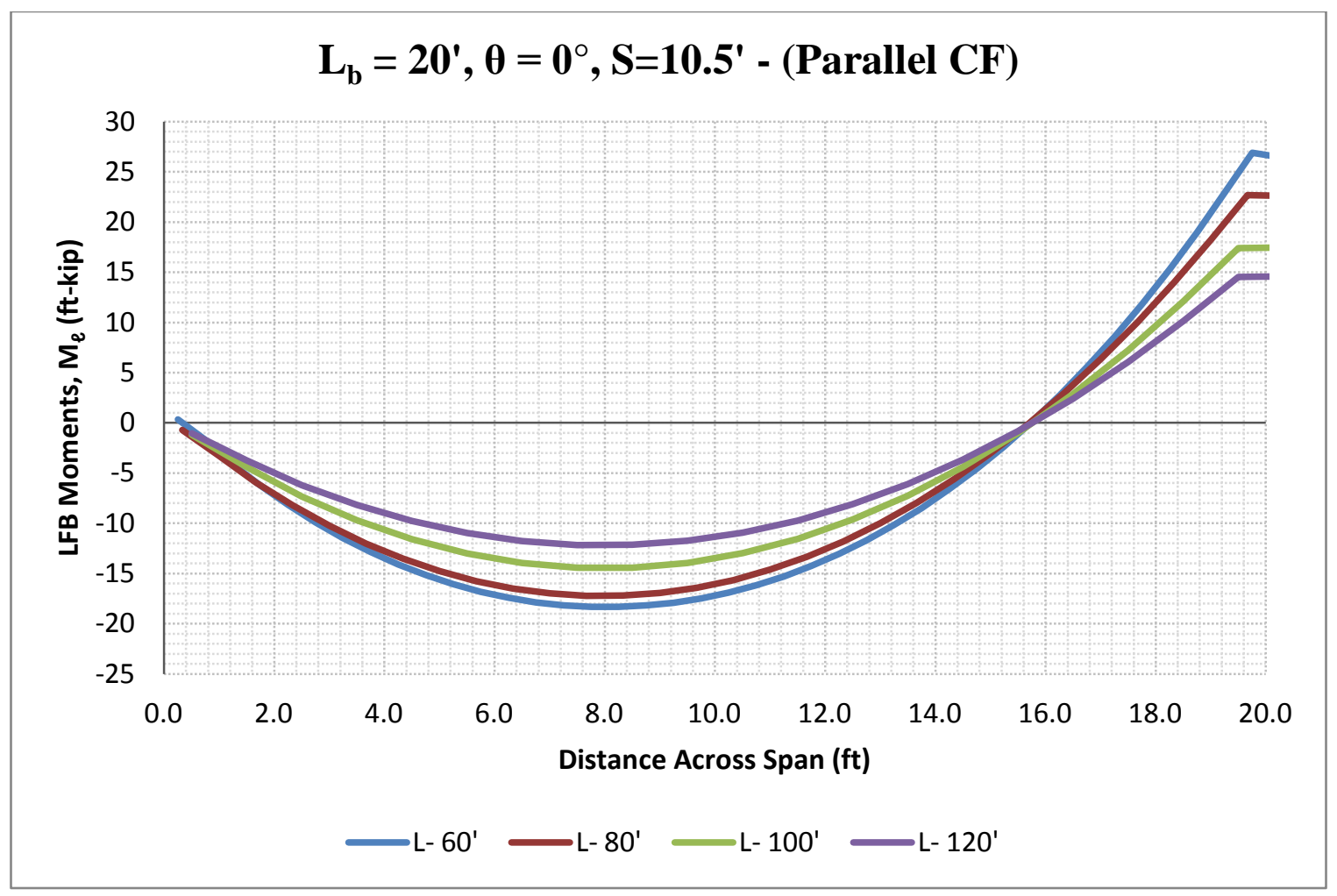

Figure 5.19: FEA Span Length Comparison Plot

\subsubsection{Assessment of Girder Spacing}

Girder spacing was a parameter that was not investigated in the parametric matrix discussed in Section 5.2, therefore, was included in this parametric matrix. Figure 5.20 shows a plot of moment ratios for the girder spacing of 6 feet and 10.5 feet for span lengths from 60 feet to 120 feet. There is an increase in the ratio as the girder spacing increases for the longer span bridges. For the shorter span bridges the ratio decreases as the girder spacing increases. Figure 5.21 shows the same plot in a different manner to give the reader a different view of the data. Note that by looking at Figures 5.17 and 5.18 you can see the same trend in data between girder spacing's as in Figure 5.21. 


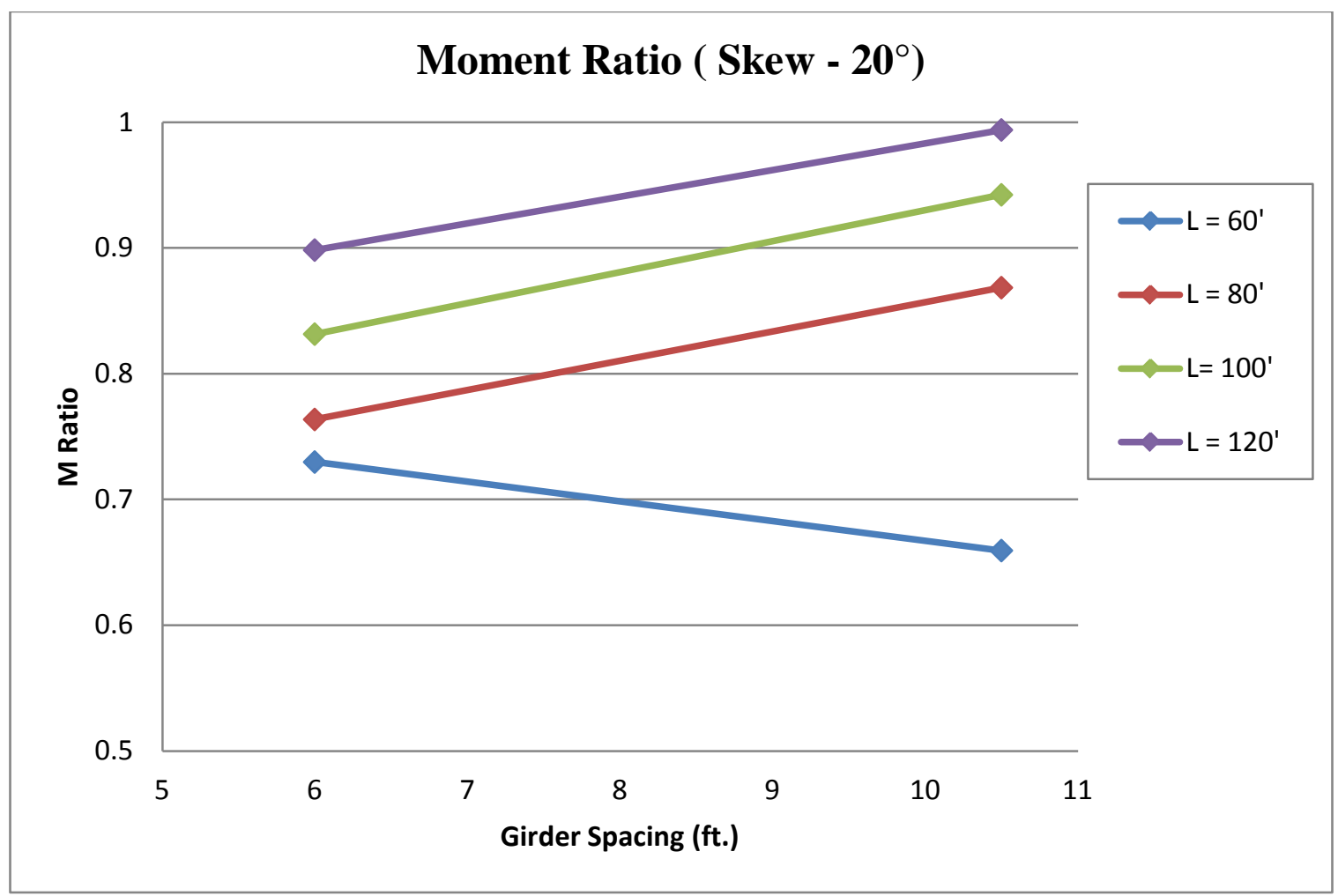

Figure 5.20: Moment Ratio Plot Span Length/Girder Spacing Comparison

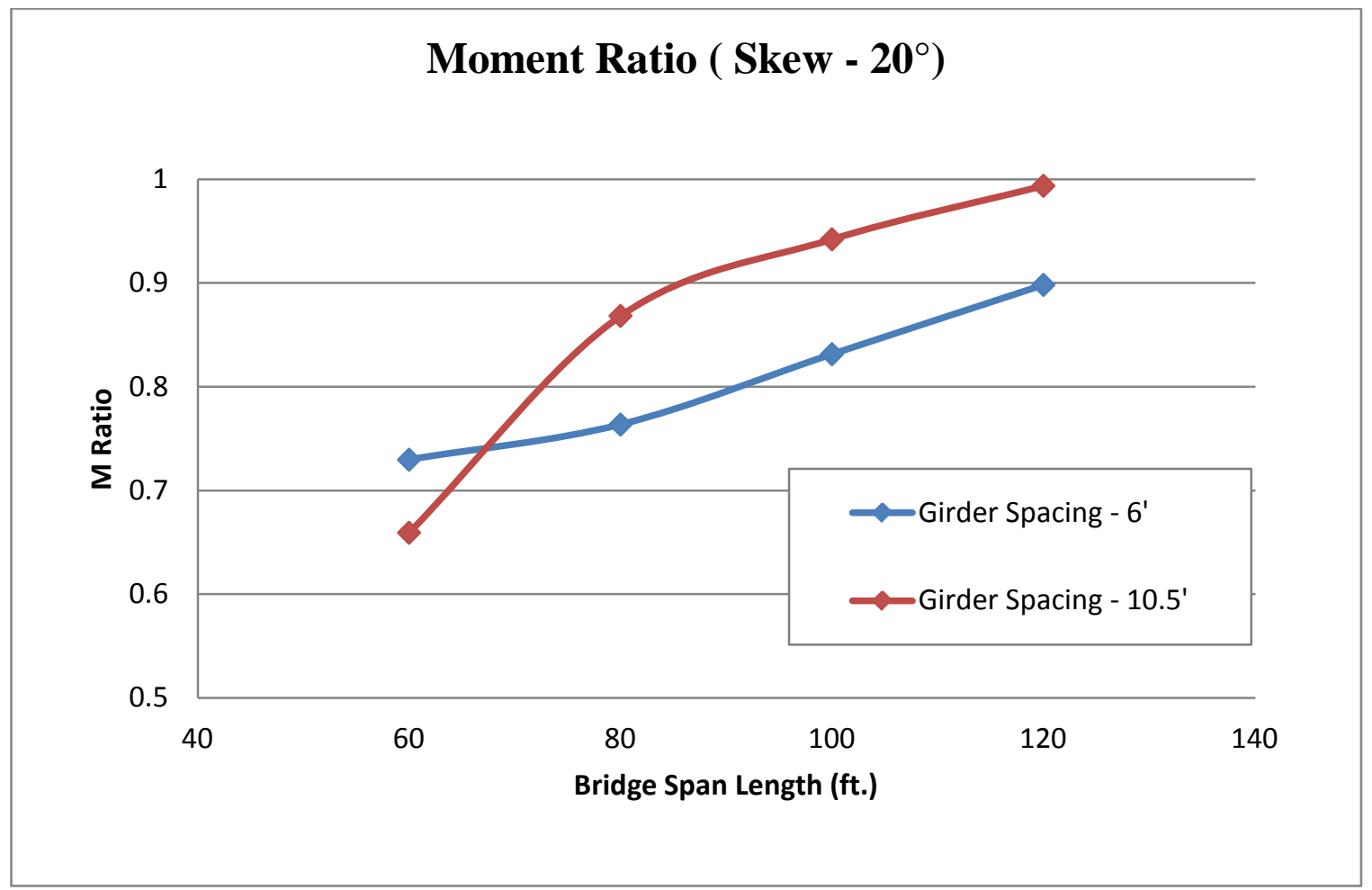

Figure 5.21: Moment Ratio Plot Span Length/Girder Spacing Comparison \#2 
Figures 5.22 and 5.23 shows an LFB moment comparison for girder spacing's of $6 \mathrm{ft}$ and $10.5 \mathrm{ft}$. Like the moment ratio plots the LFB plots show an increase in LFB with an increase in girder spacing for a shorter span of $60 \mathrm{ft}$. However, in the longer span of $120 \mathrm{ft}$ a decrease in girder spacing increases LFB Moment.

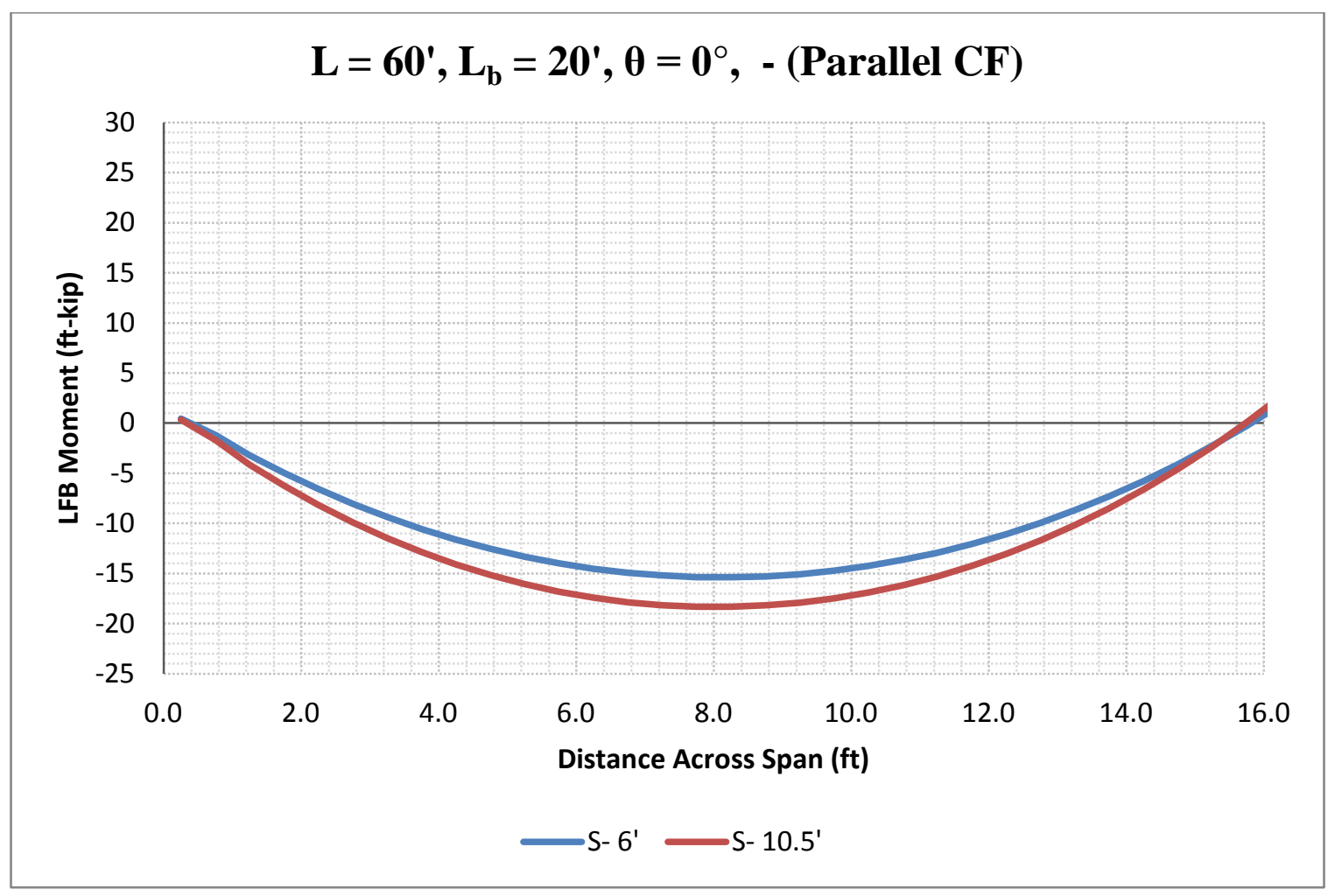

Figure 5.22: Girder Spacing Comparison for Span Length=60 ft. 


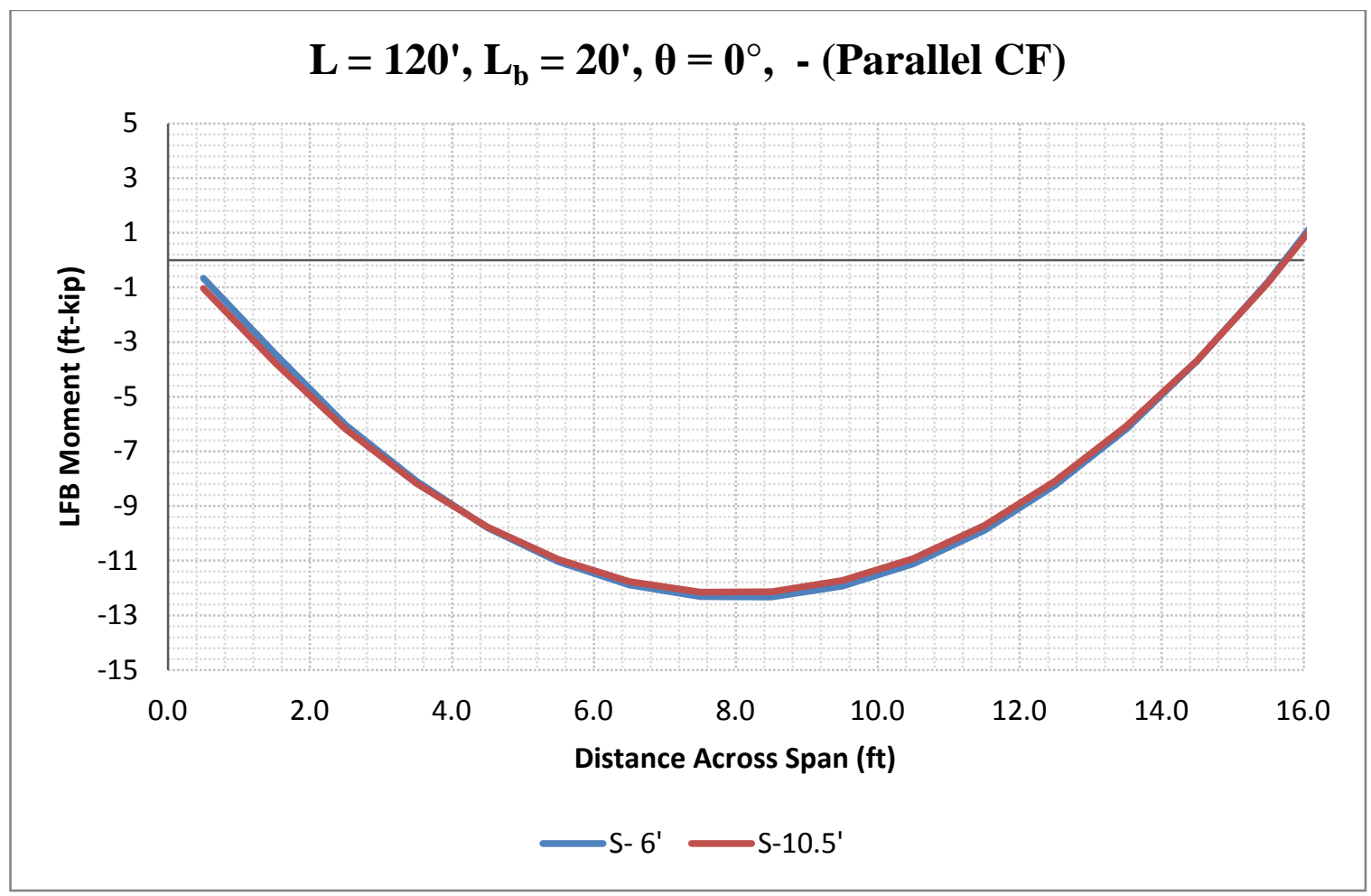

Figure 5.23: Girder Spacing Comparison for Span Length=120 ft.

\subsubsection{Assessment of Skew}

Finally the effects of skew on LFB can be seen in this parametric study in addition to the parametric study of Section 5.3. Figures 5.17 and 5.18 both show an increase in moment ratio with an increase in skew angle; the $20^{\circ}$ skew angle has significantly higher moment ratios than the $0^{\circ}$ skew. This is supported by plot provided in Figure 5.24 which shows a comparison plot of two skew angles up the to the end of the first unbraced length. It can be easily seen that there is an increase in the LFB moment with an increase in skew. 


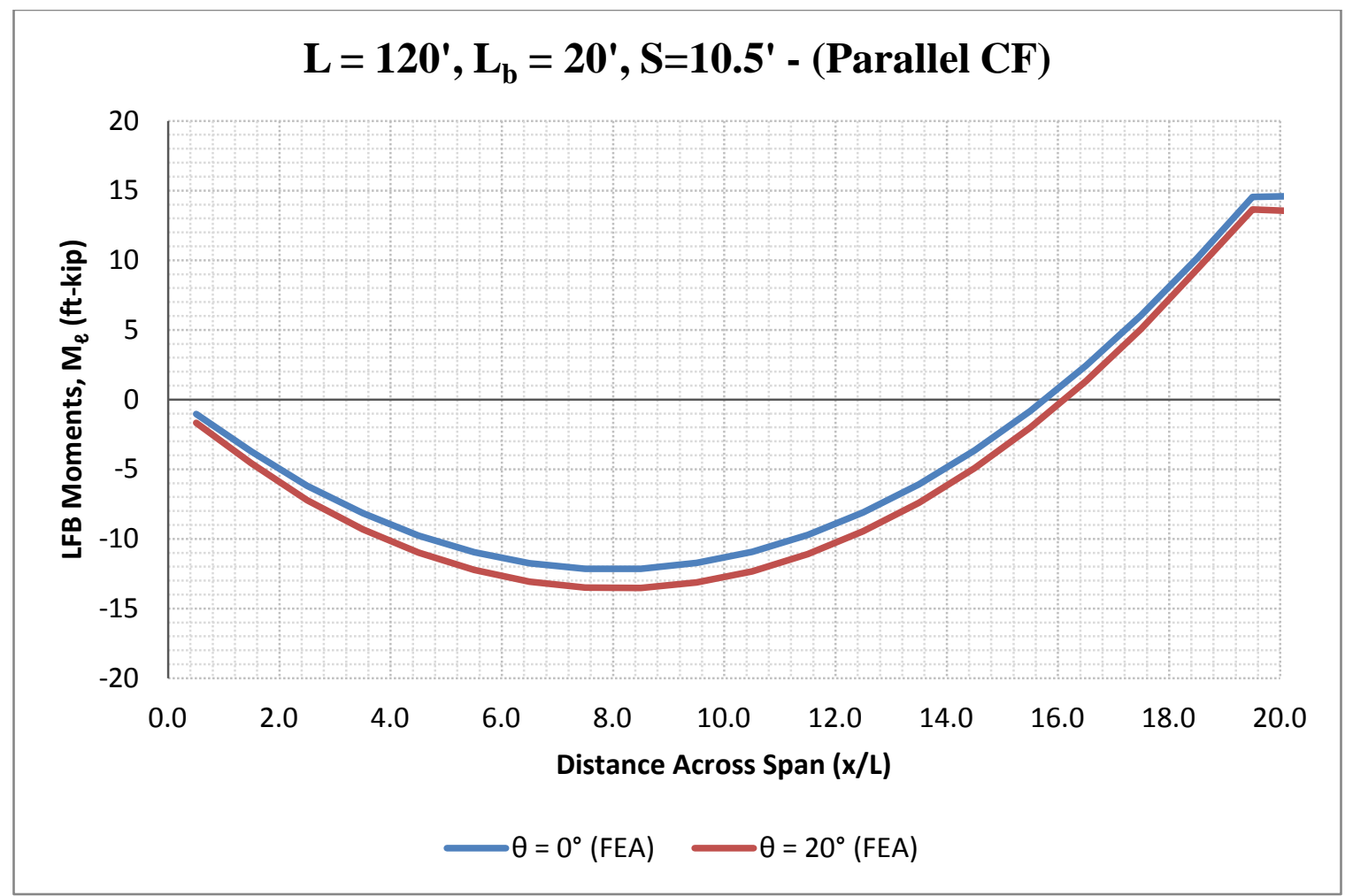

Figure 5.24: Skew Comparison Plot

\subsection{SUMMARY}

In summary there is an over estimation of LFB moments in the spans between the crossframes made by the AASHTO approximation in both parametric matrices. There were four key parameters that were isolated as having an effect on skew from the two parametric matrices of this chapter. These parameters include:

- skew

- unbraced length

- girder spacing

- span length

These identified parameters will be used in Chapter 6 for the formulation of the modified approximation for LFB. Finally it should be noted that it was a trend in the Moment Ratio plots that the AASHTO approximation became more accurate as the span length of the bridge increased. 


\section{CHAPTER 6: DEVELOPMENT OF THE MODIFIED AASHTO APPROXIMATION FOR LATERAL FLANGE BENDING}

\subsection{INTRODUCTION}

This chapter discusses the parametric matrix developed for the formulation of the modified approximation for LFB. A description of the parametric matrix is provided in this chapter along with a description of the formation of the modified approximation. Finally, a comparison with the original AASHTO approximation is presented as well.

\subsection{MOdified APPROXIMATION PARAMETRIC MATRIX}

The parameters identified in Section 5.6 to have a key effect on LFB were used to develop a new parametric matrix. This matrix focused on varying these parameters in order to well represent each parameter and their effect on LFB. In this matrix a total of 54 bridges were modeled for the formulation of the modified approximation. The constant parameters were parameters that were found to have no significant effect on LFB. Finally a description of the girder dimensions is provided.

\subsubsection{Constant Parameters}

The following parameters were found to have little or no effect on LFB moments, therefore were kept constant in this matrix:

- Slab thickness $=8.25$ inches

- Integral wearing surface $=0.25$ inches

- Effective slab thickness $=8.5$ inches

- Haunch $=2$ inches

- Number of Girders $=4$

- Overhang = 39 inches 
- K-style cross-frames ( see Figure 5.1)

Note that overhangs are a known parameter to have effects on LFB, however the range of width of a typical overhang is not very large. The author selected an average overhang dimension that well represents the overhang parameter.

\subsubsection{Varied Parameters}

The following parameters were found in Chapter 5 to have a significant effect on LFB and were varied in this parametric matrix in order to assess theses parameters adequately:

- Ten span lengths: Ranging from $40 \mathrm{ft}$. to $140 \mathrm{ft}$. in increments of $20 \mathrm{ft}$.

- Three skew angles: $0^{\circ}, 20^{\circ}$, and $40^{\circ}$.

- Four unbraced $\left(\mathrm{L}_{\mathrm{b}}\right)$ lengths: Ranging from $20 \mathrm{ft}$. to $35 \mathrm{ft}$. (listed in girder dem. table)

- Three girder spacing's: $6 \mathrm{ft}$., $8.25 \mathrm{ft}$. and $10.5 \mathrm{ft}$.

\subsubsection{Girder Design}

The girders selected for this parametric matrix were adapted from the Steel Market Development Institute (SMDI) short span bridge details (Morgan, 2010). The girders used in this matrix have constant flange transitions. Table 6.1 gives the plate sizes for each of the girders in this parametric matrix.

Table 6.1: Girder Dimensions

\begin{tabular}{|c|c|c|c|c|c|c|c|c|c|}
\hline \multirow{2}{*}{$L(f t)$} & \multicolumn{2}{|c|}{ Top Flange } & \multicolumn{2}{|c|}{ Bottom Flange } & \multicolumn{2}{|c|}{ Web } & \multirow{2}{*}{$\frac{\mathbf{L}_{\mathbf{b}}}{(\mathrm{ft})}$} & \multicolumn{2}{|c|}{ Stiffeners } \\
\hline & $b_{t f}(\mathrm{in})$ & $t_{t f}(i n)$ & $b_{t f}(\mathrm{in})$ & $t_{t f}(i n)$ & $d_{w}(\mathrm{in})$ & $t_{w}(\mathrm{in})$ & & $t_{b r g}($ in) & $t_{\text {int }}$ (in) \\
\hline 40 & 12 & 0.75 & 12 & 0.75 & 24 & 0.5 & 20 & 0.625 & 0.625 \\
\hline 60 & 12 & 0.75 & 14 & 1.5 & 24 & 0.5 & 20 & 0.625 & 0.625 \\
\hline 80 & 16 & 1 & 16 & 1.5 & 32 & 0.5 & 20 & 0.625 & 0.625 \\
\hline 100 & 18 & 0.75 & 18 & 2 & 40 & 0.5 & 25 & 0.625 & 0.625 \\
\hline 120 & 18 & 1 & 20 & 2 & 48 & 0.5 & 30 & 0.625 & 0.625 \\
\hline 140 & 20 & 1 & 20 & 2 & 54 & 0.5 & 35 & 0.625 & 0.625 \\
\hline
\end{tabular}




\subsection{DeVelopment of Modified LFB Moment Approximation}

\subsubsection{Methodology}

A commercial data correlation package, DataFit 9.0.59 (Oakdale Engineering, 2008), was used to develop the empirical modification factor for AASHTO LFB approximations. Datafit is a statistical analysis tool that incorporates both multivariable capabilities as well as linear and nonlinear curve-fitting routines which can be employed to develop an accurate expression for a random data set. However, the curve fitting process becomes more complex with more than two independent variables, and, by default, DataFit attempts to plot such relationships in $\mathbb{R}^{\mathrm{n}}$ space as either a multilinear function or an exponential function, where " $n$ " is the number of independent variables.

\subsubsection{Proposed Modification Factor for Simple-Span Bridges}

Using the data set described in Section 6.2 and Appendix B, the following modification factor for the AASHTO approximation for lateral flange bending is proposed:

$$
M F=0.65 \exp \left(\left(\frac{S-L_{b}}{80}\right)+\left(\frac{L}{40}\right)+\left(\frac{\theta}{285}\right)\right)
$$

where the following variables represent the following parameters that were identified to have direct effect on LFB:

- $\mathrm{S}=$ The girder spacing.

- $\mathrm{L}_{\mathrm{b}}=$ The unbraced length between cross-frames.

- $\mathrm{L}=$ The total span length

- $\theta=$ The skew angle

Using these parameters from any select short span bridge one can obtain a modification factor. The modification factor is then multiplied to the current AASHTO approximation for LFB 
moments in the spans between the cross-frames to obtain the modified LFB moment. The regions at the cross-frames the AASHTO approximation is used without any modification being that it was found that the AASHTO approximation was adequate at these locations.

The plots in Figures 6.1 and 6.2 show a comparison between the FEA results at mid span of the first unbraced length of the parametric matrix presented in Section 6.1 and the results of the modification factor. The results from the modification factor are reasonably accurate for the bridges presented in this matrix as seen in the charts. A tabular comparison of the results is also provided in Appendix B.2.

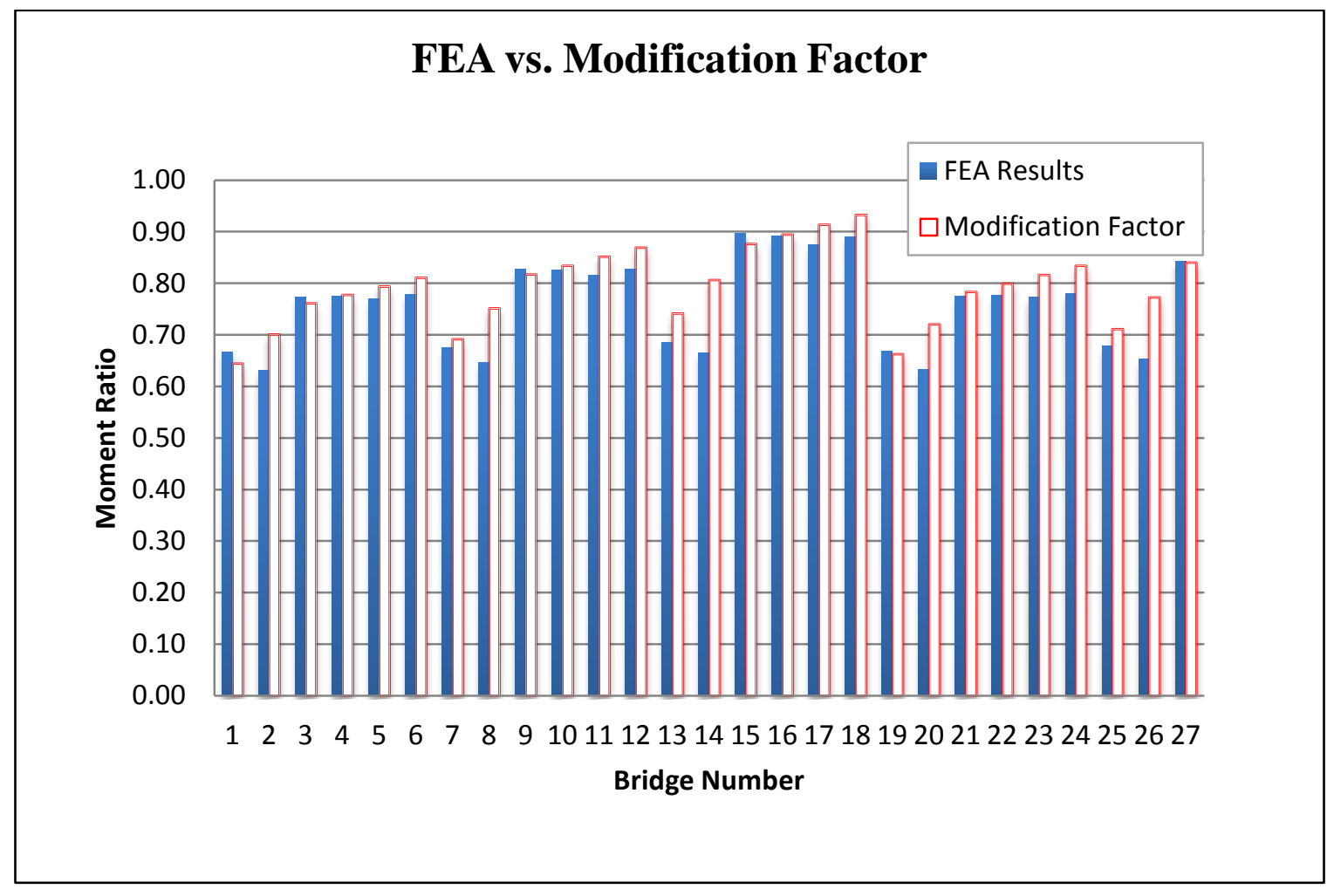

Figure 6.1: Comparison of FEA Results vs. Modification Factor 


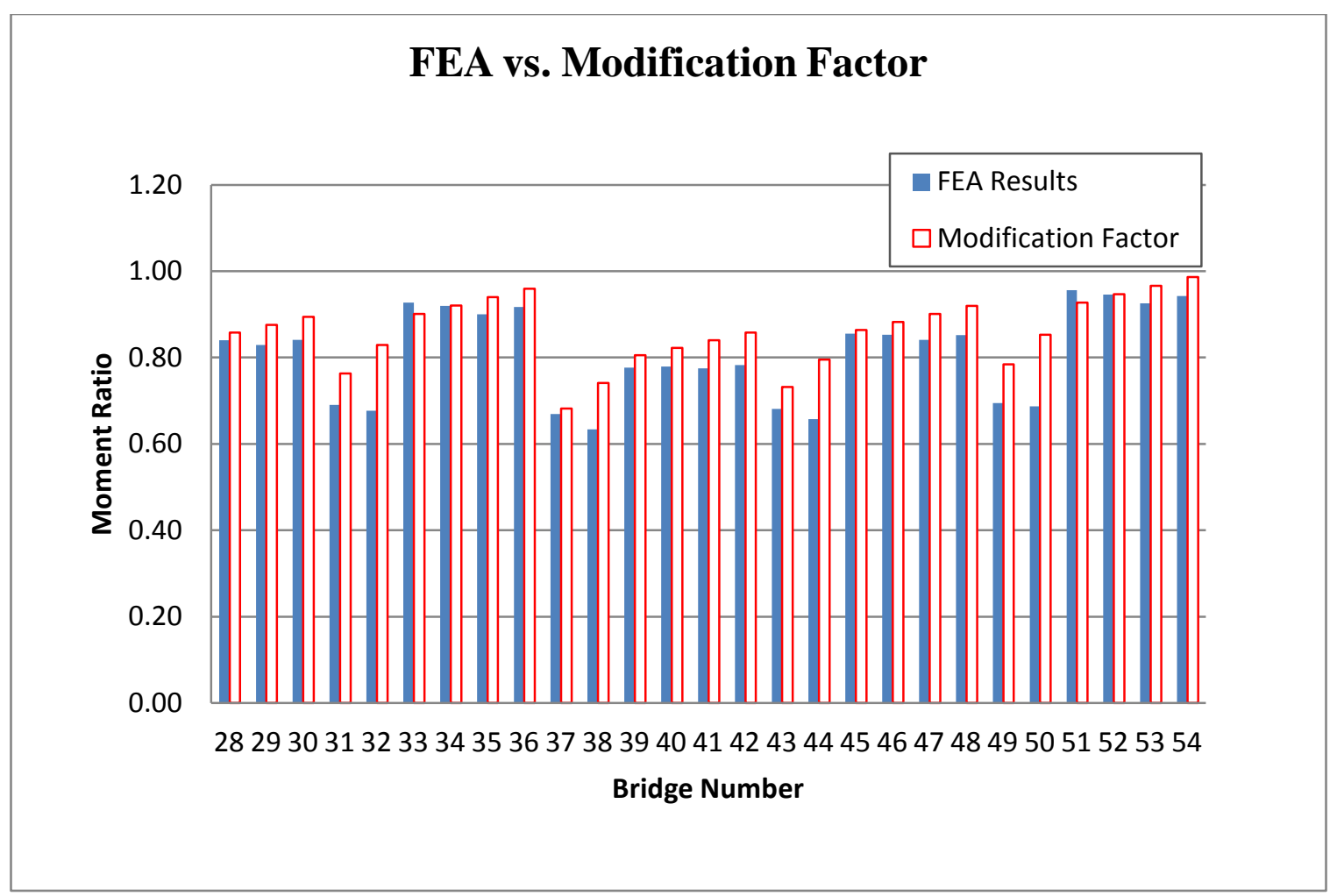

Figure 6.2: Comparison of FEA Results vs. Modification Factor

\subsection{Assessment of Modification FActor For Simple SPAN BRIDGES}

The modification factor is shown to be reasonably accurate by the plots in Figures 6.3 and 6.4. Figure 6.3 shows a plot of the FEA results of LFB moments for a parallel cross-frame orientation while Figure 6.4 shows the results for a staggered cross-frame orientation. The solid blue lines represent the FEA results, the current AASHTO approximation is represented by the dashed blue lines, and finally the modification factor is represented by the red dotted lines. It can be seen by both plots that the modification factor produces a more accurate prediction than the AASHTO approximation for LFB moments in the regions between the cross-frames. 


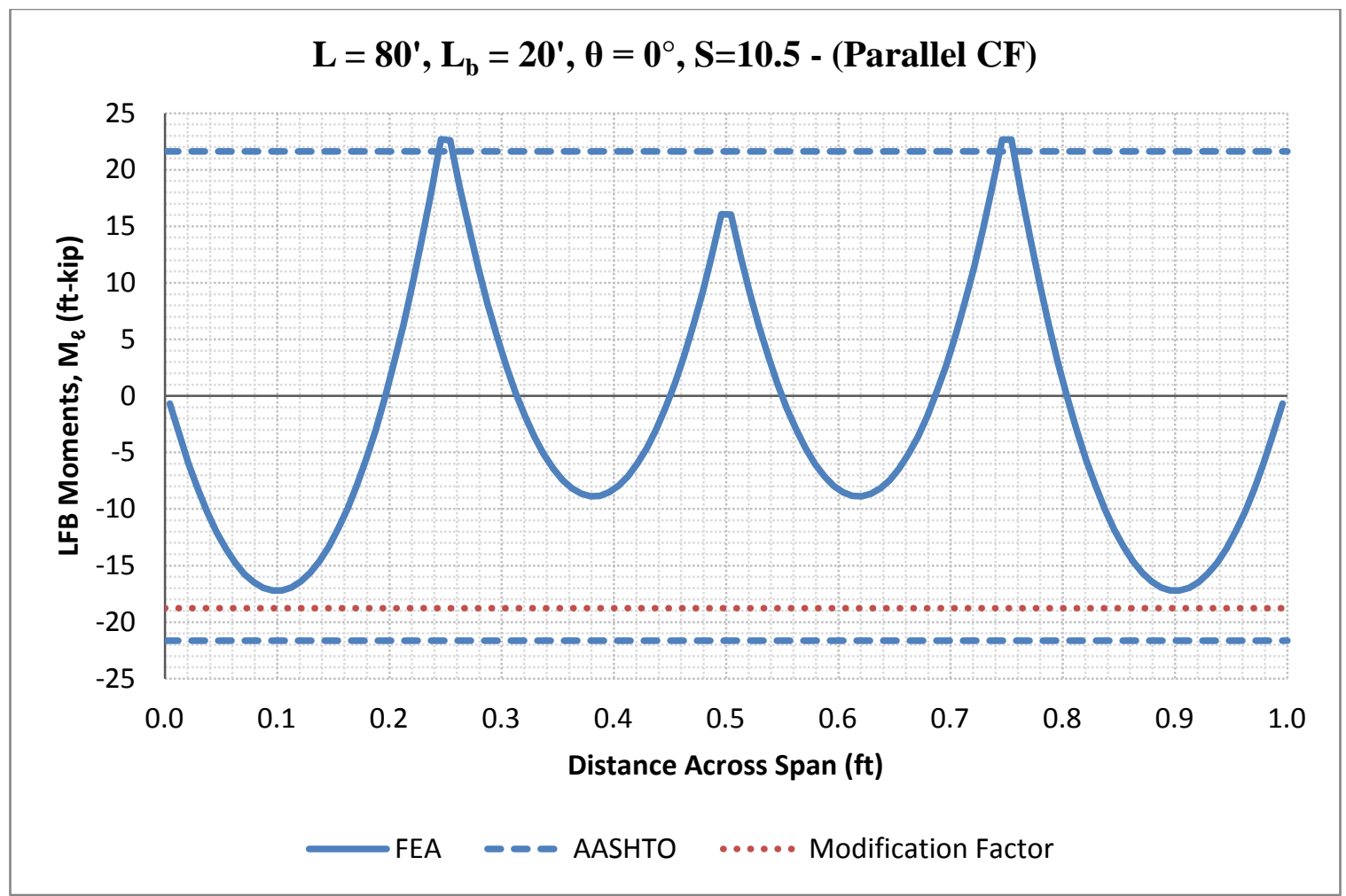

Figure 6.3: Parallel Cross-frame Results with Modification Factor Comparison

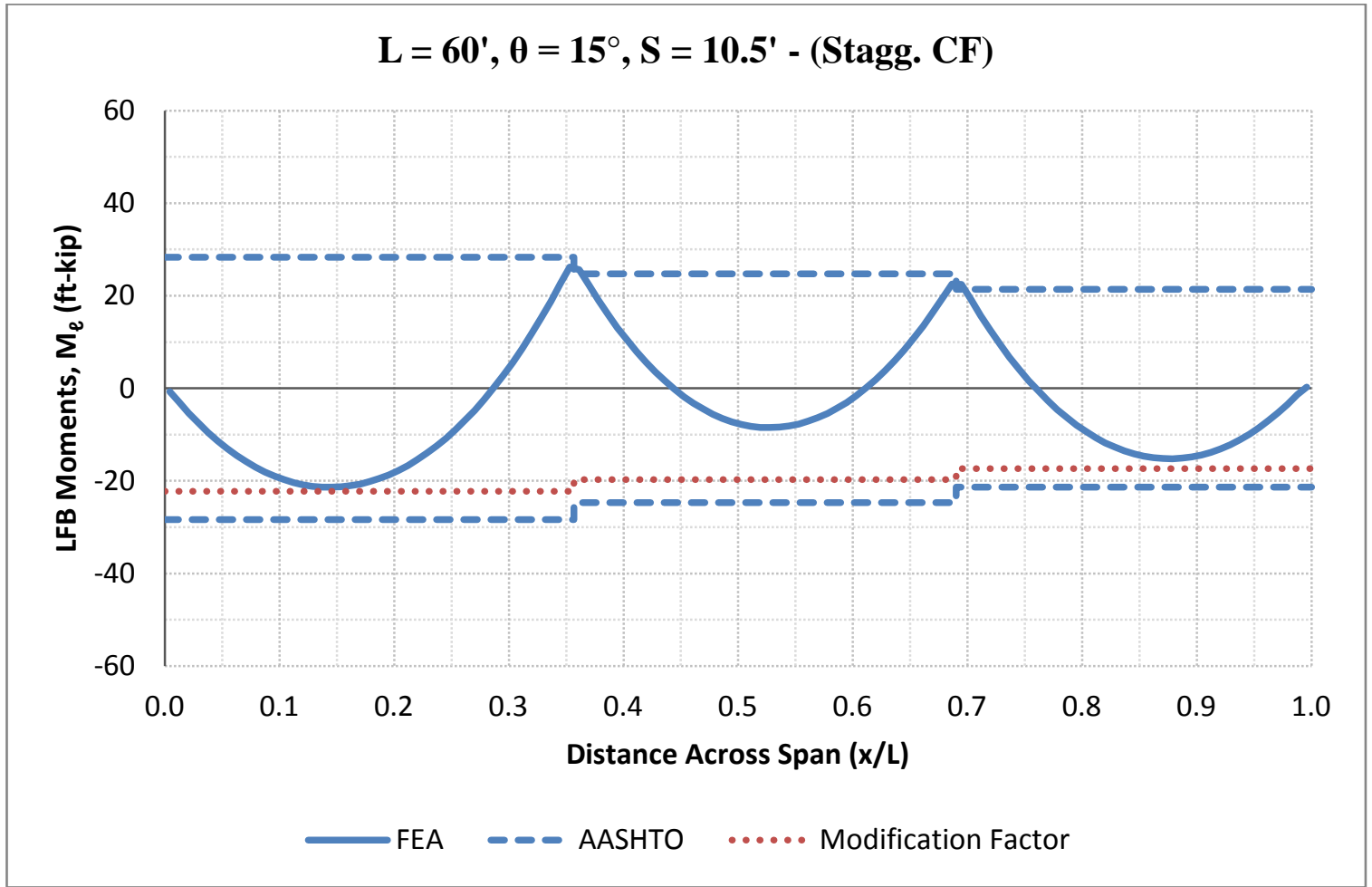

Figure 6.4: Staggered Cross-frame Results with Modification Factor Comparison 


\subsection{SUMMARY AND CONCLUSION}

In summary a parametric matrix was developed based on the parameters found in Chapter 5 to have a direct effect on LFB moments. This matrix was used to develop the modification to the LFB moment AASHTO approximation for simple span bridges using the commercial data correlation package, DataFit 9.0.59. The modified approximation was verified with comparison plots with the FEA results.

It should be noted, however, that these equations should only be applied within the ranges and parameters of the parametric matrix defined in Section 6.2. These equations need to be tested more thoroughly before being applied to a wider range of bridges. These and other suggestions for future work, along with a summary of this project, are presented in Chapter 7. 


\section{CHAPTER 7: SUMMARY AND CONCLUDING REMARKS}

\subsection{PROJECT SUMMARY}

The focus of this research was to investigate the AASHTO approximation and develop a modification to the approximation in order to obtain more accurate results for LFB in simple span steel I-girder bridges. As stated in 1.2, the objectives and scope of this project was as follows.

- A literature review that focuses on lateral flange bending, the causes and parameters that are known to have a significant effect.

- A description of the finite element modeling technique is along with a description of an algorithm developed to model simple span bridges.

- A pair of parametric matrices for simple span bridges developed for the assessment of key parameters on lateral flange bending.

- The key parameters identified to have a significant effect on lateral flange bending were used to develop a new parametric matrix for the formulation of a new LFB approximation using a commercial data correlation software tool (Oakdale Engineering, 2008).

- The empirical modification factor developed improves the accuracy of the AASHTO approximation for LFB moment in the regions in between the crossframes, which can result in more efficient designs of simple span I-girder bridges. 


\subsection{RECOMMENDATIONS FOR FUTURE WORK}

The author recommends the following takes for future work and/or expansion to this project.

- Expand the simple span parametric matrices presented in this project to include more parameters in order to verify the proposed empirical equation.

- Use physical load test data to verify the validity of these equations.

- Create a similar parametric matrix for a continuous span bridges to assess the AASHTO approximation for continuous span bridges and if needed formulate an modified approximation for these bridges. 


\section{REFERENCES}

AASHTO. (2010). LRFD Bridge Design Specifications, Customary U.S. units (5th ed.) - 2010 Interim Revisions. Washington, DC.

Bakht, B. (1988). Analysis of Some Skew Bridges as Right Bridges. Journal of Structural Engineering, 114, 2307-2322.

Barth, K.E., Michaelson, G.K., Galindez, N.Y. (2011). An Evaluation of Lateral Flange Bending in Straight and Skewed Short-span Steel Bridges. West Virginia University, Morgantown, WV.

Beckmann, F., \& Medlock, R. (2005). Skewed Bridges and Girders Movements due to rotations and differential deflections. Paper presented at 2005 World Steel Bridge - Symposium and Workshops, National Steel Bridge Alliance, Orlando, FL.

Choo, T., Linzell, D., Lee, J., \& Swanson, J. (2005). Response of a continuous, skewed, steel bridge during deck placement. Journal of Constructional Steel Research, 61(5), 567-586.

Coletti, D., Chavel, C., \& Gatti, W. (2011) The Challenges of Skew. Transportation Research Board, Raleigh, NC.

Coletti, D., \& Yadlosky, J. (2005). Behavior and analysis of curved and skewed steel girder bridges. Paper presented at 2005 World Steel Bridge - Symposium and Workshops, National Steel Bridge Alliance, Orlando, FL.

Fasl, J., Romage, M., Helwig, T., Herman, R., \& Frank, K. (2009). Field Measurements on Steel Girder Bridge with Skewed Supports Utilizing Lean-on Bracing. Structure Congress: Don't Mess with Structural Engineers - Expanding our Role, 124.

Galindez, N. (2009). Levels of Lateral Flange Bending in Straight, Skewed and Curved Steel Igirder Bridges during Deck Placement (Ph.D. Dissertation). West Virginia University, Morgantown, WV.

Grace, N., J. Hanson, \& H. Abdel-Messih. (2004). Inspection and Deterioration of Bridge Decks Constructed Using Stay-in-Place Metal Forms and Epoxy-Coated Reinforcement. Department of Civil Engineering, Lawrence Technological University, Southfield, MI.

Grubb, M. (1991). Design for Concrete Deck Overhang Loads. Paper presented at the National Steel Construction Conference, American Institute of Steel Construction, Washington, DC. 
Guthrie, N., Frost, S. Birdshall, A. Linford, E. Ross, A. Crane, \& R. Egget, D. (2006). Effect of Stay-in-Place Metal Forms on Performance of Concrete Bridge Decks. Department of Civil Engineering, Brigham Young University, Providence, UT.

Herman, R., Helwig, T., Holt, J., Medlock, R., Romage, M., \& Zhou, C., (2005). Lean-On CrossFrame Bracing for Steel Girders with Skewed Support. Texas Department of Transportation, University of Houston, Houston, Tx.

Mertz, D., (2001). Designers' Guide to Cross-frame Diaphragms. American Iron and Steel Institute, University of Delaware, Newark, DE.

Michaelson, K., Gregory (2010). Live Load Distribution Factors for Exterior Girders in Steel IGirder Bridges. West Virginia University, Morgantown, WV.

Morera, F., (2010). Lateral Flange Bending in Heavily Skewed Steel Bridges (Ph.D. Dissertation). North Carolina State University, Raleigh, NC.

Morgan, A., Scott, (2010). Towards the Development of Efficient and Economical Short Span Modular Bridges. Steel Market Development Institute, West Virginia University, Morgantown, WV.

Murphy, S., \& Linzell, D. (2012). Skewed steel bridge cross-frame live load performance. Department of Civil and Environmental Engineering, Pennsylvania State University, University Park, PA.

Norton, E., Linzell, D., \& Laman, J. (2003). Examination of Response of a Skewed Steel Bridge Superstructure during Deck Placement. Transportation Research Record, 1845, 66 - 75.

NSBA. (2013). Design Example 1: Three-Span Continuous Straight Composite I Girder, Part of The Steel Bridge Design Handbook, National Steel Bridge Alliance. Chicago, IL.

Oakdale Engineering. (2008). DataFit 9.0.59. Oakdale, PA: Oakdale Engineering.

Roddis, K., Kriesten, M., \& Liu, Z. (1999). Torsional Analysis for Exterior Girders, Report No. K-TRAN: KU-96-3, Department of Transportation of Kansas, Lawrence, KS.

Roddis, K., Kulseth, P., Lui, Z., \& Zhao, Y. (2003). Torsional Analysis for Exterior Girders, Transportation Research Board, Department of Civil and Environmental Engineering University of Kansas, Lawrence, KS.

Sanchez, T. A. (2011). Influence of Bracing Systems on the Behavior of Curved and Skewed Steel I-Girder Bridges during Construction, Ph.D. Dissertation, Georgia Institute of Technology, Atlanta, GA. 
Seaburg, P., \& Carter, C. (1997). Steel Design Guide No. 9: Torsional Analysis of Structural Members, American Institute of Steel Construction, Chicago, IL.

Seongyeong, Y., Helwig, T., Klinger, R., Engelhardt, M., \& Fasl, J. (2010). Impact of Overhang Construction on Girder Design, Texas Department of Transportation, Center for Transportation Research at The University of Texas at Austin, Austin Tx.

Wang, L. \& Helwig, T. A. (2008). "Stability Bracing Requirements for Steel Bridge Girders with Skewed Supports" Journal of Bridge Engineering, 13, 149-157. 


\section{APPENDiX A: LATERAL FLANGE BENDING IN SIMPLE-SPAN I- GIRDER BRIDGES}

The following appendix provides a series of plots from the two parametric matrices discussed in Chapter 5. These plots provide the FEA LFB moment results obtained from Abaqus 6.10-1/CAE and the AASHTO approximation for LFB superimposed. The FEA results are represented by the solid blue line, while the dashed blue lines represent the AASHTO approximation. The plots were generated from the algorithm presented in Section 4.7 with a naming scheme. The naming scheme labeled the title of the plots with a series of variables. The variables are as follows:

- L- Span length of the bridge

- S- Girder Spacing

- N- Number of girders

- SK- Skew angle

- CF- Number of cross-frames

- PG- Plate girders

Also, parallel cross-frame orientations have a straight line for AASHTO approximation. The staggered cross-frame orientation will have jumps in the AASHTO approximation line. This is because of the varying unbraced length in the staggered cross-frame orientation. 

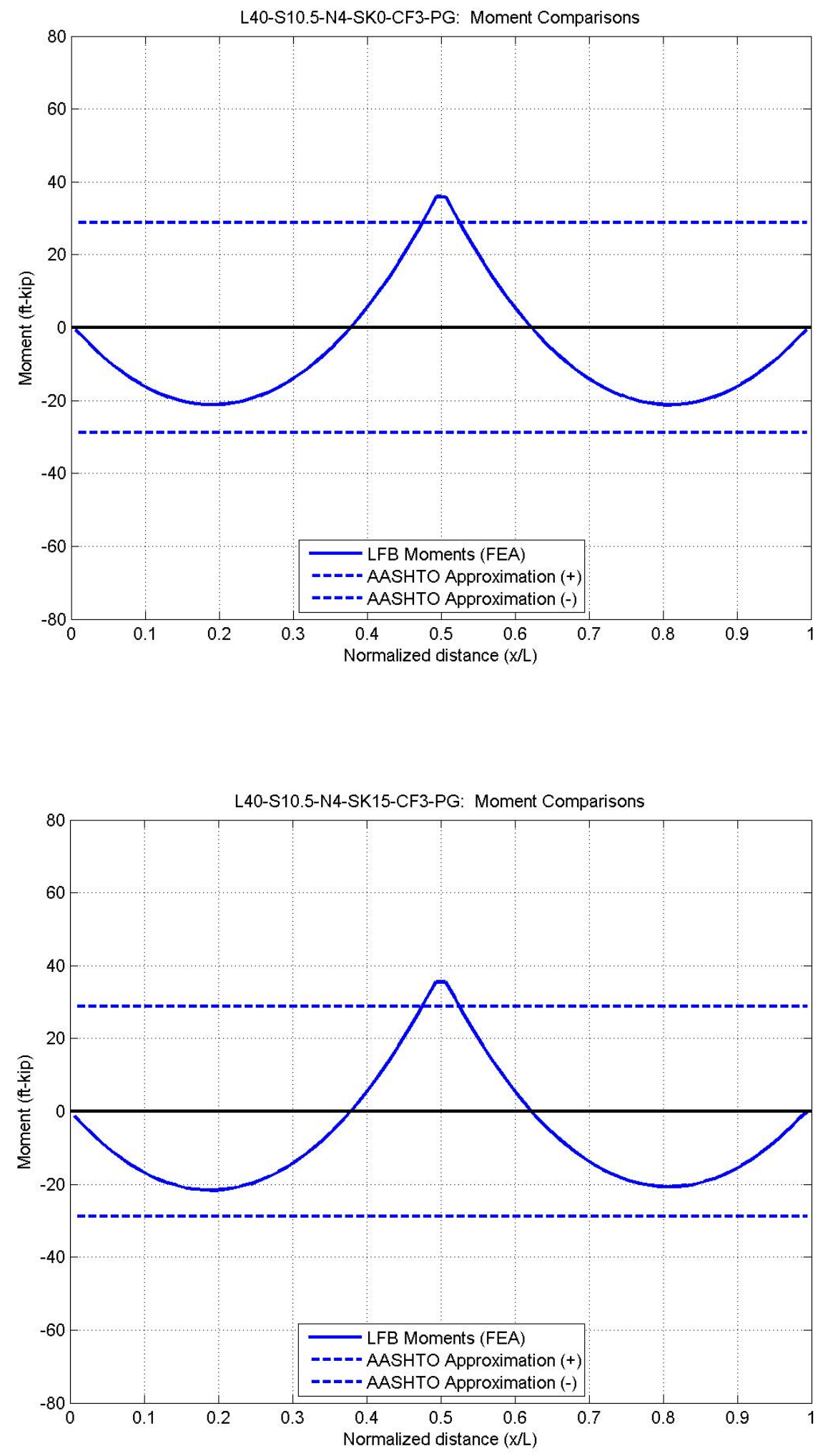

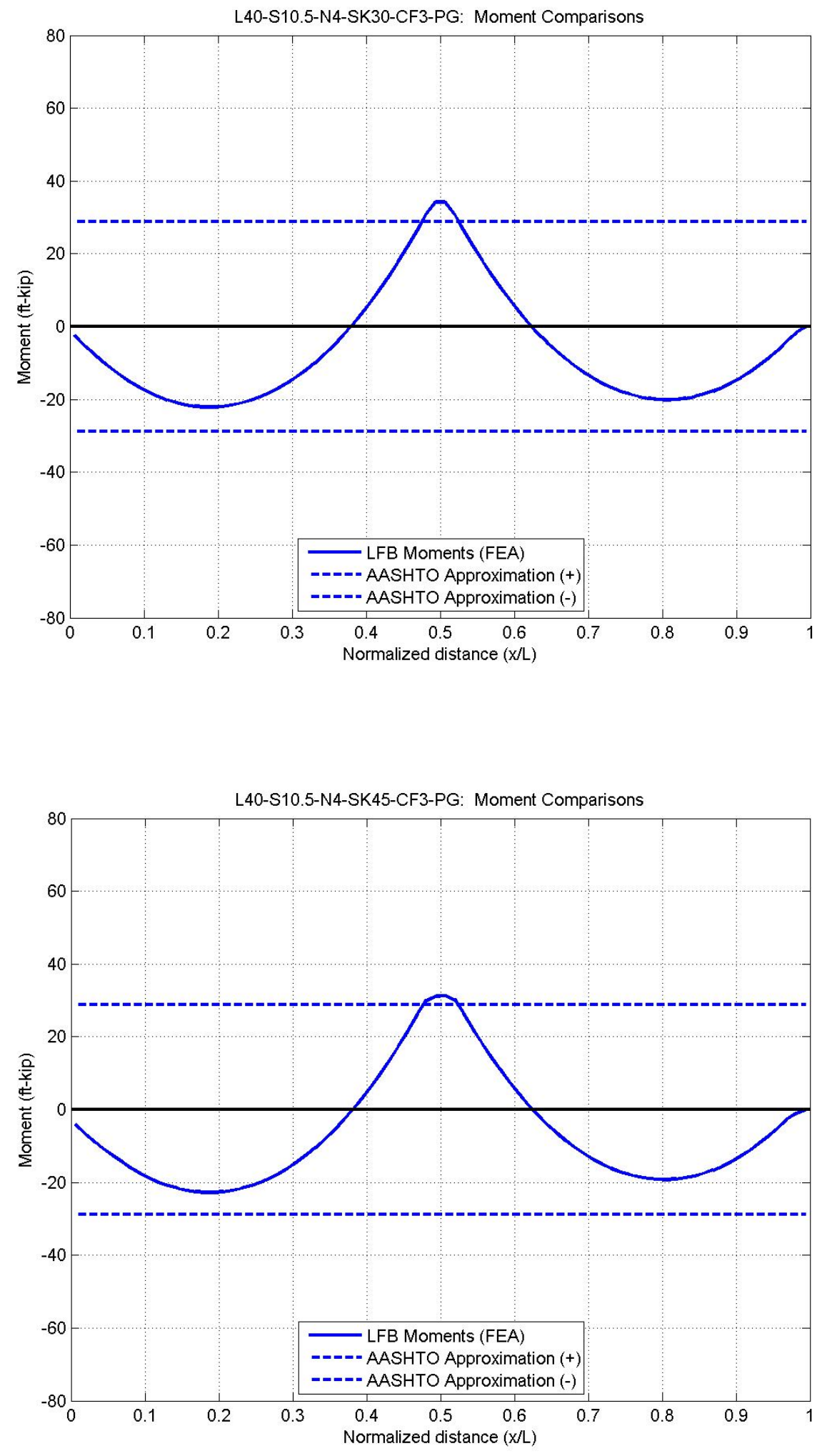

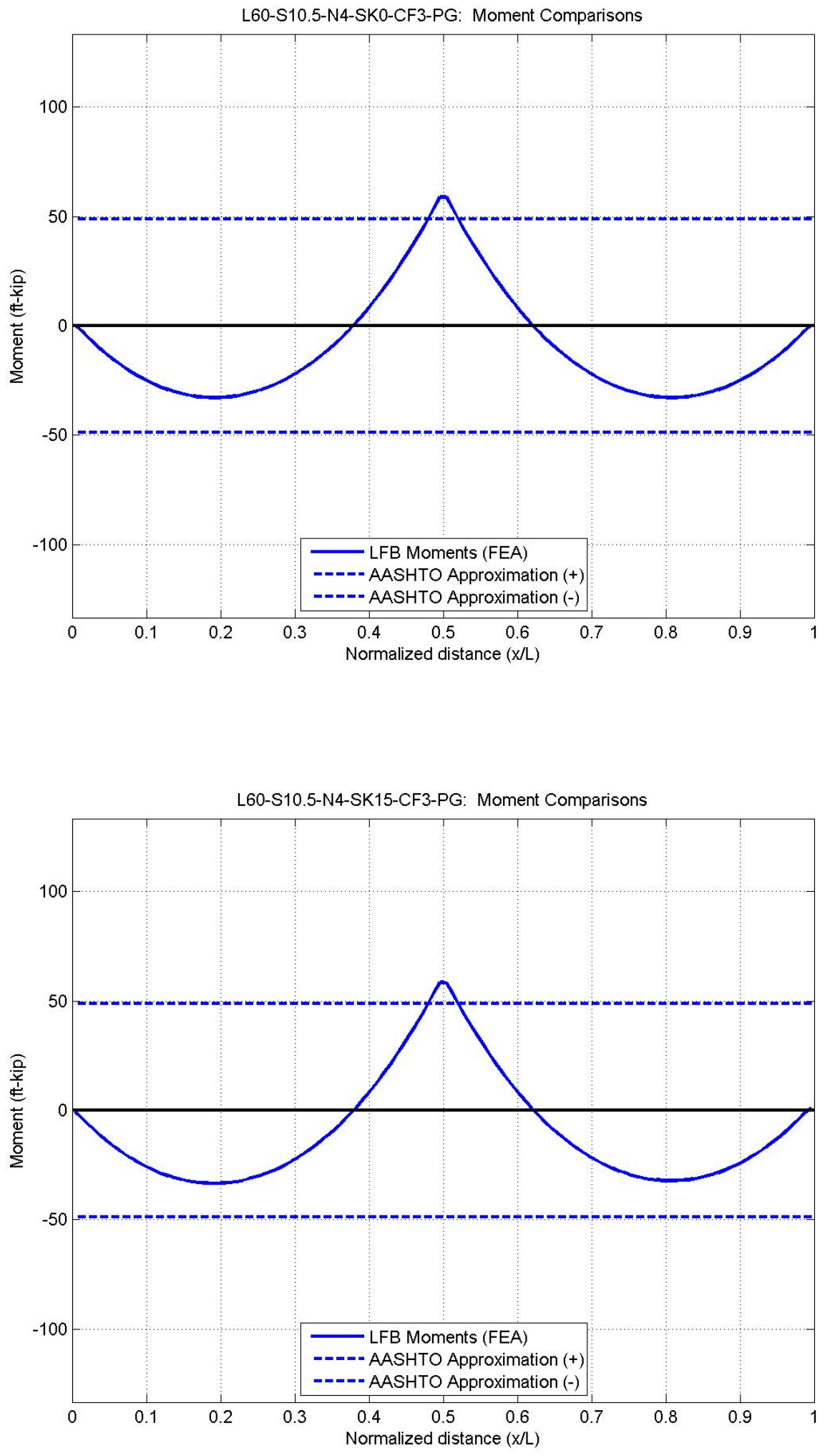

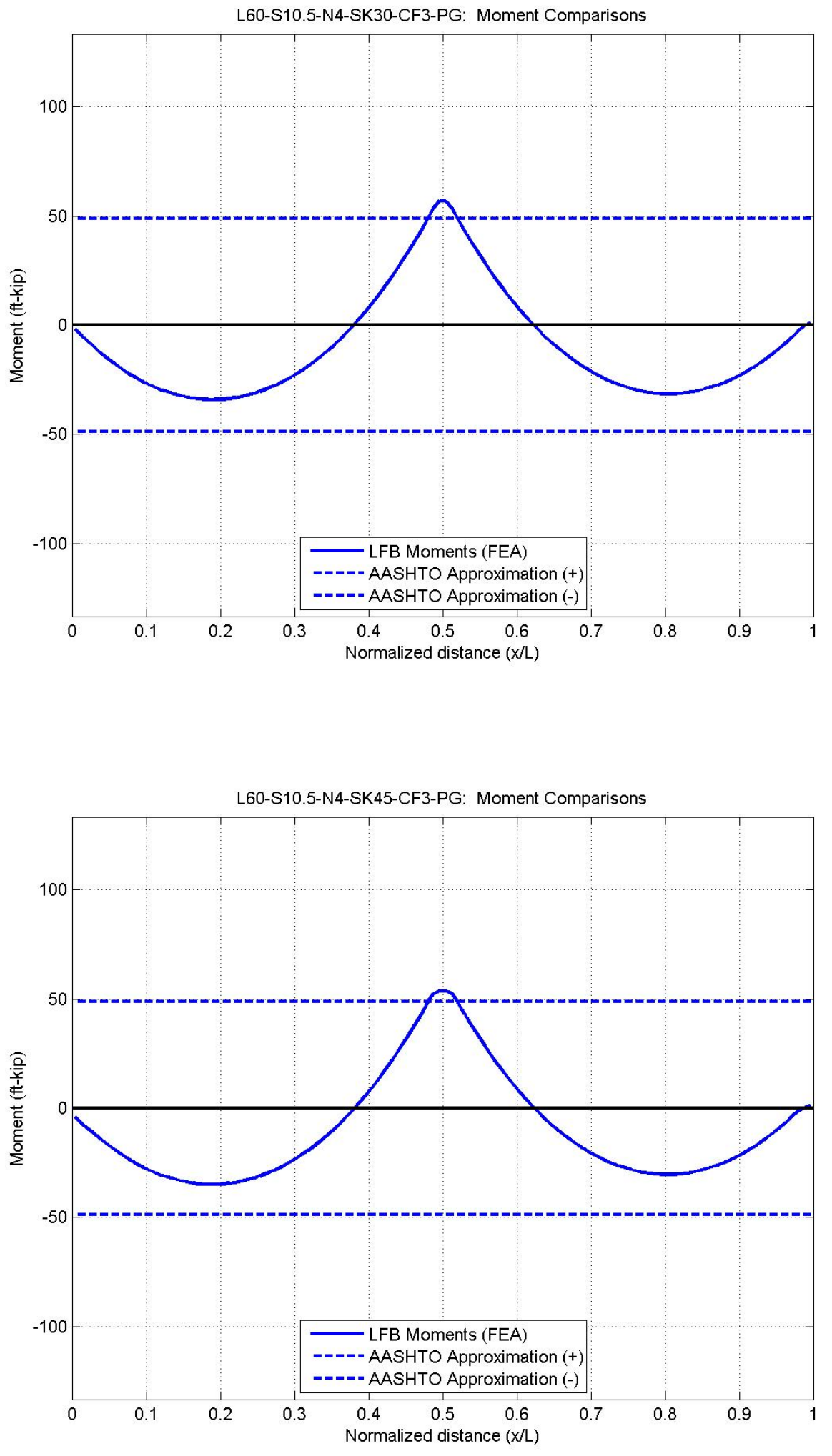

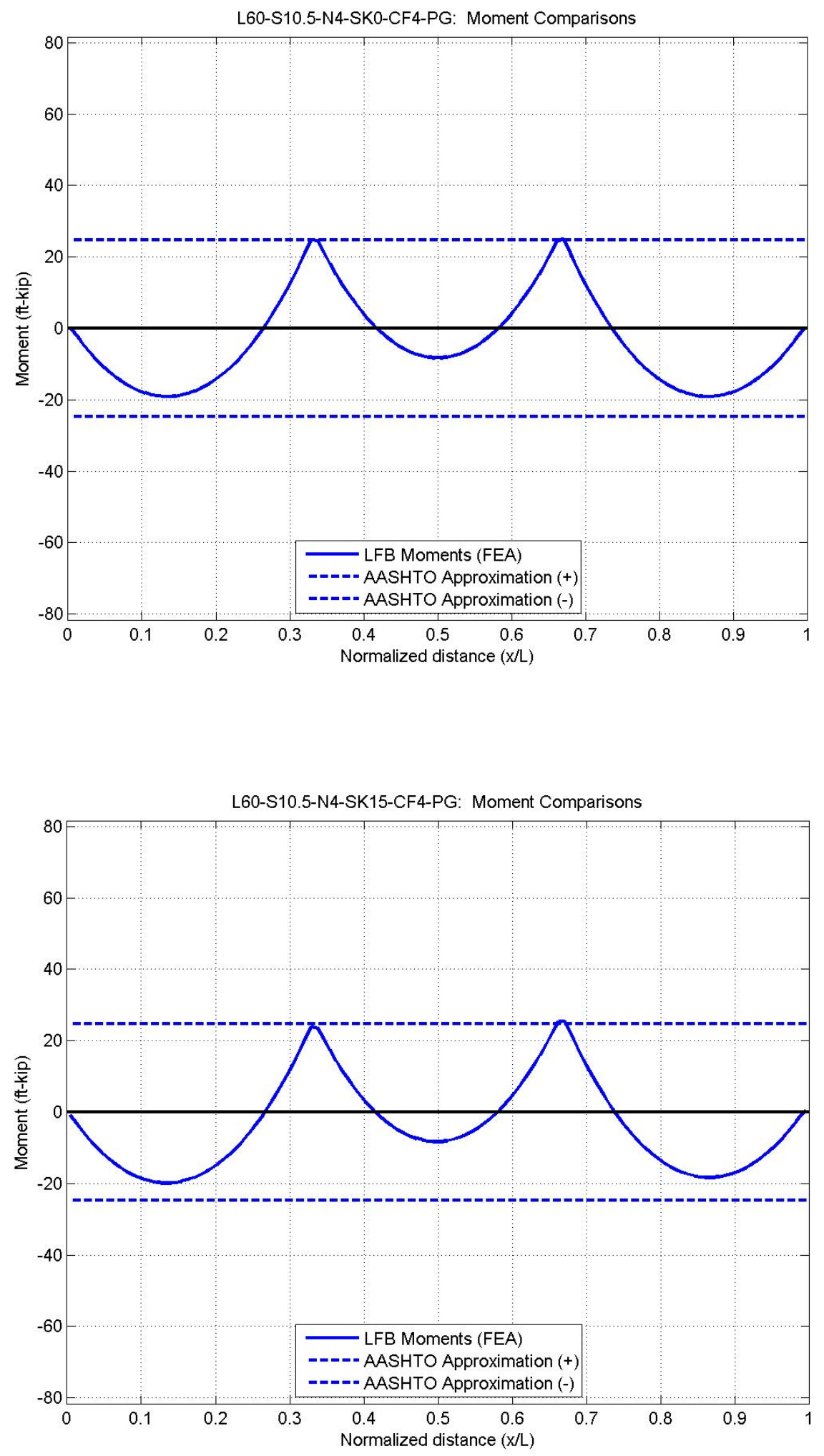

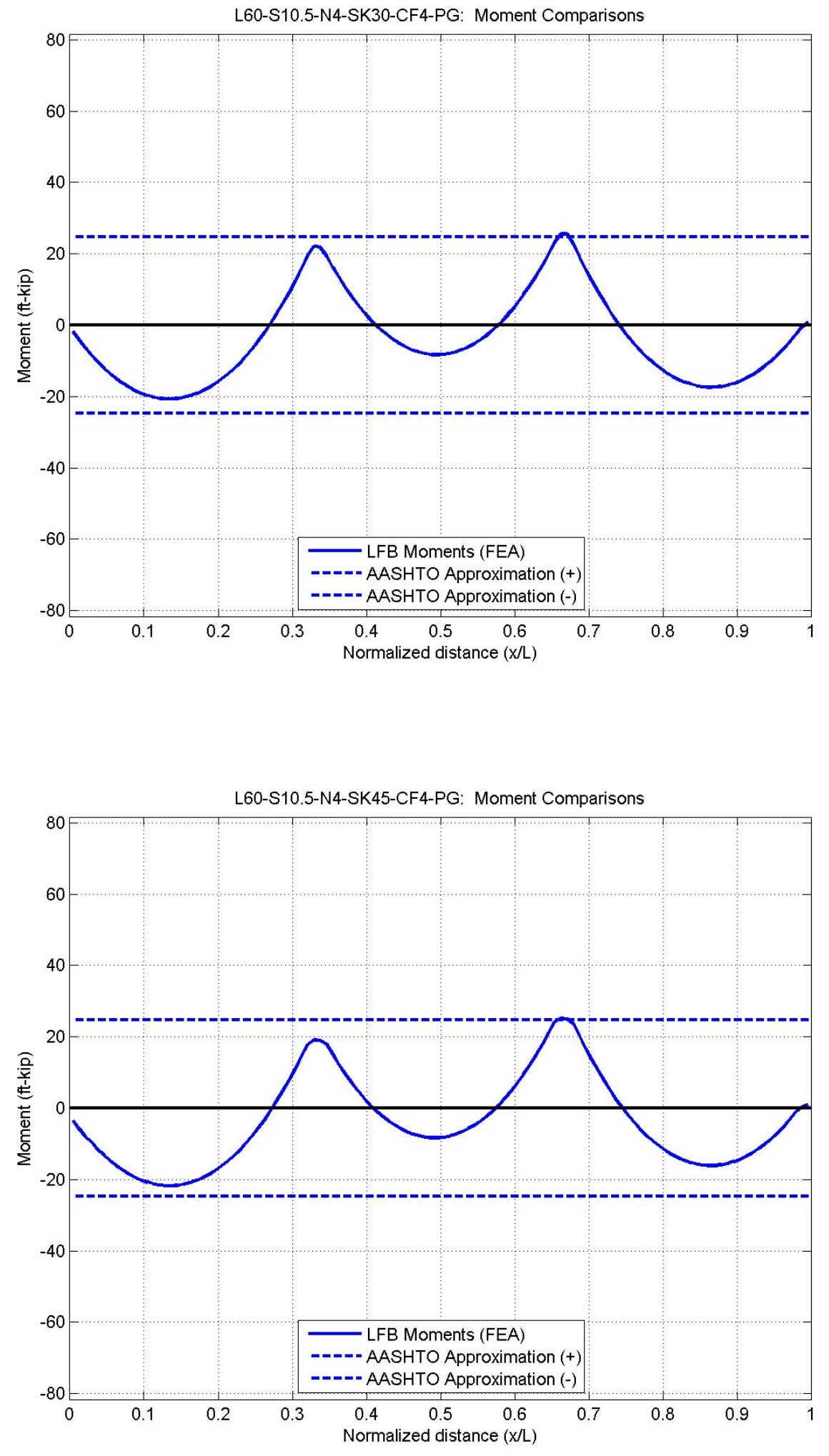

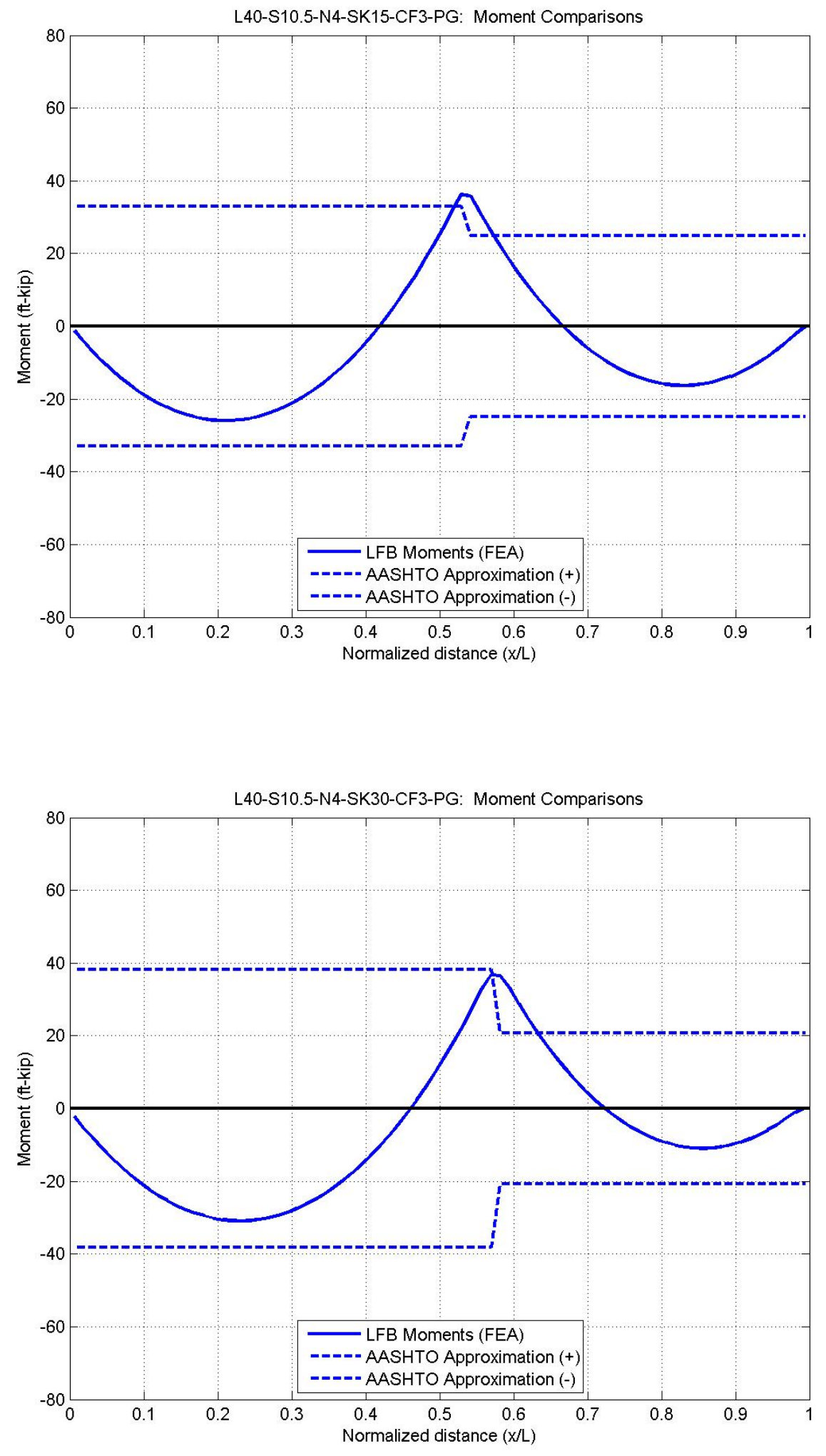

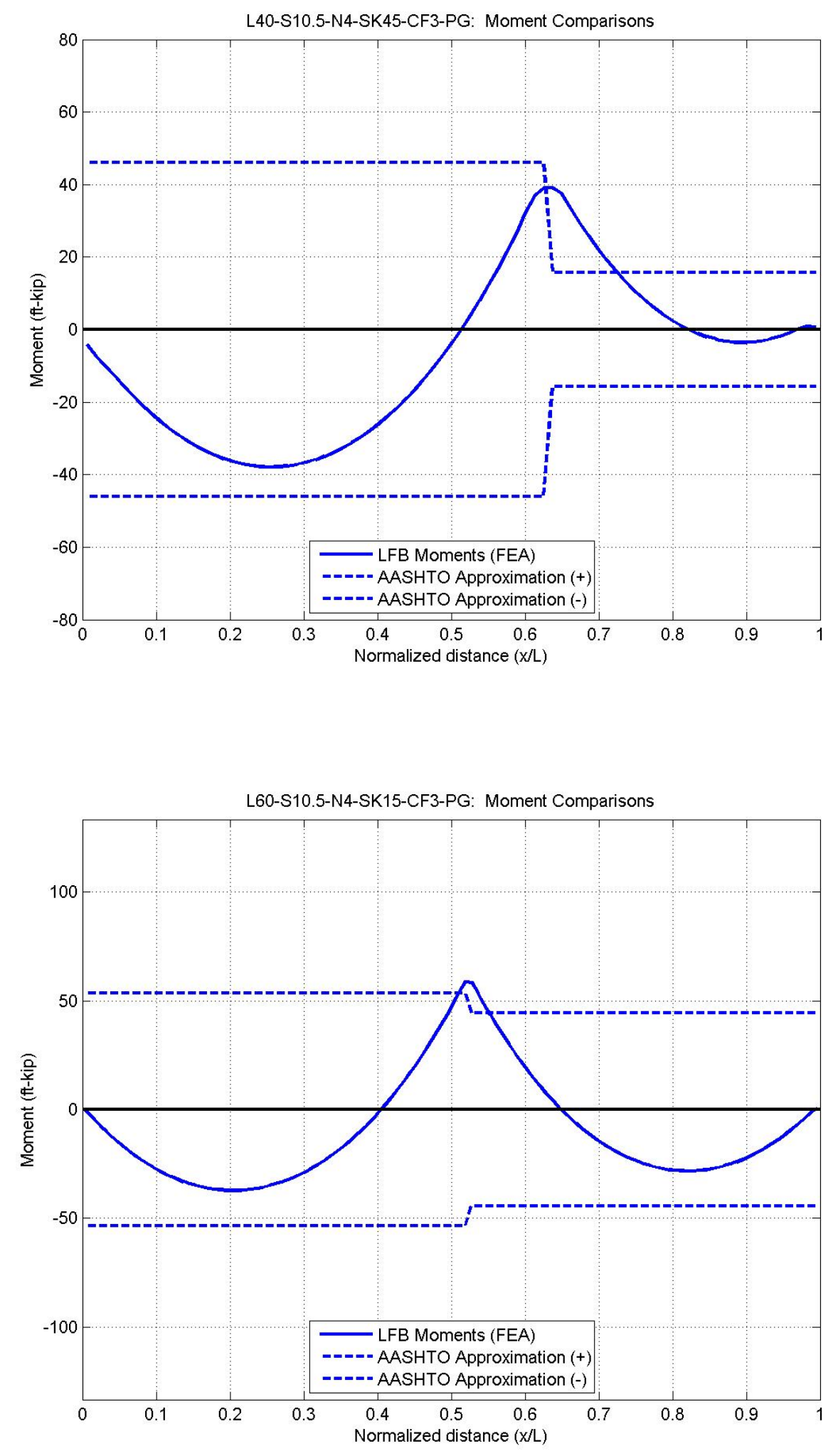

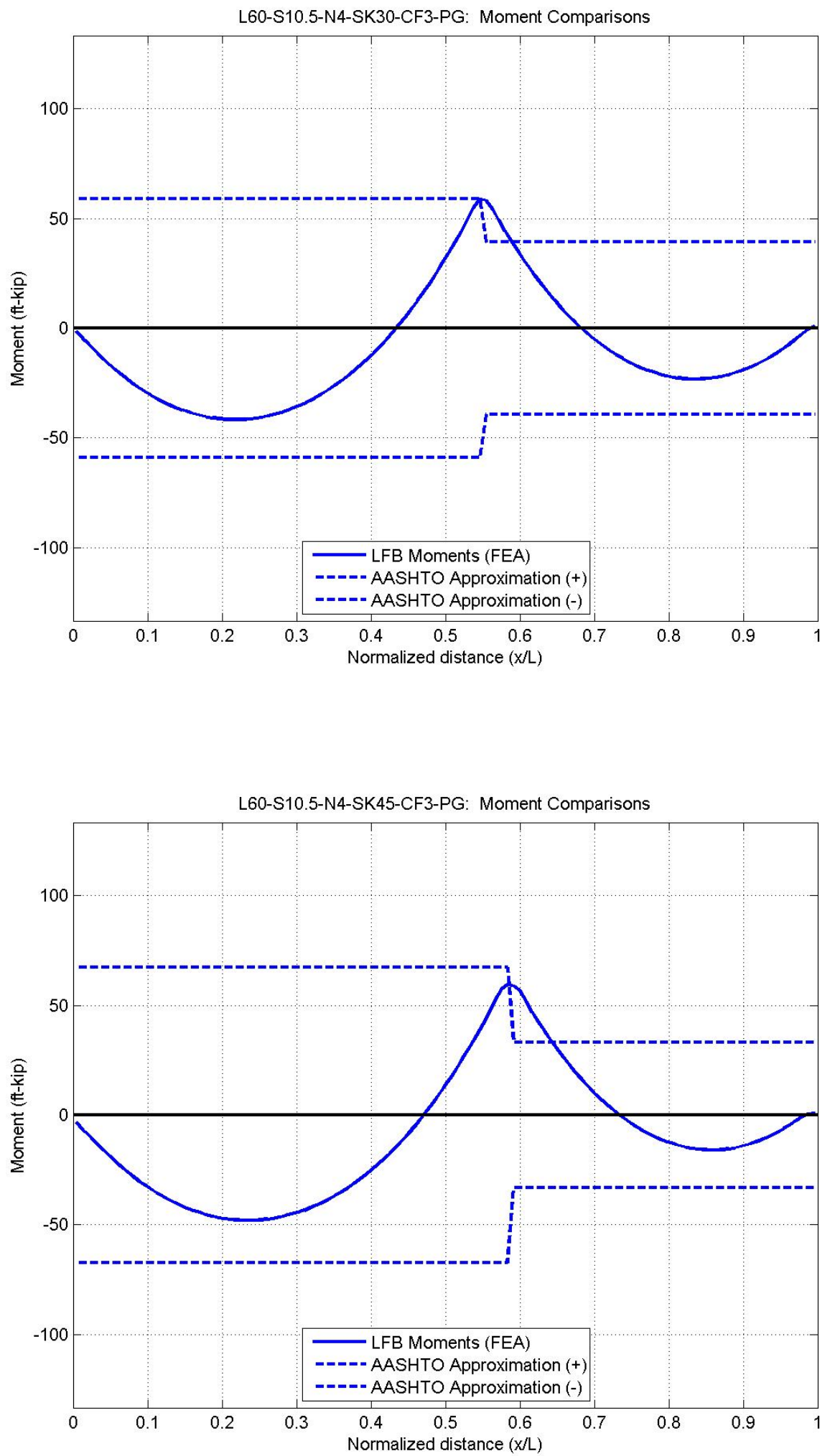

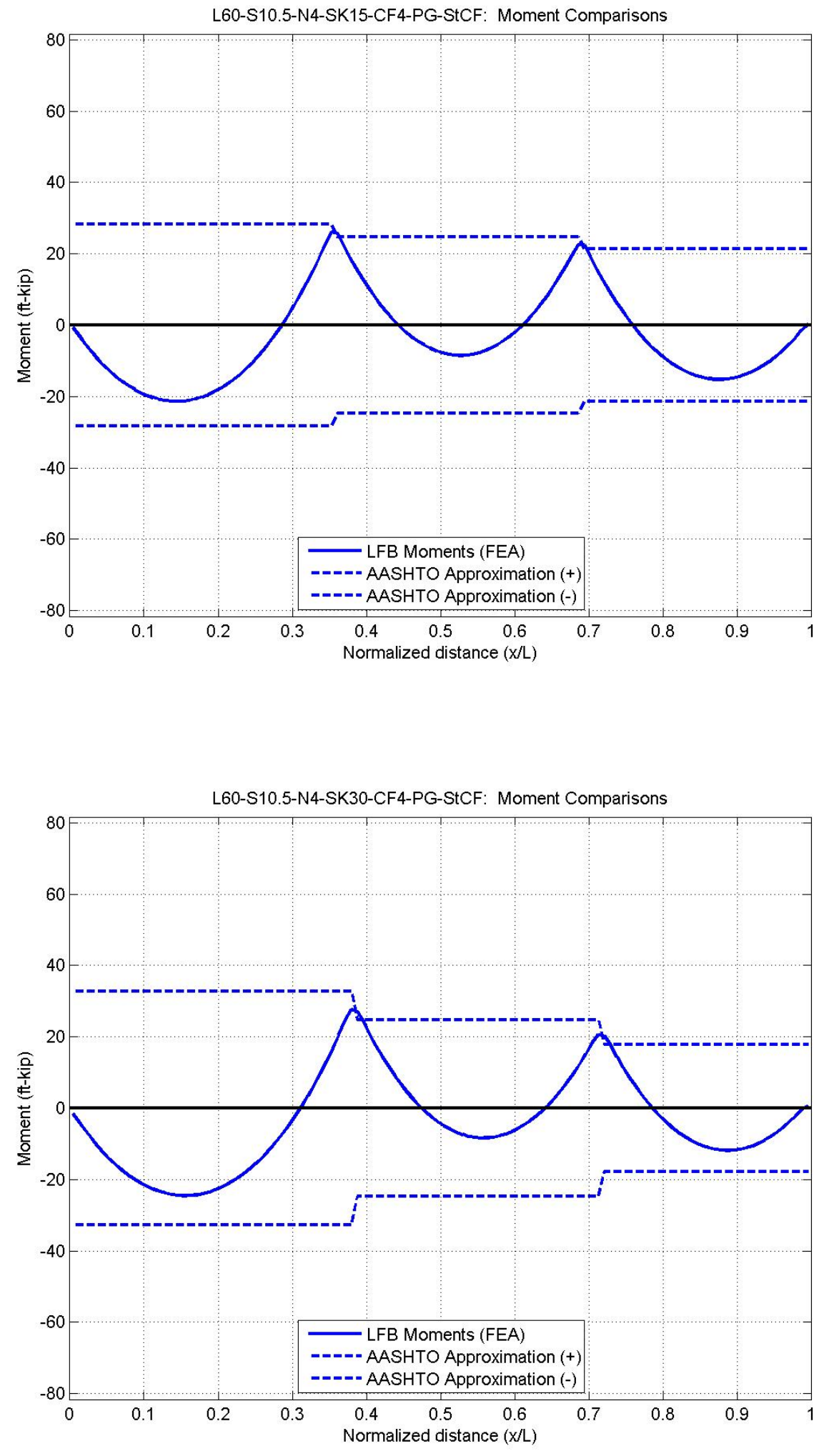

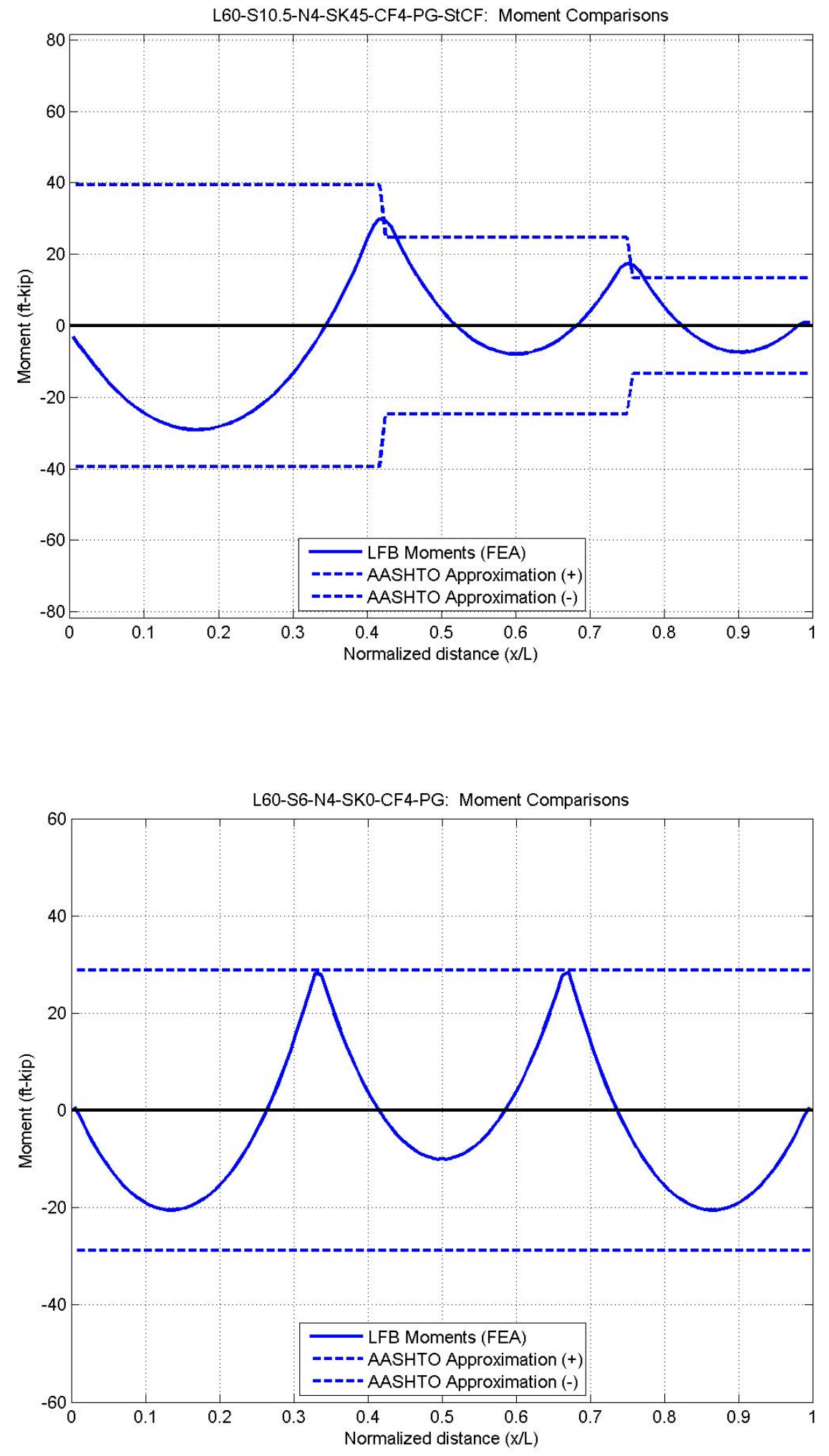

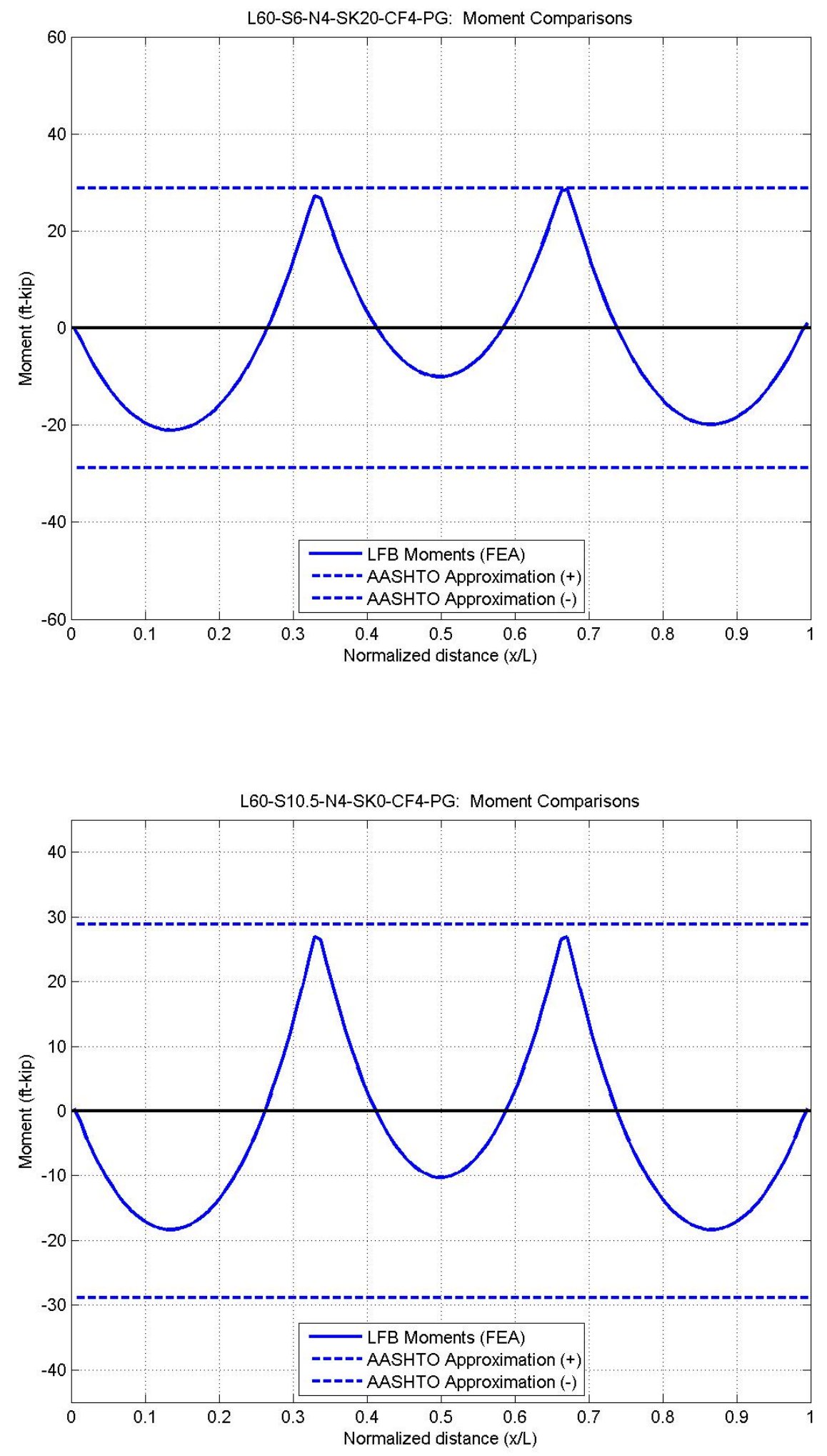

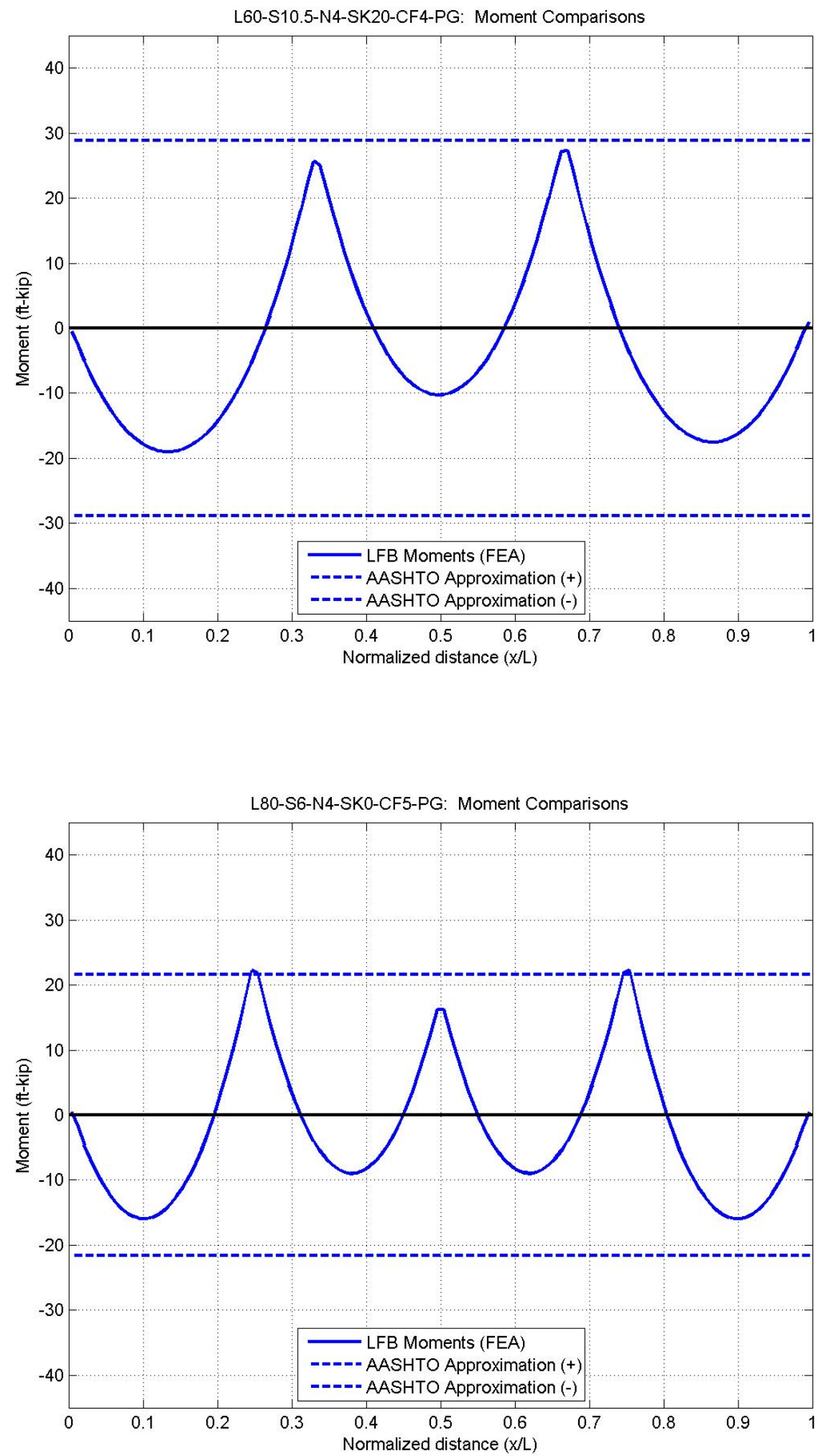

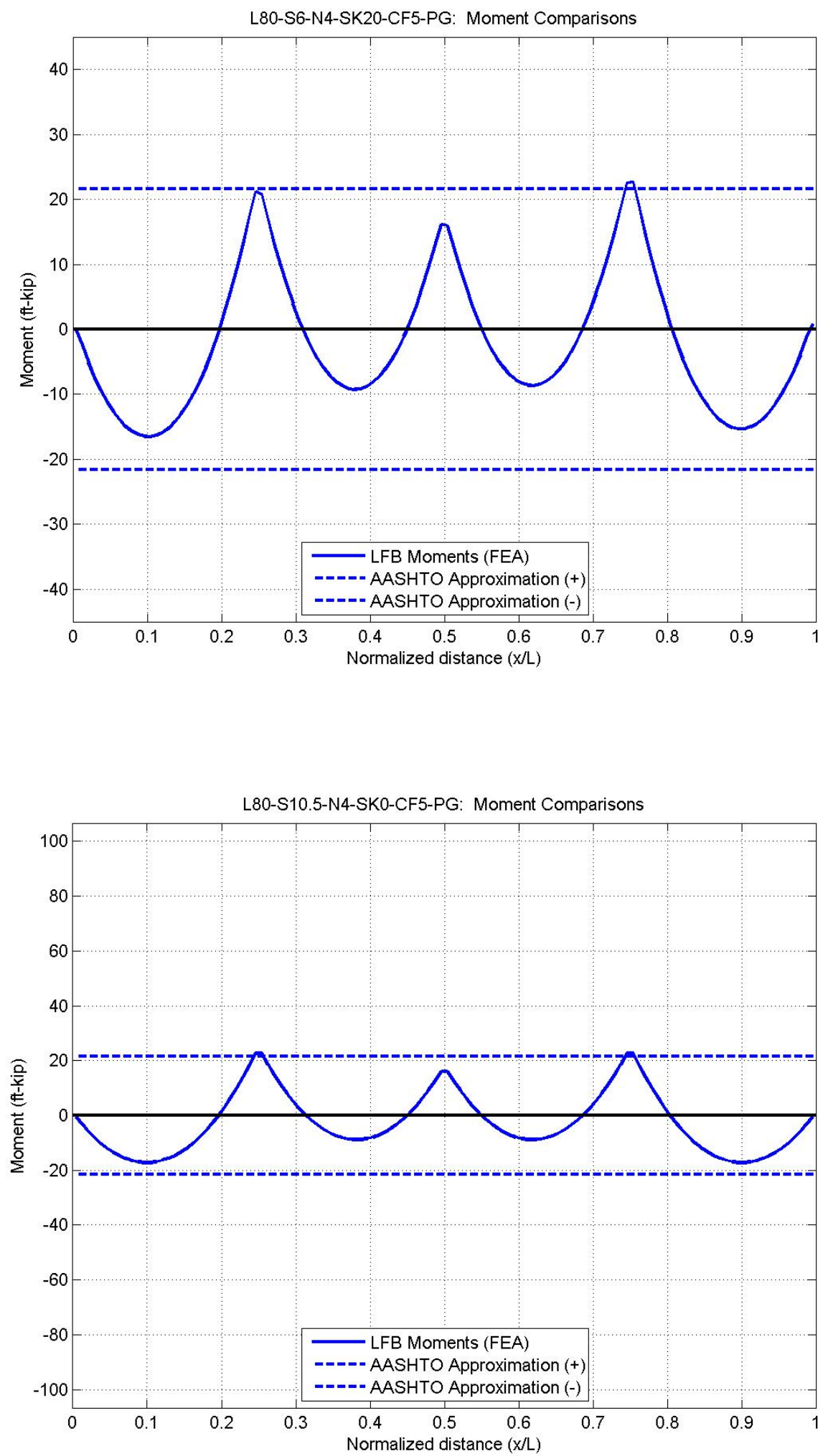

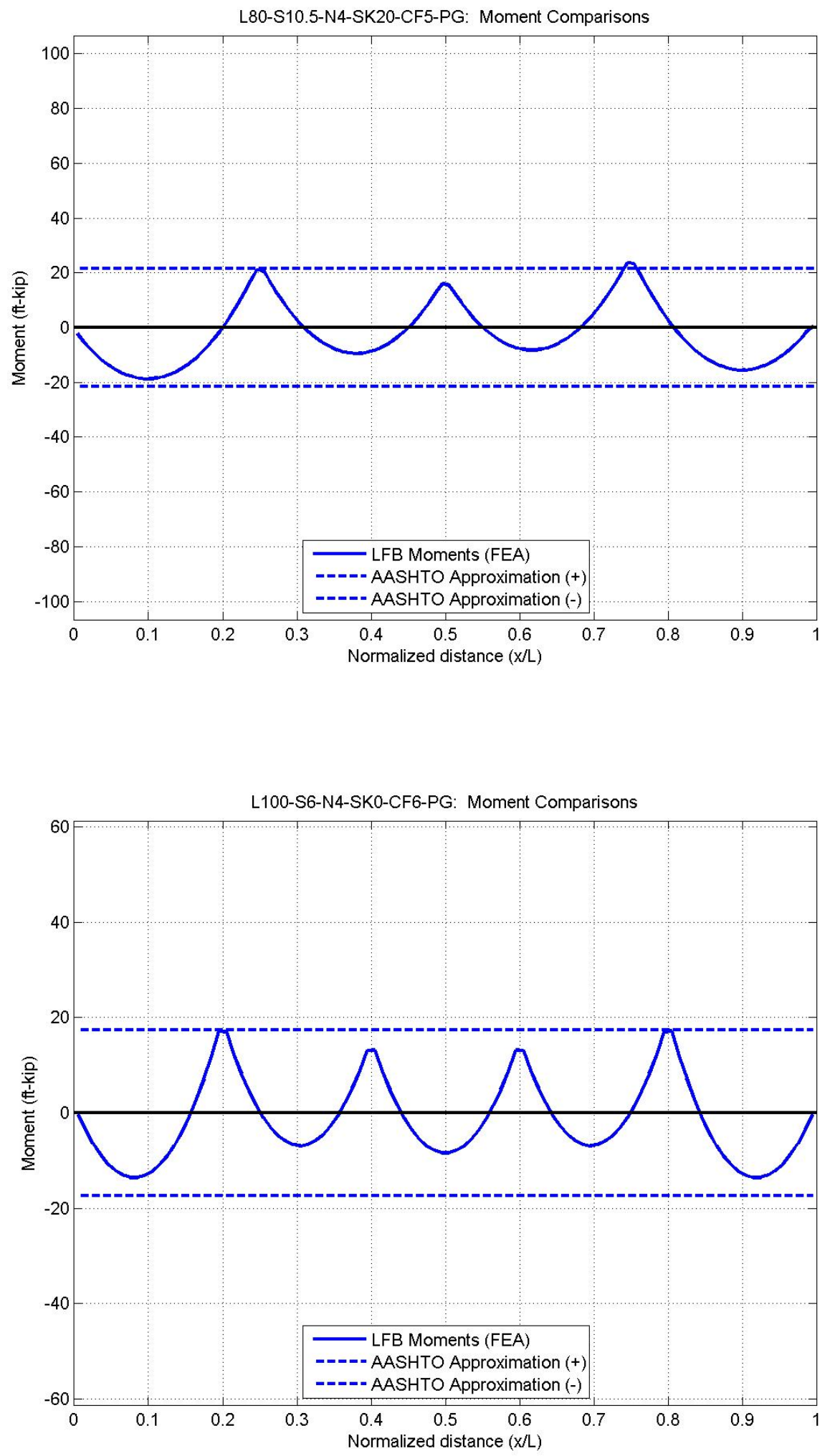

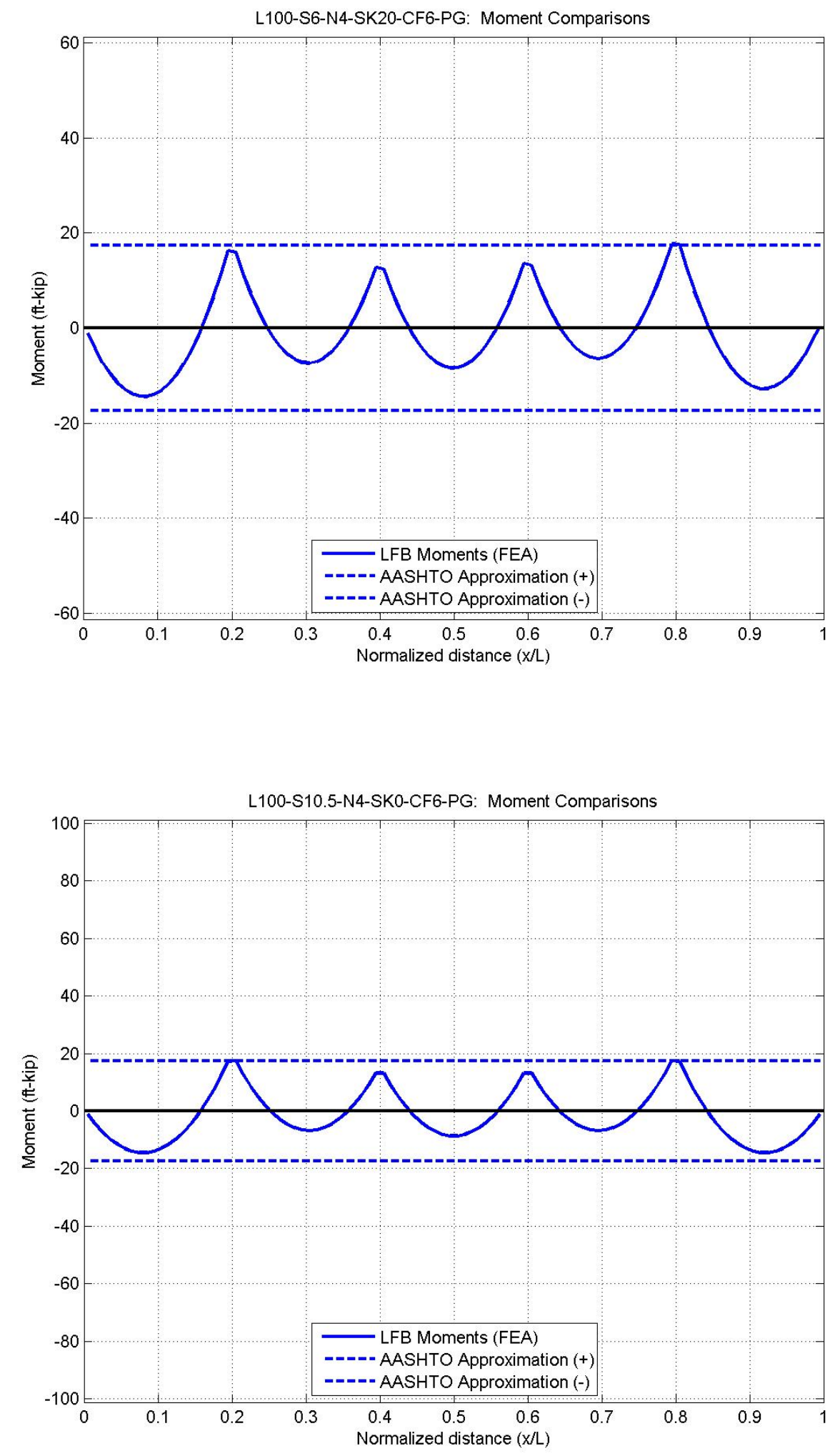

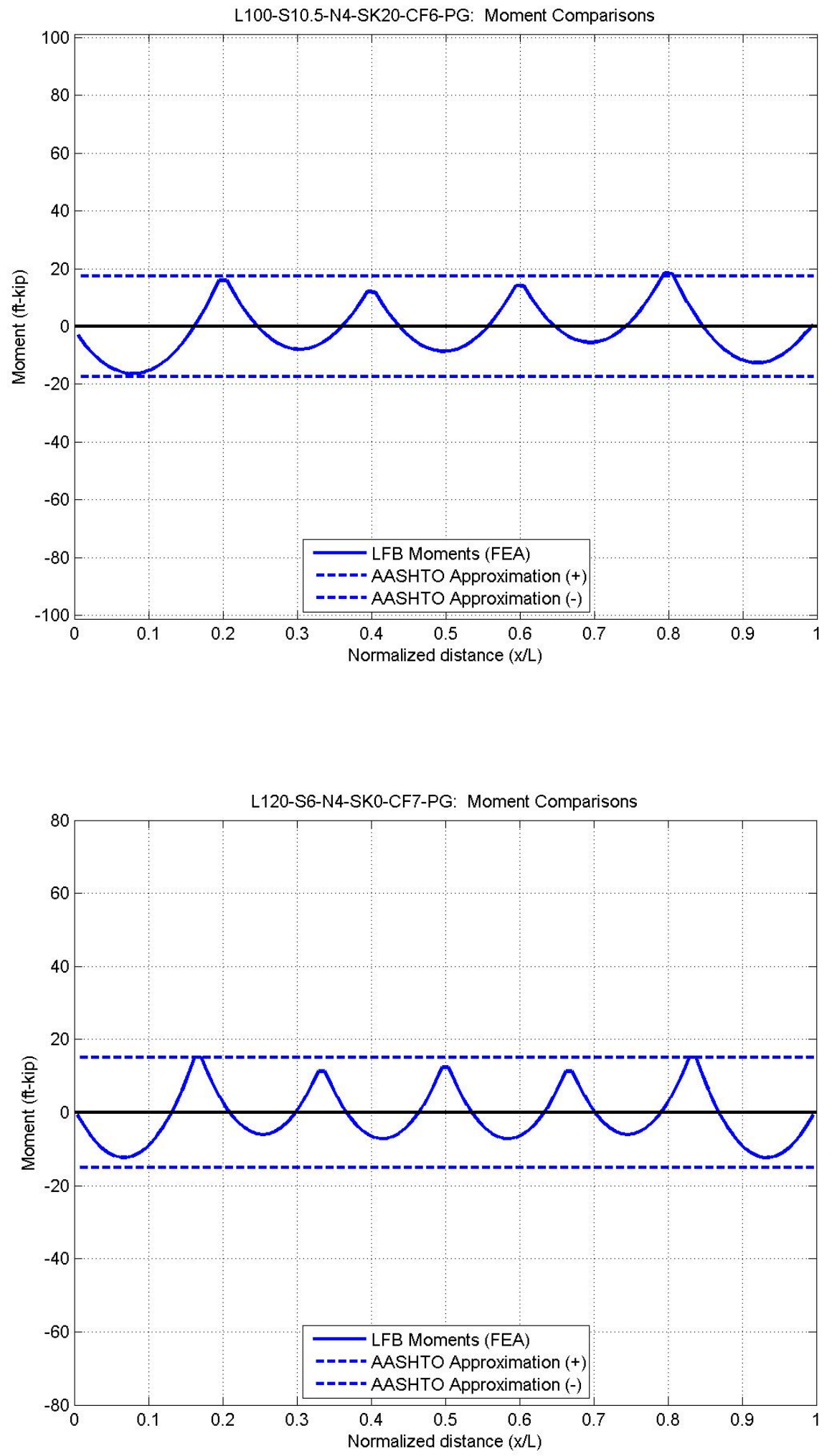

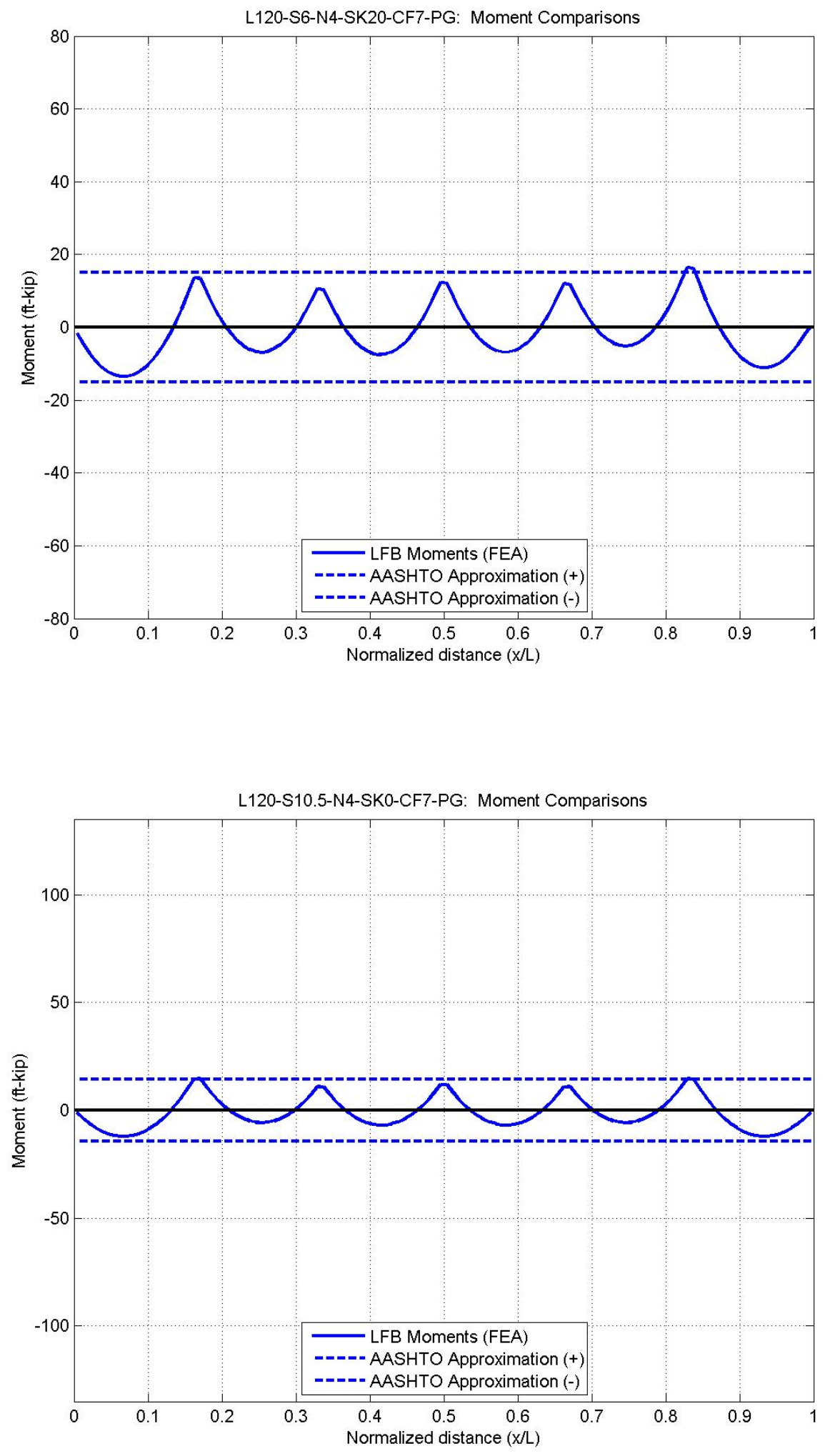


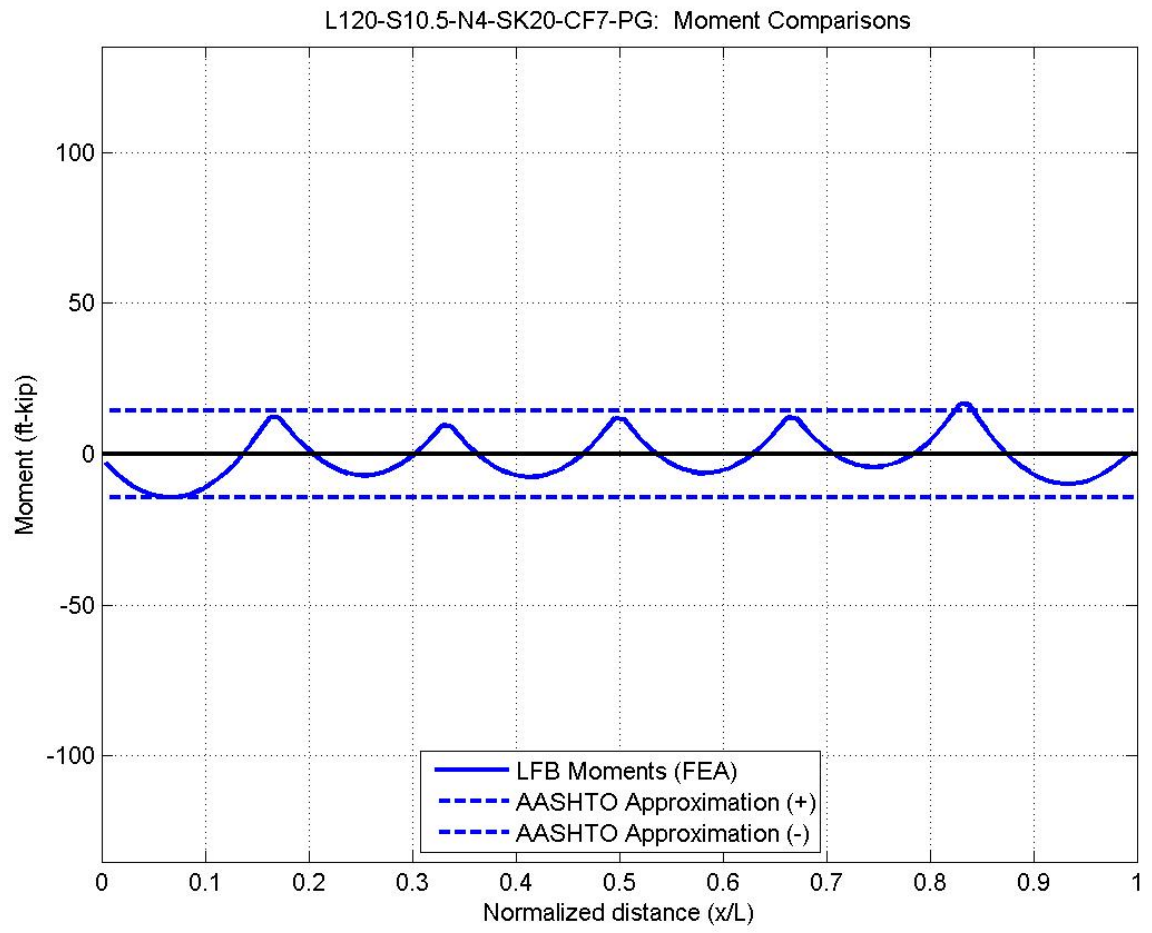




\section{APPENDiX B: PARAMETRIC MATRIX FOR THE DEVELOPMENT OF THE MODIFICATION FACTOR}

\section{B.1 Results Of Parametric Matrix}

The following appendix provides a series of plots from the parametric matrices discussed in Chapter 6. These plots provide the FEA LFB moment results obtained from Abaqus 6.101/CAE, AASHTO approximation for LFB, and the modification factor approximation for LFB superimposed. The FEA results are represented by the solid blue line, while the blue dashed line represents the AASHTO approximation and the red dash-dot lines represent the modification factor. The plots were generated from the algorithm presented in Section 4.7 with a naming scheme. The naming scheme labeled the title of the plots with a series of variables. The variables are as follows:

- L- Span length of the bridge

- S- Girder Spacing

- N- Number of girders

- SK- Skew angle

- CF- Number of cross-frames

- PG- Plate girders 

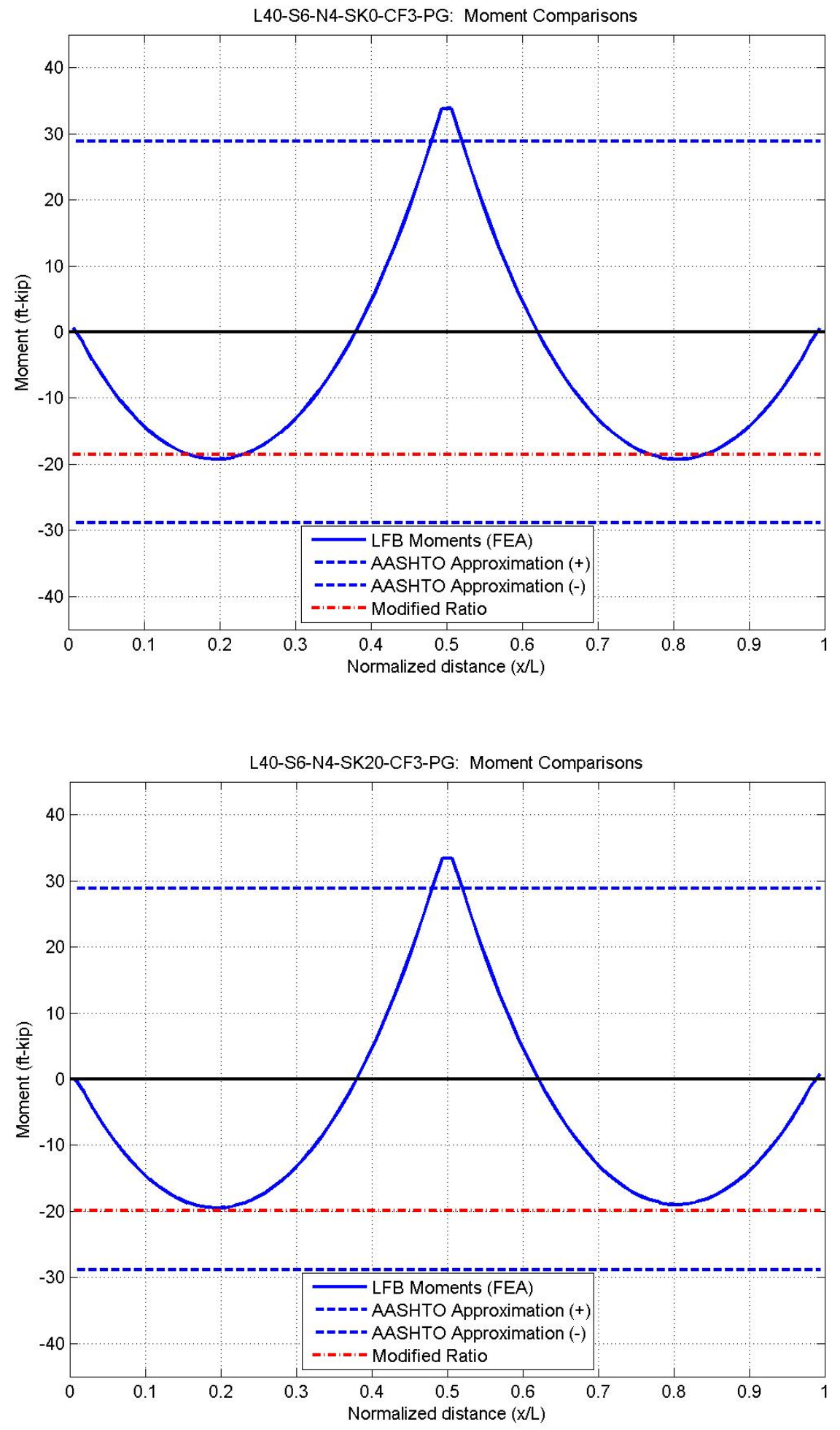

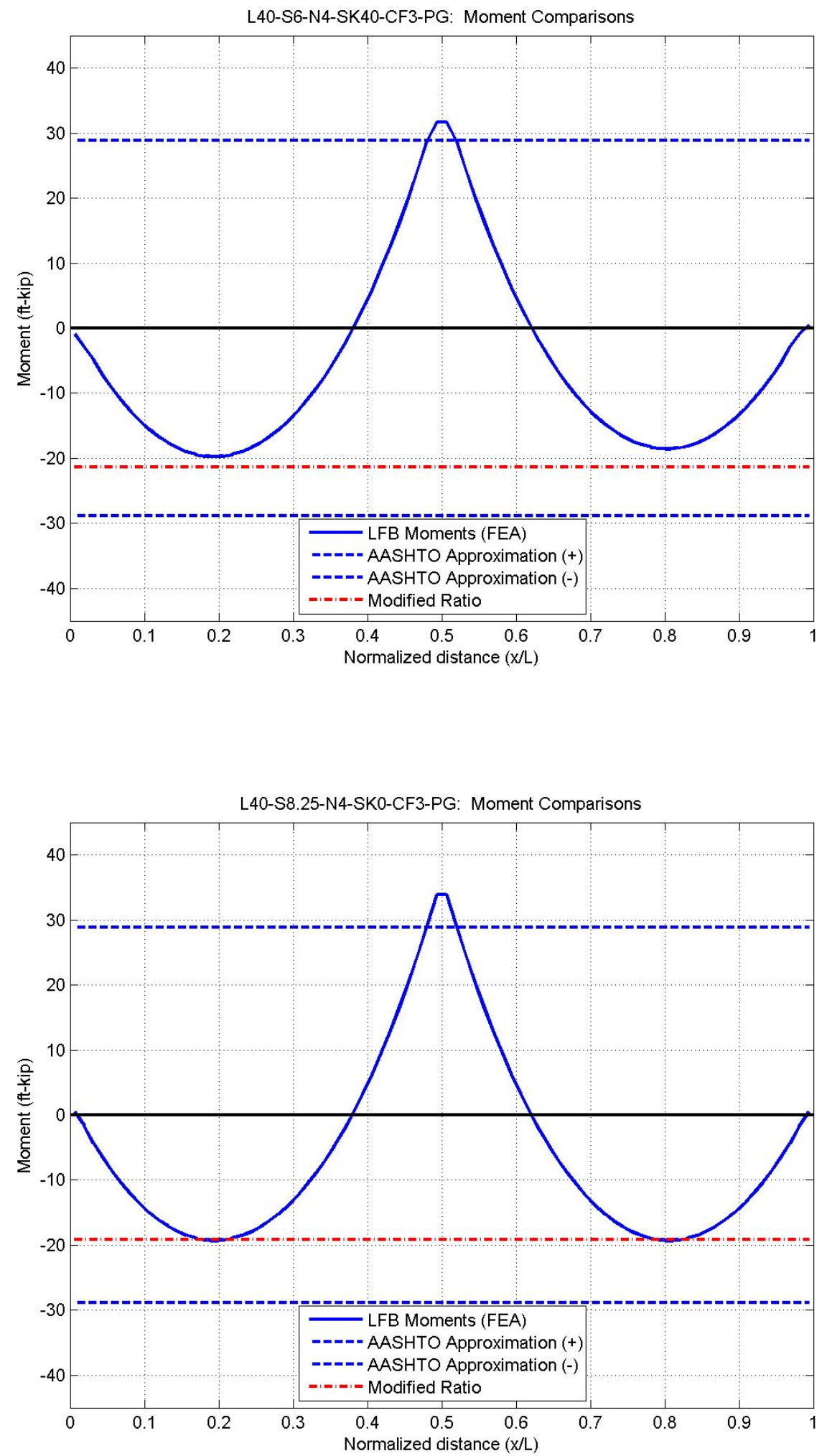

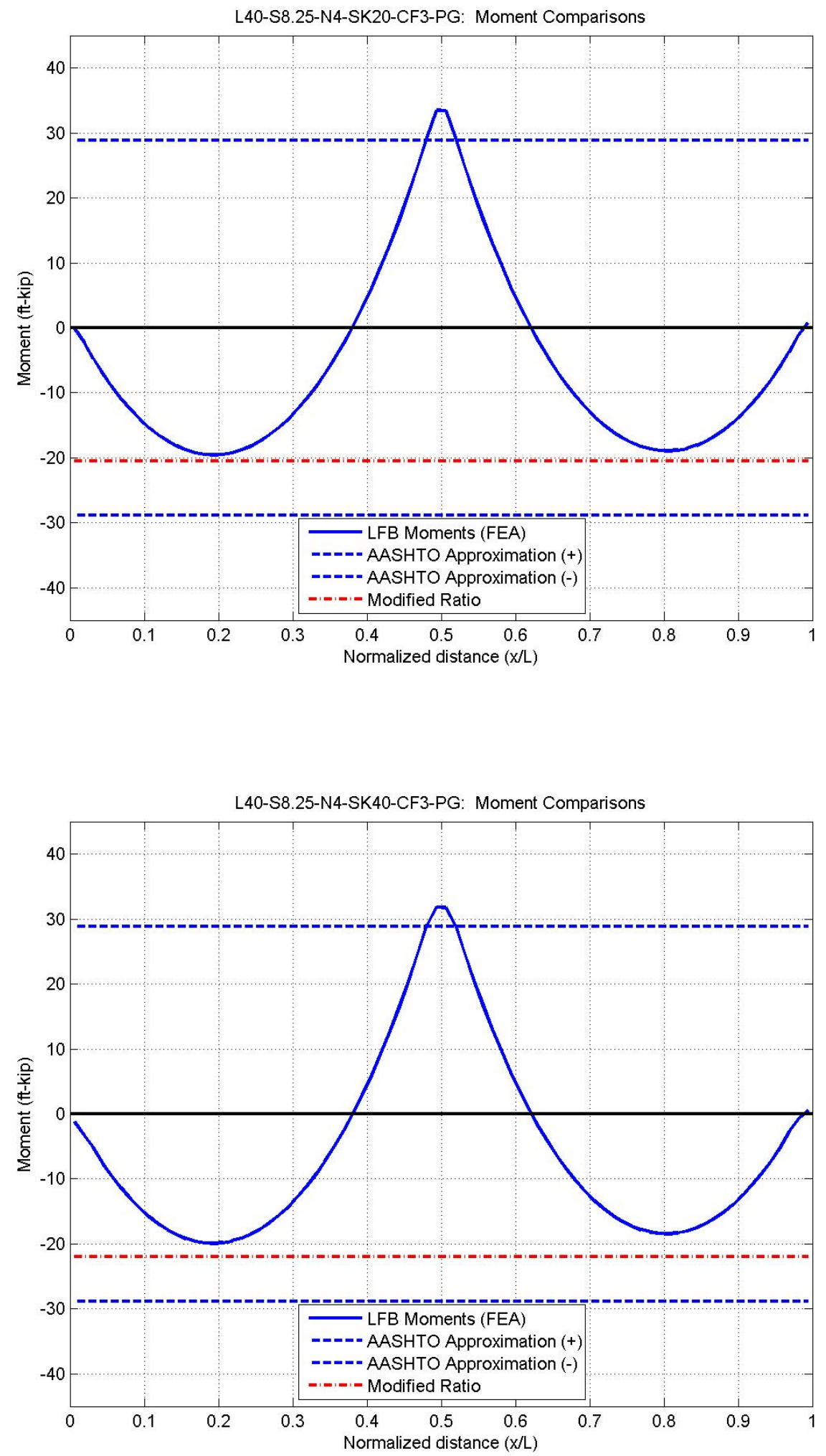

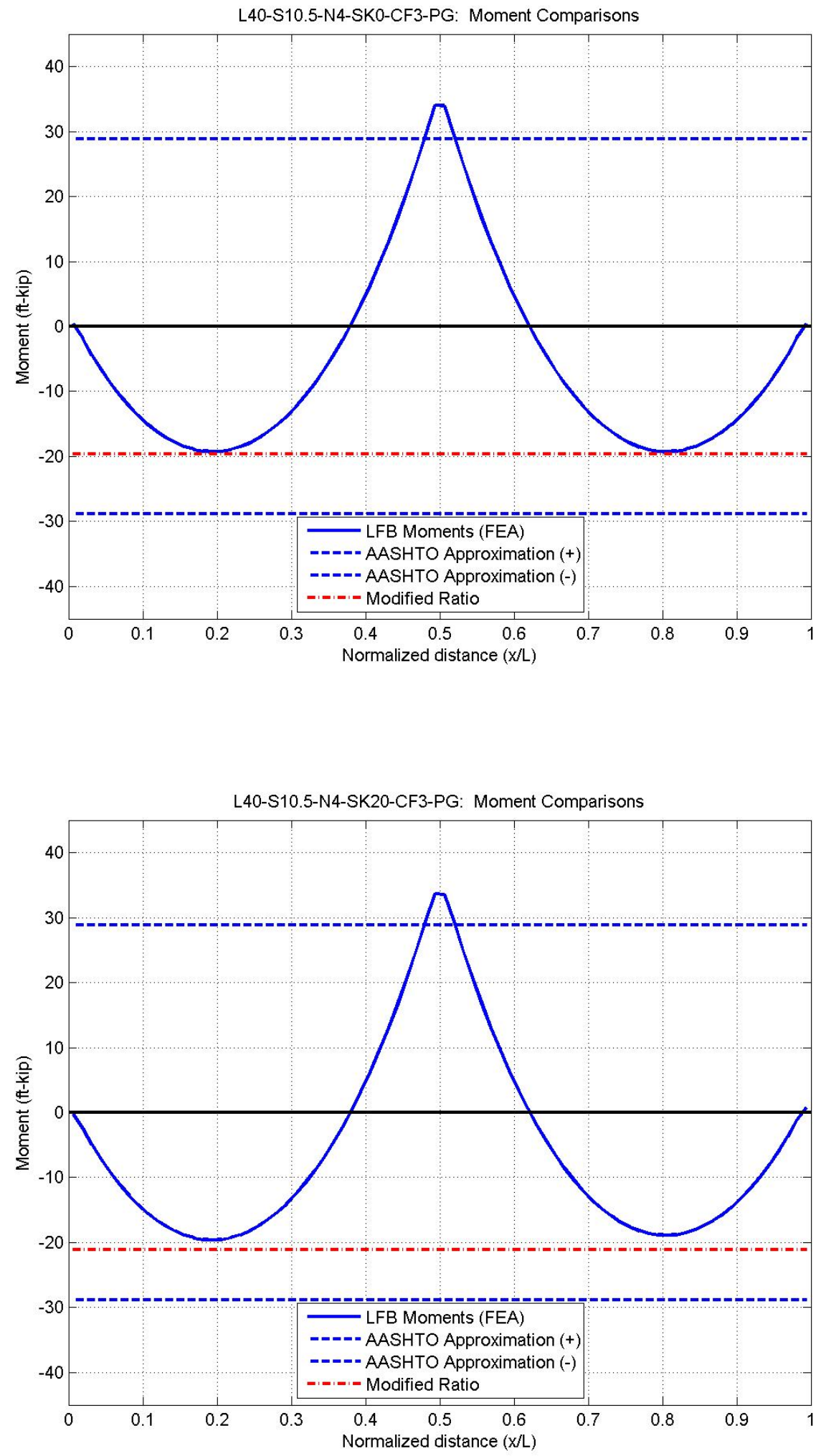

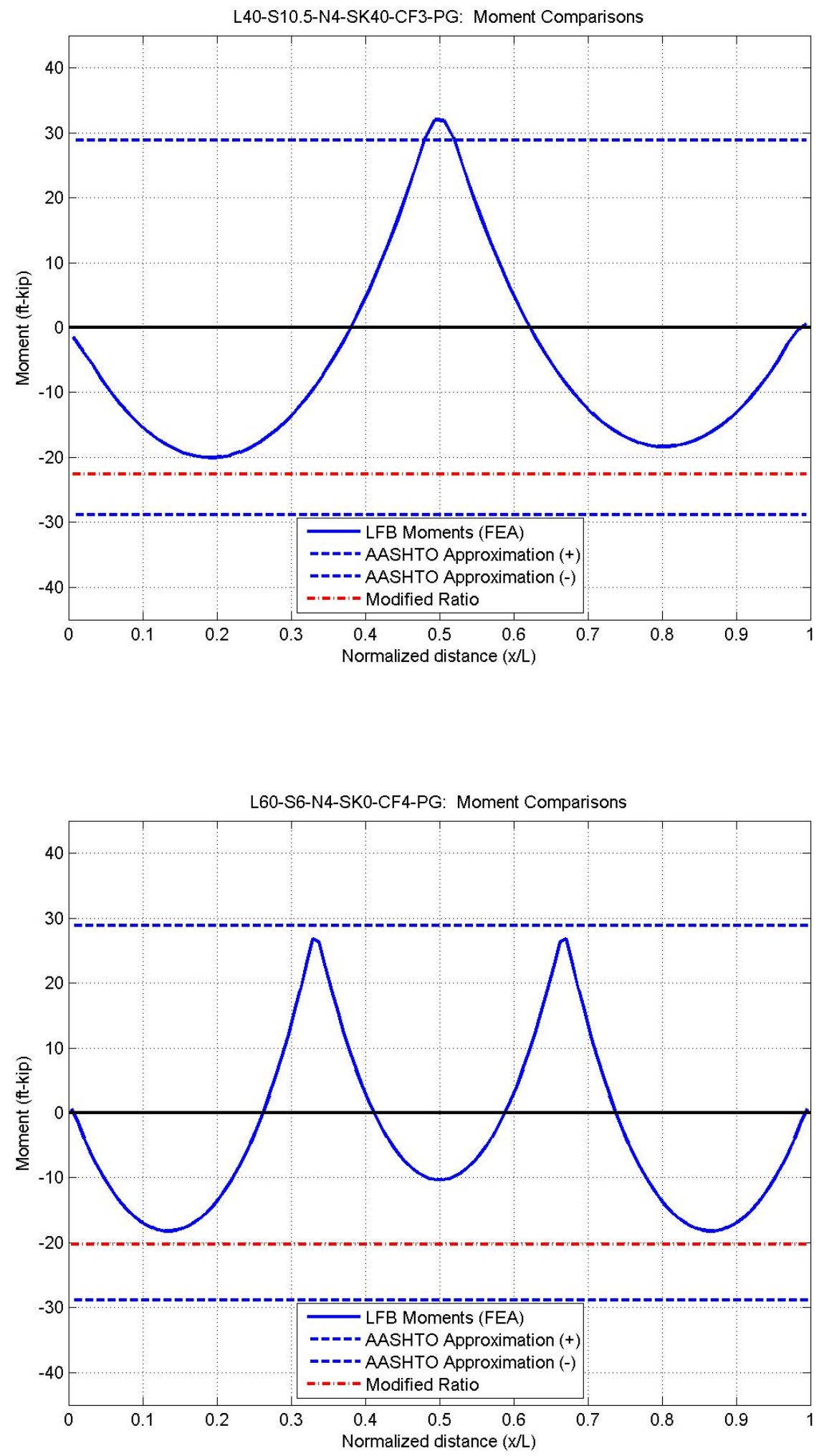

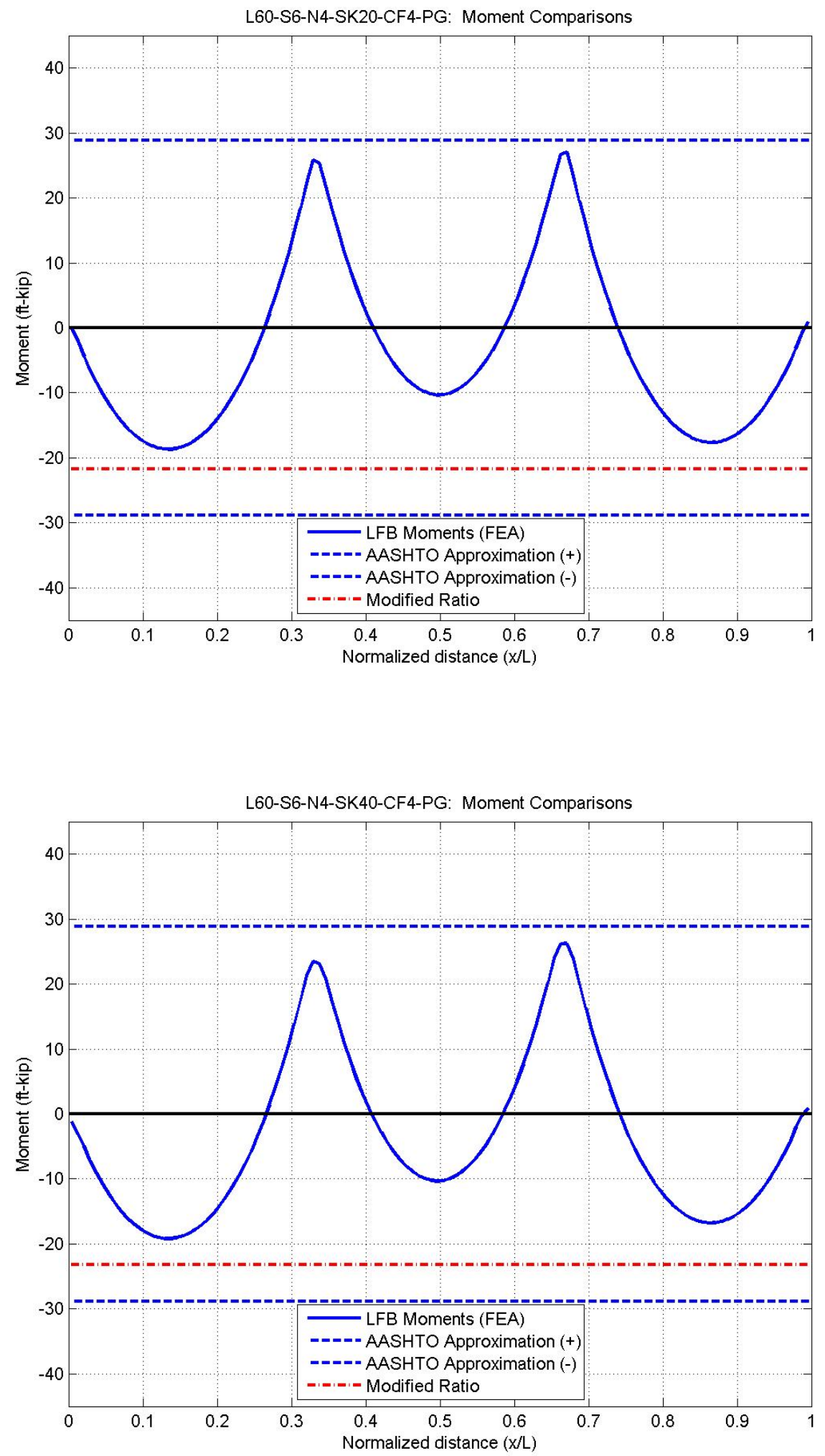

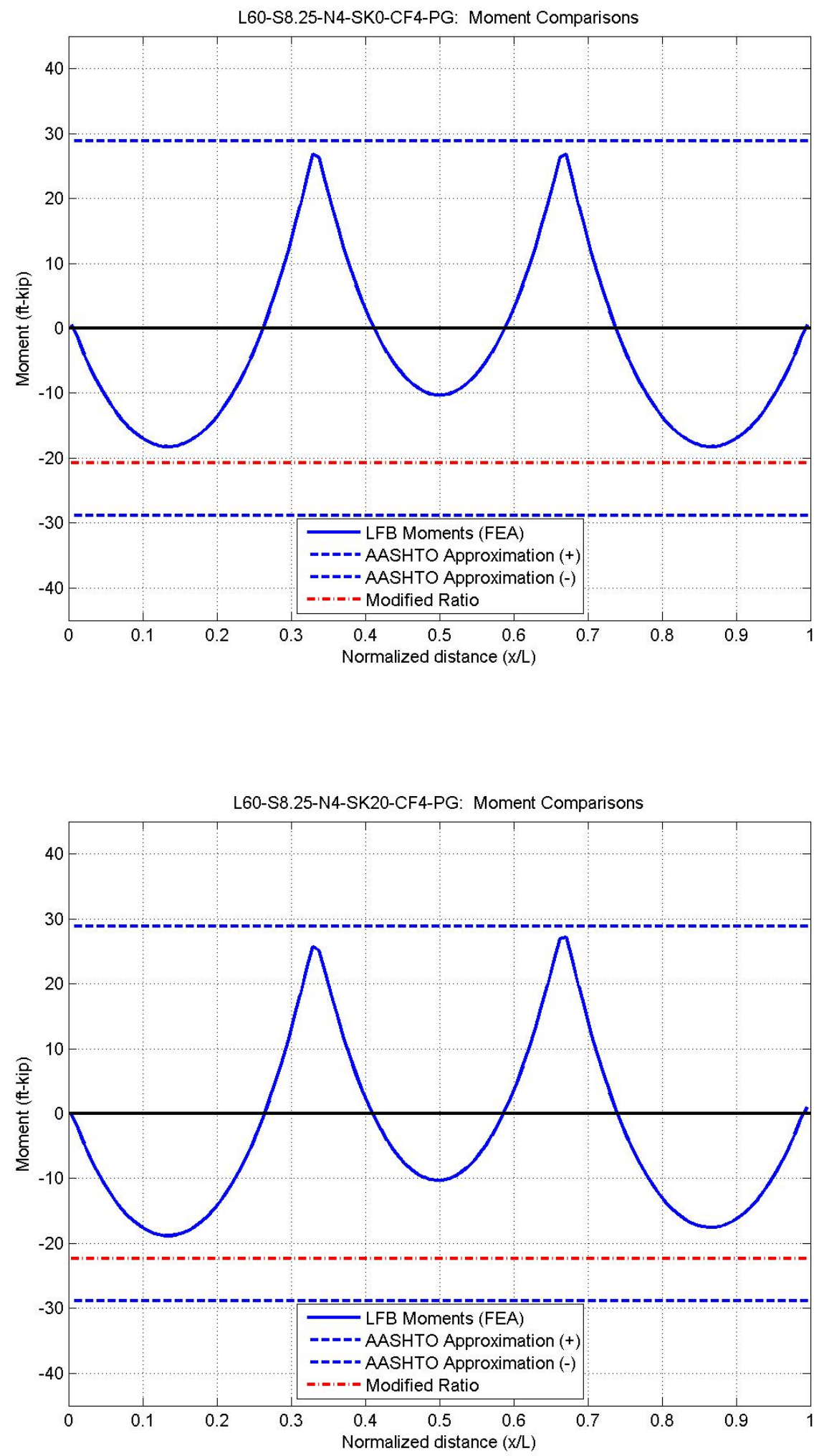

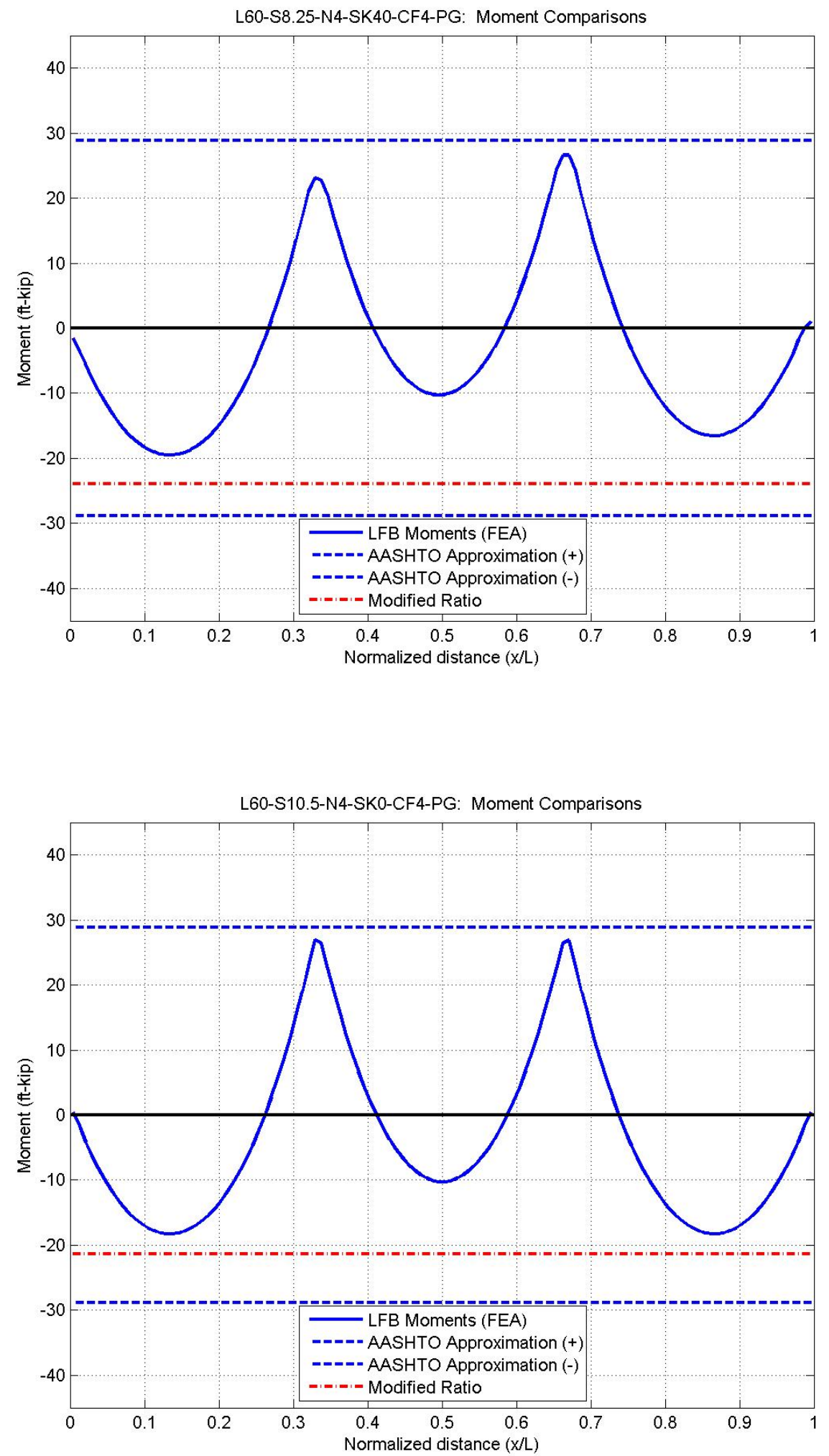

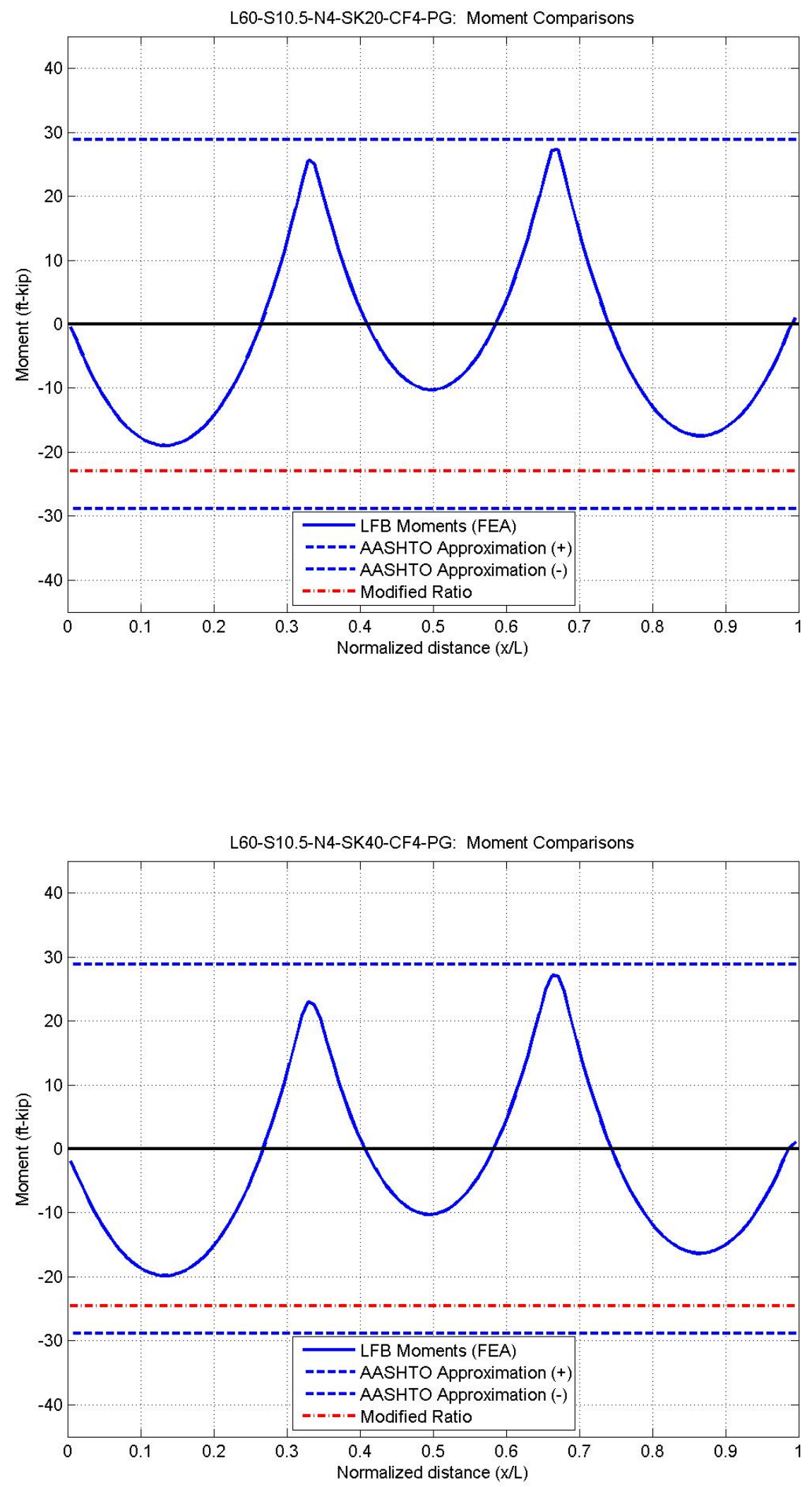

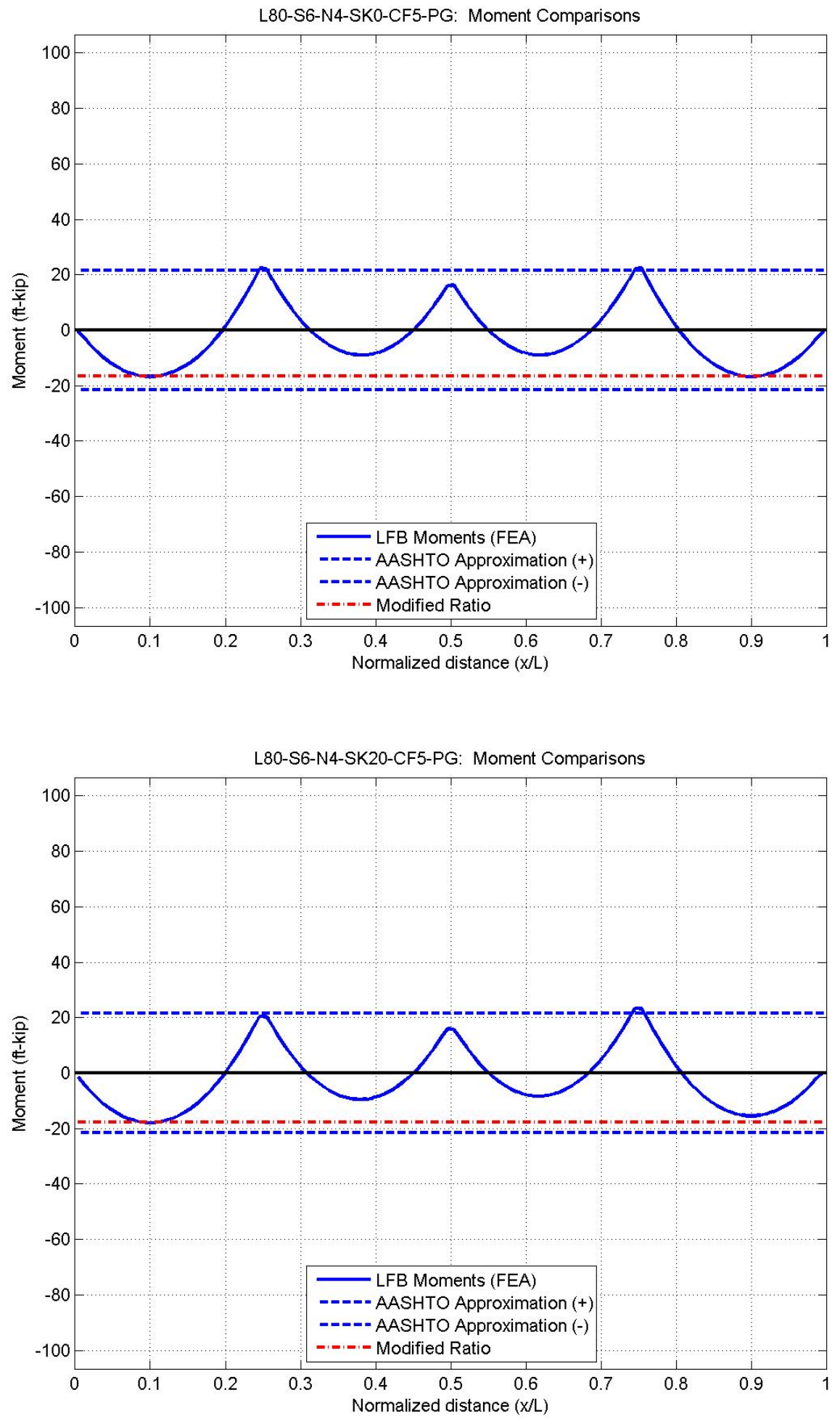

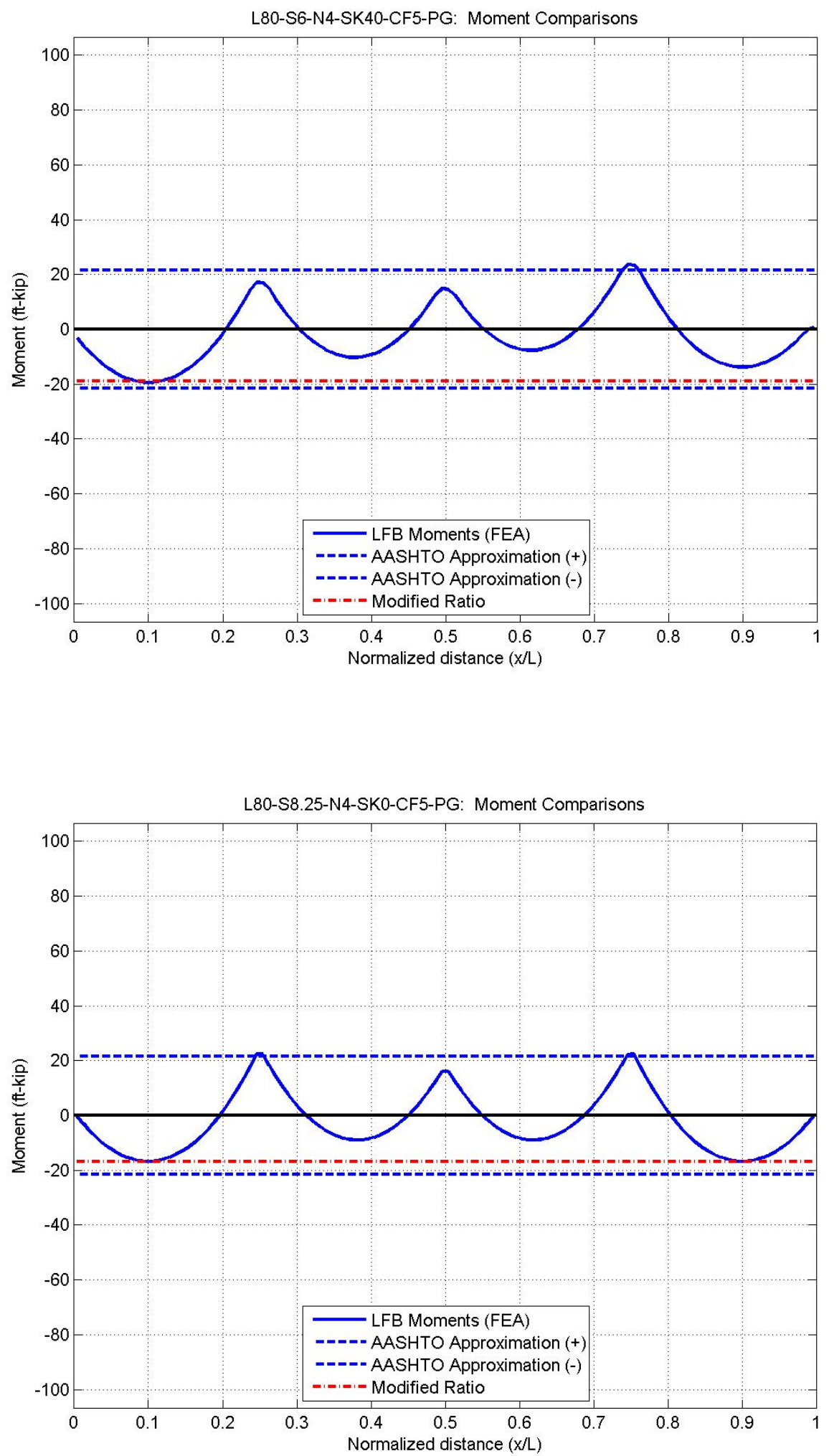

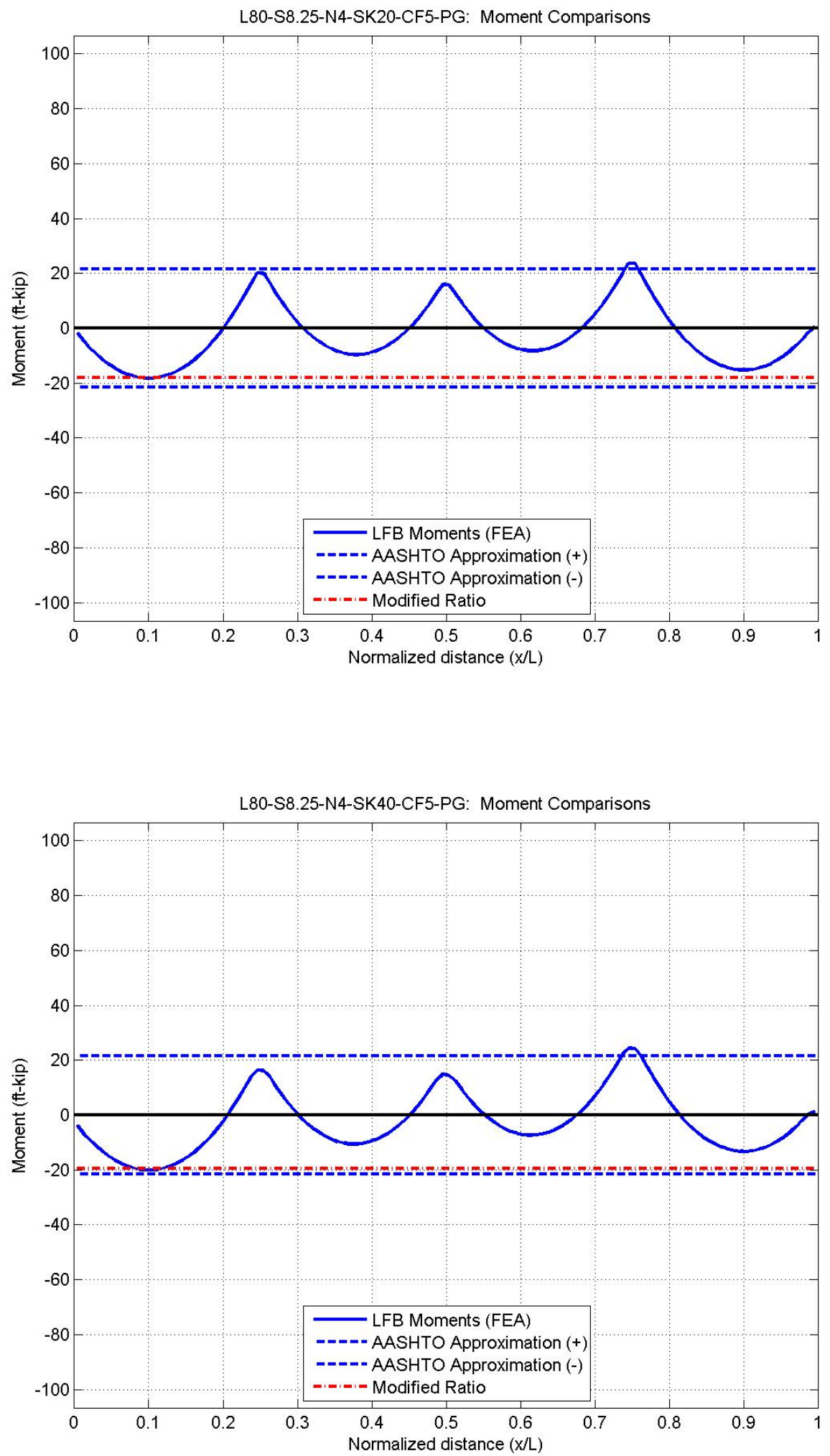

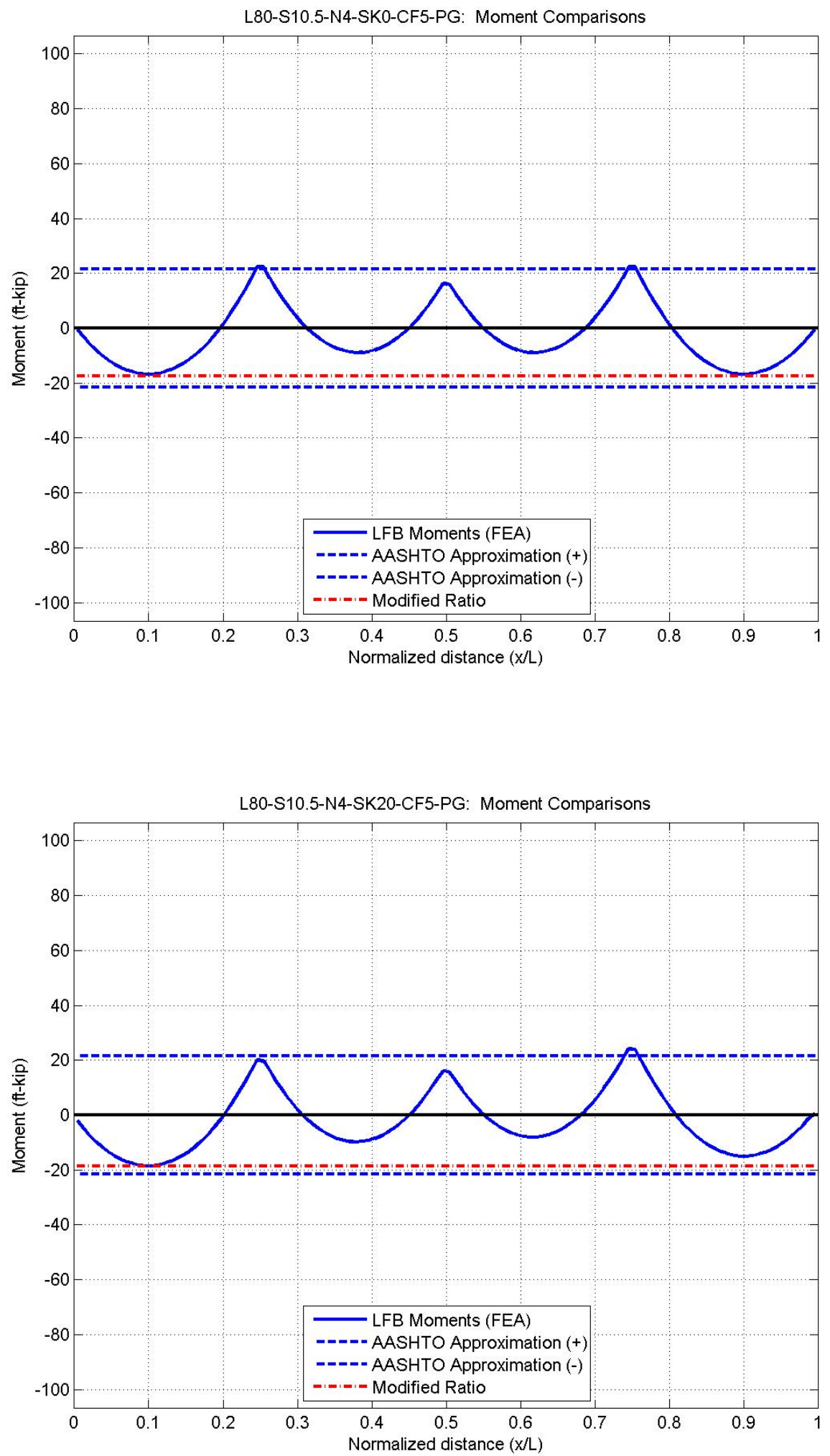

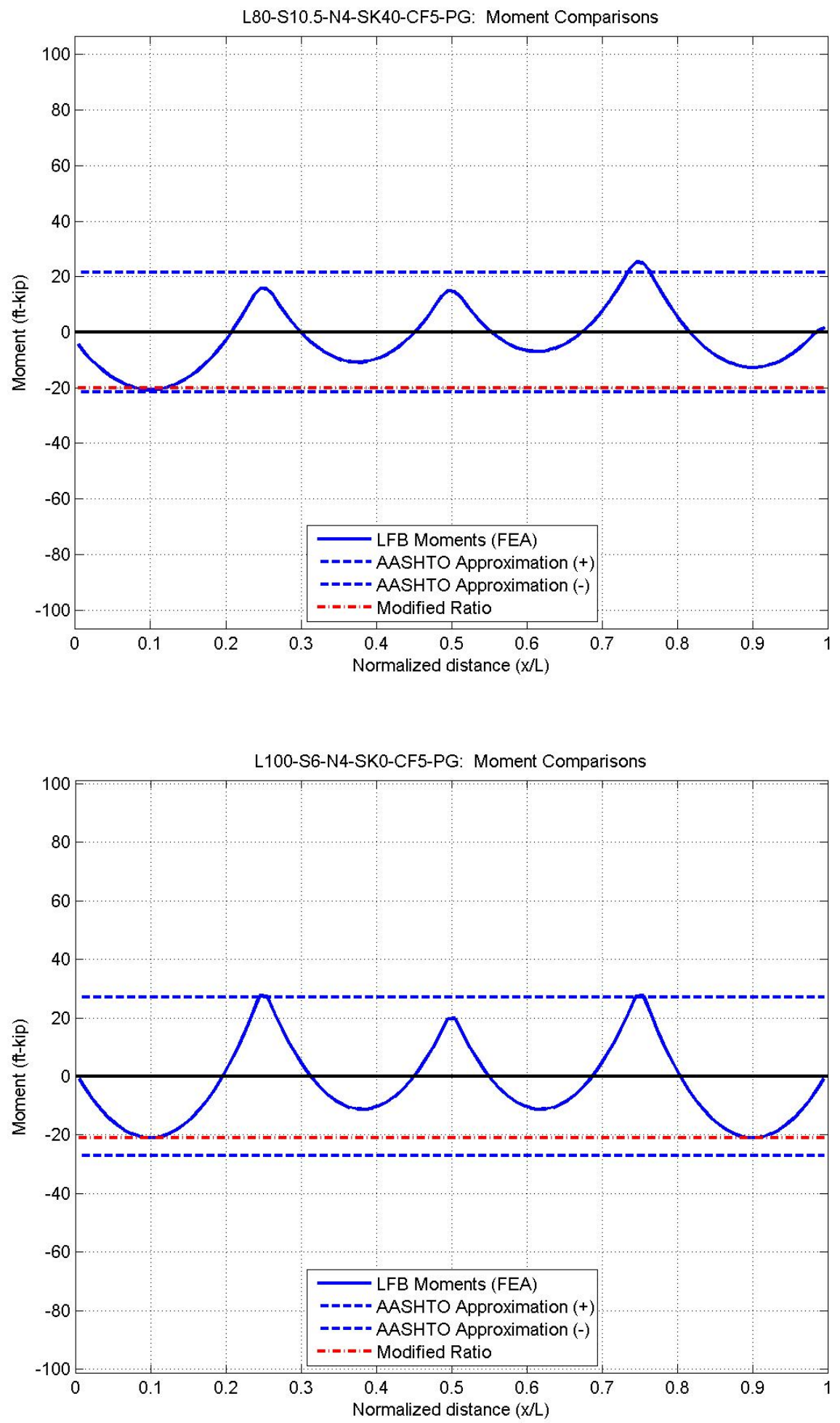

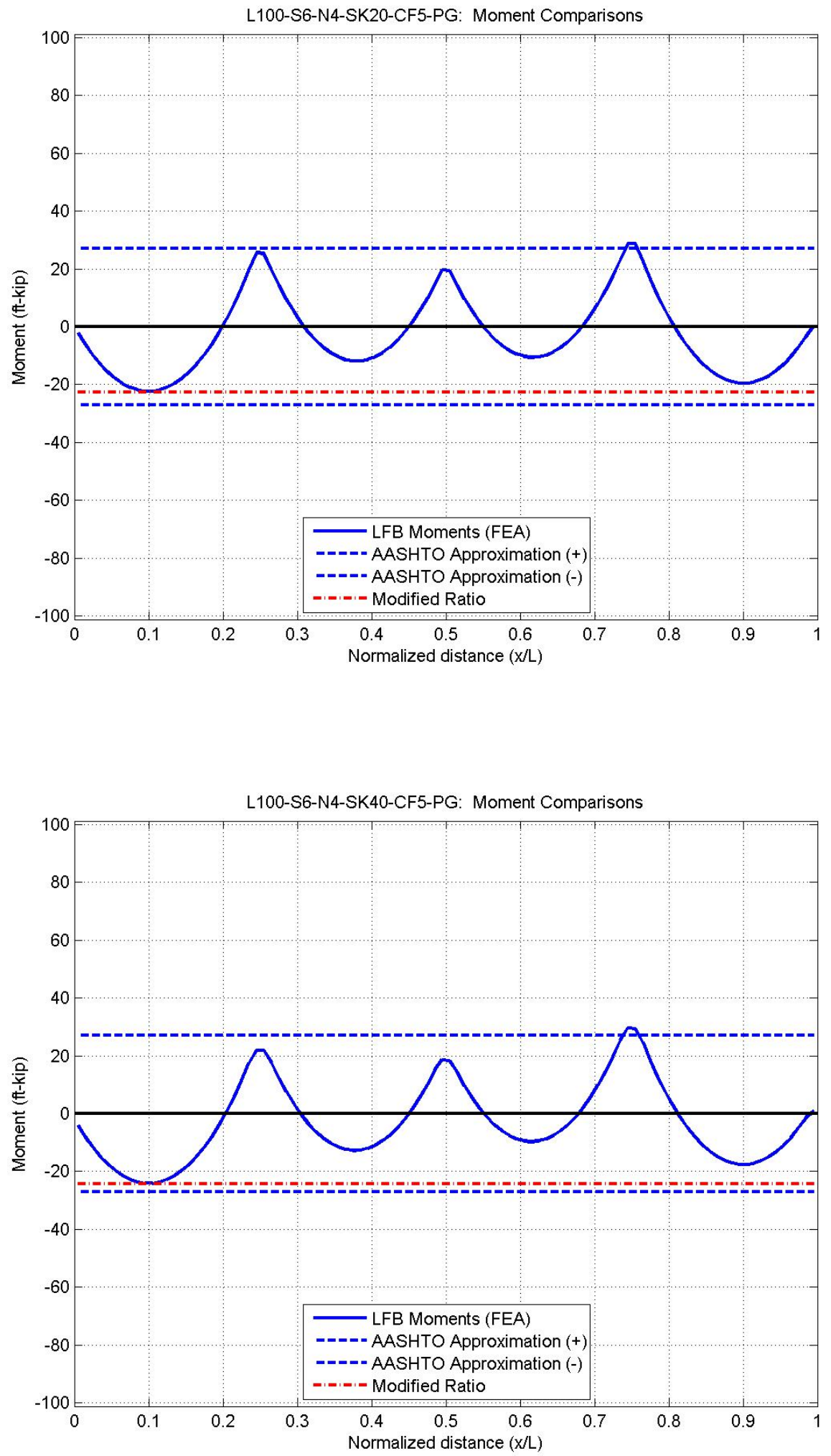

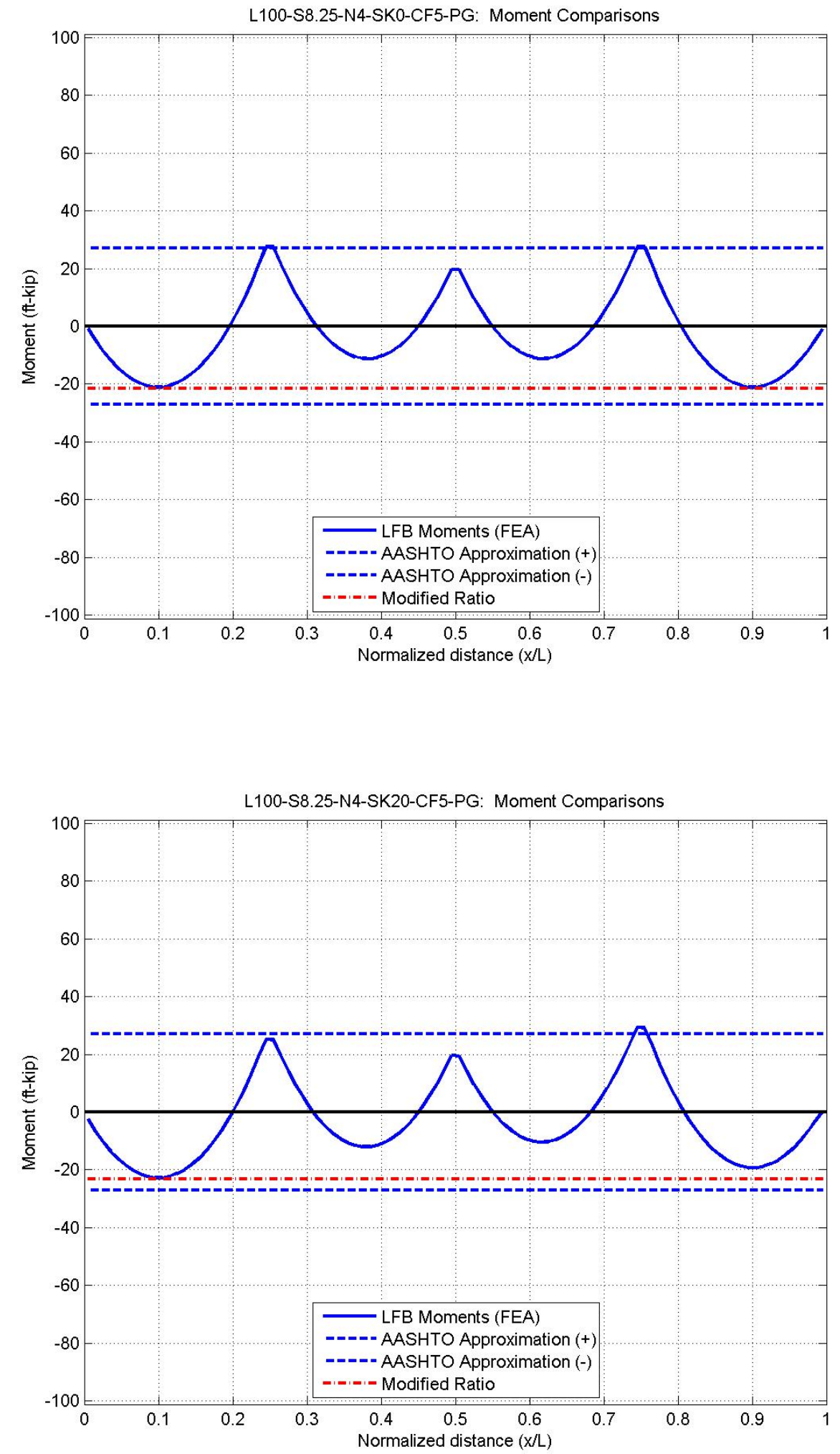

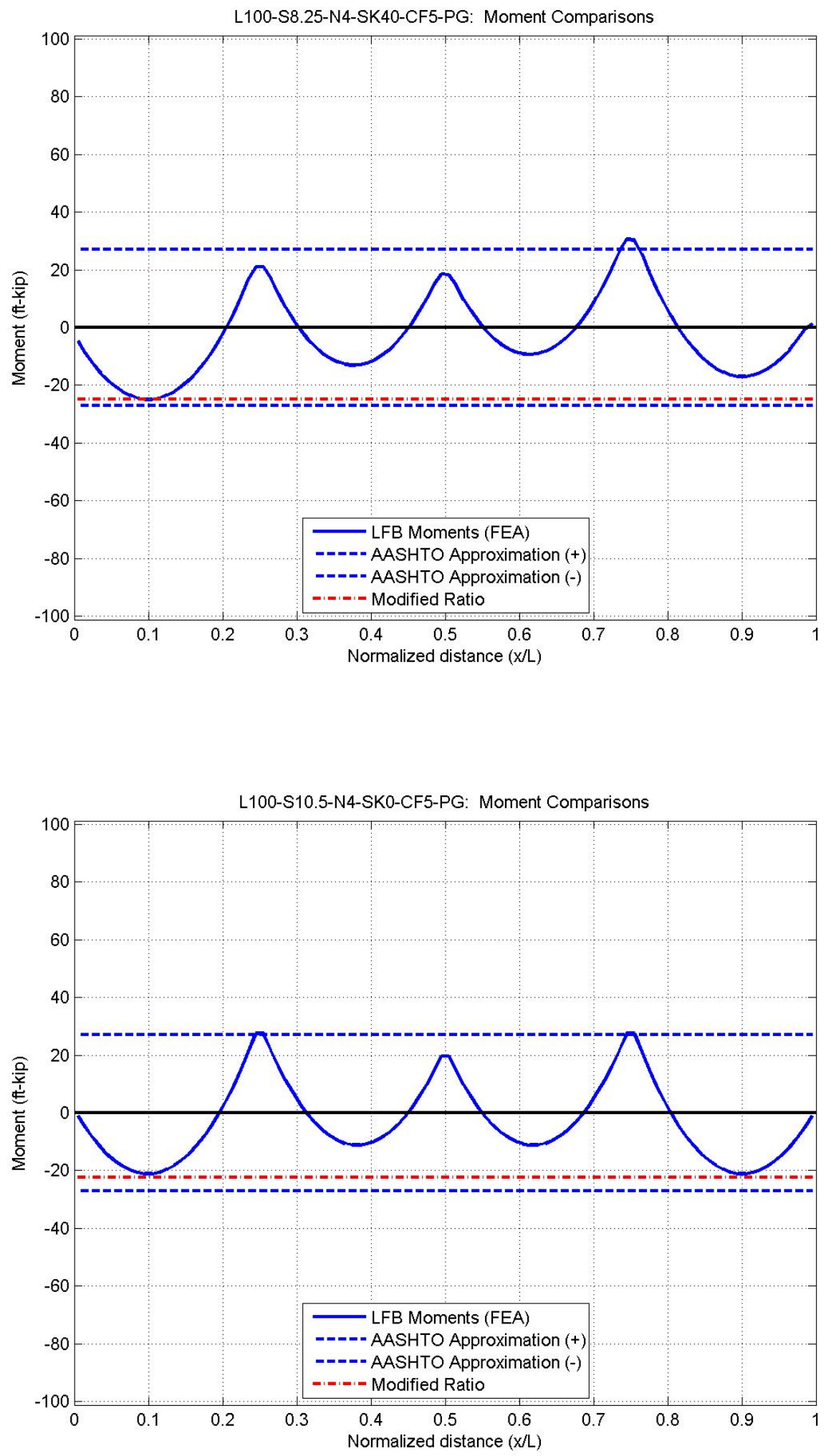

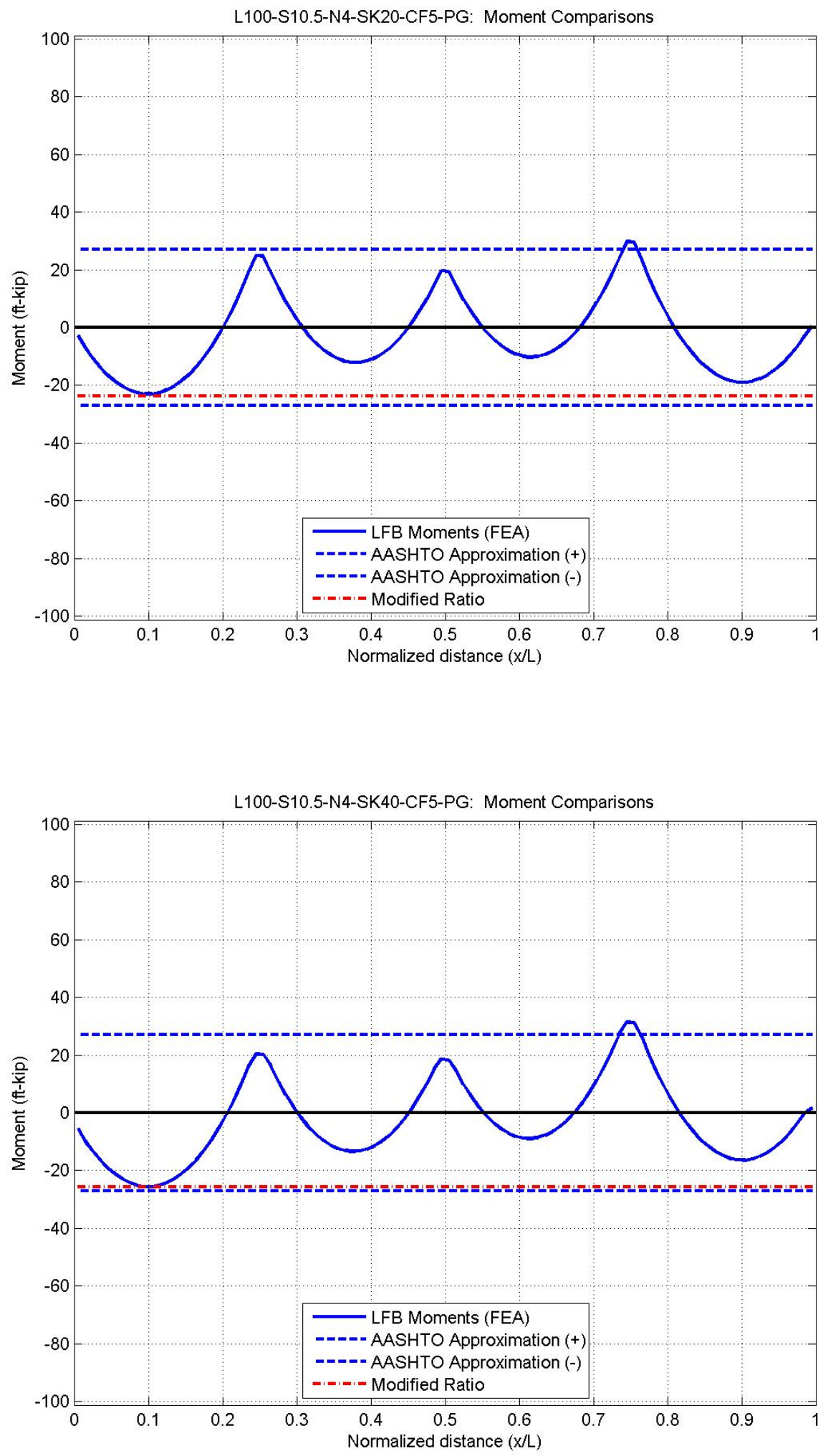

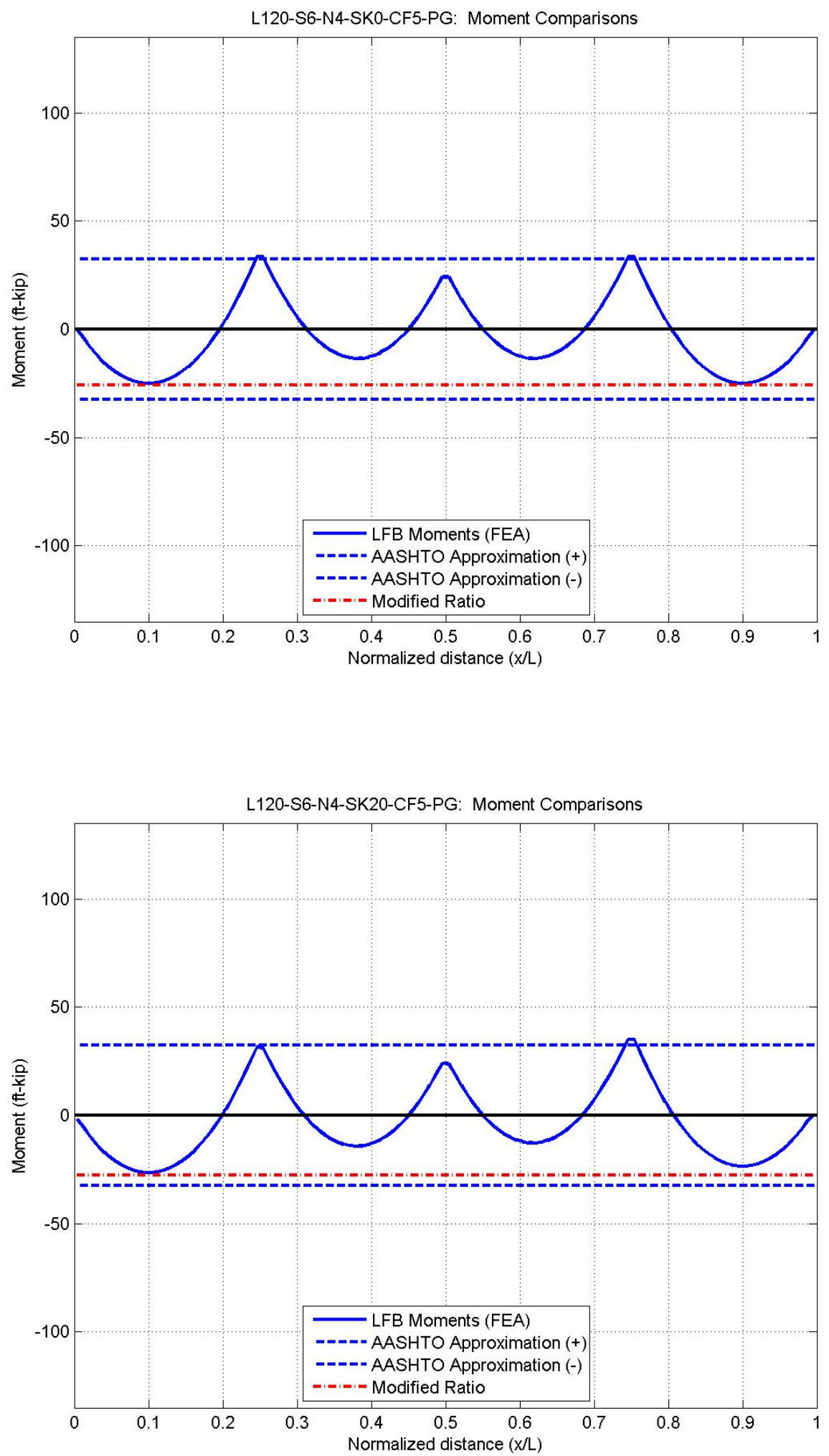

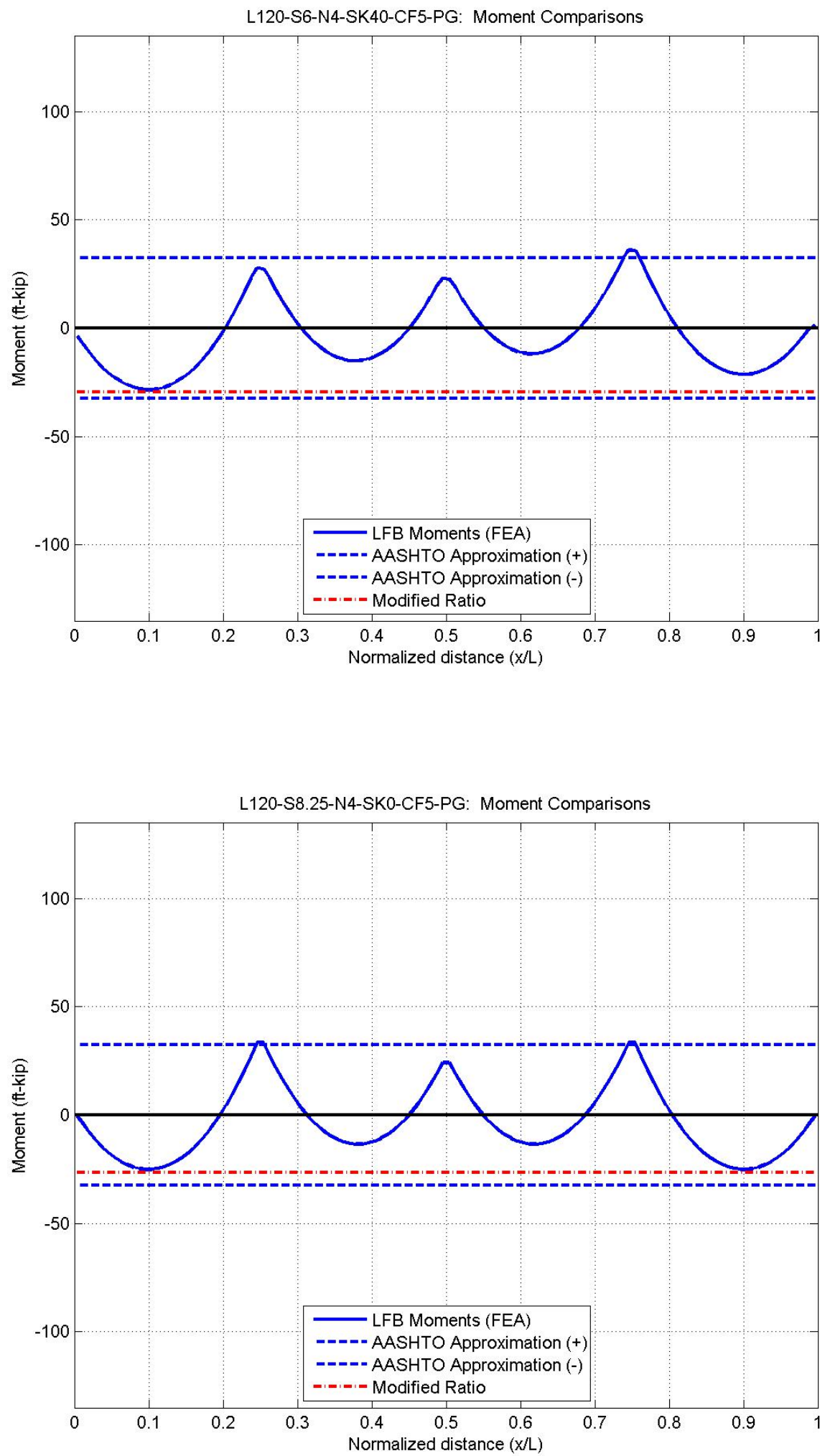

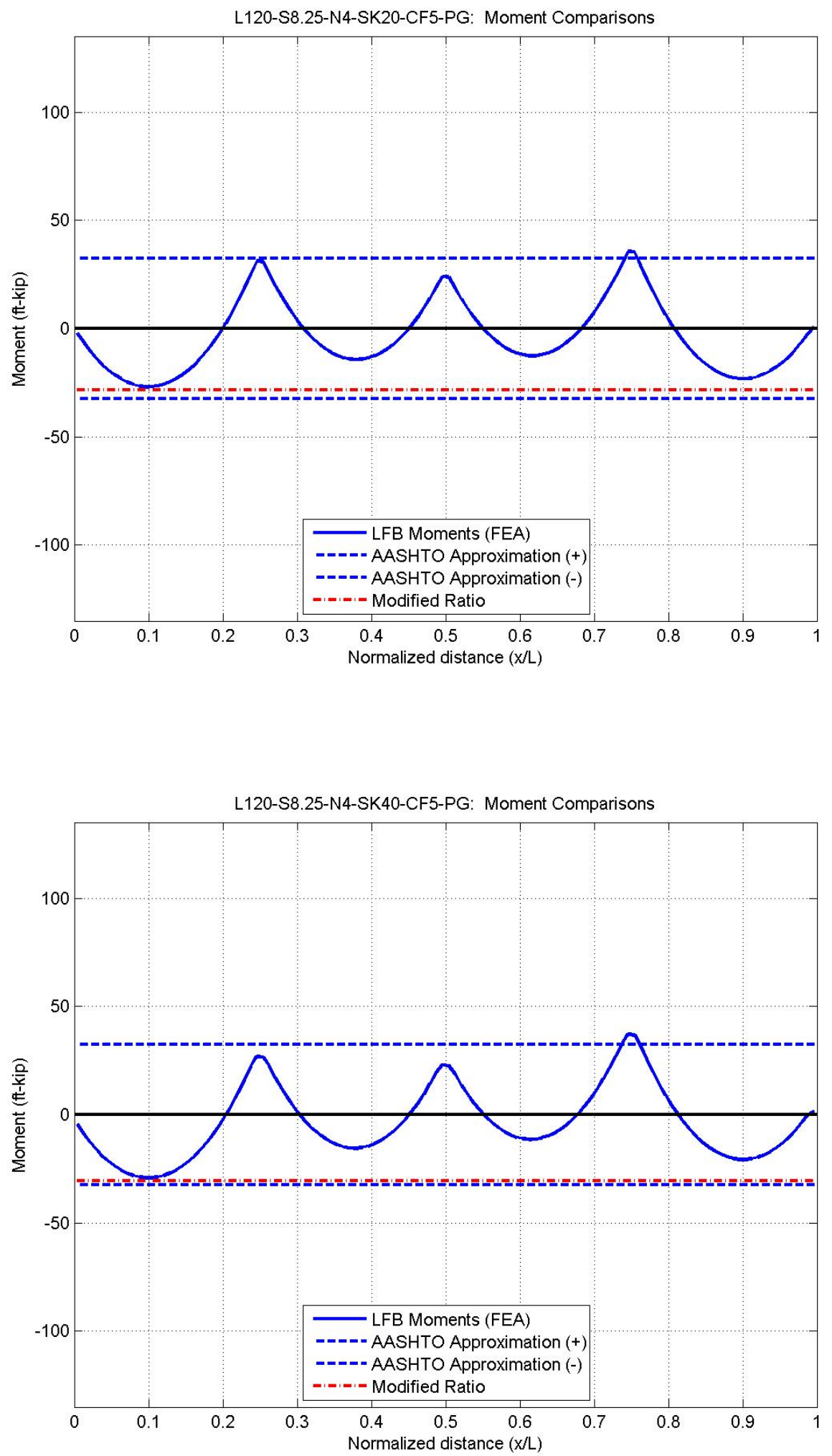

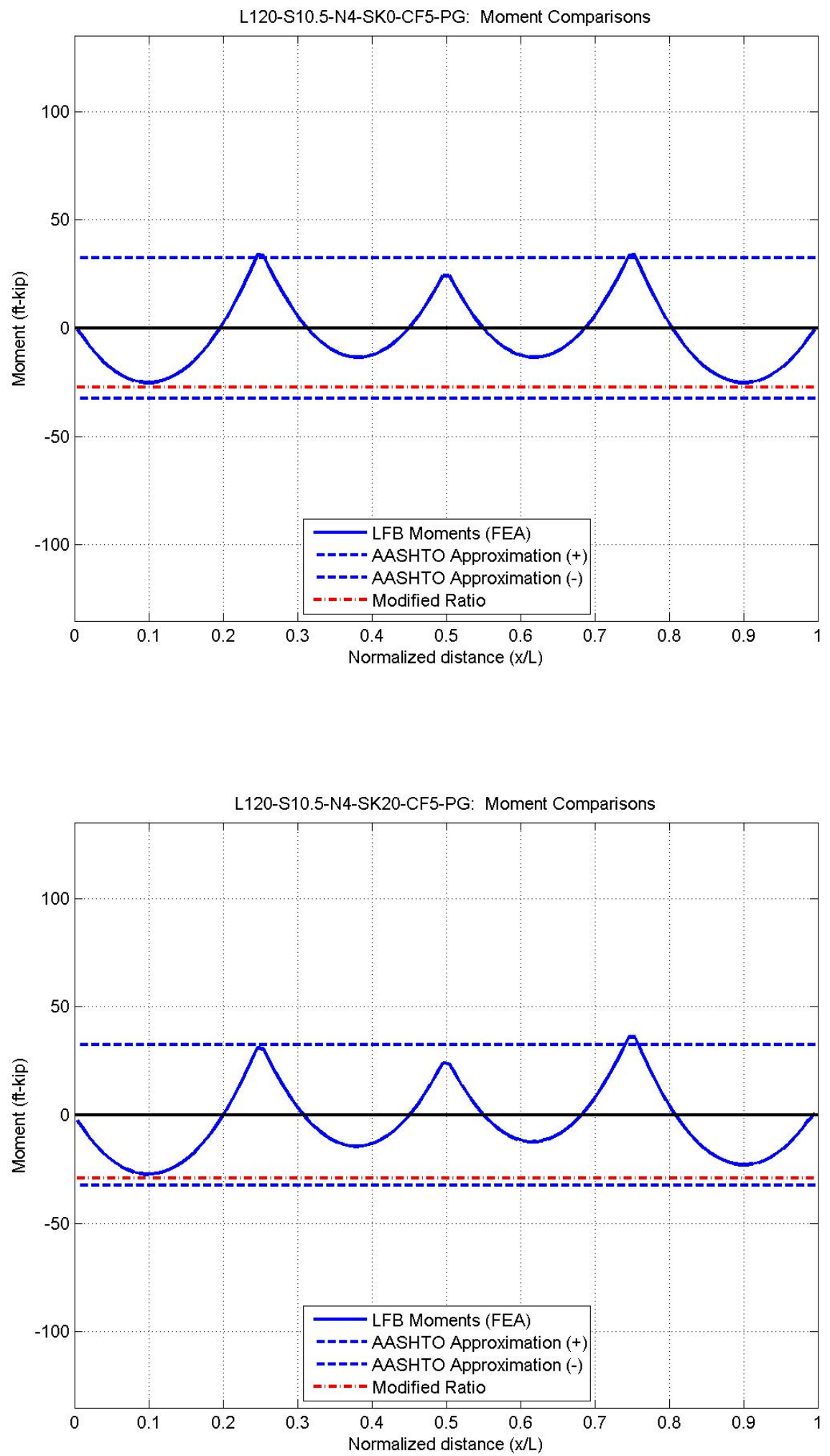

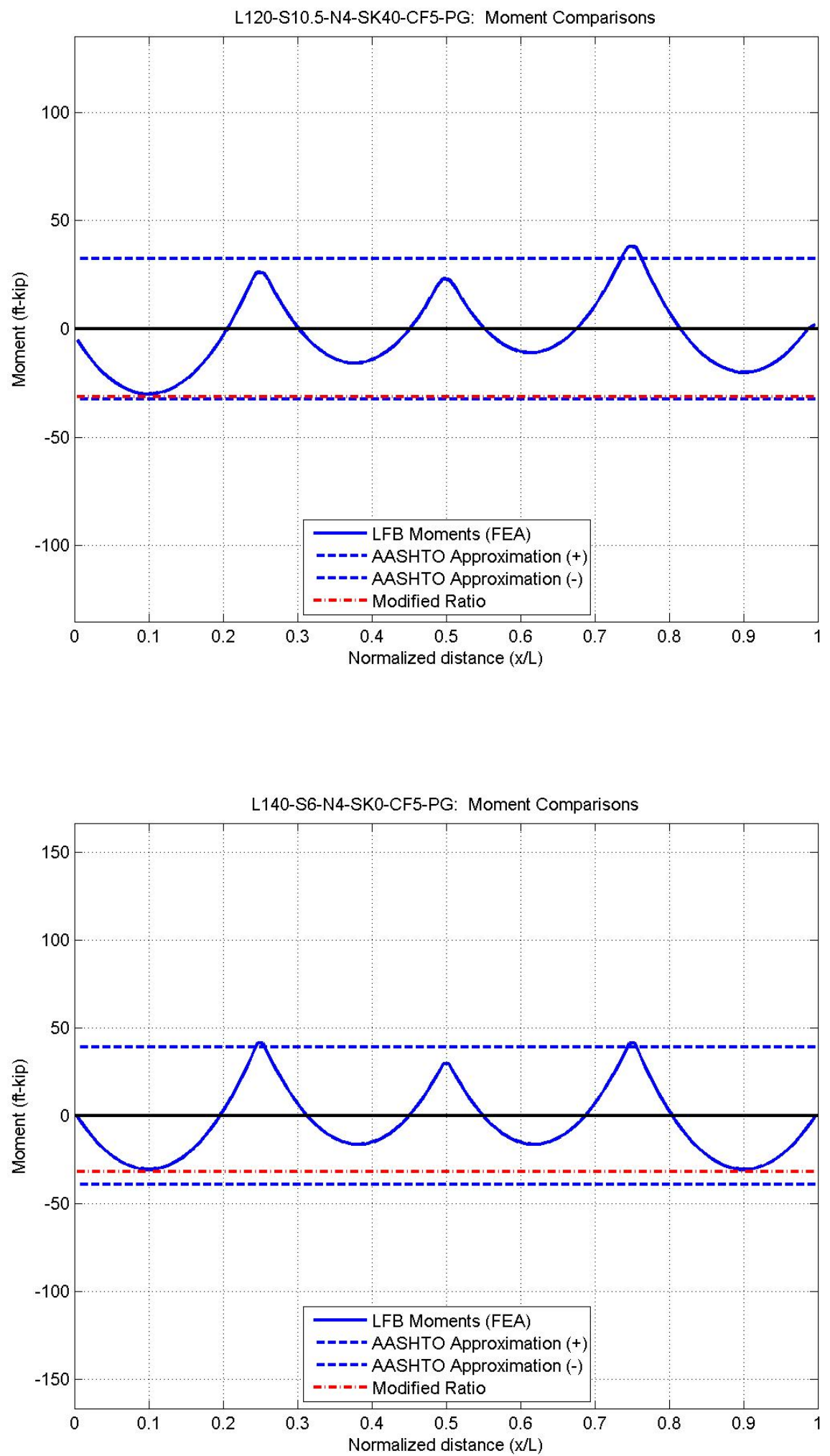

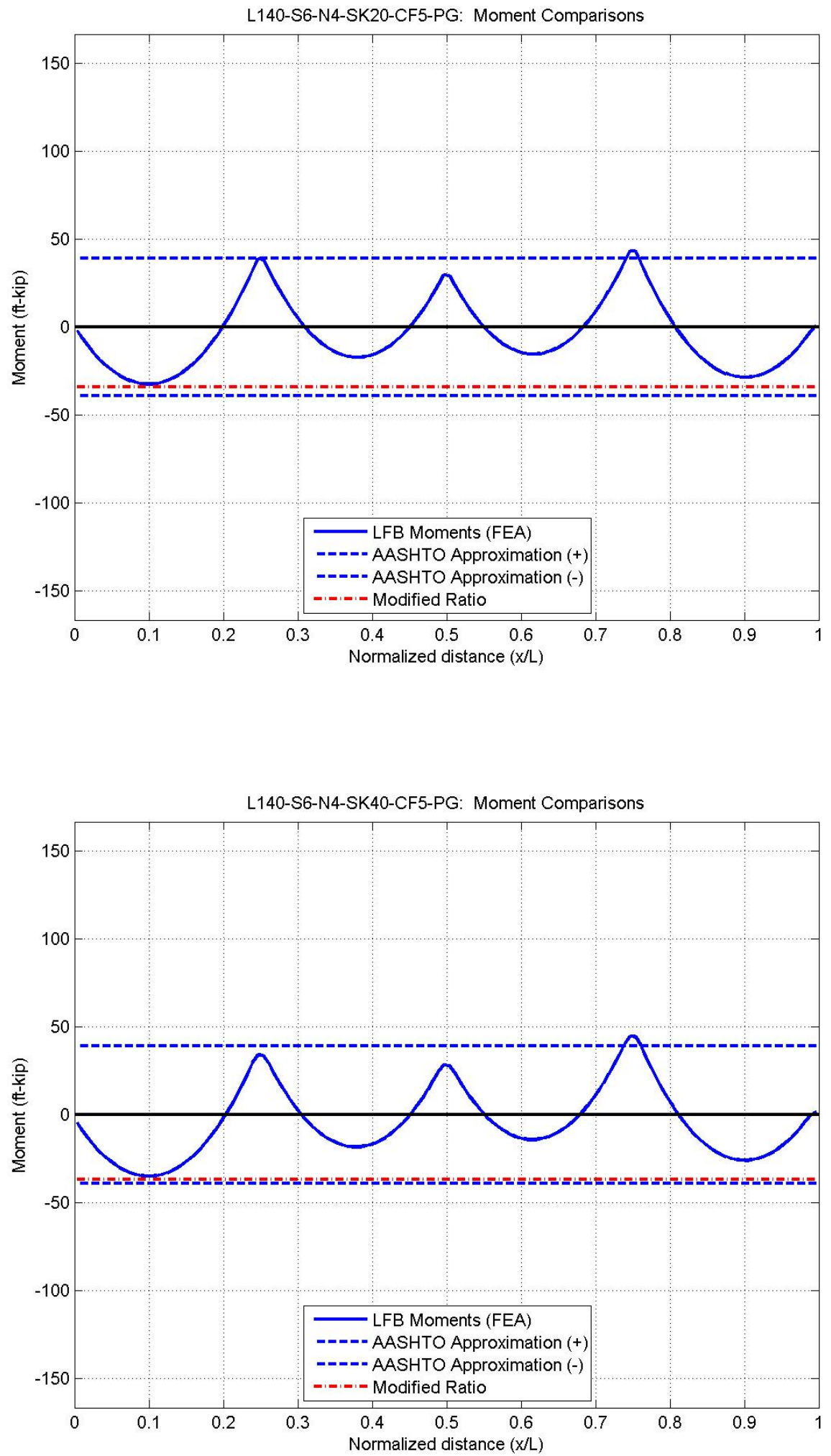

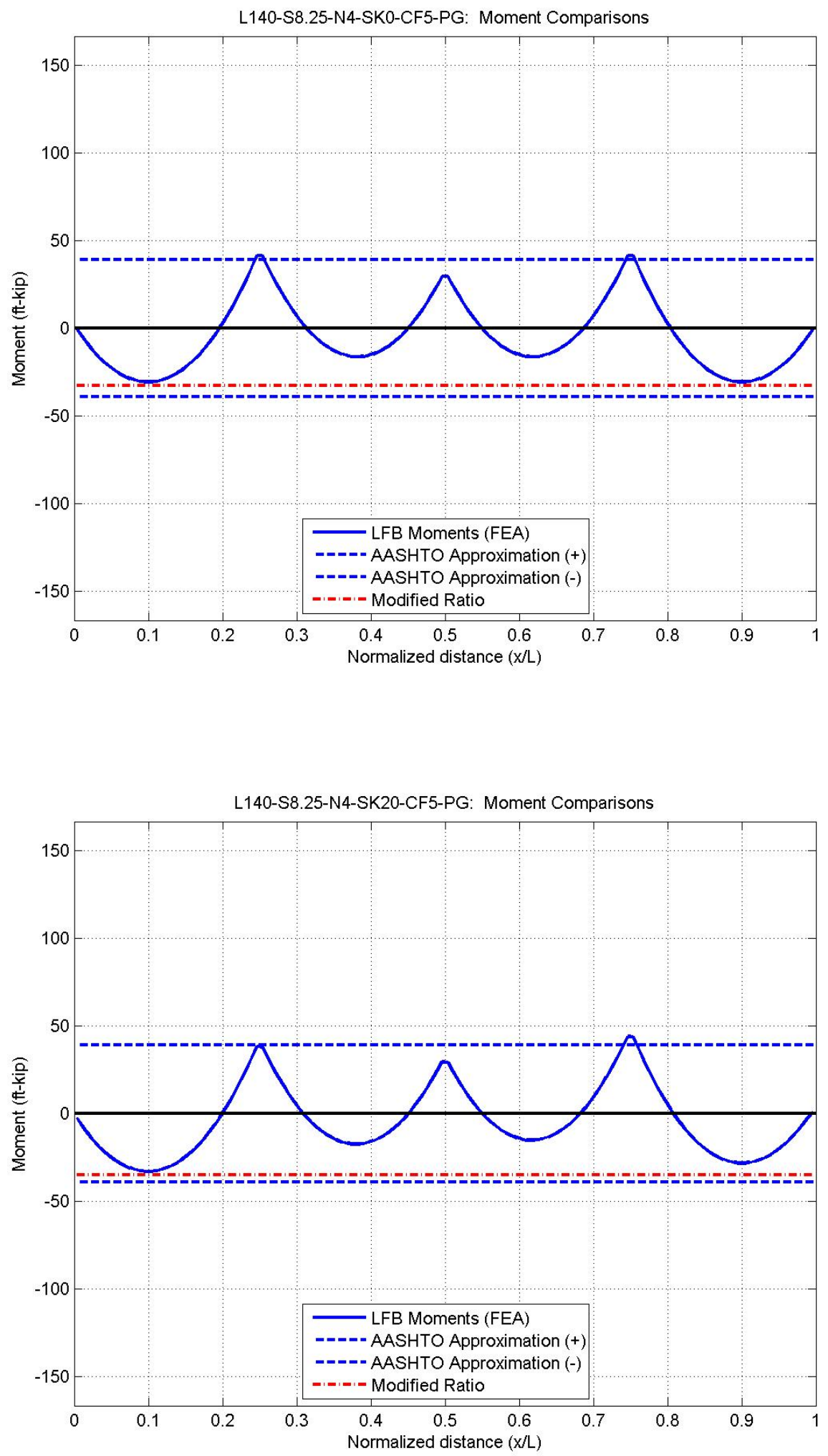

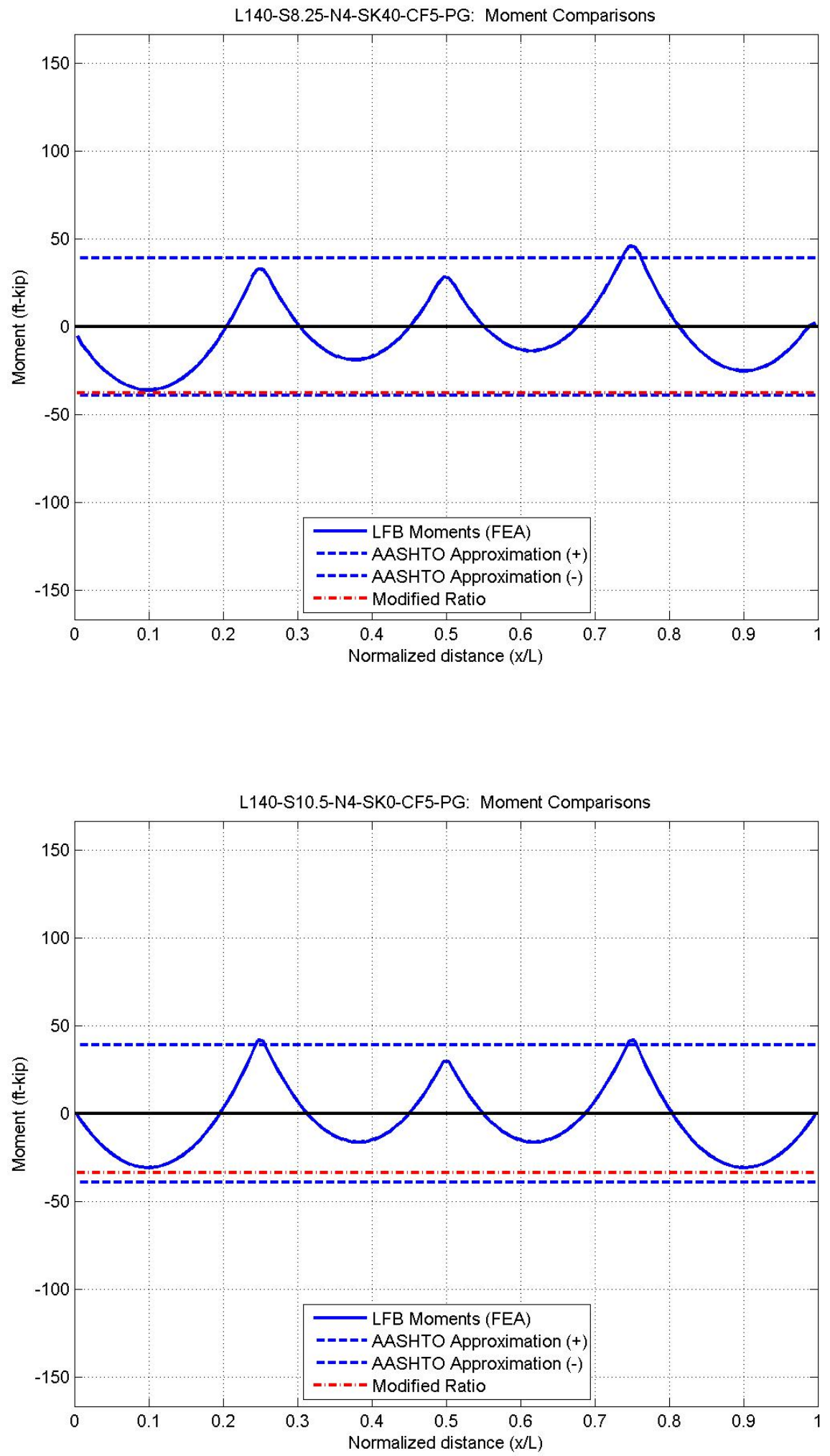

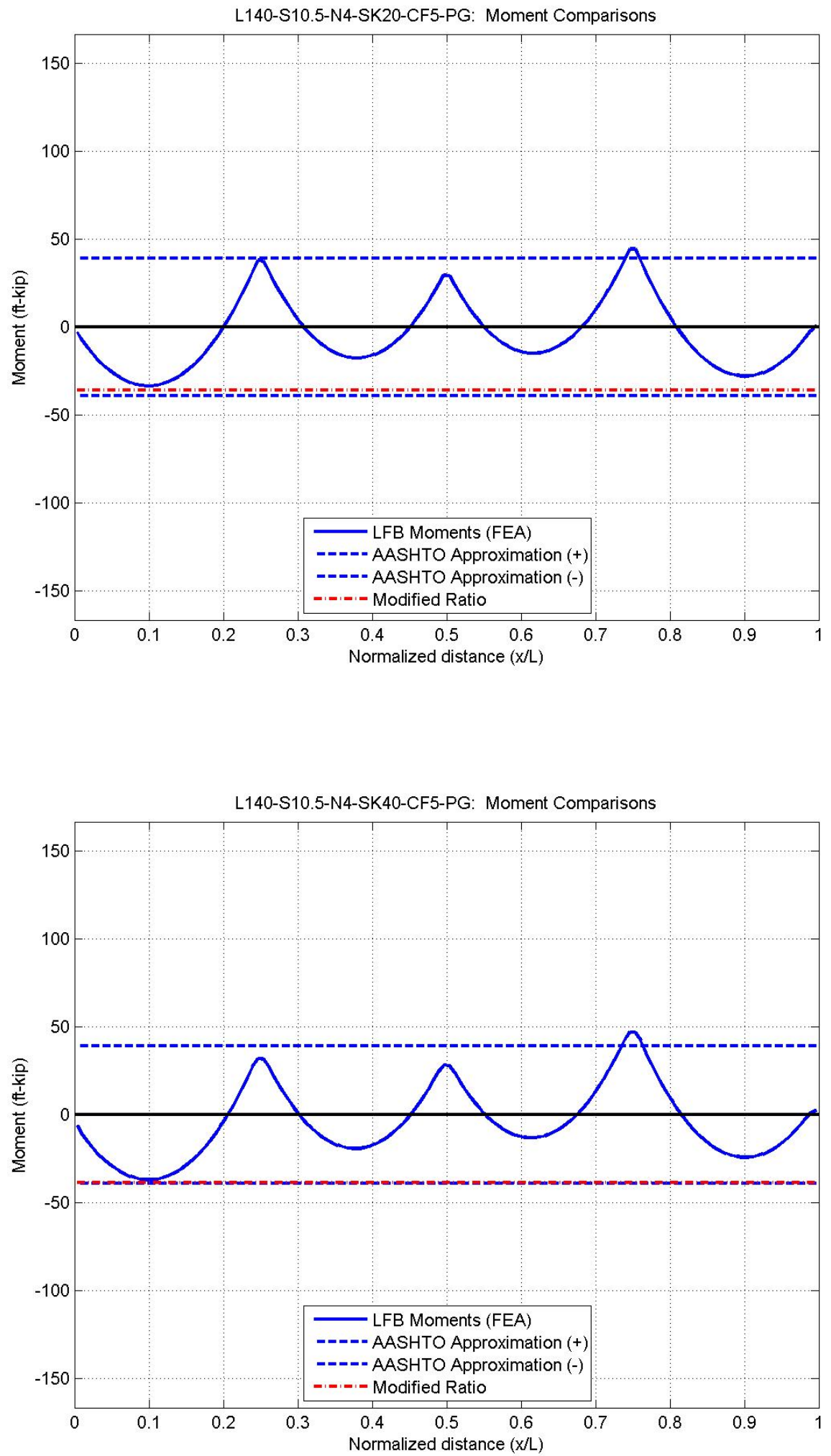


\section{B.2 COMPARISON OF FEA vs. MODIFICATION FACTOR}

\begin{tabular}{|c|c|c|c|c|c|c|}
\hline \multirow{2}{*}{ Bridge } & \multicolumn{4}{|c|}{ Parameters } & \multicolumn{2}{|r|}{ Ratios } \\
\hline & $L(f t)$ & $S$ (ft) & Lb (ft) & $\theta$ (deg) & FEA & Mod. Factor \\
\hline 1 & 40 & 6 & 20 & 0 & 0.67 & 0.64 \\
\hline 2 & 60 & 6 & 20 & 0 & 0.63 & 0.70 \\
\hline 3 & 80 & 6 & 20 & 0 & 0.77 & 0.76 \\
\hline 4 & 100 & 6 & 25 & 0 & 0.78 & 0.78 \\
\hline 5 & 120 & 6 & 30 & 0 & 0.77 & 0.79 \\
\hline 6 & 140 & 6 & 35 & 0 & 0.78 & 0.81 \\
\hline 7 & 40 & 6 & 20 & 20 & 0.68 & 0.69 \\
\hline 8 & 60 & 6 & 20 & 20 & 0.65 & 0.75 \\
\hline 9 & 80 & 6 & 20 & 20 & 0.83 & 0.82 \\
\hline 10 & 100 & 6 & 25 & 20 & 0.83 & 0.83 \\
\hline 11 & 120 & 6 & 30 & 20 & 0.82 & 0.85 \\
\hline 12 & 140 & 6 & 35 & 20 & 0.83 & 0.87 \\
\hline 13 & 40 & 6 & 20 & 40 & 0.68 & 0.74 \\
\hline 14 & 60 & 6 & 20 & 40 & 0.67 & 0.81 \\
\hline 15 & 80 & 6 & 20 & 40 & 0.90 & 0.88 \\
\hline 16 & 100 & 6 & 25 & 40 & 0.89 & 0.89 \\
\hline 17 & 120 & 6 & 30 & 40 & 0.88 & 0.91 \\
\hline 18 & 140 & 6 & 35 & 40 & 0.89 & 0.93 \\
\hline 19 & 40 & 8.25 & 20 & 0 & 0.67 & 0.66 \\
\hline 20 & 60 & 8.25 & 20 & 0 & 0.63 & 0.72 \\
\hline 21 & 80 & 8.25 & 20 & 0 & 0.78 & 0.78 \\
\hline 22 & 100 & 8.25 & 25 & 0 & 0.78 & 0.80 \\
\hline 23 & 120 & 8.25 & 30 & 0 & 0.77 & 0.82 \\
\hline 24 & 140 & 8.25 & 35 & 0 & 0.78 & 0.83 \\
\hline 25 & 40 & 8.25 & 20 & 20 & 0.68 & 0.71 \\
\hline 26 & 60 & 8.25 & 20 & 20 & 0.65 & 0.77 \\
\hline 27 & 80 & 8.25 & 20 & 20 & 0.84 & 0.84 \\
\hline
\end{tabular}




\begin{tabular}{|c|c|c|c|c|c|c|}
\hline \multirow{2}{*}{ Bridge } & \multicolumn{4}{|c|}{ Parameters } & \multicolumn{2}{|r|}{ Ratios } \\
\hline & $L(f t)$ & $S(f t)$ & Lb (ft) & $\theta(\mathrm{deg})$ & FEA & Mod. Factor \\
\hline 28 & 100 & 8.25 & 25 & 20 & 0.84 & 0.86 \\
\hline 29 & 120 & 8.25 & 30 & 20 & 0.83 & 0.88 \\
\hline 30 & 140 & 8.25 & 35 & 20 & 0.84 & 0.89 \\
\hline 31 & 40 & 8.25 & 20 & 40 & 0.69 & 0.76 \\
\hline 32 & 60 & 8.25 & 20 & 40 & 0.68 & 0.83 \\
\hline 33 & 80 & 8.25 & 20 & 40 & 0.93 & 0.90 \\
\hline 34 & 100 & 8.25 & 25 & 40 & 0.92 & 0.92 \\
\hline 35 & 120 & 8.25 & 30 & 40 & 0.90 & 0.94 \\
\hline 36 & 140 & 8.25 & 35 & 40 & 0.92 & 0.96 \\
\hline 37 & 40 & 10.5 & 20 & 0 & 0.67 & 0.68 \\
\hline 38 & 60 & 10.5 & 20 & 0 & 0.63 & 0.74 \\
\hline 39 & 80 & 10.5 & 20 & 0 & 0.78 & 0.81 \\
\hline 40 & 100 & 10.5 & 25 & 0 & 0.78 & 0.82 \\
\hline 41 & 120 & 10.5 & 30 & 0 & 0.77 & 0.84 \\
\hline 42 & 140 & 10.5 & 35 & 0 & 0.78 & 0.86 \\
\hline 43 & 40 & 10.5 & 20 & 20 & 0.68 & 0.73 \\
\hline 44 & 60 & 10.5 & 20 & 20 & 0.66 & 0.80 \\
\hline 45 & 80 & 10.5 & 20 & 20 & 0.86 & 0.86 \\
\hline 46 & 100 & 10.5 & 25 & 20 & 0.85 & 0.88 \\
\hline 47 & 120 & 10.5 & 30 & 20 & 0.84 & 0.90 \\
\hline 48 & 140 & 10.5 & 35 & 20 & 0.85 & 0.92 \\
\hline 49 & 40 & 10.5 & 20 & 40 & 0.69 & 0.78 \\
\hline 50 & 60 & 10.5 & 20 & 40 & 0.69 & 0.85 \\
\hline 51 & 80 & 10.5 & 20 & 40 & 0.96 & 0.93 \\
\hline 52 & 100 & 10.5 & 25 & 40 & 0.95 & 0.95 \\
\hline 53 & 120 & 10.5 & 30 & 40 & 0.93 & 0.97 \\
\hline 54 & 140 & 10.5 & 35 & 40 & 0.94 & 0.99 \\
\hline
\end{tabular}




\section{Appendix C: Algorithm for Modeling Simple Span Steel I- GIRDER BRIDGES}

\section{C.1 Parametric Modeling Algorithm}

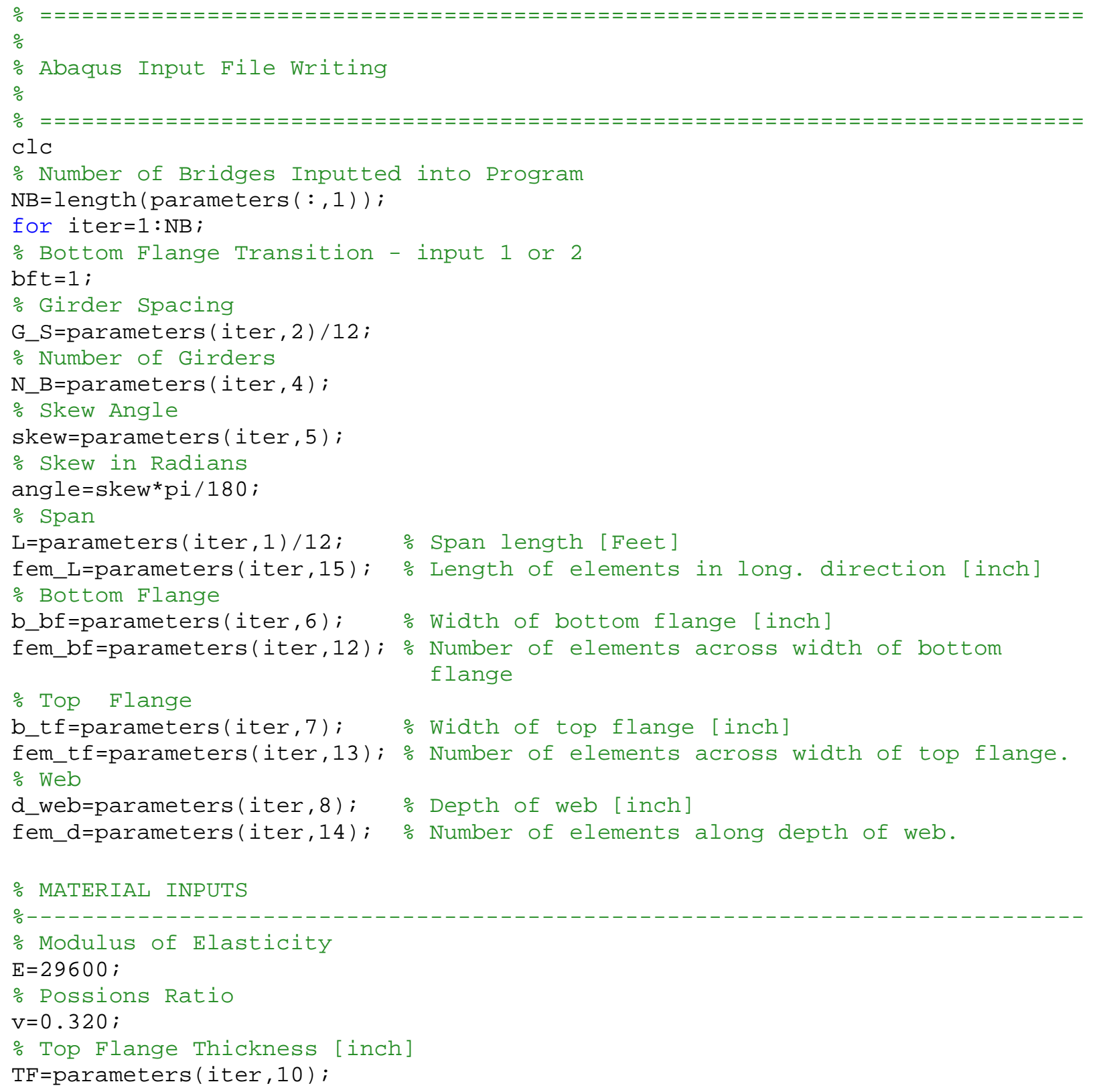




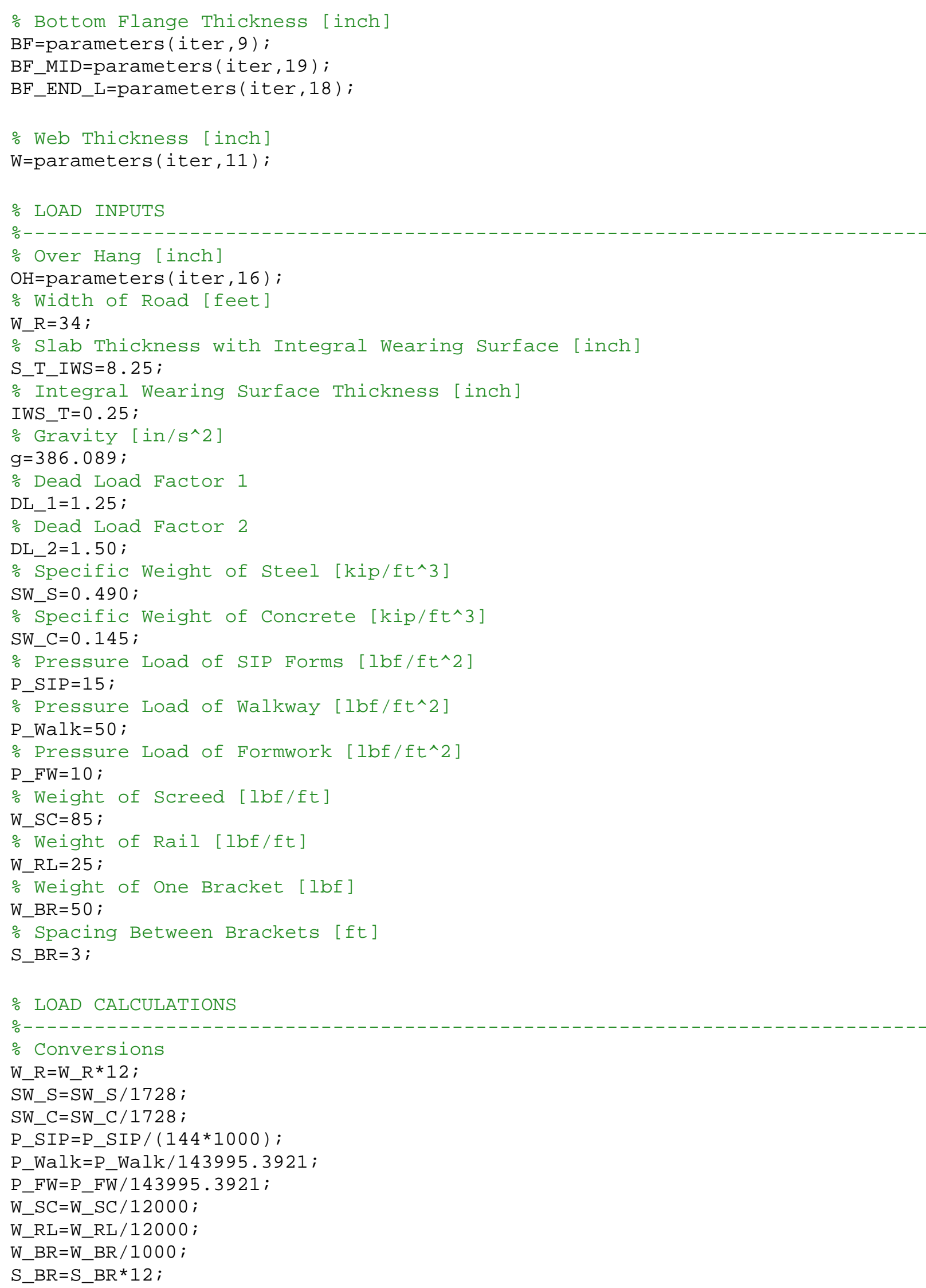


$\%$ Slab Thickness

S_T=S_T_IWS - IWS_T ;

$\%$ Width of Bridge out to out

W_Out $=G \_S * 12 *\left(N \_B-1\right)+2 * 0 H$;

$\%$ Width of Barrier

W_B $=\left(\right.$ W_Out $\left.-W \_R\right) / 2$;

$\%$ Angle between Girder and Over Hang Bracket

$\operatorname{alpha}=\operatorname{atan}\left(\mathrm{OH} /\left(\mathrm{d} \_\right.\right.$web $\left.)\right)$;

\% STEP-1: GRAVITY LOADS -

\% Factored Gravity Load

$\mathrm{GL}=\mathrm{DL} \_1^{*} \mathrm{~g}$;

$\%$ STEP- 2 CONSTRUCTION LOADS-

$\%$ Vertical Load on Interior Girders of Top Flange

VL_IG_TF_CONST=DL_2*fem_L*(G_S*12*P_Walk);

$\%$ Vertical Load on Exterior Girders of Top flange

VL_EG_TF_CONST $=D L \_2 *$ fem_L* $\left(0.5^{*}\left(P \_F W^{*} \mathrm{OH}+\left(\mathrm{P} \_\right.\right.\right.$Walk* $\left.\left.\left.\left(\left(G \_S^{*} 12\right)+\mathrm{OH}\right)\right)\right)\right)$;

$\%$ Vertical Load on Exterior Girders of Bottom flange

VL_EG_BF_CONST $=D L \_2{ }^{*} f e m \_L^{*}\left(\left(W \_B R / S \_B R\right)+W \_S C+\left(P \_W a l k^{*} O H / 2\right)+W \_R L+\left(P \_F W^{*} O H / 2\right)\right)$;

$\%$ Horizontal Load on Top Flange of Exterior Girder

HL_EG_TF_CONST=VL_EG_BF_CONST *tan (alpha) ;

$\%$ Horizontal Load on Bottom Flange of Exterior Girder

HL_EG_BF_CONST=VL_EG_BF_CONST *tan (alpha) ;

$\%$ STEP-3 CASTING LOADS

$\%$ Vertical Load on Interior Girders of Top Flange

VL_IG_TF_CAST $=D L \_1{ }^{*}$ fem_L* $\left(G \_S^{*} 12\right) *\left(S \_T \_I W{ }^{*}\right.$ SW_C+P_SIP $)$;

$\%$ Vertical Load on Exterior Girders of Top Flange

$V L \_E G \_T F \_C A S T=D L \_1 *$ fem_L* $\left(0.5^{*}\left(S W \_C * S \_T^{*} O H\right)\right)+\left(V L \_I G \_T F \_C A S T / 2\right)$;

$\%$ Vertical Load on Exterior Girders on Bottom Flange

VL_EG_BF_CAST $=D L \_1{ }^{*}$ fem_L* $\left(\odot .5^{*}\left(\mathrm{SW} \_\mathrm{C}^{*} \mathrm{~S} \_\mathrm{T}^{*} \mathrm{OH}\right)\right)$;

$\%$ Horizontal Load on Top Flange of Exterior Girder

HL_EG_TF_CAST=VL_EG_BF_CAST ${ }^{*} \tan ($ alpha ) ;

$\%$ Horizontal Load on Bottom Flange of Exterior Girder

HL_EG_BF_CAST=VL_EG_BF_CAST *tan(alpha ) ;

\% BRIDGE GEOMETRY

$\%$

$\%$ Bottom Flange \#1

$\%$ Note: length $(x)=$ number of terms in vector " $x "$.

$\%$ Nodes Along Length of Bottom Flange \# 1.

node_y_bf $=0:$ fem_L:L*12; \% Nodes start at $\odot$ and increase by Elm_L until L

( $L{ }^{*} 12$ conversion $\mathrm{ft}$ to in)

$\%$ Node Along Width of Bottom Flange \# 1.

node_x_bf=-b_bf/2:b_bf/fem_bf:b_bf/2; \% Nodes start at -Width/2 increases by with of BF/num of BF elements up to

width of $\mathrm{BF} / 2$ 


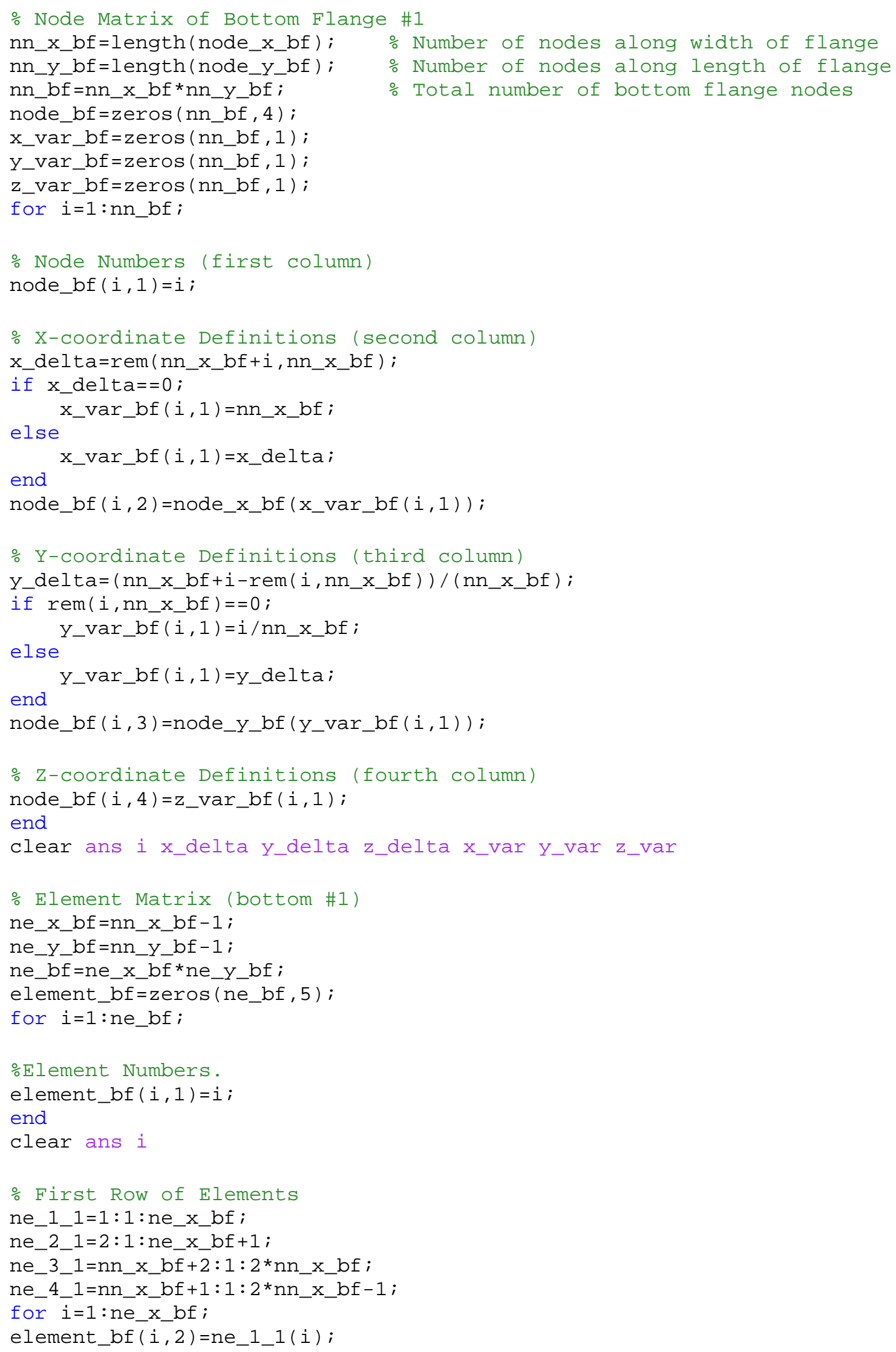




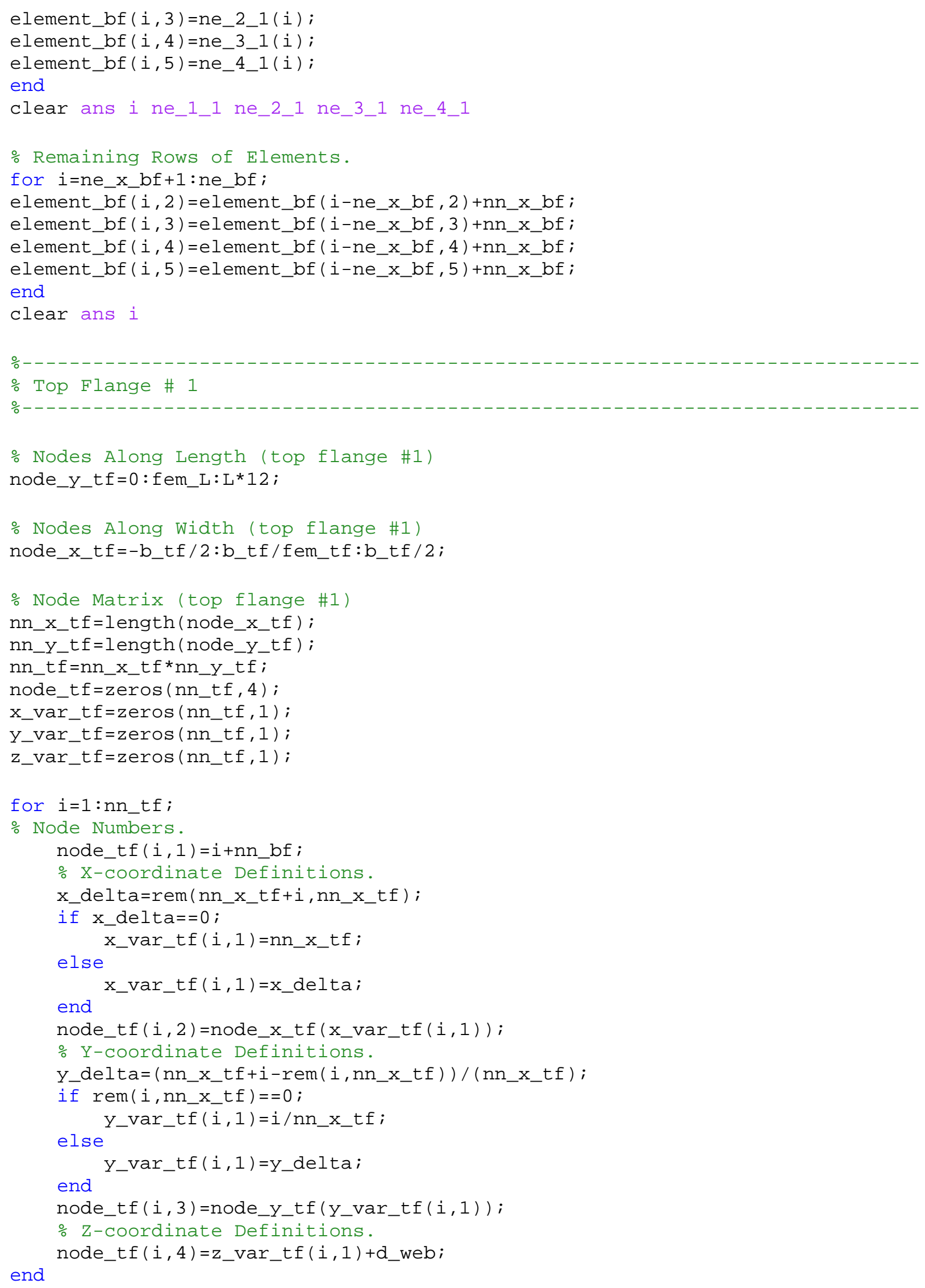




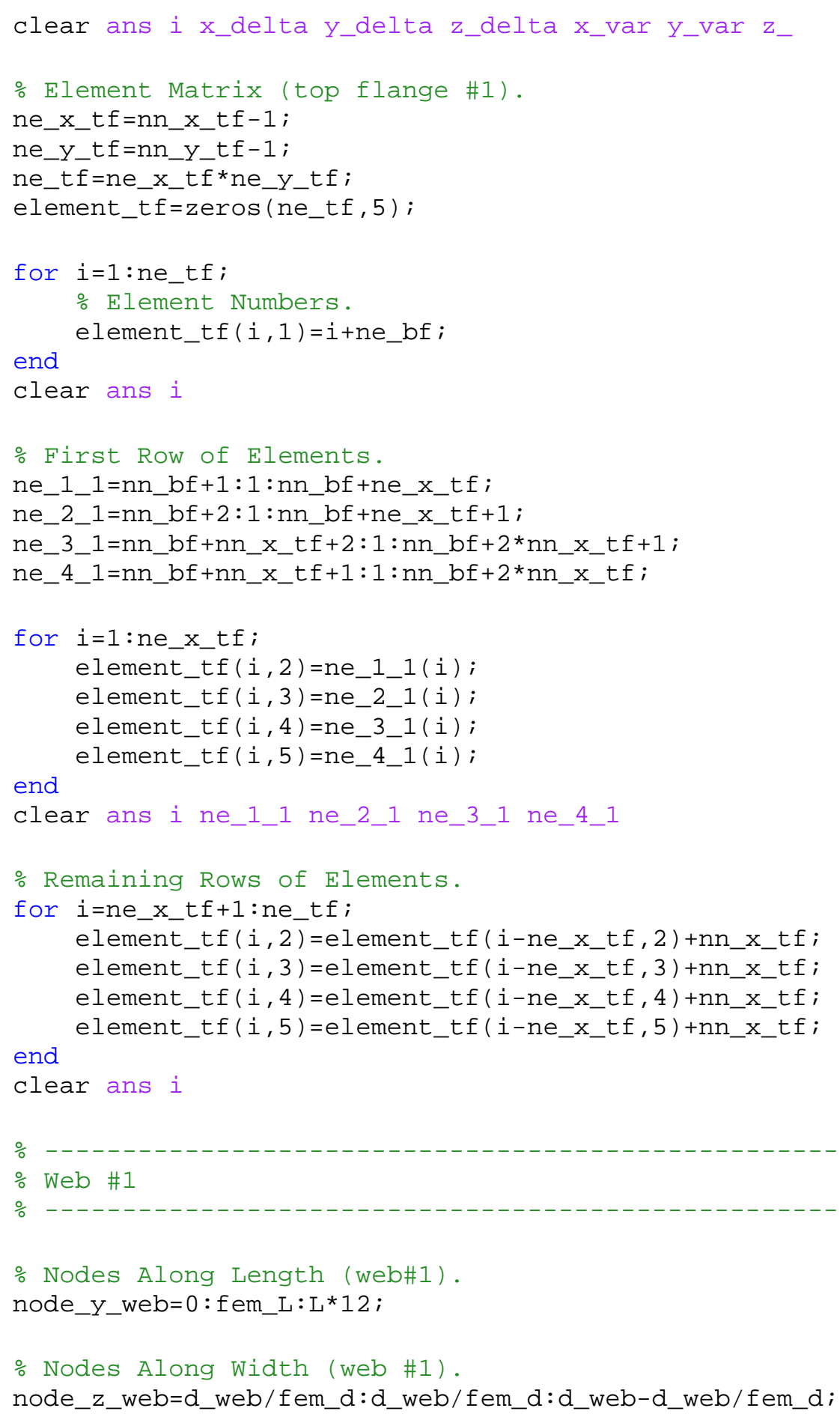




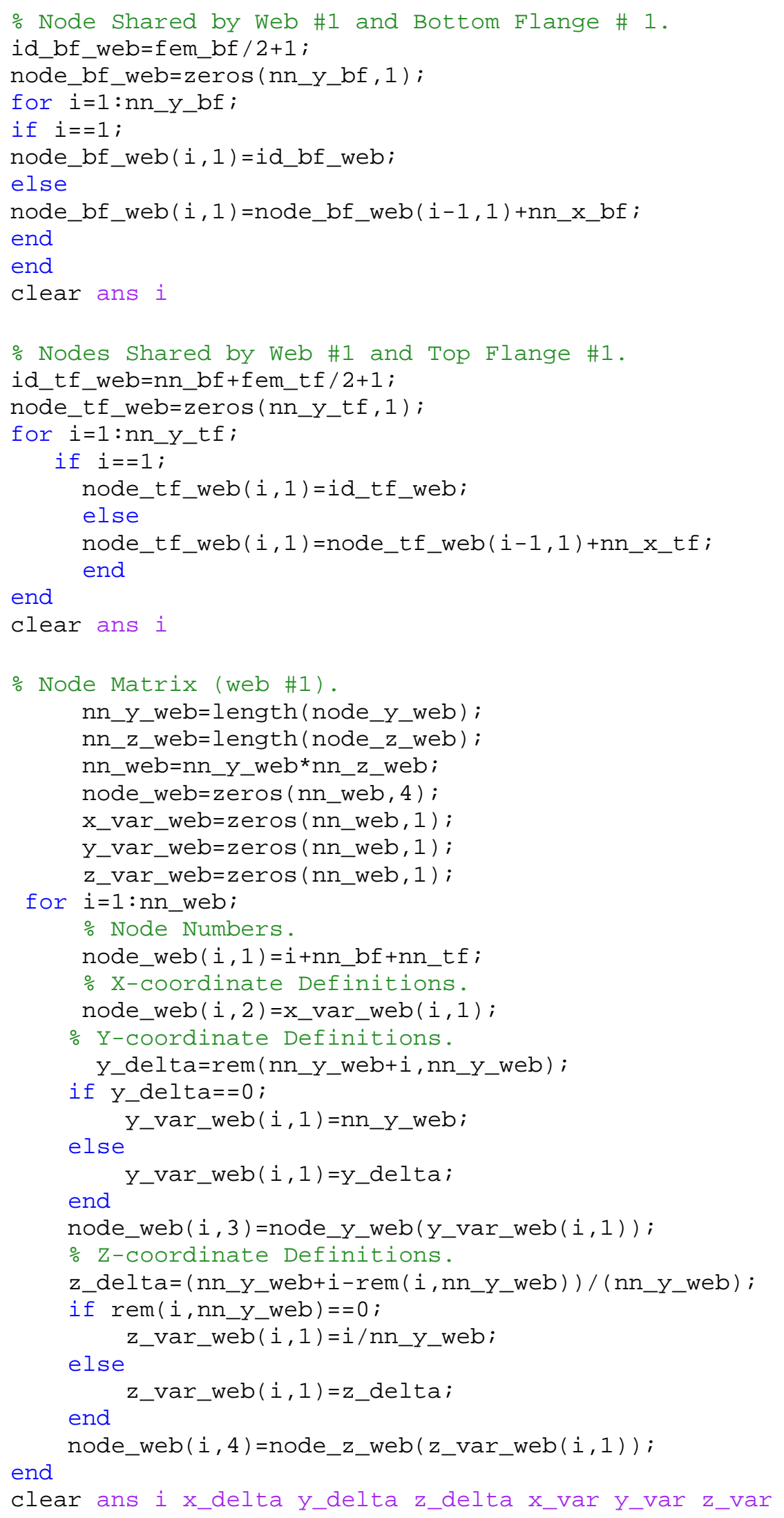




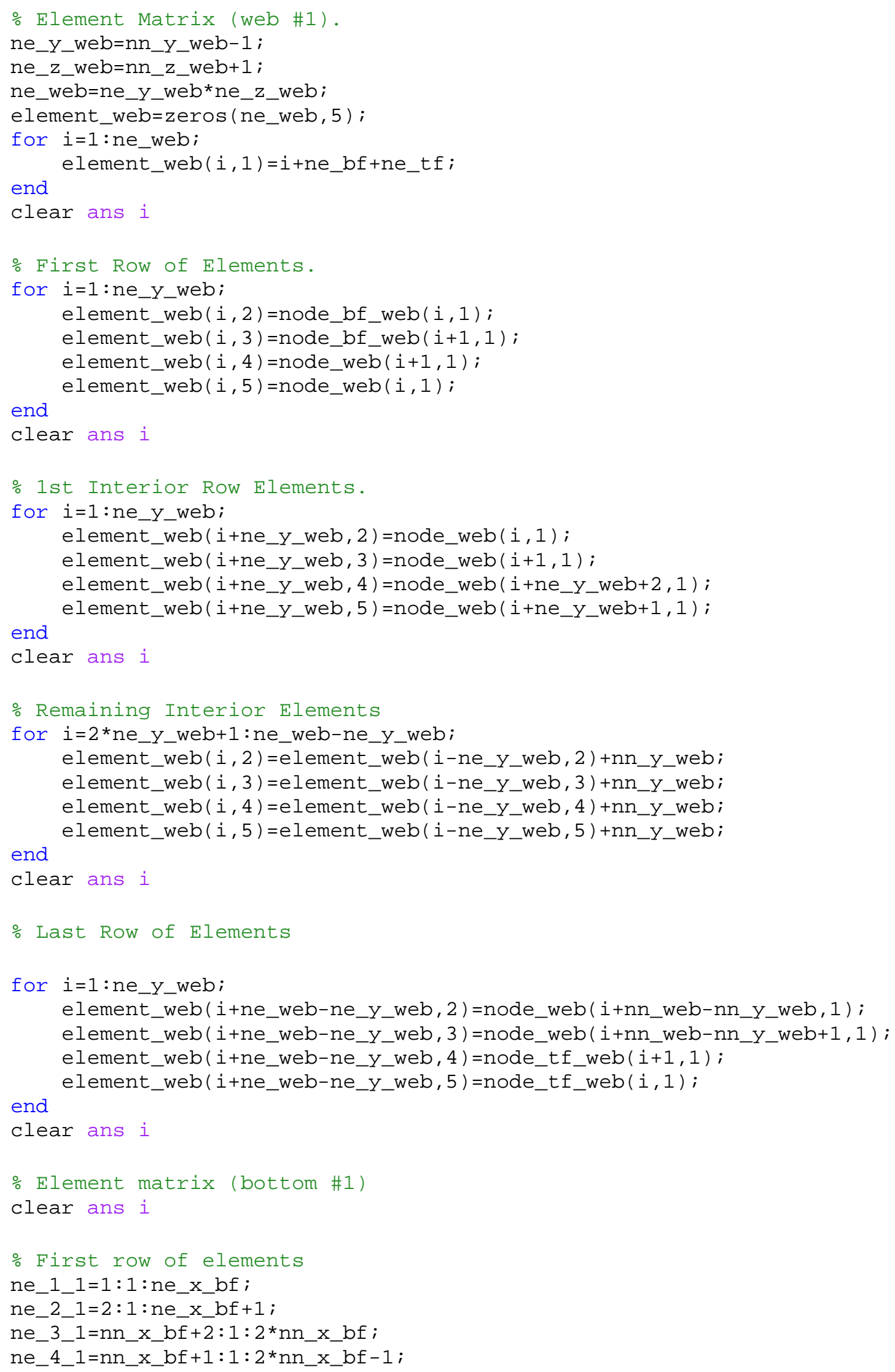




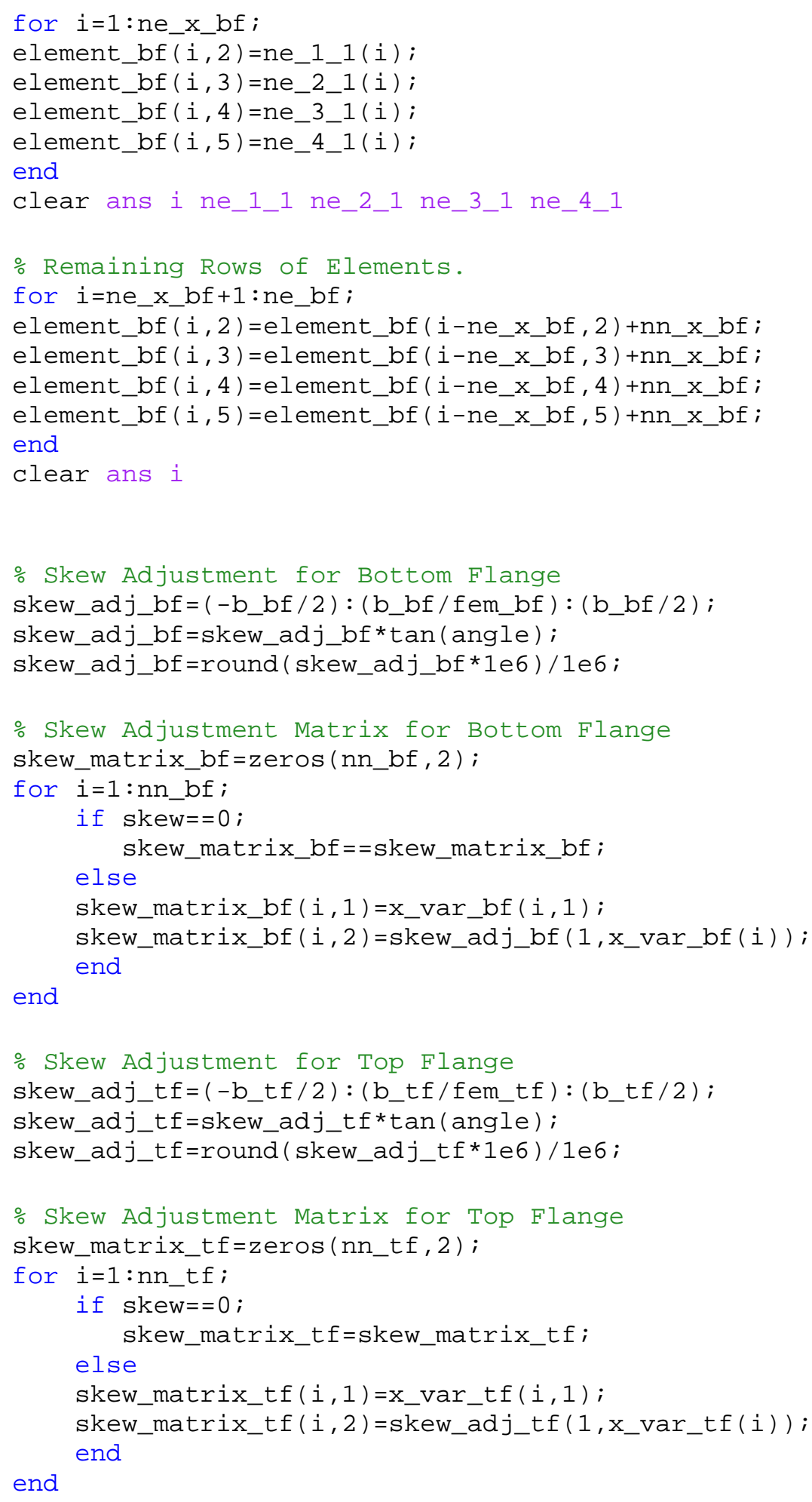




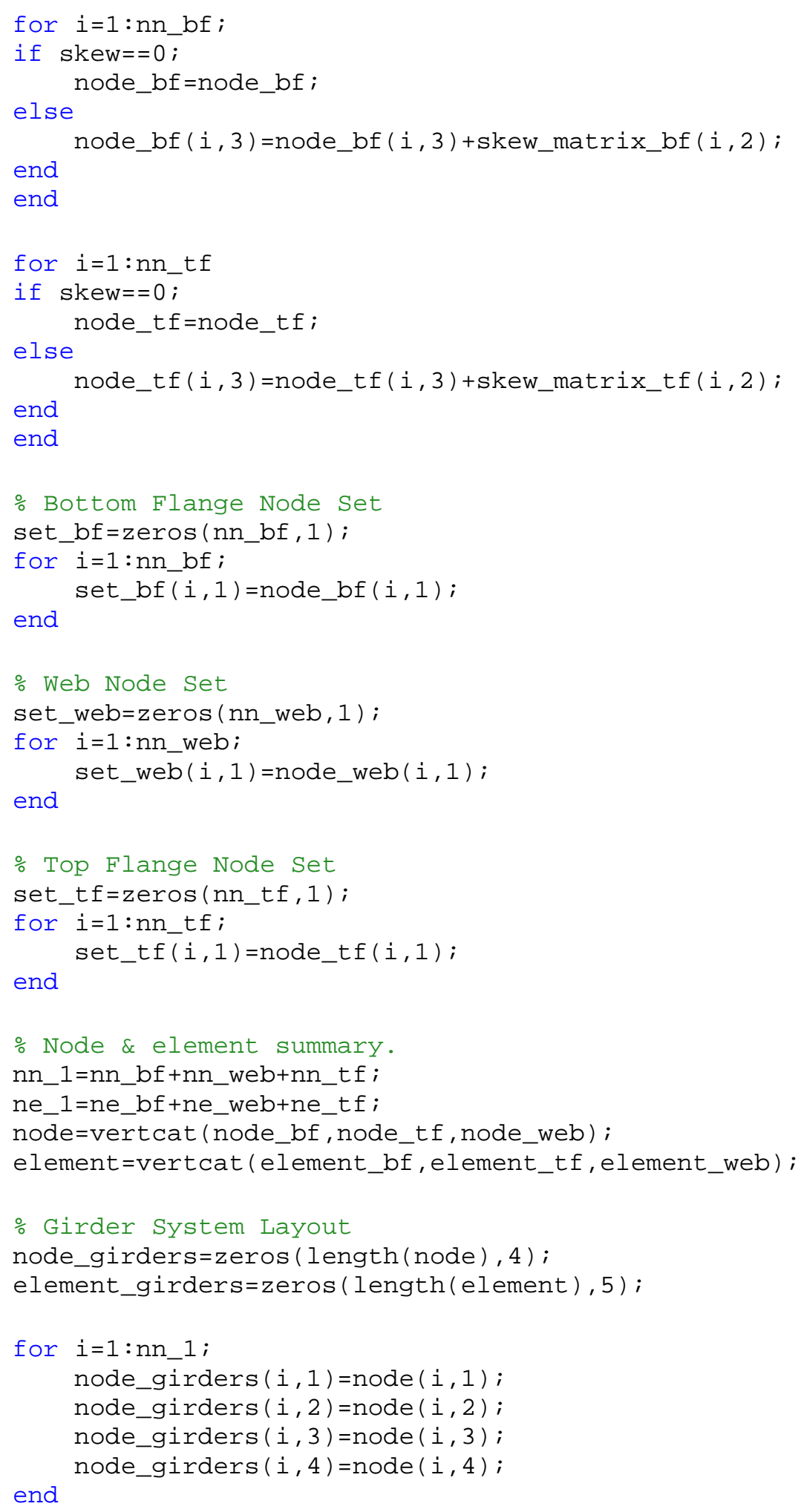




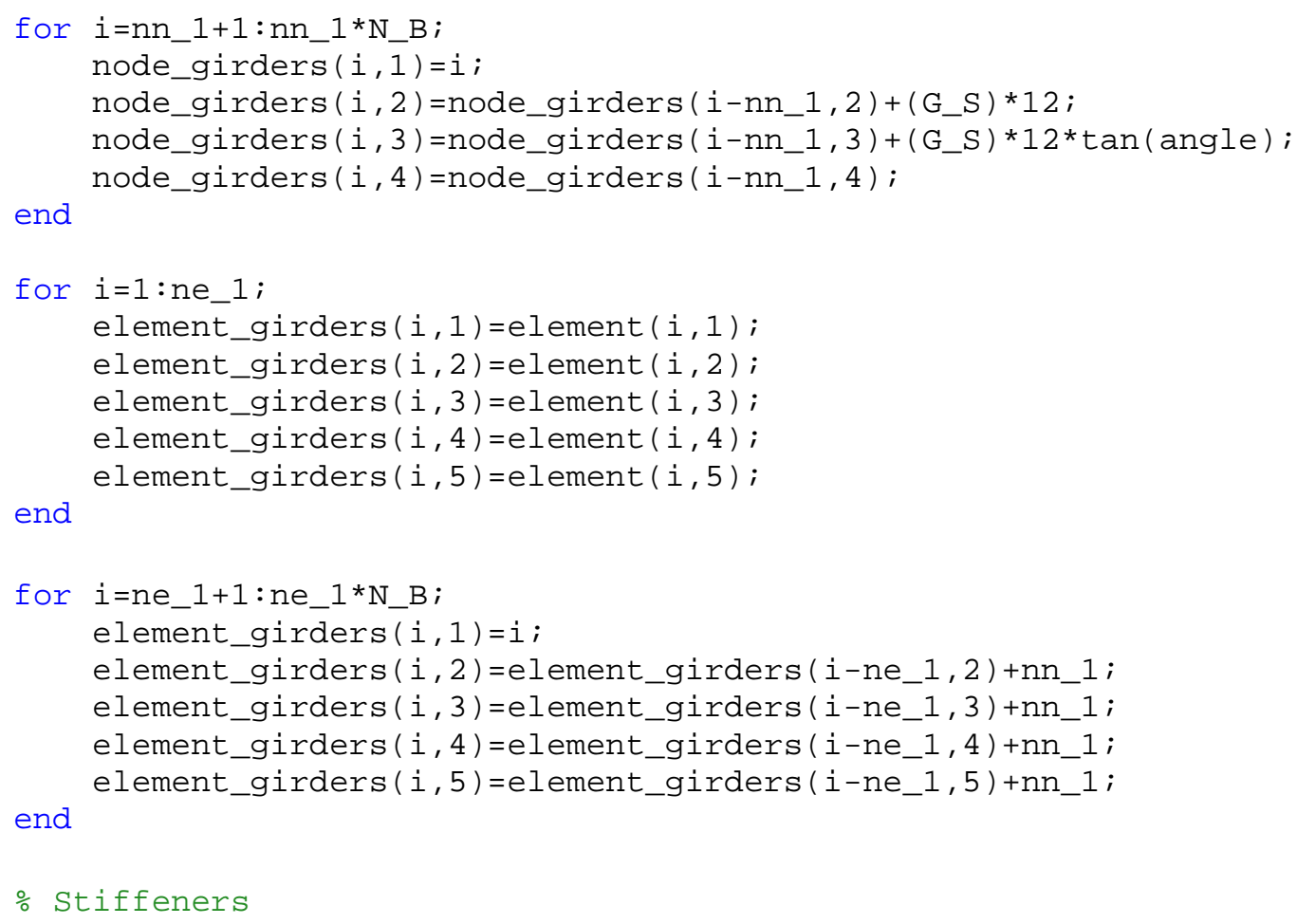




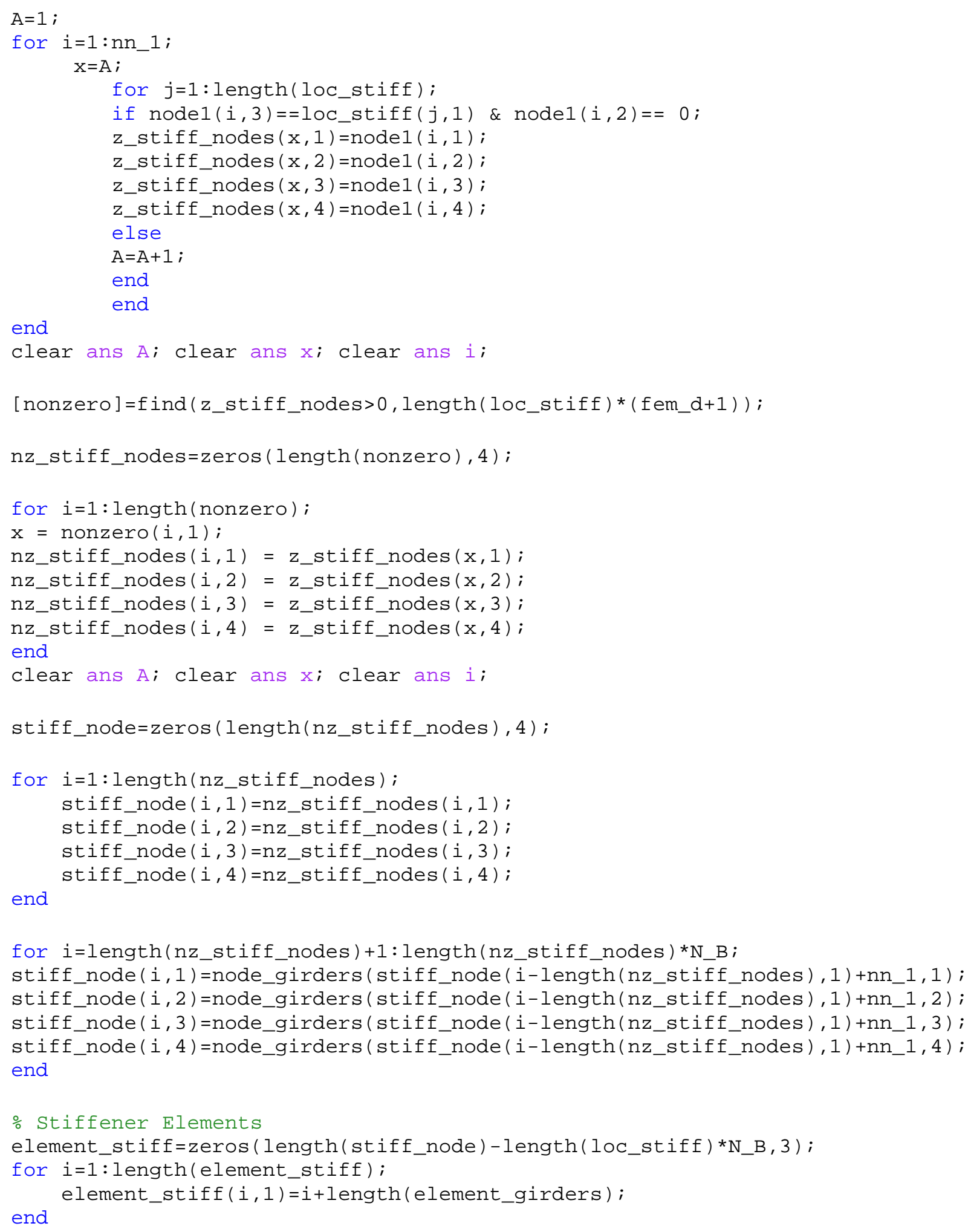




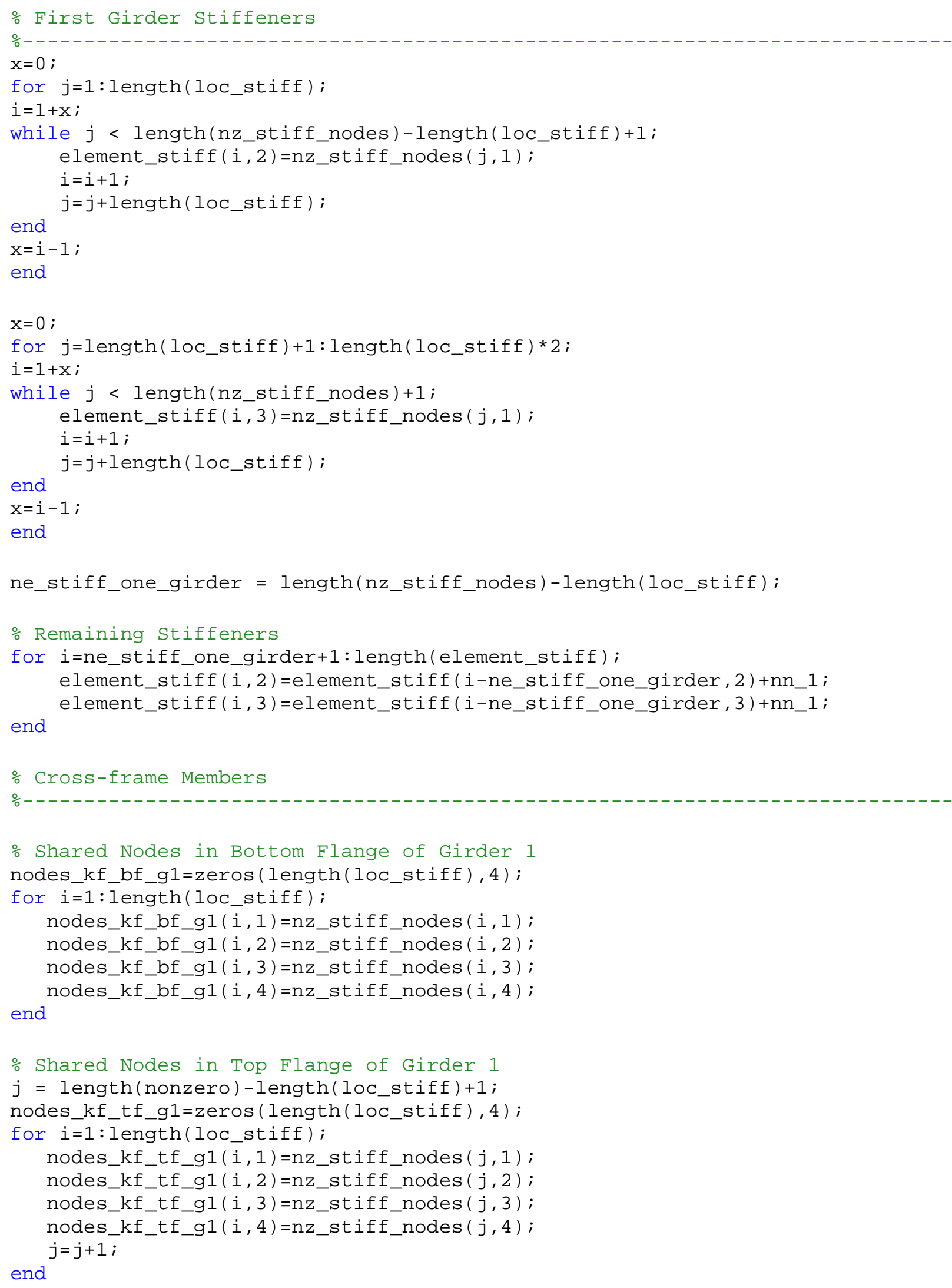




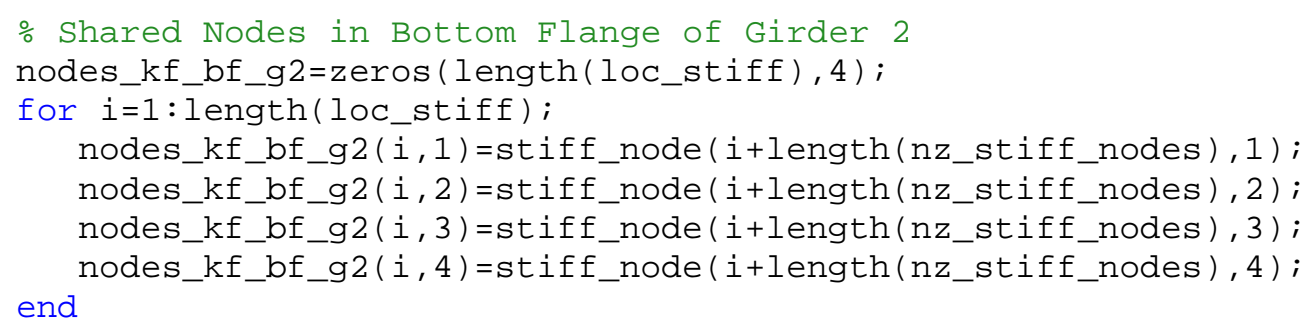




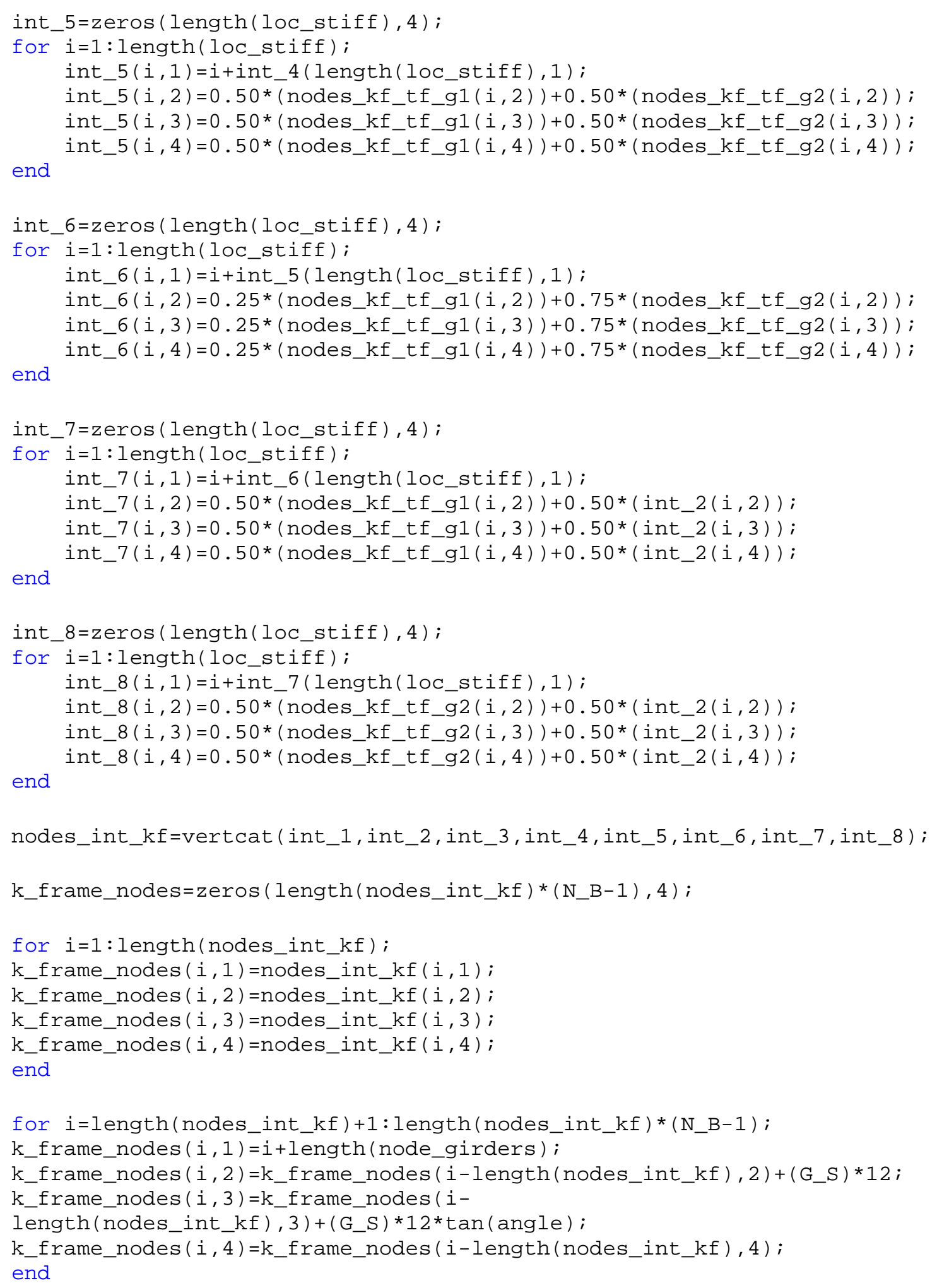




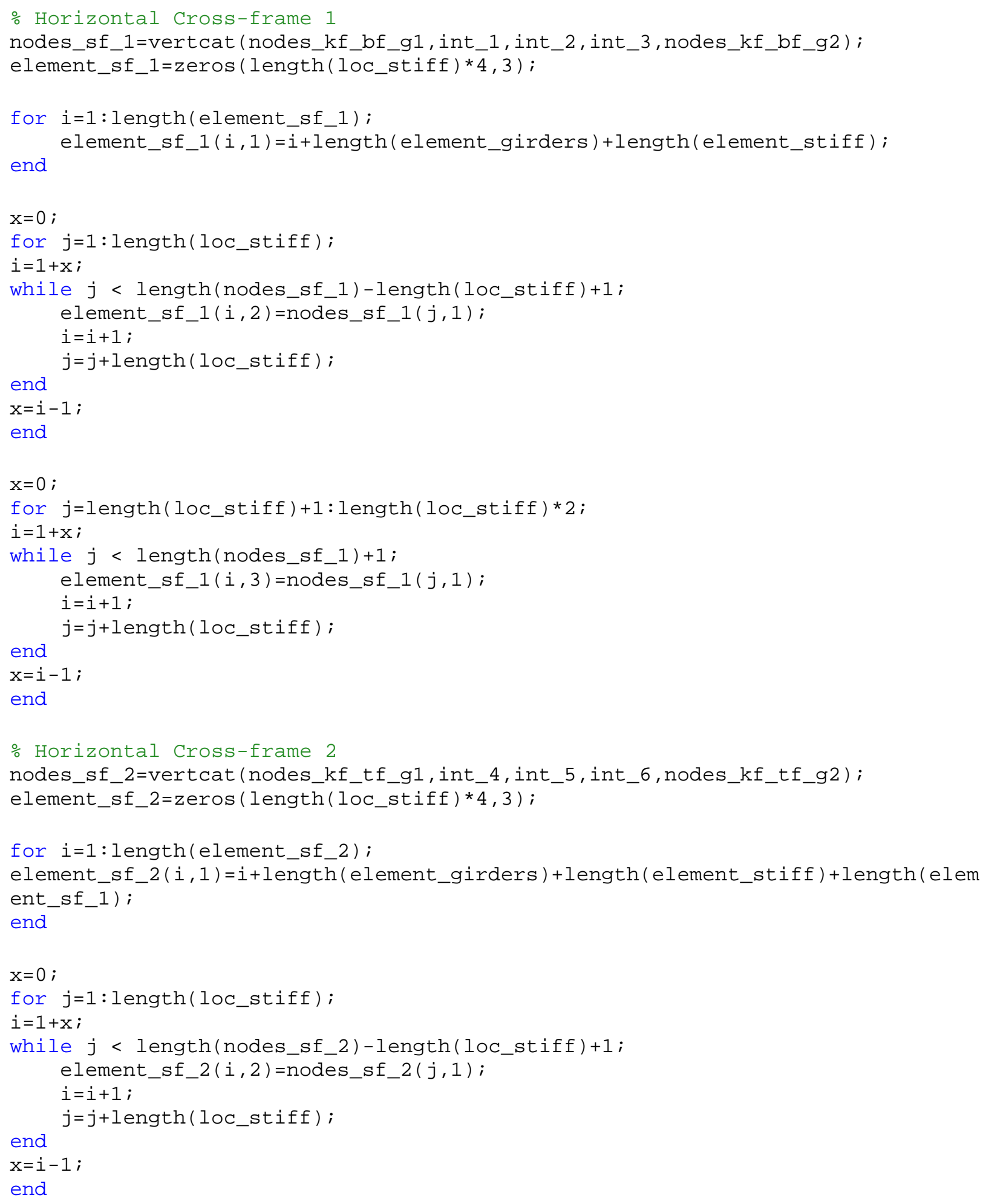




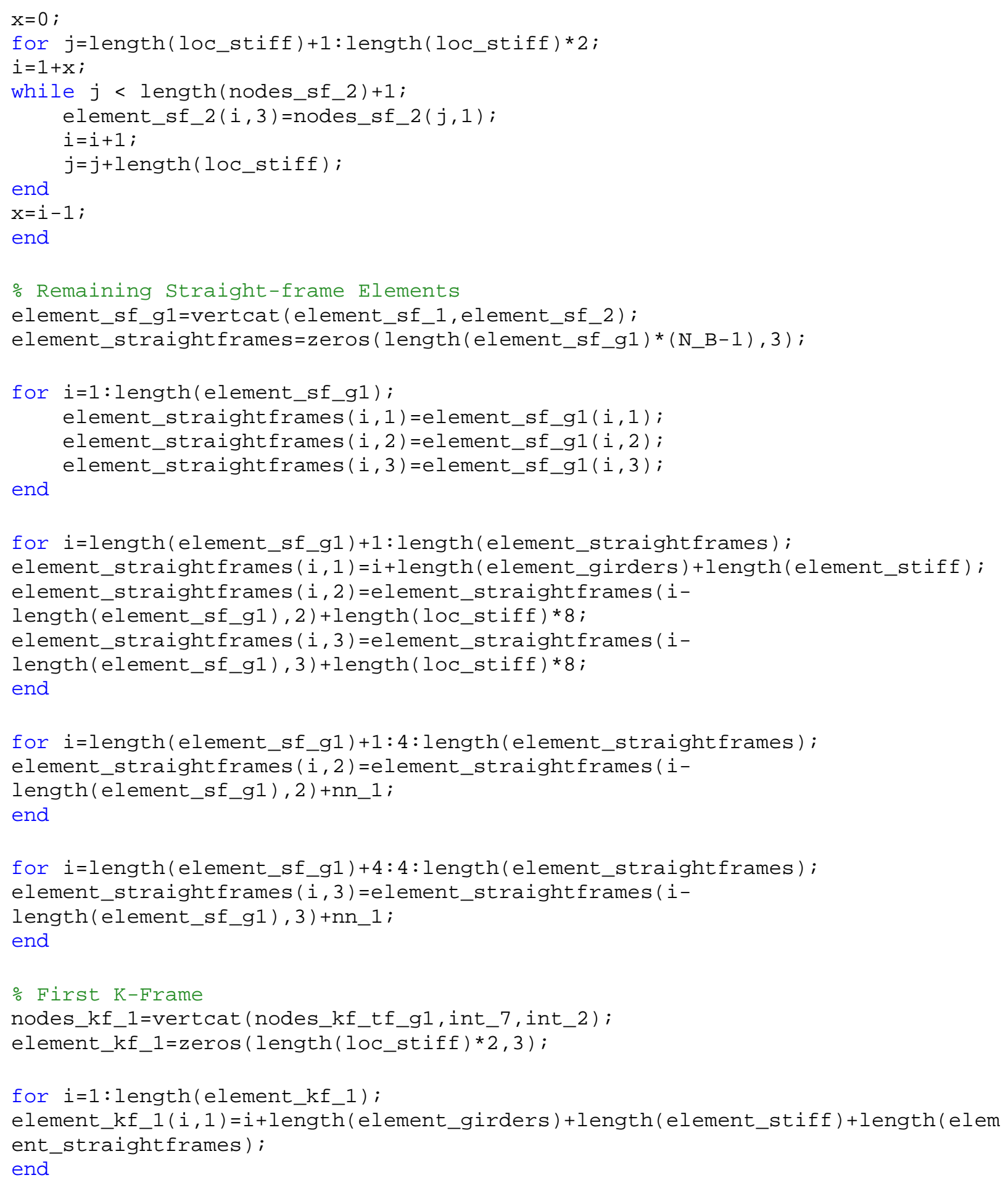




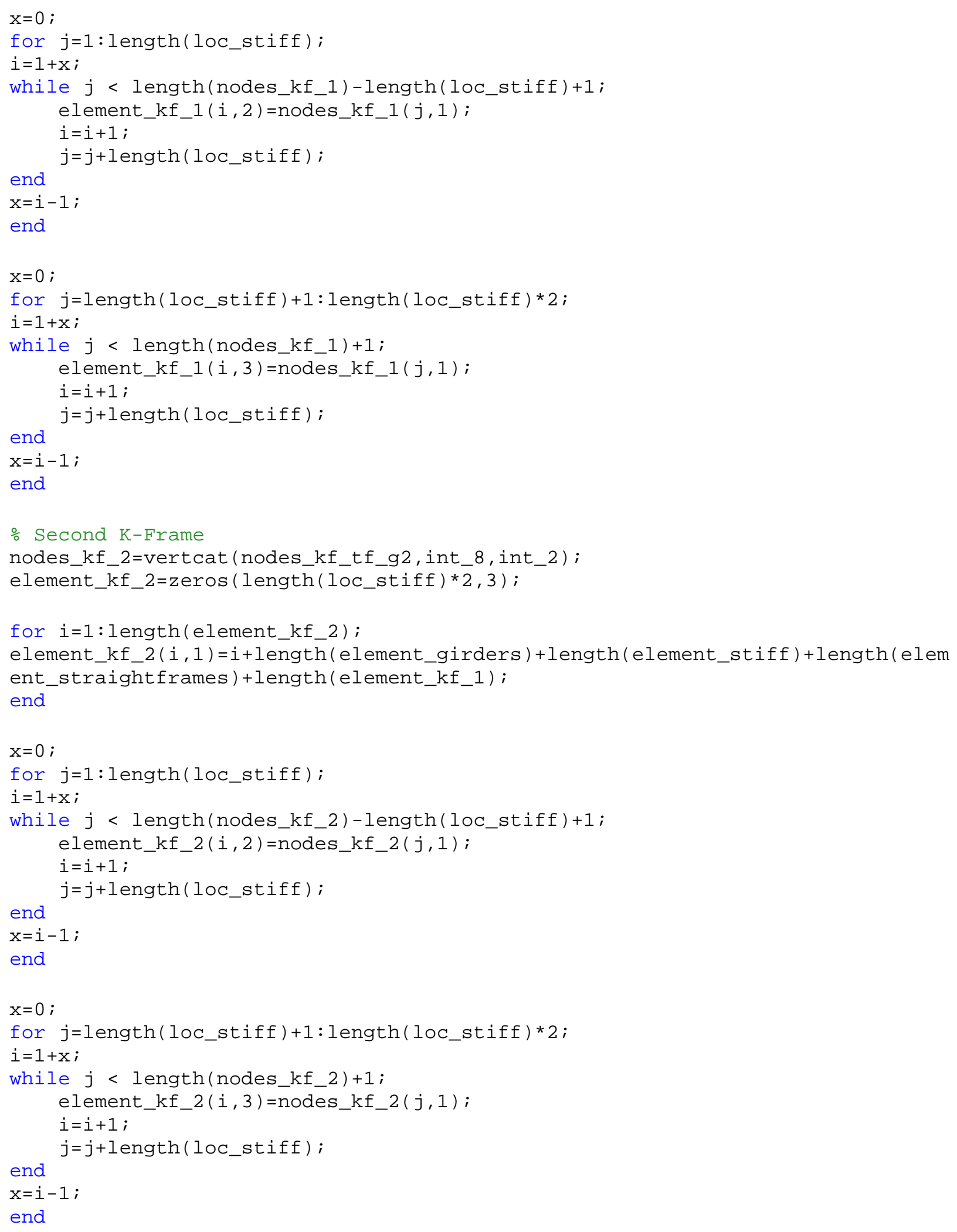




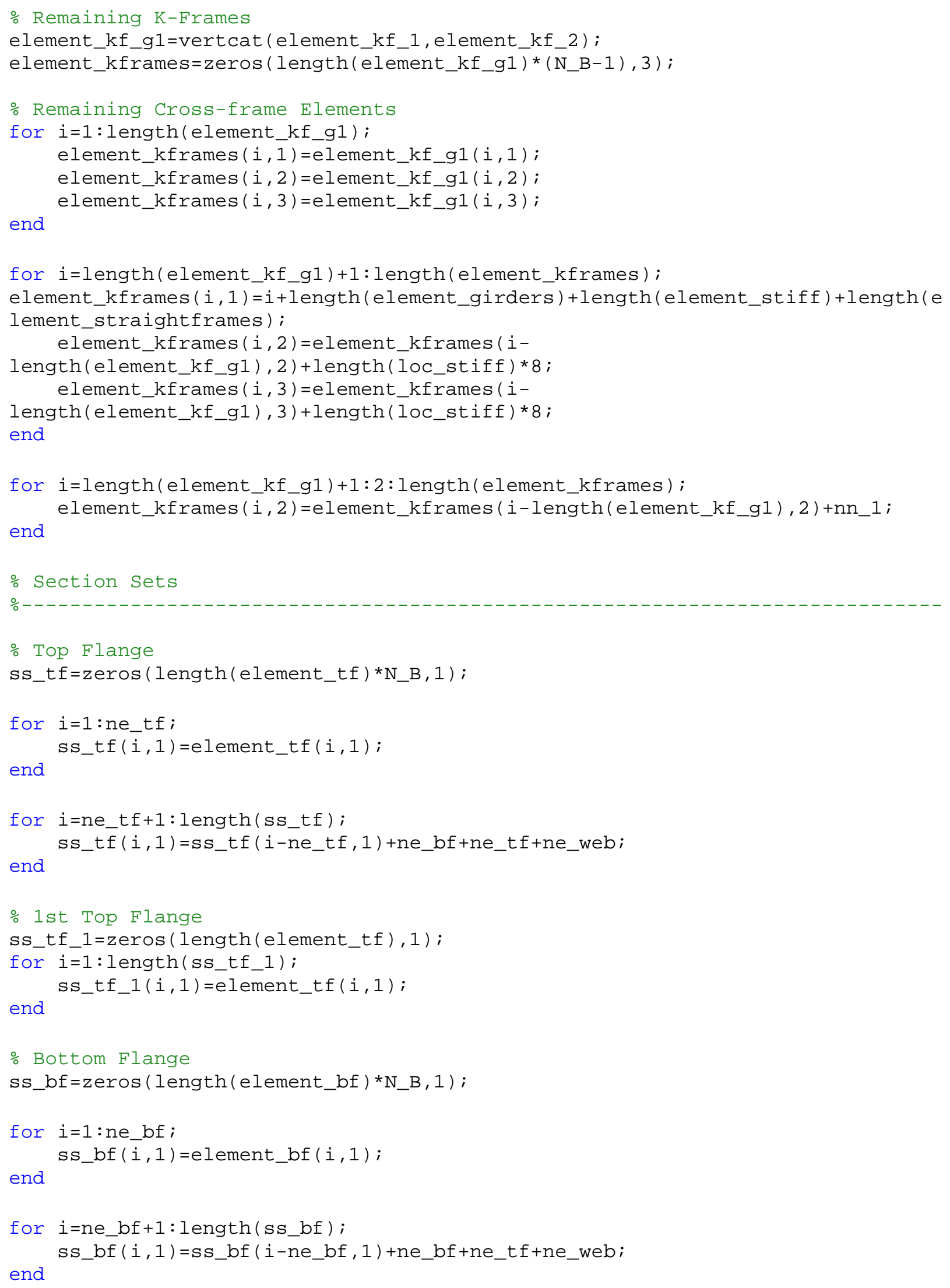




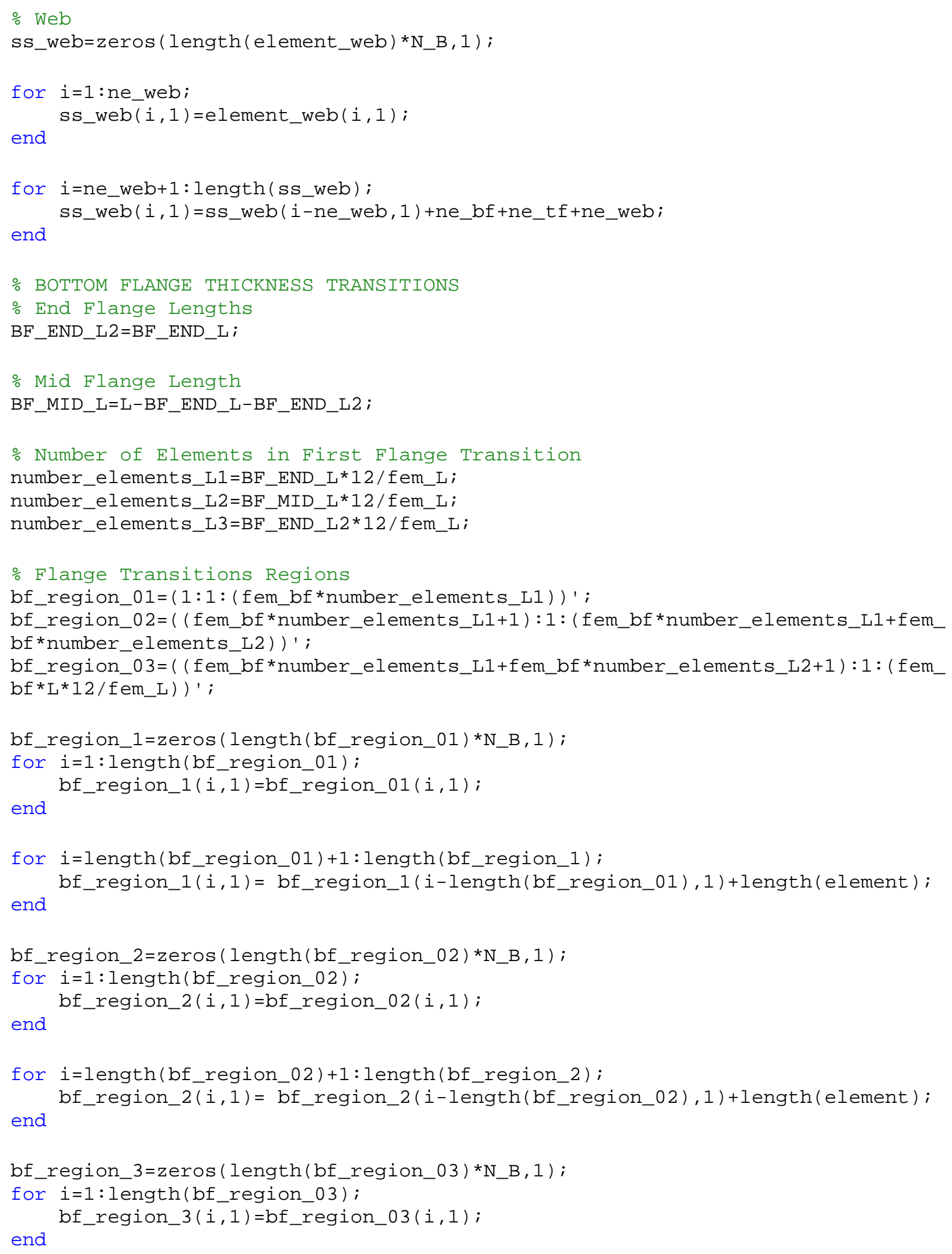




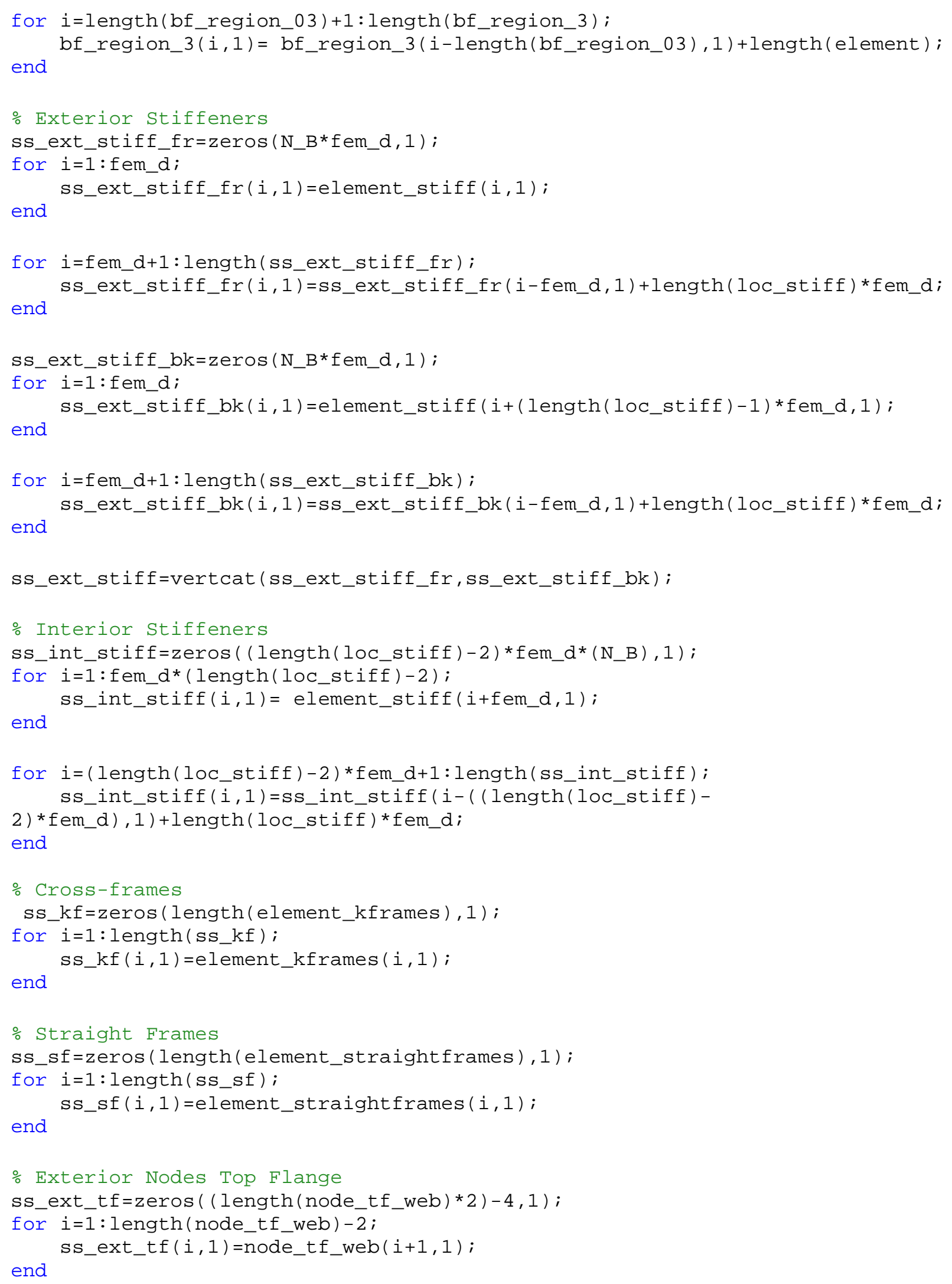




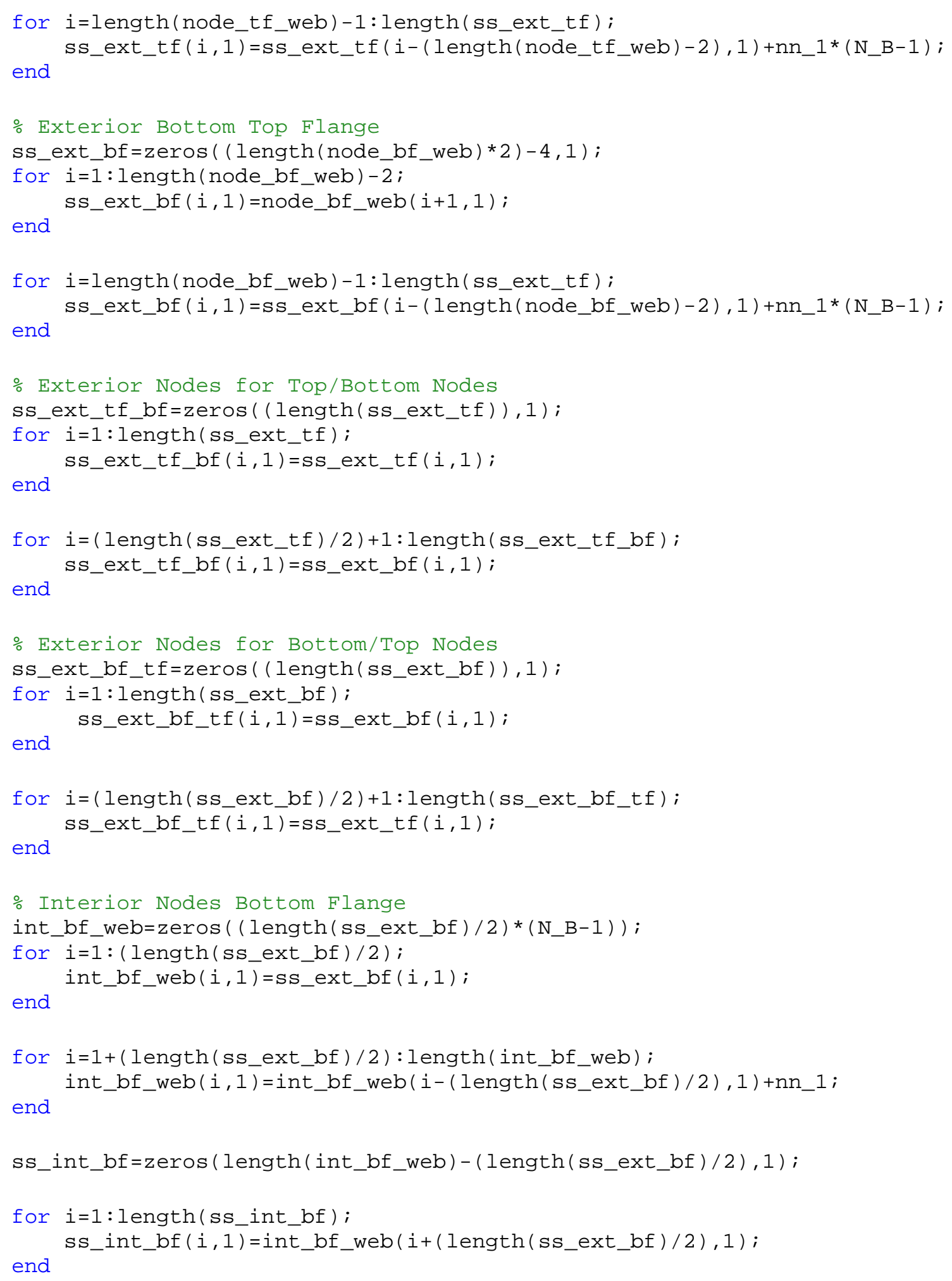




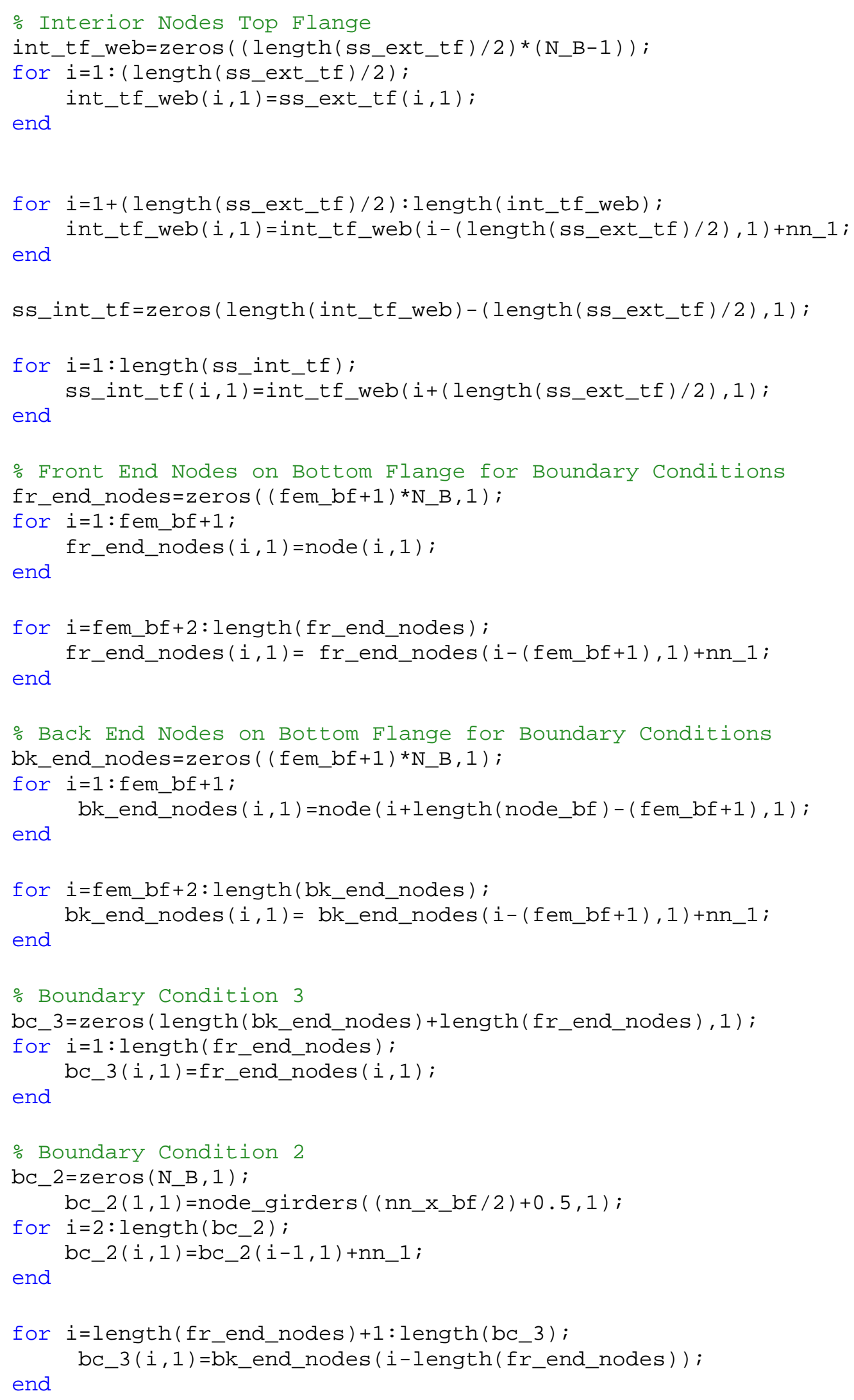




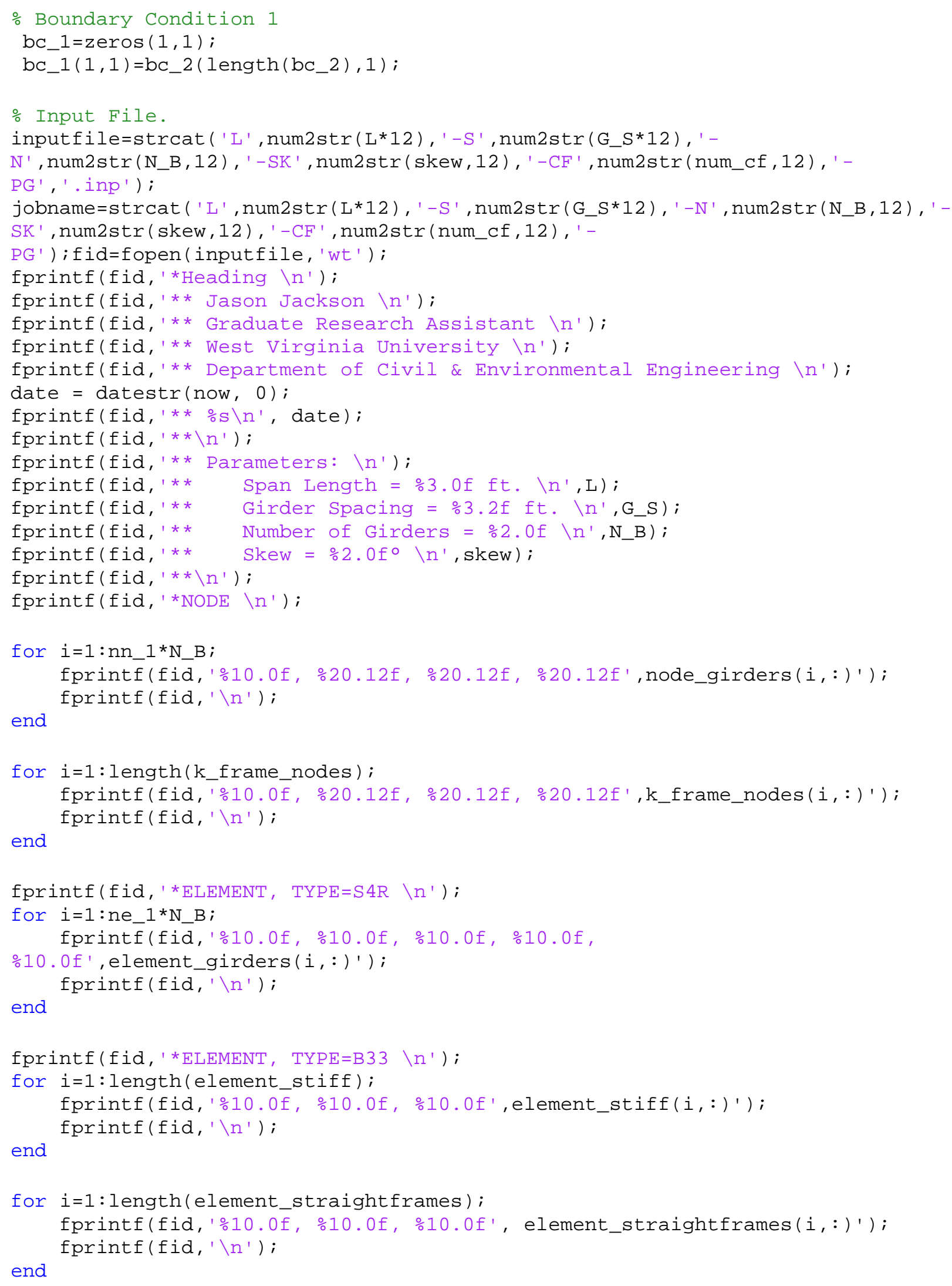




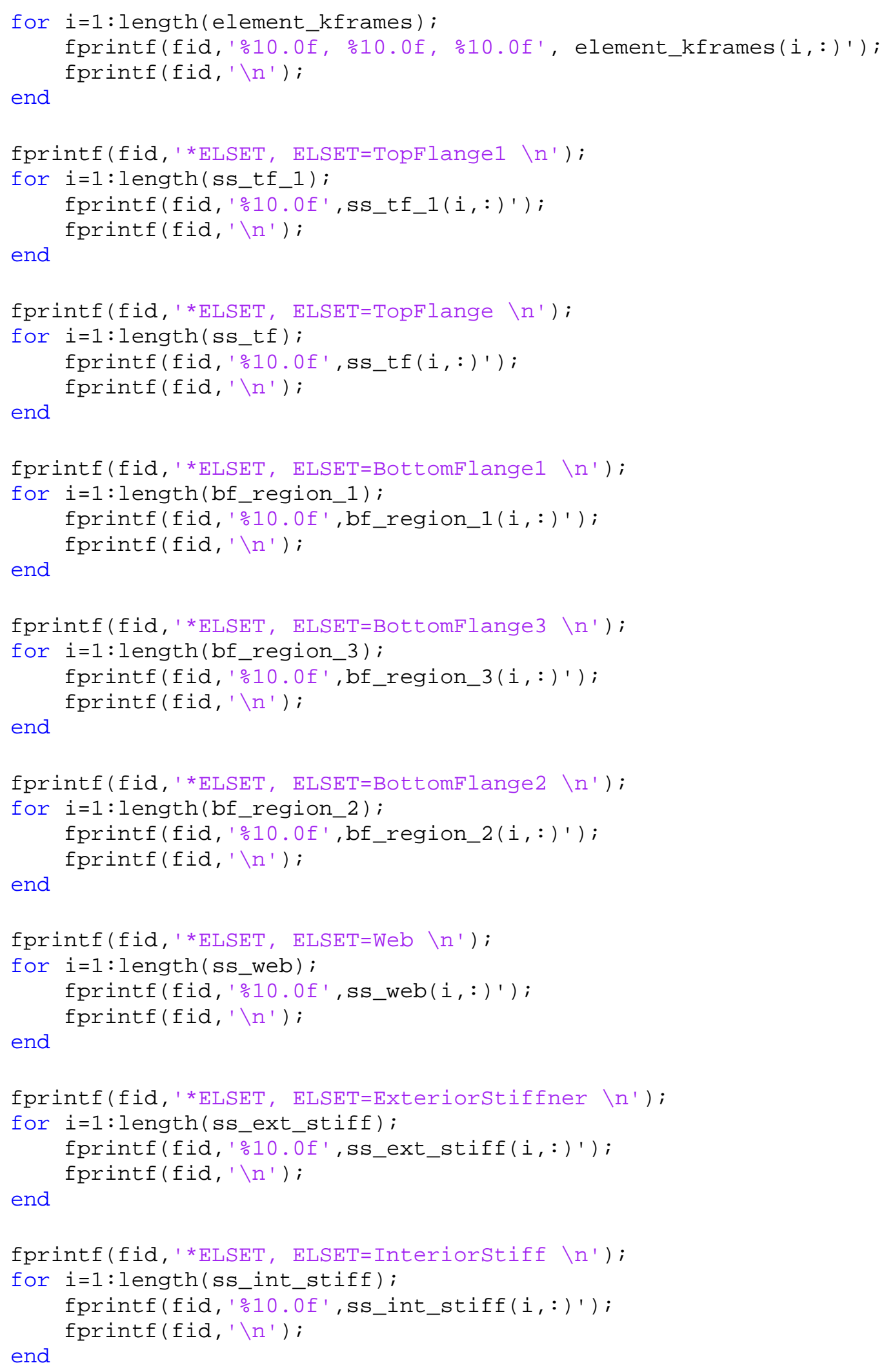




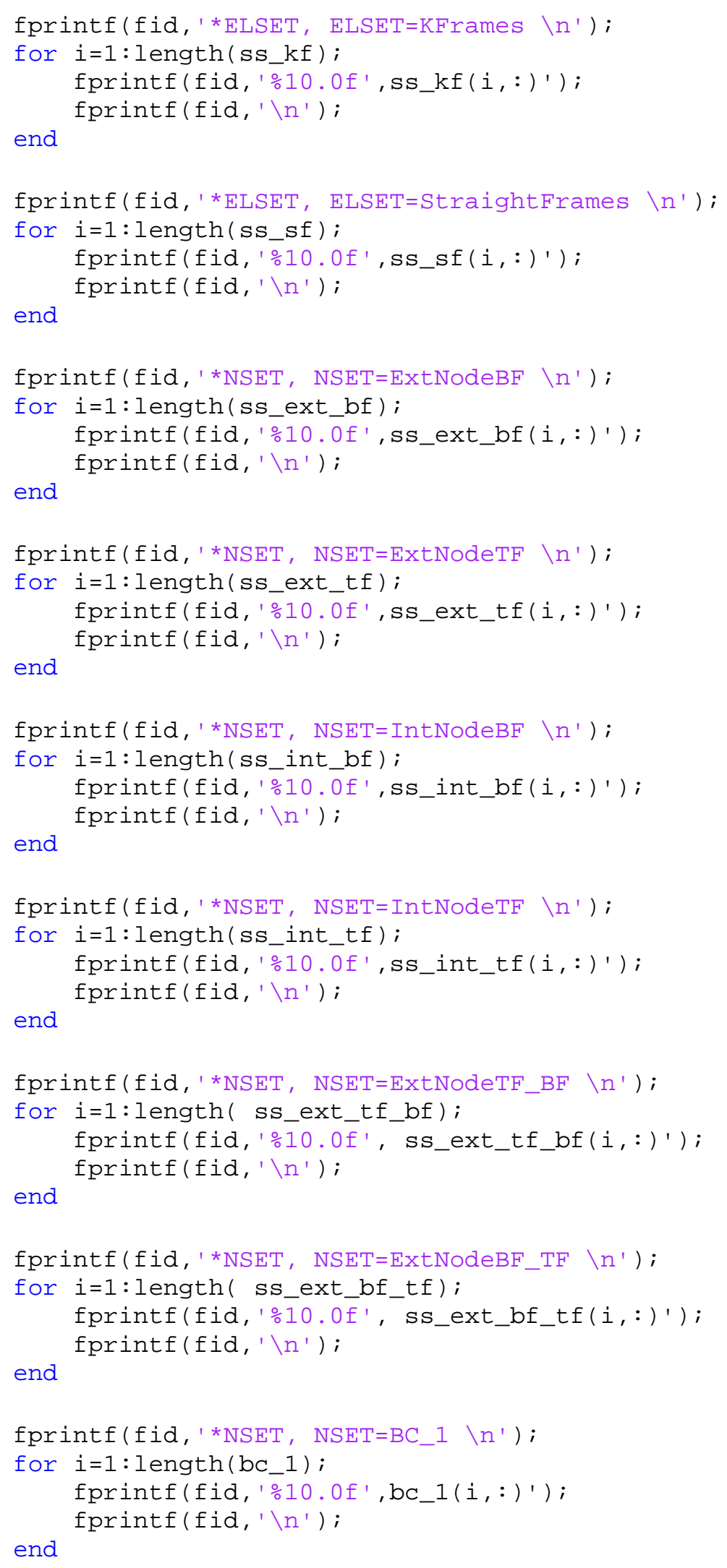




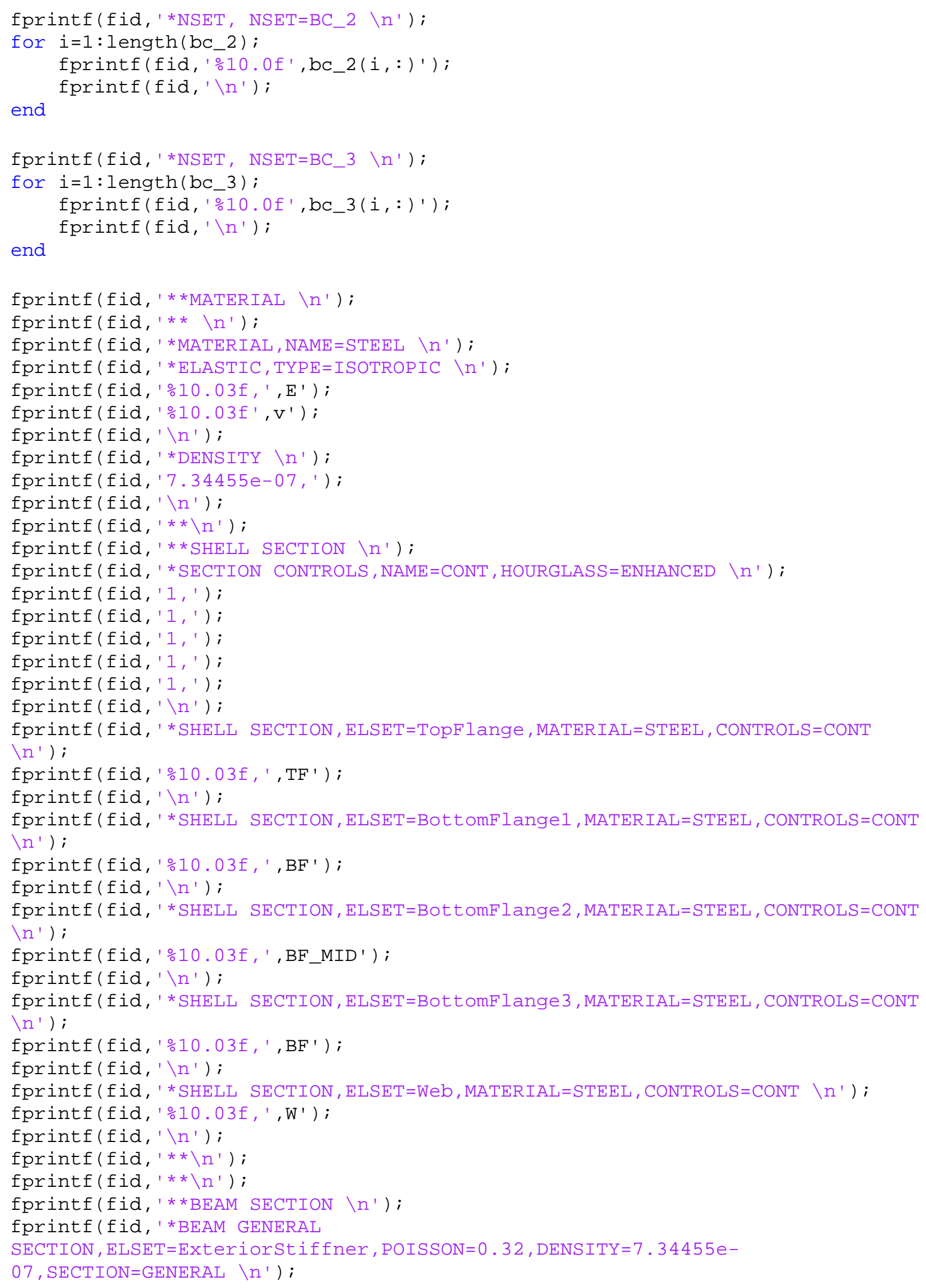




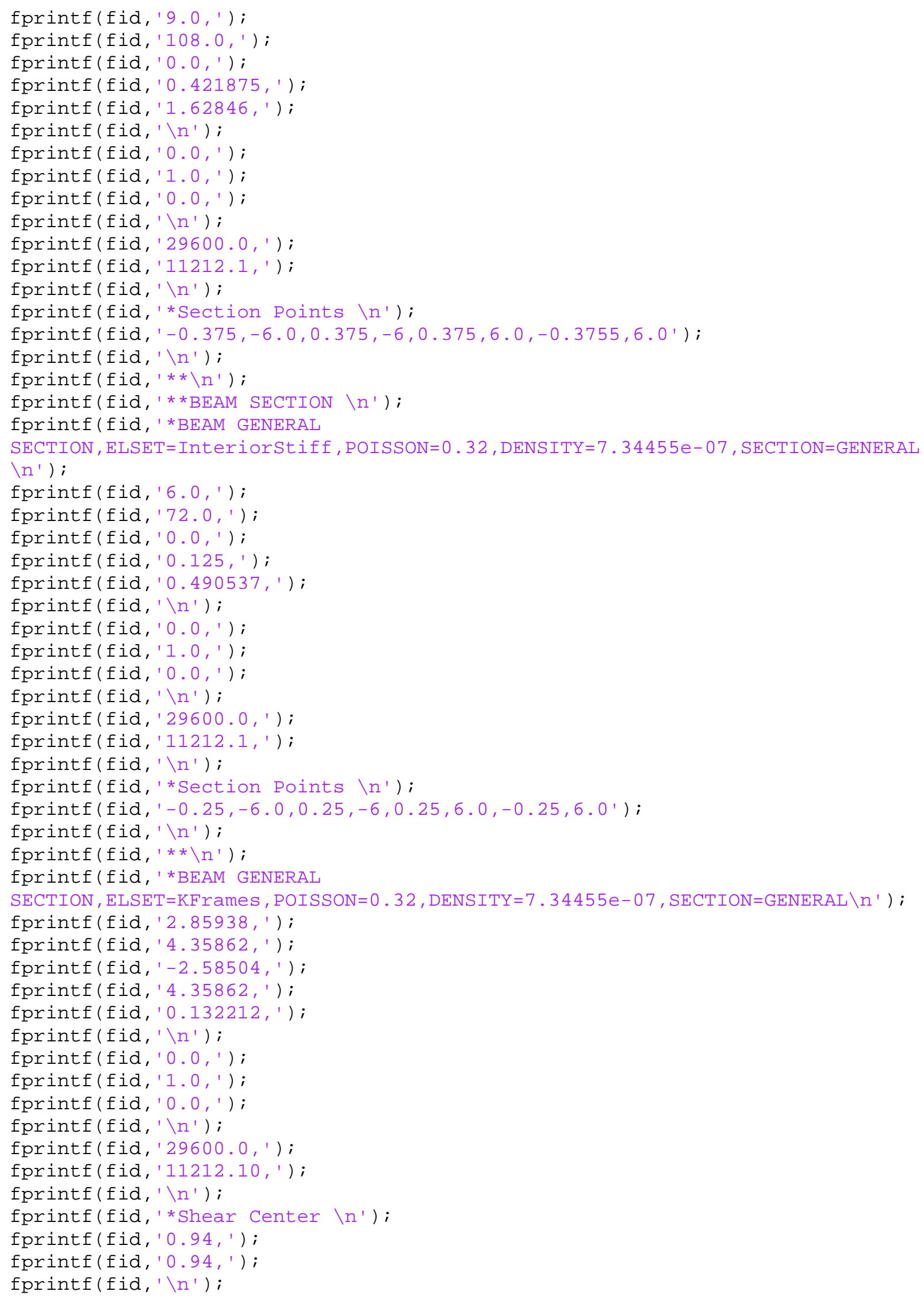




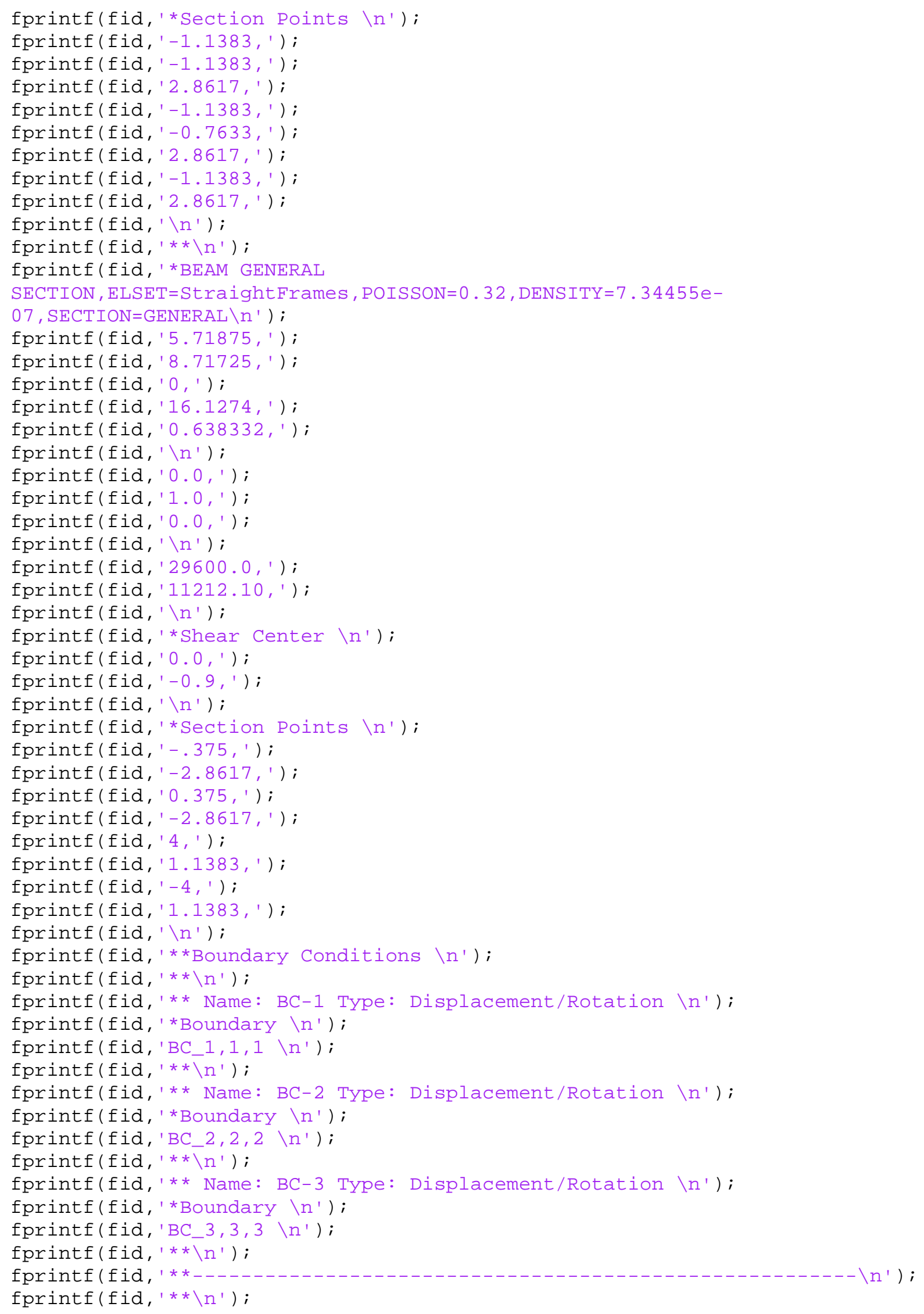




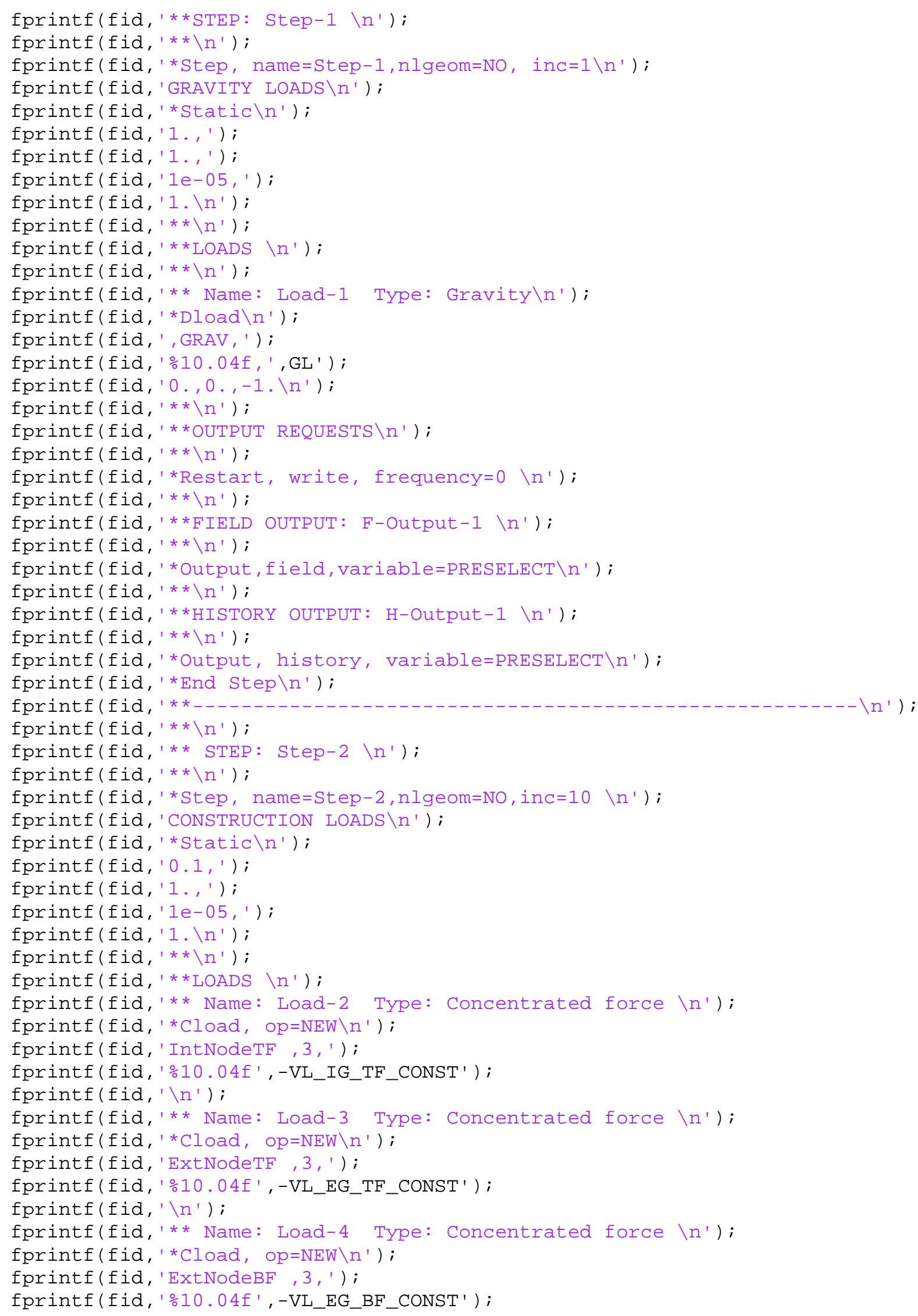




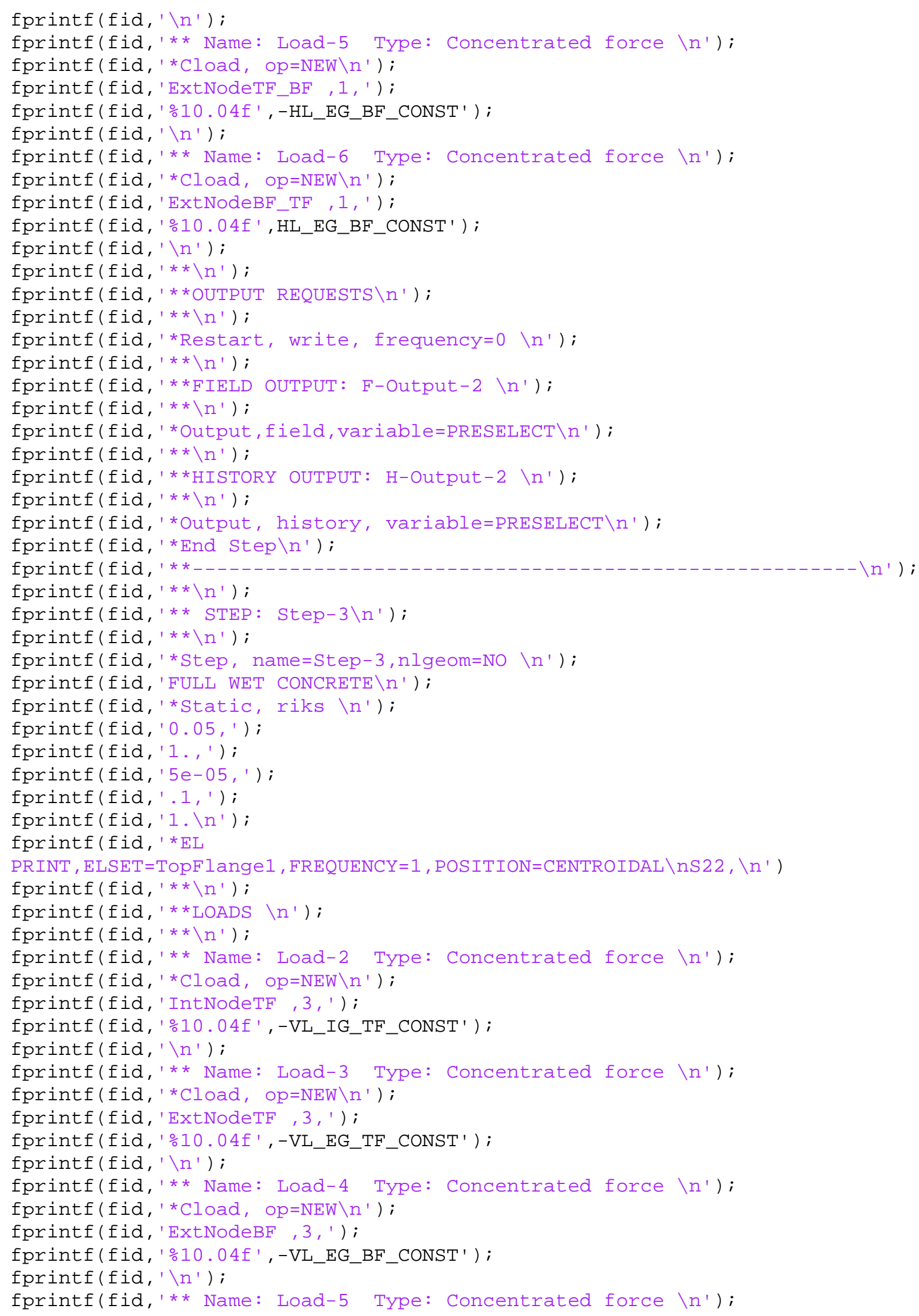


fprintf(fid, ' *Cload, op=NEW $\left.\backslash n^{\prime}\right)$;

fprintf(fid, 'ExtNodeTF_BF , 1, ');

fprintf(fid, '\%10.04f', -HL_EG_BF_CONST' ) ;

fprintf(fid, '\n');

fprintf(fid, '** Name: Load-6 Type: Concentrated force $\left.\backslash n^{\prime}\right)$;

fprintf(fid, ' ${ }^{*}$ Cload, op=NEW $\left.\backslash n^{\prime}\right)$;

fprintf(fid, 'ExtNodeBF_TF , 1,' );

fprintf(fid, '\%10.04f',HL_EG_BF_CONST') ;

fprintf(fid, '\n');

fprintf(fid, '** Name: Load-7 Type: Concentrated force $\backslash n ')$;

fprintf(fid, ' ${ }^{*}$ Cload, op=NEW $\left.\backslash n '\right)$;

fprintf(fid, 'IntNodeTF , 3, ');

fprintf(fid, '\%10.04f', -VL_IG_TF_CAST');

fprintf(fid, '\n');

fprintf(fid, '** Name: Load-8 Type: Concentrated force \n');

fprintf(fid, ' ${ }^{*}$ Cload, op=NEW $\left.\backslash n '\right)$;

fprintf(fid, 'ExtNodeTF , 3, ');

fprintf(fid, '\%10.04f', -VL_EG_TF_CAST');

fprintf(fid, '\n');

fprintf(fid, '** Name: Load-9 Type: Concentrated force $\backslash n ')$;

fprintf(fid, ' ${ }^{*}$ Cload, op=NEW $\left.\backslash n '\right)$;

fprintf(fid, 'ExtNodeBF , 3, ');

fprintf(fid, '\%10.04f', -VL_EG_BF_CAST');

fprintf(fid, '\n');

fprintf(fid, '** Name: Load-10 Type: Concentrated force \n');

fprintf(fid, ' *Cload, op=NEW $\backslash n$ ');

fprintf(fid, 'ExtNodeTF_BF , 1,' );

fprintf(fid, '\%10.04f',-HL_EG_BF_CAST') ;

fprintf(fid, ' $\left.\backslash n^{\prime}\right)$;

fprintf(fid, '** Name: Load-11 Type: Concentrated force $\left.\backslash n^{\prime}\right)$;

fprintf(fid, ' ${ }^{*}$ Cload, op=NEW $\left.\backslash n '\right)$;

fprintf(fid, 'ExtNodeBF_TF, 1, ');

fprintf(fid, '\%10.04f', HL_EG_BF_CAST' ) ;

fprintf(fid, '\n');

fprintf(fid, $\left.{ }^{* *} \backslash n^{\prime}\right)$;

fprintf(fid, '**OUTPUT REQUESTS $\backslash n$ ');

fprintf(fid, '** $\backslash n$ ');

fprintf(fid, '*Restart, write, frequency=0 $\left.\backslash n^{\prime}\right)$;

fprintf(fid, $\left.{ }^{* *} \backslash \mathrm{n}^{\prime}\right)$;

fprintf(fid, '**FIELD OUTPUT: F-Output-3 $\left.\backslash \mathrm{n}^{\prime}\right)$;

fprintf(fid, $\left.{ }^{* *} \backslash \mathrm{n}^{\prime}\right)$;

fprintf(fid, '*output, field, variable=PRESELECT $\backslash n^{\prime}$ ) ;

fprintf(fid, $\left.1 * * \backslash n^{\prime}\right)$;

fprintf(fid, '**HISTORY OUTPUT: H-Output-3 \n');

fprintf(fid, $\left.1 * * \backslash n^{\prime}\right)$;

fprintf(fid, '*Output, history, variable=PRESELECT \n');

fprintf(fid, ' *End Step\n');

fprintf(fid,

fclose(fid);

clear ans $i$ 


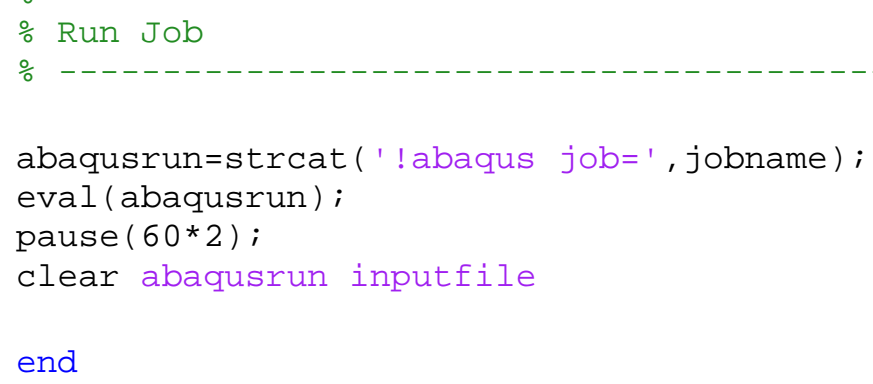




\section{C.2 Parametric Modeling Post-Processing Algorithm}
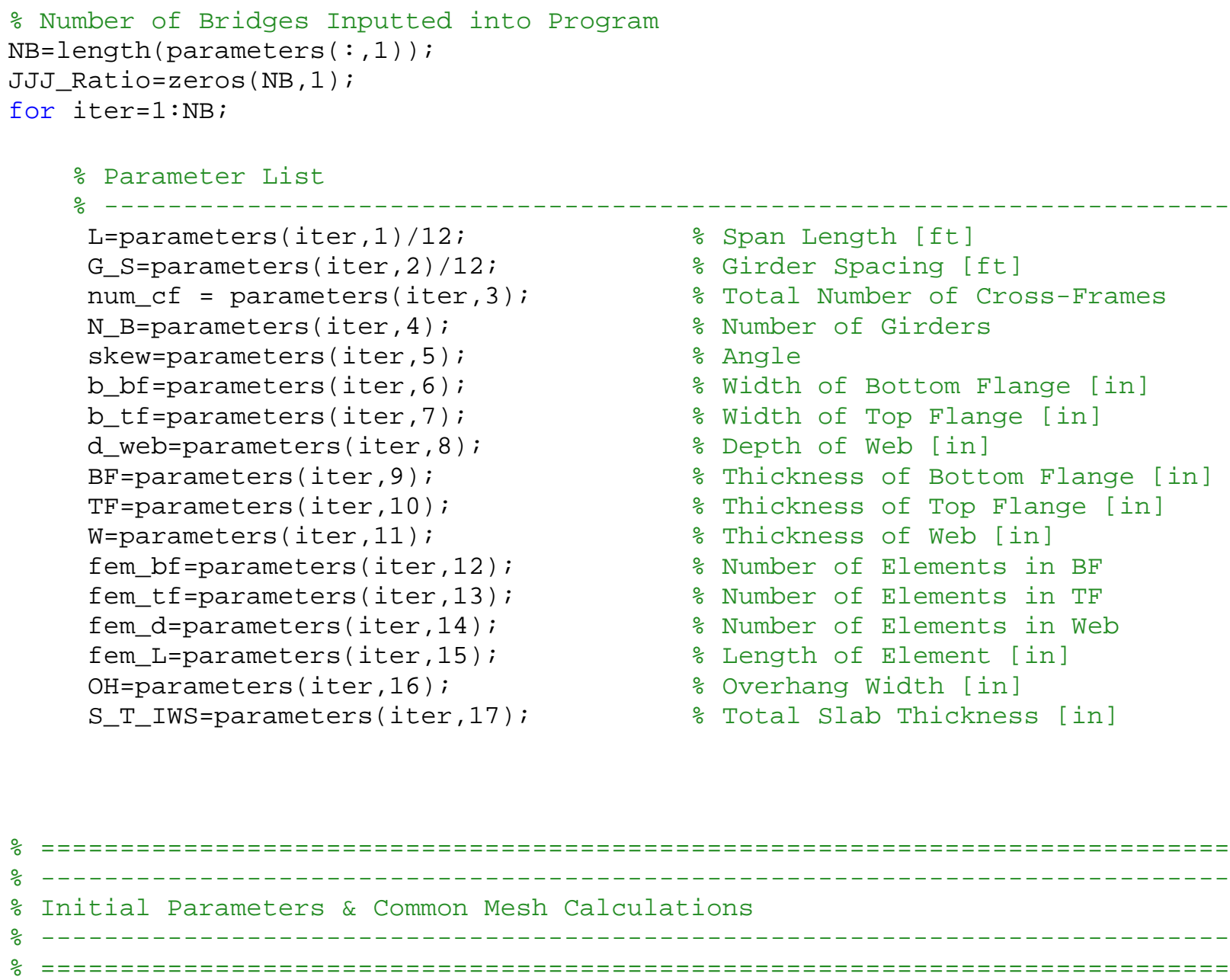

inputfile=strcat ( 'L', num2str $\left(L^{*} 12\right)$, ' -S ', num2str (G_S*12), ' $\mathrm{N}^{\prime}, \operatorname{num} 2 \mathrm{str}\left(\mathrm{N} \_B, 12\right), \mathrm{I}^{\prime}, \operatorname{num} 2 \mathrm{str}($ skew, 12), ' -CF ', num2str(num_cf, 12), ' PG', '. inp');

jobname=strcat ( 'L', num2str $\left(L^{*} 12\right)$, ' -S ', num2str (G_S*12), ' - N ', num2str (N_B, 12), 'SK', num2str(skew, 12), '-CF', num2str(num_cf,12), '-PG');

angle $=$ skew $^{*} \mathrm{pi} / 180$;

SecMod $=T F^{*}$ b_tf^2/6;

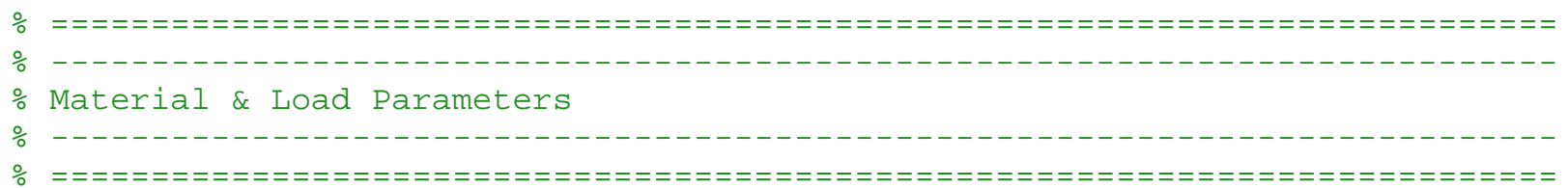




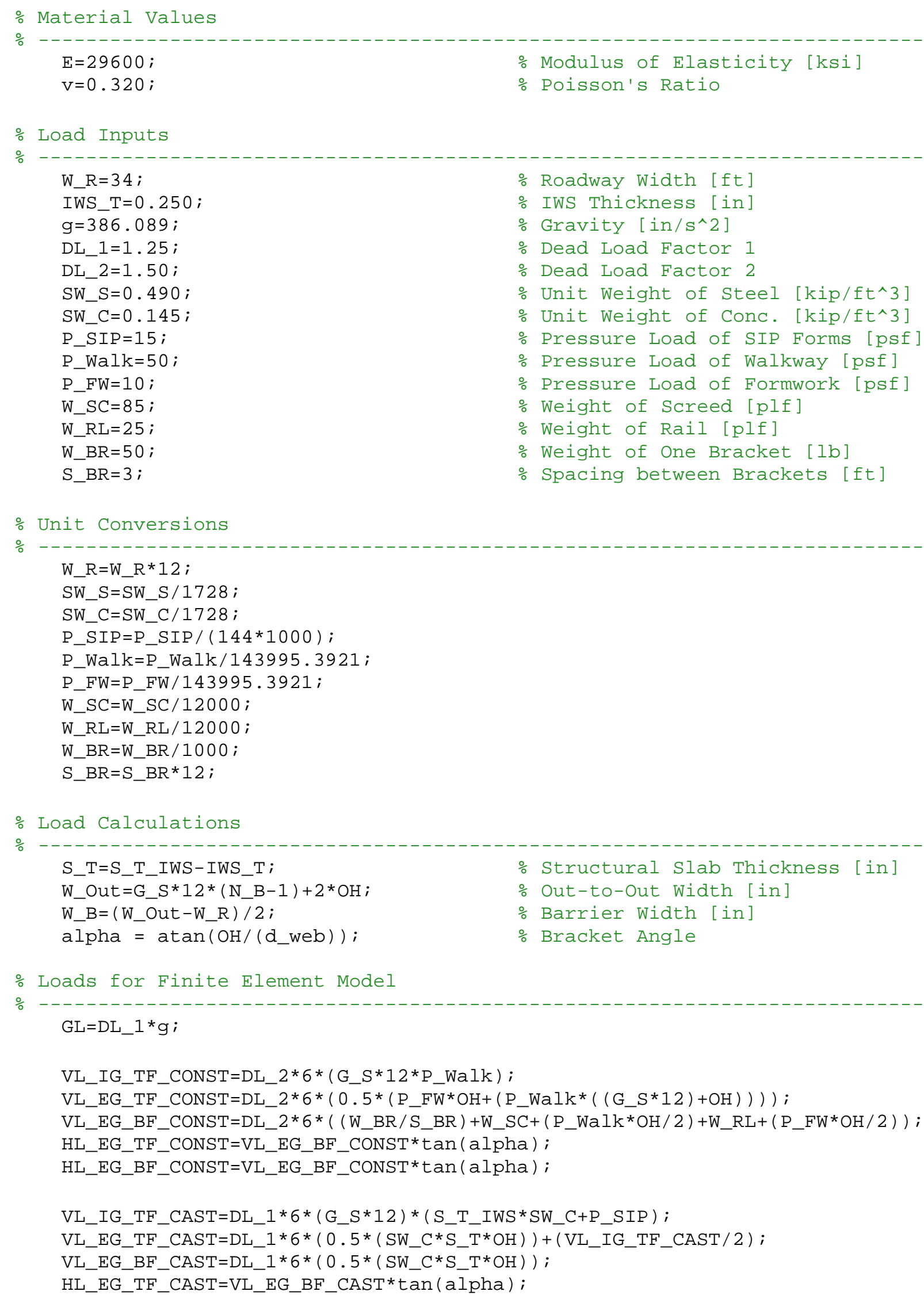


HL_EG_BF_CAST=VL_EG_BF_CAST ${ }^{*} \tan ($ alpha $)$;

$\mathrm{Lb}=\mathrm{L} * 12 /($ num_cf -1$)$;

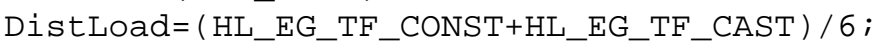

MAASHTO=Dis t Load ${ }^{*} \mathrm{Lb}^{\wedge} 2 / 12$;

MAASHTOpos $=+$ abs (MAASHTO $)$;

MAASHTOne $=-$ abs $($ MAASHTO $)$;

My $=50 *$ SecMod；

$\%$

$\%$ open .dat file

$\%$ dat $=$ opening . dat file

$\% \ldots \ldots \ldots \ldots$

datfile=strcat ( jobname, ' . dat' ');

dat=fopen (datfile, ' $r$ ');

clear datfile

$\%$

$\%$ Load Proportionality Factor

$\%$

lpf $=0$;

$\mathrm{ch}=[]$;

while lpf<1;

while length (ch) =7;

tline $=$ fgets $($ dat $)$;

if length(tline $)>=12$

t $r=$ tline $(6: 12) \sim=$ ' CURRENT ' ;

$\mathrm{ch}=\mathrm{find}(\mathrm{tr}==0)$;

else

end

$\mathrm{ch}=[]$

end

lpf=str2num(tline(49: length(tline)));

end

$\%$

$\%$ Stresses

$\%$

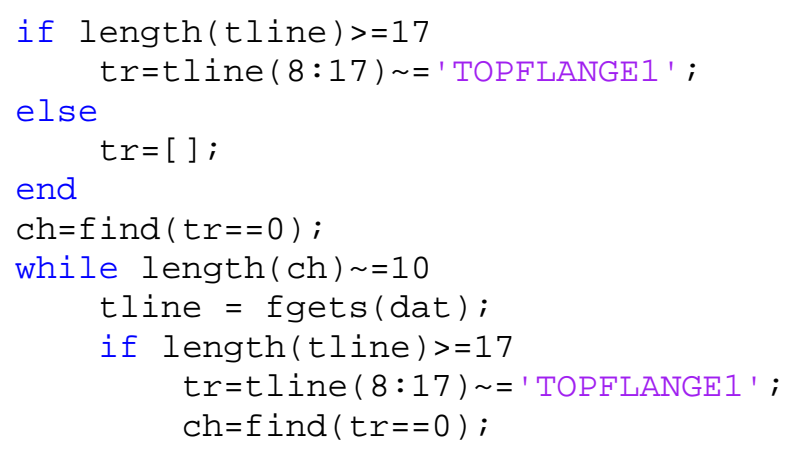




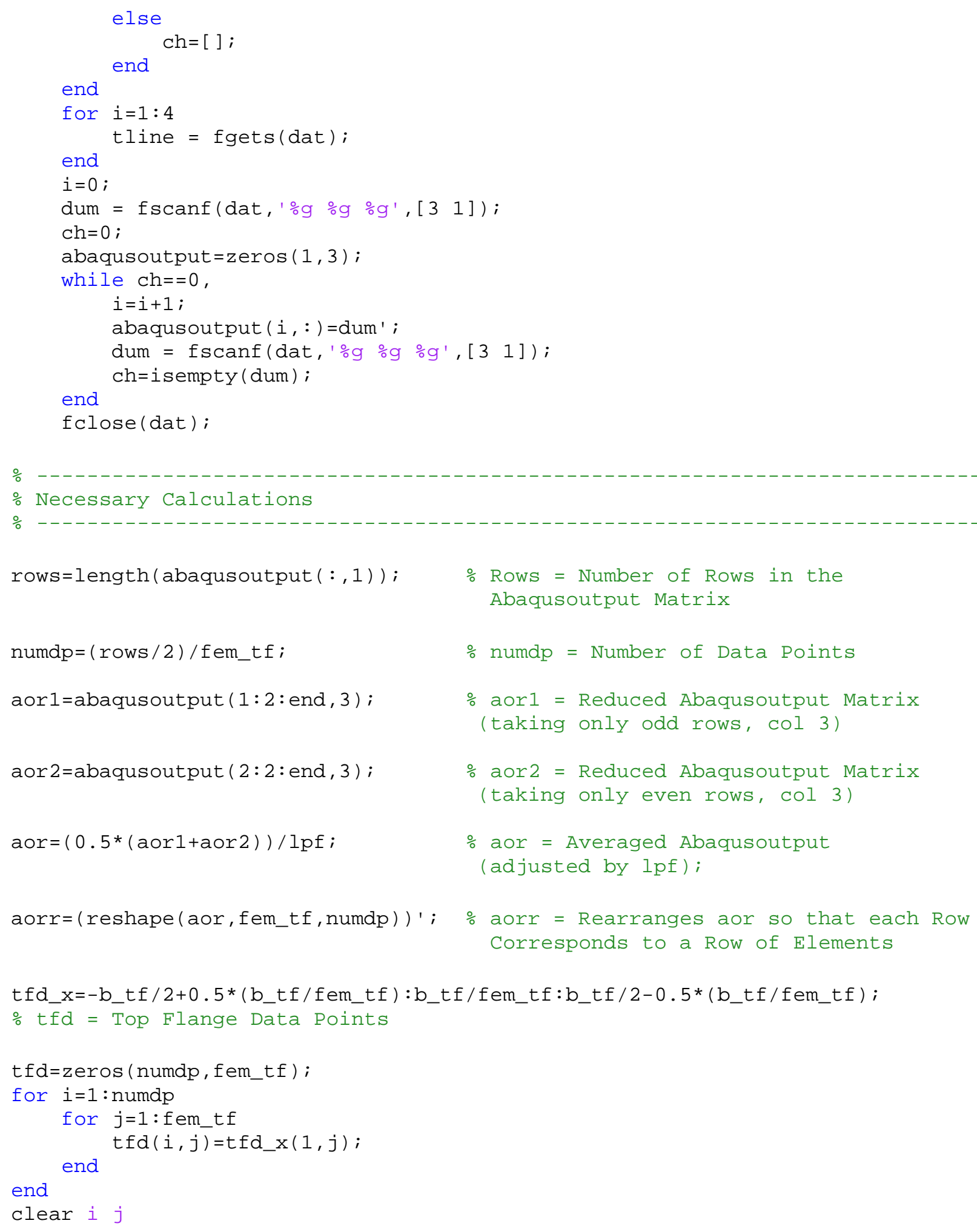


$\%$

$\%$ Curve Fitting

$\%$

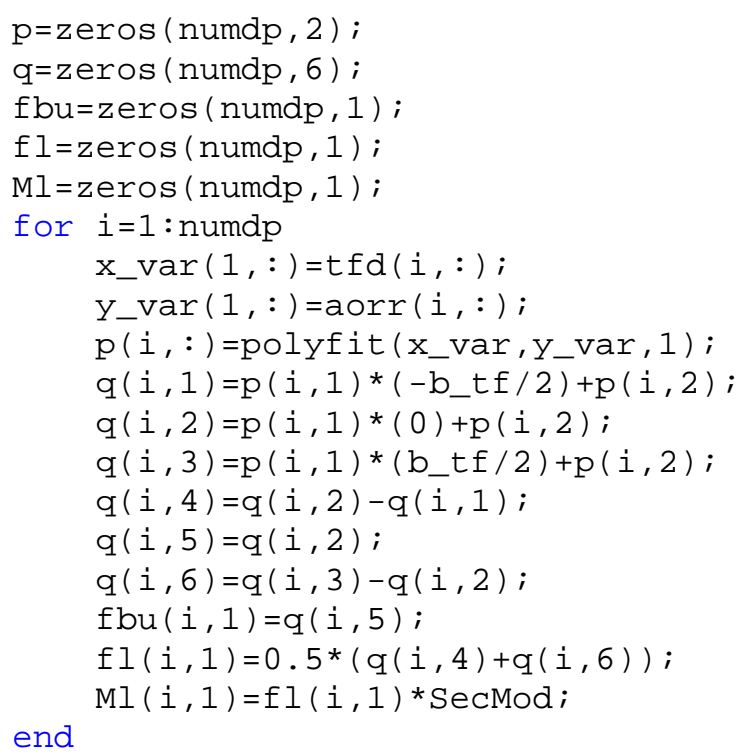

assignin('base ', genvarname(strcat ('L', num2str( L*12), '_S', num2str(G_S*12), '_N ' , num2str(N_B), '_SK', num2str(skew, 12), ' - CF ', num2str(num_cf), ' PG', '_OUTPUT' )), results );

clear fbu h=figure(iter);

hold on

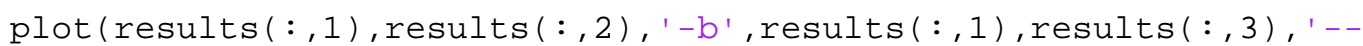
$b^{\prime}$, results $(:, 1)$, results $(:, 4),{ }^{\prime}--b^{\prime},\left[\begin{array}{ll}0 & 1\end{array}\right],[00],{ }^{\circ}$ ' k', 'Linewidth ', 2);

legend('LFB Moments (FEA)', 'AASHTO Approximation (+)', 'AASHTO Approximation $(-)^{\prime}$, 'Location', 'South');

xlabel('Normalized distance $(\mathrm{x} / \mathrm{L})$ ');

ylabel('Moment (ft-kip)');

title (strcat('L', num2str( L, 12), '-S', num2str (G_S, 12), ' $N^{\prime}, \operatorname{num} 2 \operatorname{str}($ N_B, 12), ' -SK', num2str ( skew, 12), ' -CF ', num2str(num_cf, 12), ' - PG ' , ' : Moment Comparisons')); 


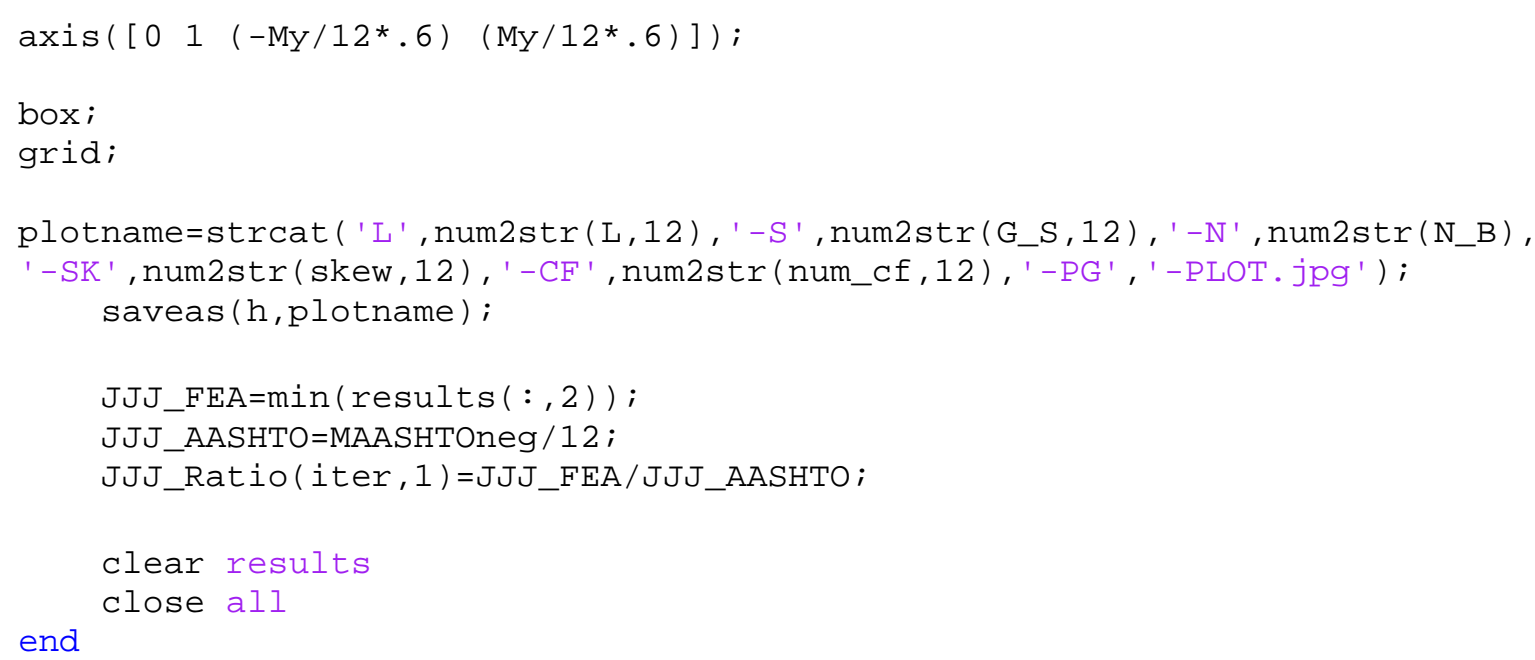

